Aus der Abteilung Rechtsmedizin

(Komm. Leiter: Prof. Dr. med. Dr. jur. h.c. K.-S. Saternus)

im Zentrum Arbeits-, Sozial-, Umwelt- und Rechtsmedizin und Dermatologie der Medizinischen Fakultät der Universität Göttingen

\title{
Untersuchung der Geschosswirkung in der sehr frühen Phase unter besonderer Berücksichtigung der Hochgeschwindigkeitsmunition
}

\author{
INAUGURAL - DISSERTATION \\ zur Erlangung des Doktorgrades \\ der Medizinischen Fakultät \\ der Georg-August-Universität zu Göttingen
}

vorgelegt von

Bernward Siegmund

aus

Telgte

Göttingen 2006 
Dekan:

I. Berichterstatter: $\quad$ PD Dr. med. Dr. rer. nat. H. Kijewski

II. Berichterstatter/in:

III. Berichterstatter/in:

Tag der mündlichen Prüfung:

Prof. Dr. med. C. Frömmel 
1. Einleitung und Aufgabenstellung 1

2. Vorgehensweise und Aufbau der Arbeit 3

3. Material und Methodik 5

3.1. Labor und Laborausstattung 5

3.1.1. Grundriss und die baulichen Bedingungen für die Sicherheit 5

3.1.2. Zielhalterung 6

$\begin{array}{ll}\text { 3.1.3. Waffenhalterung } & 7\end{array}$

3.1.4. Lauflinie und Visierlinie 7

3.1.5. Geschwindigkeitsmessgeräte 8

3.1.6. Hochgeschwindigkeitskamera 9

3.1.7. Druckmessgerät 10

3.1.8. Ballistisches Pendel 10

3.1.9. Sicherheitskugelfang 11

3.2. Munition 11

3.2.1. Kaliber .223 Rem 11

3.2.2. Kaliber .222 Rem 12

3.2.3. Wiederladetechnik 12

3.2.4. Laborierung der Munition 13

3.2.5. Verwendete Geschosse 14

3.2.6. Treibmittel 15

3.2.7. Computerprogramm QuickLOAD® 15

3.3. Versuchswaffen 16

3.3.1. Repetierbüchse Savage 10 FP (.223 Rem) 16

3.3.2. Kipplaufbüchse CZ (.222 Rem) 16

3.3.3. Kleinkarabiner Krico (.22 Ir) 16

3.4. Versuchsziele 17

3.4.1. Gelatineblöcke (250 Bloom, Typ A) 17

3.4.2. Wassercontainer 17

3.4.3. Stickstoffcontainer 18

3.4.4. PVC-Hartschaumplatten und Rigips-Platten 18

3.4.5. Schlachttierteile 18

3.4.6. Melonen (Cucumis melo) 19

3.5. Kalibrierung und Laborierung 19

3.5.1. Kalibrierung der Geschwindigkeitsmessgeräte 19

3.5.2. Laborierungsentwicklung 19

3.5.3. Kalibrierung des ballistischen Pendels 20

3.6. Schussversuche und Sicherheit 20 
4. Ergebnisse eigener Untersuchungen 21

4.1. Ergebnisse der Kalibrierung und Laborierung 21

4.1.1. Kalibrierung Chronygraph A-C mit Laborierung .22 Ir 21

4.1.2. Kalibrierung Chronygraph 1-2 mit Laborierung 223.1 22

4.1.3. Kalibrierung der laborierten Munition 23

4.1.4. Kalibrierung des elektrooptischen Systems 25

4.1.5. Kalibrierung des ballistischen Pendels 28

4.1.6. Temperatur der Gelatineblöcke im zeitlichen Verlauf 30

4.2. Ergebnisse der Schussversuche 30

4.2.1. Schusstrichter von Zerlegungsgeschossen an technischen Materialien $\quad 30$

4.2.2. Eindringtiefe und Energieverlust von VMJ in Gelatine 37

4.2.3. Zielmaterial an der Ausschussseite von Cucumis melo 41

4.2.4. Zielmaterial an der Ein- und Ausschussseite von Cucumis melo 43

4.2.5. Geschwindigkeit einer Höhlenfront in Gelatine (bis $154 \mu \mathrm{s}$ ) 45

4.2.6. Geschwindigkeit einer Höhlenfront in Gelatine (bis $700 \mu \mathrm{s}$ ) $\quad 48$

4.2.7. Geschwindigkeit einer Höhlenfront in Stickstoff 52

4.2.8. Maximaler Durchmesser einer temporären Höhle 54

4.2.9. Gasballonkollaps in Wasser abseits vom Schusskanal $\quad 57$

4.2.10. Zielprofil eines massiven Messinggeschosses in Gelatine $\quad 60$

4.2.11. Schwärme von Gasblasen abseits der temporären Höhle 65

4.2.12. Fokus von Gasblasen im rotationssymmetrischen Ziel 67

4.2.13. Wellenfront und Schwärme von Gasblasen 69

4.2.14. Wellenfront mit Reflexion 71

4.2.15. Wellenfront und einseitige Reflexion 74

4.2.16. Druckmessung einer Wellenfront 77

4.2.17. Durch Gasblasenkollaps beschleunigtes Zielmaterial 80

4.2.18. Wellenfront in Stickstoff 82

5. Diskussion $\quad 85$

5.1. Sicherheit und bauliche Bedingungen 85

5.2. Diskussion im Vorfeld der Untersuchung 86

5.2.1. Material und Methodik 86

5.2.1.1. Spezialgeschosse $\quad 86$

5.2.1.2. Versuchswaffen $\quad 86$

5.2.1.3. Versuchsziele 87

5.2.2. Fehlerquellen und Fehlerberechnungen 88

5.3. Diskussion der Ergebnisse eigener Untersuchungen 94

5.3.1. Diskussion der Kalibrierung und Laborierung 94

5.3.2. Diskussion der Schussversuche 95

5.3.2.1. Schusstrichter von Zerlegungsgeschossen an technischen Materialien 95

5.3.2.2. Eindringtiefe und Energieverlust von VMJ in Gelatine 98

5.3.2.3. Zielmaterial an der Ausschussseite von Cucumis melo 101

5.3.2.4. Zielmaterial an der Ein- und Ausschussseite von Cucumis melo 102

5.3.2.5. Geschwindigkeit einer Höhlenfront in Gelatine (bis $154 \mu \mathrm{s}) \quad 103$

5.3.2.6. Geschwindigkeit einer Höhlenfront in Gelatine (bis $700 \mu \mathrm{s}) \quad 105$

5.3.2.7. Geschwindigkeit einer Höhlenfront in Stickstoff 106 
5.3.2.8. Maximaler Durchmesser einer temporären Höhle 107

5.3.2.9. Gasballonkollaps in Wasser abseits vom Schusskanal 108

5.3.2.10. Zielprofil eines massiven Messinggeschosses 109

5.3.2.11. Schwärme von Gasblasen abseits der temporären Höhle 111

5.3.2.12. Fokus von Gasblasen im rotationssymmetrischen Ziel 114

5.3.2.13. Wellenfront und Schwärme von Gasblasen 114

$\begin{array}{ll}\text { 5.3.2.14. Wellenfront mit Reflexion } & 115\end{array}$

$\begin{array}{ll}\text { 5.3.2.15. Wellenfront und einseitige Reflexion } & 117\end{array}$

5.3.2.16. Druckmessung einer Wellenfront 117

5.3.2.17. Durch Gasblasenkollaps beschleunigtes Zielmaterial 123

5.3.2.18. Wellenfront in Stickstoff 126

6. Zusammenfassung und Ausblick 128

$\begin{array}{ll}\text { 7. Anhang } & 130\end{array}$

7.1. Schusstabelle 130

$\begin{array}{ll}\text { 7.1.1. Mit Kamerakontrolle } & 130\end{array}$

7.1.2. Ohne Kamerakontrolle 132

7.2. Umrechnungsfaktoren 138

7.3. Photographien 139

7.4. Das ballistische Pendel 143

7.5. Maximale Rückstoßberechnung 147

7.6. Lichtreflexion an Grenzflächen (Gasblasen) 151

7.7. Datenblatt der Laborierung 223.5

7.8. Historische Entwicklung der Kaliber 153

8. Literaturverzeichnis 155 


\section{Abkürzungsverzeichnis}

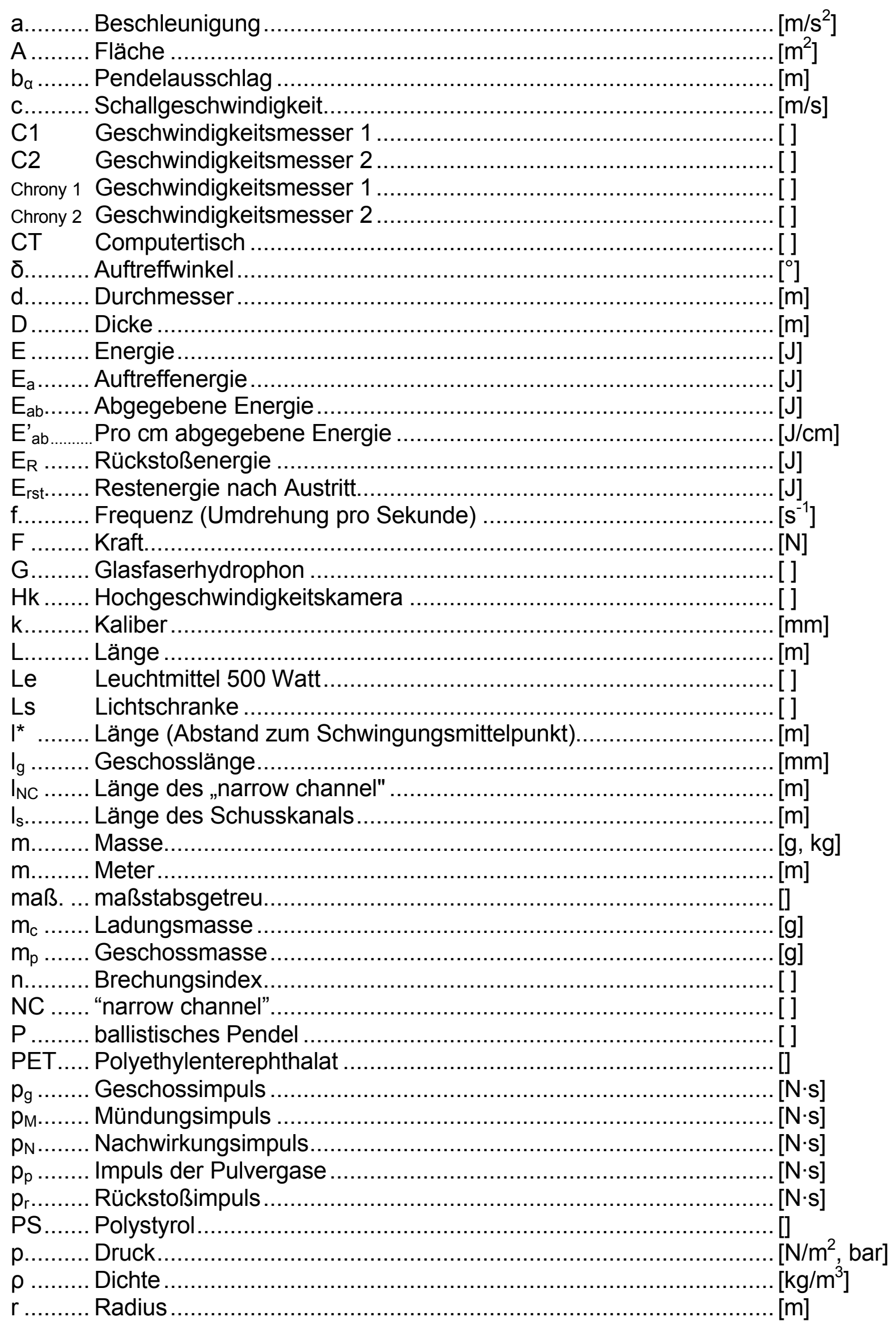




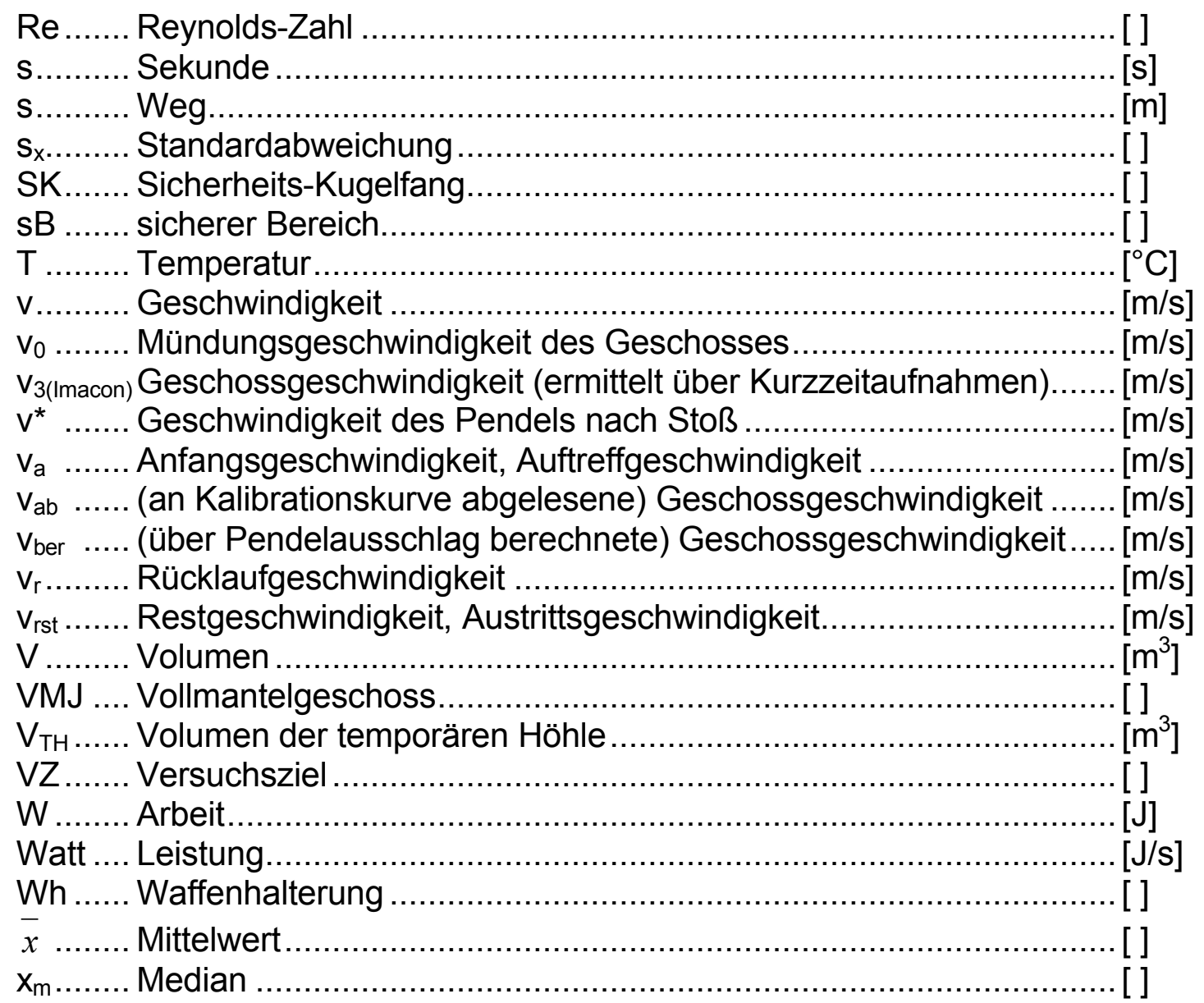


Skizzen-, Photo-, Graphen-, und Tabellenverzeichnis:

Skizze 3.1.1.: Grundriss des Labors 5

Skizze 3.1.2.: Zielhalterung $\quad 6$

Skizze 3.1.4.: $\quad$ Lauflinie $\quad 7$

Skizze 3.1.5.: Chronygraph 8

$\begin{array}{lll}\text { Skizze 7.4.: } & \text { Ballistisches Pendel } & 144\end{array}$

$\begin{array}{lll}\text { Skizze 7.5.: } & \text { Rückstoß } & 147\end{array}$

Photo s-01: $\quad 25$

Photo 15: Vergrößerung Fragmente s-100 31

Photo 20: Vergrößerung Rigips-Platte ausschussseitig s-206 34

Photo 21: Vergrößerung Rigips-Platte ausschussseitig s-207 34

Photo s-13: $\quad 41$

Photo s-11: $\quad 43$

Photo s-03: $\quad 45$

Photo s-17: $\quad 48$

Photo s-17.5: $\quad 50$

Photo s-43: $\quad 52$

Photo s-18: $\quad 54$

Photo s-66: $\quad 57$

Photo s-66.6: $\quad 59$

Photo s-23: $\quad 60$

Photo s-23.2: $\quad 61$

Photo s-25: $\quad 65$

$\begin{array}{ll}\text { Photo s-58: } & 67\end{array}$

Photo s-58.8: $\quad 68$

Photo s-53: $\quad 69$

Photo s-54: $\quad 71$

$\begin{array}{ll}\text { Photo s-54.3: } & 72\end{array}$

Photo s-33: $\quad 74$

$\begin{array}{ll}\text { Photo s-33.3: } & 75\end{array}$

Photo 19: Vergrößerung entspricht s-33.3 mit Graphikfilter $\quad 76$

$\begin{array}{ll}\text { Photo s-51: } & 77\end{array}$

$\begin{array}{ll}\text { Photo s-51.3: } & 78\end{array}$

Photo s-36: $\quad 80$

Photo s-36.7: $\quad 81$

Photo s-46: $\quad 82$

Photo s-46.7: $\quad 83$

Photo 16: Vergrößerung Maxilla Schlachttier 96

Photo 17: Vergrößerung Eindringtiefe s-03 98

Photo 18: Vergrößerung VMJ Fragmente s-03 99

Photo 1: Stativ 139

Photo 2: Kammerverschluss und Laserpointer 139

Photo 3: Chronygraph $\quad 139$

Photo 4: Savage $\quad 139$

Photo 5: Brünner 139

Photo 6: Krico 139

Photo 7: Pendel 140 
Photo 8: Matrizen .223 Rem 140

Photo 9: Hülsentrimmer 140

Photo 10: Pulverwaage $\quad 140$

Photo 11: Ladepresse $\quad 140$

Photo 12: Verwahrung 141

Photo 13: VMJ, Solid, Sand, Messingspäne, Holzdübel 141

Photo 14: Wachsmatrize 141

Photo 15: Fragmente s-100 141

Photo 16: Maxilla Schlachttier $\quad 141$

Photo 17: Eindringtiefe s-03 141

Photo 18: VMJ Fragmente s-03 141

Photo 19: Reflexion s-33 142

Photo 20: Einschusstrichter s-206 142

Photo 21: Einschusstrichter s-207 142

Photo 22: VMJ 3,56 g und VMJ 3,0 g 142

Graph 4.1.1.: Kalibrierung Chrony A-C mit Laborierung .22 Ir $\quad 21$

Graph 4.1.2.: $\quad$ Kalibrierung Chrony 1 und 2 mit Laborierung 223.1

Graph 4.1.3.: $\quad$ Geschwindigkeit der laborierten Munition 23

Graph 4.1.5.: $\quad$ Kalibrierung des ballistischen Pendels 29

Graph 4.1.6.: $\quad$ Temperatur der Gelatineblöcke im zeitlichen Verlauf 30

Graph 4.2.1a.: $\quad$ Schusstrichter von Zerlegungsgeschossen auf PVC 33

Graph 4.2.1b.: $\quad$ Schusstrichter von Zerlegungsgeschossen auf Rigips 36

Graph 4.2.2a.: $\quad$ Eindringtiefe von VMJ in Gelatine 37

Graph 4.2.2b.: Energieverlust von VMJ in Gelatine 38

Graph 4.2.8.: $\quad$ Entwicklung des maximalen Durchmessers der temporären Höhle s-18 56

Graph 4.2.10a:: Drehwinkel des Messinggeschosses in Gelatine 62

Graph 4.2.10b.: Geschwindigkeit des Messinggeschosses in Gelatine 63

Graph 4.2.10c.: $\quad$ Energieverlust des Messinggeschosses in Gelatine 64

Graph 5.3.2.2a.: relativer Energieverlust von VMJ $(961-1086$ m/s) 100

Graph 5.3.2.2b.: relativer Energieverlust von VMJ $(1101-1157 \mathrm{~m} / \mathrm{s})$

Graph 5.3.2.5a.: Geschwindigkeit der Höhlenfront s-03 (bis 154 us) 103

Graph 5.3.2.5b.: Energieverlust von s-03 104

Graph 5.3.2.6a.: Geschwindigkeit der Höhlen- u. Fragmentfront 105

Graph 5.3.2.6b.: Energieverlust von s-17 und s-03 106

Graph 5.3.2.9.: Gasballonkollaps in Wasser unter Annahme

einer Kugelform 108

Graph 5.3.2.10.: Energieverlust und Drehwinkel eines Messinggeschosses $\quad 110$

Graph 5.3.2.16a.: Druckmessung s-50

118

Graph 5.3.2.16b.: Druckberechnung s-50

119

Graph 5.3.2.16c.: Frontgeschwindigkeit nach Wellenweg 120

Graph 5.3.2.16d.: Spitzendruck für unterschiedliche Initialradien 121

Graph 5.3.2.16e.: Geschwindigkeit der Verdichtungswelle s-51 123

Graph 5.3.2.17.: Blasenkollaps an freier Wasser-Luft-Grenzfläche 124 
Tab. 3.2.4.:

Tab. 4.1.1.:

Tab. 4.1.2.:

Tab. 4.1.3a.:

Tab. 4.1.3b.:

Tab. 4.1.4a.:

Tab. 4.1.4b.:

Tab. 4.1.4c.:

Tab. 4.1.4d.:

Tab. 4.1.4e.:

Tab. 4.1.5:

Tab. 4.2.1a.:

Tab. 4.2.1b.:

Tab. 4.2.2a.:

Tab. 4.2.2b.:

Tab. 4.2.2c.:

Tab. 4.2.2d.:

Tab. 4.2.2e.:

Tab. 4.2.3.:

Tab. 4.2.4a.:

Tab. 4.2.4b.:

Tab. 4.2.5a:

Tab. 4.2.5b.:

Tab. 4.2.6a.:

Tab. 4.2.6b.:

Tab. 4.2.6c.:

Tab. 4.2.7.:

Tab. 4.2.8.:

Tab. 4.2.9.:

Tab. 4.2.10a.:

Tab. 4.2.10b.:

Tab. 4.2.10c.:

Tab. 4.2.14.:

Tab. 4.2.16a.:

Tab. 4.2.16b.:

Tab. 4.2.16c.:

Tab. 4.2.18a.:

Tab. 4.2.18b.:

Tab. 4.2.18c.:

Tab. 5.2.2a.:

Tab. 5.2.2b.:

Tab. 5.3.2.16.:

Tab. 5.3.2.17.:

Tab. 7.1.1.:

Tab. 7.1.2:
Laborierung der Munition

Kalibrierung Chrony A-C mit Laborierung .22 Ir 21

Kalibrierung Chrony 1 und 2 mit Laborierung 223.1 22

Geschwindigkeit der laborierten Munition 23

Standardabweichung der laborierten Munition 24

Geschossfront s-01

Geschossfront s-06

26

27

Geschossfront s-07 27

Geschossfront s-30 27

Abweichungen der Chronygraphen $\quad 28$

Kalibrierung des ballistischen Pendels 28

Schusstrichtergröße auf PVC-Hartschaumplatten von

Zerlegungsgeschossen

32

Schusstrichtergröße auf Rigips-Platten von

Zerlegungsgeschossen

35

Eindringtiefe von VMJ in Gelatine

37

Energieverlust von VMJ $(961-1086 \mathrm{~m} / \mathrm{s})$ in Stickstoff

39

Energieverlust von VMJ $(965-1080 \mathrm{~m} / \mathrm{s})$ in Wasser

39

40

40

Energieverlust von VMJ $(1110-1144 \mathrm{~m} / \mathrm{s})$ in Wasser

Material an der Ausschussseite s-13

Material an der Einschussseite s-11

Material an der Ausschussseite s-11

Geschwindigkeit der Höhlenfront s-03 (bis $154 \mu \mathrm{s}$ )

Energieverlust s-03 (bis $154 \mu \mathrm{s}$ )

Geschwindigkeit der Höhlenfront s-17 (bis $700 \mu \mathrm{s}$ )

42

44

44

46

47

49

50

51

53

55

58

62

63

64

73

79

79

79

84

84

84

91

92

122

123

132

137 


\section{Einleitung und Aufgabenstellung}

Die Beurteilung von Schussverletzungen und die Rekonstruktion von Schusswaffendelikten sind von jeher ein wichtiges Aufgabenfeld der Rechtsmedizin. Das kommt unter anderem darin zum Ausdruck, dass schon VON HOFMANN (1895) in dem Lehrbuch der gerichtlichen Medizin ein Kapitel der Schusswirkungsproblematik gewidmet hat. Seitdem ist das rechtsmedizinische Schrifttum zu den Schusswaffen und Schusswirkungen nahezu unübersehbar geworden. Einen Anhaltspunkt und eine Einführung speziell im Hinblick auf rechtsmedizinische Fragen finden wir in den Monographien von SELLIER $(1969,1977)$. Die Arbeiten von Sellier sind insbesondere dadurch gekennzeichnet, dass ein theoretischer Hintergrund gesucht und erarbeitet wurde. Dabei wurde versucht mathematische Zusammenhänge darzustellen, wobei ein umfassendes und noch bis heute gültiges Arbeitsgebiet erschlossen wurde.

Die theoretische Aufarbeitung der Schusswaffenwirkung ist aber noch lange nicht abgeschlossen und es ergeben sich zahlreiche noch offene Fragen, für deren theoretische Lösung weitere experimentelle Grundlagen erarbeitet werden müssen. Es fällt beim Studium der Literatur auf, dass außerordentlich viele empirische und deskriptive Arbeiten durchgeführt wurden, von denen allerdings sehr viele versäumen, grundlegende Zusammenhänge quantitativ zu erfassen.

Überdies haben seit den siebziger Jahren die neuen Militärkaliber mit Hochgeschwindigkeitsmunition weite Verbreitung gefunden, wobei sich aber erhebliche regionale Unterschiede ergaben. Auch bei Tötungsdelikten und Jagdunfällen ist der prozentuale Anteil von Hochgeschwindigkeitsmunition gestiegen; INCl et al. (1998, S. 438) beschreiben sogar, dass „penetrating thoracic trauma, especially that due to high-velocity gunshot wounds, is increasing at an alarming rate in our region". Auch bei den terroristischen Gewalttaten ist davon auszugehen, dass zunehmend Hochgeschwindigkeitsmunition eingesetzt wird.

Während die in der Rechtsmedizin beschriebenen Fälle von Schussverletzungen bislang meist durch langsam fliegende Geschosse aus Faustfeuerwaffen verursacht wurden, führt die Waffenentwicklung im miliärischen Bereich zu insgesamt kleineren Kalibern mit immer höherer Geschossgeschwindigkeit (ZIEGLER 1990, HAUCK 1990, SCHMECHTA 1990, MARKAKIS et al. 1992, PEREY und TIGGES 2003). Es ist schwierig, Schusswunden sicher zu beurteilen. Wenn sie durch schnelle Geschosse verursacht wurden, ist das besonders schwierig. Teilweise können dann nicht einmal mehr Ein- und Ausschuss sicher voneinander unterschieden werden (PIETTE et al. 2002). Auch im Institut für Rechtsmedizin Göttingen wurde seit Jahren an den Grundlagen der Wundballistik mit Hochgeschwindigkeitsmunition gearbeitet (KLATT 1996, KLATT und KIJEWSKI 1998, KEGEL 2003). Bislang wurden insbesondere die quantitativen Veränderungen der Energieabgabemechanismen von Geschossen mit Geschwindigkeiten bis $1300 \mathrm{~m} / \mathrm{s}$ in feuchten Zielmedien aufgezeigt.

Dabei blieb der Entstehungsmechanismus der exponentiell steigenden Energieverluste in wasserreichen ballistischen Zielen jedoch bis heute unklar. Es gibt verschiedene Meinungen zur starken Energieabsorption von Hochgeschwindigkeitsgeschossen. JANZON und SEEMAN (1985) erklären die hohe Energieabsorption mit der Bildung temporärer Höhlen. KLATT (1996) stellt hochfrequente Zielpulsationen als Ursache in den Vordergrund. COUPLAND (1999) erklärt die Geschossverzögerung mit Fragmentation, WARD und NOLTE (2000) hingegen erklären sie mit Geschosstaumeln. Zuletzt beschreiben CANNON (2001) und TAN et al. (2002) starke Druckwellenbildung als Ursache für den Energieverlust. Gerade grundlegende 
Mechanismen sind also bis heute nicht vollständig erforscht (DEMUTH und SMITH 1966) und bedürfen deshalb weiterer Untersuchungen (RAGSDALE und JOSSELSON 1988 b). So wurde bereits von KEGEL (2003) gefordert, bildgebende Verfahren auch für die Untersuchung von Energieabgabemechanismen in feuchten Zielmedien einzusetzen. Für die vorliegende Arbeit sollten daher mit bildgebender Technik die Energieabsorption und die Ausbreitung von Druckwellen im Ziel genauer untersucht werden:

Die Göttinger Arbeitsgruppe hat, angeregt durch einen Gutachterstreit bei einem spektakulären Mordprozess, auch speziell die Frage der Hochgeschwindigkeitsmunition bearbeitet. Hochgeschwindigkeitsmunition war im rechtsmedizinischen Schrifttum und wohl auch in der Praxis nur selten relevant und es ergaben sich sehr schnell Hinweise auf Geschosswirkungen, die in dieser Form überhaupt noch nicht erforscht waren.

In seiner Dissertation hatte KLATT (1996) erstmalig eine quantitative Untersuchung zum Energieverlust im Ziel bei Verwendung von Hochgeschwindigkeitsmunition durchgeführt. Diese Arbeit wurde von KEGEL (2003) fortgeführt, wobei die Arbeiten von Klatt bestätigt und erweitert wurden. Auch die theoretischen Schlussfolgerungen wurden bestätigt.

Es ergaben sich dabei aber auch noch weitergehende grundsätzliche Fragestellungen und es gelang, Herrn Professor Lauterborn vom dritten Physikalischen Institut Göttingen für diese Probleme zu interessieren. Er unterstützte uns personell und materiell. Das ermöglichte uns, die Untersuchungen zur sehr frühen Phase von Schusswirkungen auf eine fundierte experimentelle Basis zu stellen. Dabei wurden die Aufgaben geteilt, sowohl in der experimentellen Zielrichtung, als auch in der Durchführung der Experimente.

Die Zielrichtung der Physiker war mehr auf die Druckmessungen und deren theoretische Interpretation gerichtet. Diese Ergebnisse sollen hier nur kurz erwähnt werden (Kap. 5.3.2.16.). Unsere sowie die für die Physiker wichtigen Ergebnisse kamen gleichzeitig und gemeinsam zustande. Sie sind geeignet, sich gegenseitig zu ergänzen. Insofern sind auch die Ergebnisse der Dissertation von WOLFRUM (2004) und der von METTIN et al. $(2003,2004)$ initiierten Publikationen ad hoc zitiert und eingearbeitet worden. 


\section{Vorgehensweise und Aufbau der Arbeit}

Die komplexe Apparatur war nicht von einer Person zu bedienen, die Bedienungsfunktionen wurden daher von verschiedenen Personen wahrgenommen, wobei der Autor alle Funktionen abwechselnd übernahm.

Die Schussversuche wurden in dem ballistischen Labor des Institutes für Rechtsmedizin der Universität Göttingen durchgeführt. Im Labor wurden zunächst eine Waffenhalterung, eine Zielhalterung und ein Sicherheitskugelfang gebaut und aufgestellt. Außerdem wurde ein ballistisches Pendel hinter der Zielhalterung so befestigt, dass es frei in Schussrichtung schwingen konnte. Vom Autor der vorliegenden Arbeit wurden zunächst Schussversuche ohne Kamerakontrolle und ohne Druckmessung durchgeführt. Dabei wurden die Geschwindigkeitsmessgeräte und das ballistische Pendel kalibriert und selbst hergestellte Munition für unterschiedliche Geschwindigkeitsbereiche hergestellt. Je nach Probe- und Kalibrierungsschüssen wurden unterschiedliche Zielmaterialien ausgewählt und nacheinander in der Zielhalterung positioniert und beschossen. Auch die geometrische Form der Zielmaterialien wurde variiert und mit unterschiedlichen Geschossen in einem weiten Geschwindigkeitsbereich (von $115 \mathrm{~m} / \mathrm{s}$ bis $1575 \mathrm{~m} / \mathrm{s}$ ) beschossen.

Die Schussversuche wurden protokolliert. Die Spezifikationen der Munition und des jeweiligen Zieles wurden dokumentiert, ebenso die Geschwindigkeit vor und nach dem Ziel, der Pendelausschlag, die Anzahl der Einschläge im Pendel (bei Fragmentation), die Eindringtiefe in das Ziel und besondere Befunde einzelner Schussversuche. Von den festen Zielmaterialien wurden nach Beschuss unter Verwendung eines Maßstabes Photographien angefertigt.

Nach den Schussversuchen ohne Kamerakontrolle wurde neben der Zielhalterung eine Hochgeschwindigkeitskamera aufgebaut. Der Autor wurde von Mitarbeitern des dritten Physikalischen Institutes Göttingen in die Bedienung der Hochgeschwindigkeitskamera eingewiesen. Die Hochgeschwindigkeitskamera wurde durch eine Lichtschranke (Ls) ausgelöst, welche vom jeweiligen Geschoss vor Zieleintritt überflogen wurde.

$\mathrm{Zu}$ einem späteren Zeitpunkt stand zudem ein Glasfaserhydrophon zur Verfügung, welches den Druck in flüssigen Zielmedien messen konnte.

Durch die Kombination von Hochgeschwindigkeitskamera und Glasfaserhydrophon war eine Aussage zu den Druckverhältnissen der abgebildeten Wellenfronten möglich. Nach Durchführung aller Schussversuche wurden die erhobenen Daten zur besseren Übersicht in "Schussversuche mit Kamerakontrolle“ und in "Schussversuche ohne Kamerakontrolle" sortiert und nummeriert (s-01 bis s-190). Die Nummerierung entspricht dabei nicht der zeitlichen Folge der Schussversuche, welche in den Jahren 2003, 2004 und 2006 durchgeführt wurden.

Neben den modernen technischen Methoden wurden zusätzlich einfache Mittel eingesetzt. Durch die voneinander unabhängigen Messungen wurden systematische Fehler reduziert und weitere Ergebnisse gewonnen. So wurde z.B. vor den Eichschüssen kurzfaseriges Seidenpapier beschossen, um später aus der Form des Durchschusses auf die Fluglage des Geschosses schließen zu können.

Mit der Hochgeschwindigkeitskamera wurden das Geschoss und seine Wirkung auf das Ziel in den ersten Mikrosekunden aufgezeichnet. Neben der phänomenologischen Darstellung wurden aus den Bildsequenzen später Geschwindigkeit und 
Energieabgabe mit Hilfe eines Graphikprogramms am Computer berechnet. Um auch die Druckverhältnisse im Ziel bestimmen zu können, wurde das Glasfaserhydrophon bei einem Teil der Schussversuche eingesetzt.

Die erste Auswertung der Versuchsergebnisse im Labor veranlasste uns, die Versuchsbedingungen noch besser anzupassen und weiterführende Experimente durchzuführen. Im weiteren Verlauf wurden verschiedene Zielmaterialien eingesetzt. Neben der ballistischen Gelatine wurden reines Wasser, Wasser mit Gasblasen, flüssiger Stickstoff und weitere Simulanzien beschossen. Für die Aufzeichnung mit der Hochgeschwindigkeitskamera war dabei wichtig, ob das Zielmaterial durchsichtig war oder nicht.

Für die Auswertung von Energieabgabemechanismen war die Schallgeschwindigkeit in dem Zielmaterial von Bedeutung (KEGEL 2003).

Durch die zwei „Chronygraphen“, welche die Geschossgeschwindigkeit vor und hinter dem Ziel aufzeichneten, konnte der jeweilige Energieverlust berechnet werden. Als weitere Messmethode wurde ein ballistisches Pendel eingesetzt. Es nahm die Geschossfragmente auf und gab damit Aufschluss über eine eventuell erfolgte Geschosszerlegung sowie über die Restenergie. Alle Methoden wurden miteinander in Beziehung gesetzt, um systematische Fehler zu erkennen.

Bei dem Einschlag von schnellen Vollmantelgeschossen in ballistische Gelatine und in Wasser wurde experimentell untersucht, welchen Einfluss Druckwellen im Ziel abseits der temporären Höhle haben.

Dabei zeigten Hochgeschwindigkeitsaufnahmen die Dynamik der temporären Zielhöhlen, die Emission von primären Wellenfronten (Überdruckwellen) und im weiteren Verlauf aufschwingende Gasblasen.

Um das System zu vereinfachen, wurde zunächst ein wassergefüllter Zylinder beschossen (s-58). Durch die rotationssymmetrische Form war die Entartung von Schwingungsmöglichkeiten begrenzt.

Dann wurden auch eckige mit Wasser gefüllte Gefäße beschossen. Hier ließen sich die Zustandsänderungen (Überdruckwellen) besser darstellen. Außerdem wurde die Belichtungstechnik während der Versuche optimiert.

Als in einer Sequenz eine Wellenfront aufgezeichnet wurde, fiel auf, dass hinter der Druckwelle Schwärme von Gasblasen entstanden und sich im Anschluss wieder zurückbildeten. Um zu bestimmen, welche Eigenschaften des Zielmaterials Einfluss auf die Entstehung solcher Gasblasen haben, wurde das Zielmaterial entsprechend variiert. Dass insbesondere die Reflexion an Grenzflächen Einfluss auf die Entstehung von Blasenschwärmen hat, wurde später an unterschiedlichen Grenzflächen bildgebend dargestellt.

Ohne Kamerakontrolle wurden zudem Versuche durchgeführt, bei denen selbst hergestellte Geschosse verschossen wurden. Diese Geschosse wurden aus Holzdübeln oder aus unterschiedlichen Klebstoffmischungen hergestellt. Die Ergebnisse der Schussversuche mit diesen sich stark fragmentierenden Geschossen werden im Kap. 5.3.2.1. diskutiert. 


\section{Material und Methodik}

\subsection{Labor und Laborausstattung}

\subsubsection{Grundriss und die baulichen Bedingungen für die Sicherheit}

Die Schussversuche wurden im ballistischen Labor des Institutes für Rechtsmedizin der Uni Göttingen durchgeführt. Die in Verbindung stehenden Räume im Kellergeschoss können nur durch eine einzige, abschließbare Tür des Schießraumes betreten werden. Im gesamten Bereich verhinderte eine leistungsstarke Lüftungsanlage und regelmäßiges Auskehren die Anreicherungen von Treibladungsresten. Der gesamte Bereich ist gefliest.

Im Schießgang befanden sich linear und auf gleicher Höhe ein elektronischer Geschwindigkeitsmesser C1, das jeweilige Versuchsziel VZ, ein zweiter elektronischer Geschwindigkeitsmesser C2 und das ballistische Pendel $P$.

Das ballistische Pendel war mit zwei Schrauben an der Decke befestigt und konnte reibungsarm in Schussrichtung schwingen.

Hinter dem Pendel befand sich ein Schusskasten SK innerhalb eines abgeschlossenen Raumes mit massiven Wänden.

\section{Skizze 3.1.1.: Grundriss des Labors}

C1 = Chrony 1

C2 = Chrony 2

$\mathrm{CT}=$ Computertisch

Le $\quad=$ Leuchtmittel $500 \mathrm{~W}$

Ls = Lichtschranke als Kameraauslöser

G = Glasfaserhydrophon

$\mathrm{Hk}=$ Hochgeschwindigkeitskamera

$\mathrm{P} \quad=$ ballistisches Pendel

SK = Sicherheitskugelfang

$\mathrm{SB} \quad=$ sicherer Bereich

$\mathrm{VZ} \quad=$ Versuchsziel

$\mathrm{Wh}=$ Waffenhalterung

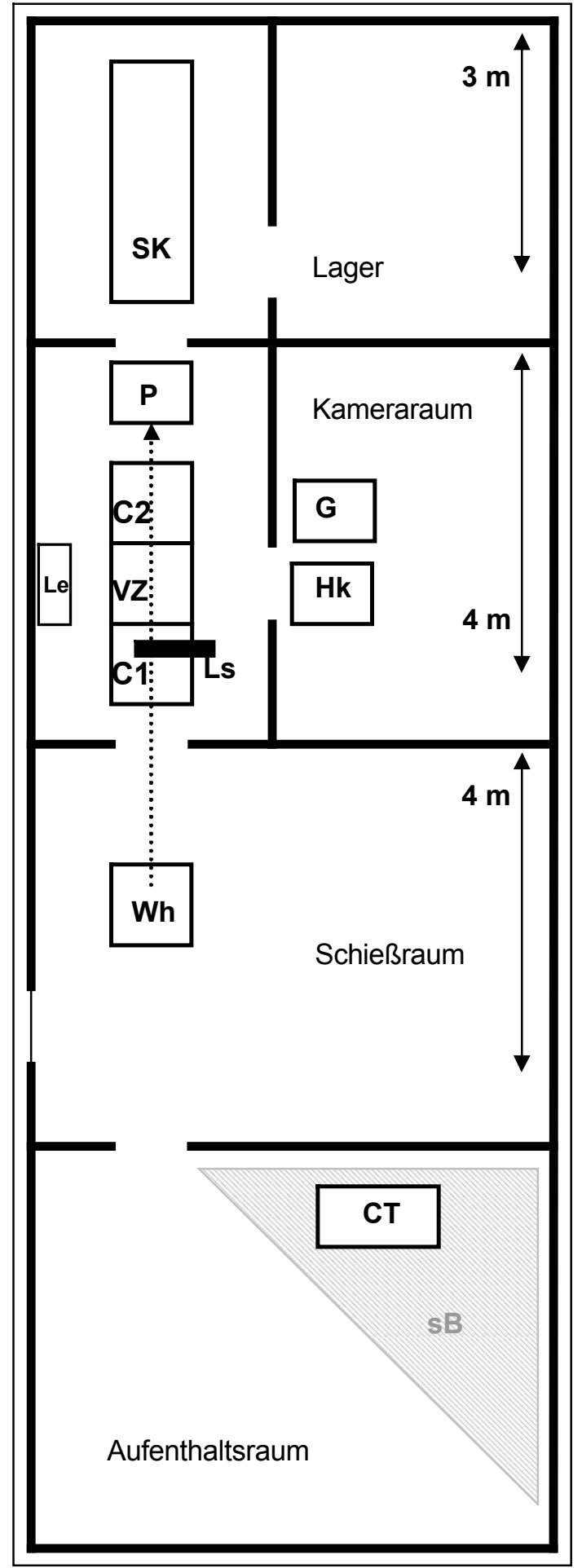


Die Hochgeschwindigkeitskamera Hk (Imacon 468) stand in der Tür zum Kameraraum, der Winkel zwischen Schussrichtung und Blickrichtung der Kamera betrug $90^{\circ}$. Neben der Kamera stand das Hydrophon G (FOPH 300), dessen Messfühler in das Versuchsziel integriert wurde.

Die Versuchswaffe war zur Schussauslösung an einem Stativ Wh verschraubt. Eine reißfeste und dehnungsarme Schnur wurde um den Abzugsbügel gelegt. Der Abzug konnte somit auch aus einer Sicherheitsentfernung gezogen werden. Zum Zeitpunkt der Schussauslösung befanden sich die am Versuch beteiligten Personen im sicheren Teil sB (schraffiert) des Aufenthaltsraumes. Im Aufenthaltsraum stand, ebenfalls im sicheren Bereich (schraffiert), der für die Steuerung der Kamera benötigte Computer CT. Während der Versuche war der gesamte Bereich verschlossen.

\subsubsection{Zielhalterung}

Zwei horizontale Holzbretter $(2,00 \times 0,40 \times 0,02 \mathrm{~m})$ wurden durch vier senkrecht stehende Bretter miteinander verbunden. Diese vier Bretter $(0,80 \times 0,40 \times 0,02 \mathrm{~m})$ hatten zentrale Durchschussöffnungen (Durchmesser $0,15 \mathrm{~m}$ ) und dienten als Blenden.

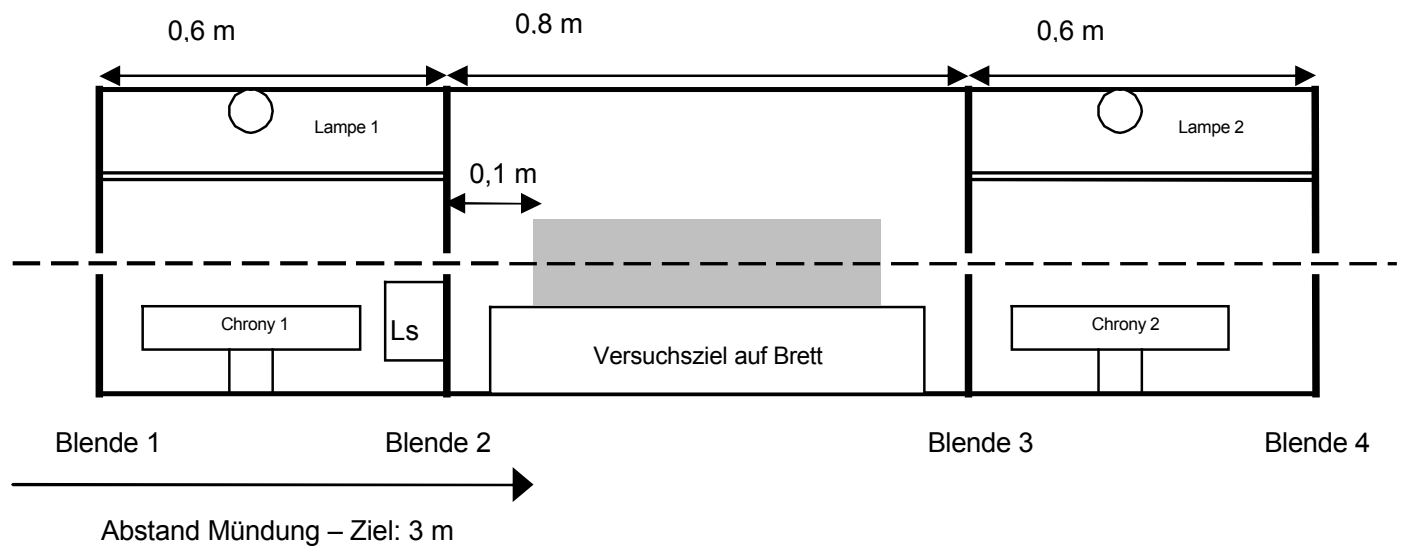

Skizze 3.1.2.: Zielhalterung (Aufriss in Seitenansicht)

Im so entstandenen Kompartiment zwischen Blende 1 und Blende 2 wurden der Chrony 1 und die Lichtschranke zur Kameraauslösung (Ls) verschraubt bzw. positioniert. Zwischen Blende 2 und Blende 3 wurde das jeweilige Versuchsziel auf einem Brett gelagert. Zwischen Blende 3 und Blende 4 war Chrony 2 verschraubt. Der Abstand zwischen Mündung und Blende 1 betrug 2,30 m. Das Ziel wurde 0,10 m hinter der Blende 2 aufgestellt. Der Mündungsabstand zum Ziel betrug immer 3,00 m.

Durch diese Anordnung war es möglich, jeweils vor und hinter einem Versuchsziel die Anfangsgeschwindigkeit $v_{a}$ und die Restgeschwindigkeit $v_{r s t}$ eines Geschosses elektronisch zu messen. Die $2,6 \mathrm{~m}$ nach Mündungsdurchtritt gemessene Geschwindigkeit entspricht der Auftreffgeschwindigkeit $v_{a}$. Die 4,0 m nach 
Mündungsdurchtritt gemessene Geschwindigkeit entspricht der Restgeschwindigkeit $v_{\text {rst. }}$ Nach Durchtritt durch Blende 4 verließen die Geschosse die Versuchszielhalterung und schlugen mit ihrer Restenergie $E_{r s t}$ in das ballistische Pendel ein.

Die Chronys wurden mit jeweils einer 100-Watt-Glühbirne beleuchtet. Zwischen einer Lampenhalterung mit Leuchtmittel und einem Chrony war jeweils eine matte Plexiglasscheibe als Diffusor angebracht.

Die Blenden wurden vor den Eichschüssen mit kurzfaserigem Seidenpapier bespannt, so konnte mittels Laserpointer auch die Lauflinie kontrolliert (Kap. 3.1.4.) werden.

\subsubsection{Waffenhalterung}

Die Waffenhalterung bestand aus diversen Winkelstücken und Schlosserschrauben, die die Versuchswaffe an sieben Punkten mittels Stellschrauben fixierten. Zur Dämpfung des Rückstoßes wurde ein sandgefüllter Leinensack $(1,8 \mathrm{~kg})$ hinter der Schaftkappe positioniert. Die Waffenhalterung war fest an einer Bühne des $138 \mathrm{~kg}$ schweren Studio-Stativ (Photo 1) verschraubt. Diese Bühne ist beweglich an dem Stativ angebracht und mittels einer Schraube in der Höhe einstellbar. Das Stativ ist auf 3 Rollen gelagert und kann leicht verschoben werden. Mittels 3 Stellschrauben kann die Position fixiert werden.

Die Waffenhalterung stand in einem festen Abstand zur ersten Blende der Zielhalterung. Der Abstand zwischen Mündung und Ziel betrug stets 3,00 m.

\subsubsection{Lauflinie und Visierlinie}

Die Lauflinie (auch „Seelenachse“) und die Visierlinie sind zwei Geraden. Die Flugbahn des Geschosses ist ohne Luftreibung eine Parabel (KUTTERER 1959). Die Lauflinie ist einer theoretischen Laufverlängerung gleichzusetzen (STANGE 1940). Die Visierlinie ist eine Verbindungsgerade zwischen Auge, Visiereinrichtung und Ziel.

Entsprechend der Skizze 3.1.4. verhalten sich Lauflinie, Visierlinie und Flugbahn zueinander.

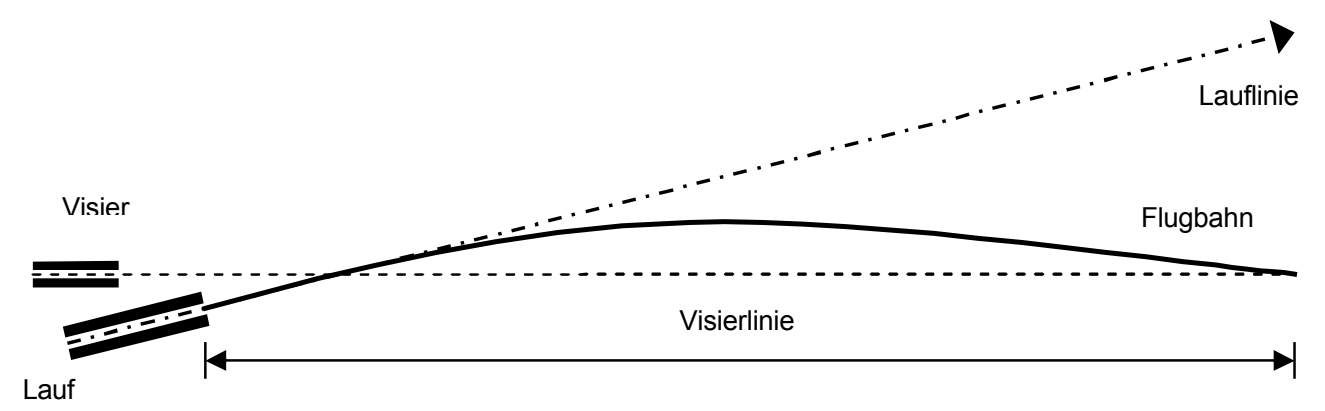

Skizze 3.1.4.: Lauflinie (Seitenansicht) 
Bei kurzen Distanzen kann die Lauflinie über und unter der Visierlinie liegen. Dieser Unterschied wurde bei der Justierung der Waffe berücksichtigt.

Die Versuchswaffe Savage 10 FP (Photo 4) wurde ohne offene Visierung geliefert. Mittels Weaver-Schiene wurde das Propoint PDP3 von Tasco ohne weitere "Montage“ flach über dem Lauf angebracht. Das beleuchtete Visierkorn eignete sich auch für kurze Entfernungen, die Visierhilfe vergrößerte nicht.

Um auf kurze Distanz gezielt visieren zu können, wurde die Lauflinie kontrolliert und die Visierlinie entsprechend angepasst. Ein Laserpointer (Photo 2 unten), der durch die symmetrische Umwicklung mit Tesafilm die Außenmaße des Kammerverschlusses (Photo 2 oben) erhielt, diente der Kontrolle der Lauflinie.

An der fixierten Waffe wurde der Kammerverschluss durch den Pointer ersetzt, dessen Licht durch den Lauf hindurch die erwartete Flugbahn nach dem Durchschlagen des Zieles, z.B. am Pendel, aufzeigte. Abweichungen von der so zuvor markierten erwarteten Flugbahn und der Flugbahn nach Durchtritt durch verschiedene Ziele (und entsprechend erfolgte Ablenkung des Geschosses) wurden so messbar.

\subsubsection{Geschwindigkeitsmessgeräte}

Verwendet wurden drei „ProChrono Digital“ (Photo 3) der Competition Electronics, Inc. (3469 Precision Dr., Rockford, IL 61109, USA, www.competitionelectronics.com). Ein Gerät bestand aus zwei Lichtsensoren, zwischen denen eine Wegstrecke von 0,305 m lag. Beide Sensoren lagen in einem Gehäuse und konnten das Licht einfangen, das annähernd senkrecht durch zwei Schächte in das Gehäuse eindrang. Beim Überflug eines Geschosses wurde durch dessen Schatten die Lichtzufuhr unterbrochen und im ersten Lichtsensor ein Zeitmesser aktiviert. Beim Überflug des zweiten Lichtsensors wurde der Zeitmesser gestoppt. Anhand der gemessenen Zeitspanne und der vorgegebenen Wegstrecke wurde die Geschossgeschwindigkeit errechnet. Die Geschwindigkeit wurde nach jedem Schuss von dem Messgerät in Metern pro Sekunde $\mathrm{m} / \mathrm{s}$ angezeigt. Ein Geschoss, welches für die Wegstrecke von 0,305 Metern [m] eine Zeitspanne von z.B. 5·10 $0^{-4}$ Sekunden [s] benötigt, fliegt demzufolge mit einer Geschwindigkeit von $610 \mathrm{~m} / \mathrm{s}$.

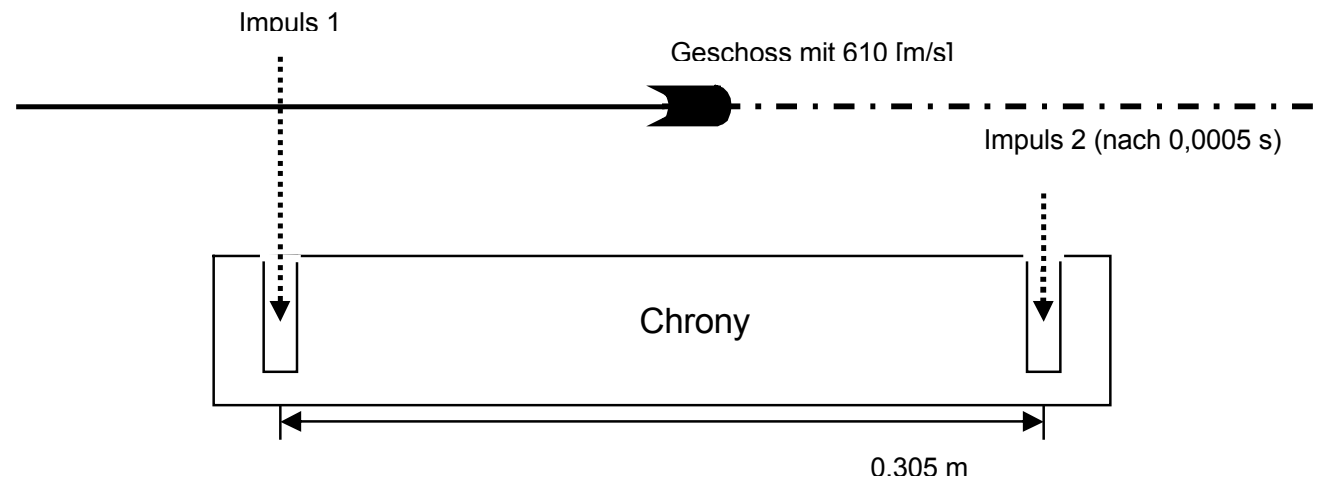

Skizze 3.1.5.: Chronygraph (Aufriss in Seitenansicht) 
Zur Verwendung in geschlossenen Räumen war eine spezielle Beleuchtung notwendig. Hierzu wurde ein Plastik-Diffusor in definiertem Abstand über den Lichtschächten von einem Leuchtmittel (100 Watt) bestrahlt. Es wurde beachtet, dass die Verwendung von Neon-Röhren das Messergebnis verfälschen konnte.

Es standen zunächst drei Chronygraphen zur Verfügung, von denen jenes mit der größten Abweichung aussortiert wurde.

Zur Kalibrierung der drei elektronischen Geschwindigkeitsmesser (Chrony A-C) wurden sie hintereinander in der Versuchszielhalterung positioniert, beleuchtet und überschossen (Kap. 3.5.1. und Kap. 4.1.1.).

Die Herstellerfirma gab folgende Spezifikationen an:

Geschwindigkeitsbereich: Temperaturbereich:

Abmessung:
$6,4-2133,6 \mathrm{~m} / \mathrm{s}$

$0-37,8^{\circ} \mathrm{C}$

$40,6 \times 10,1 \times 7,6 \mathrm{~cm}$.

\subsubsection{Hochgeschwindigkeitskamera}

Die Ultra-Hochgeschwindigkeitskamera Imacon 468 der Firma DRS (www.drs.com) ermöglichte die digitale Aufnahme von Sequenzen mit bis zu acht Bildern. Das durch ein Wechselobjektiv einfallende Licht wurde mittels Prisma auf acht unabhängige Graphiksysteme verteilt. Bei einer Zwischenbildzeit von minimal 10 Nanosekunden (10.000.000 Bilder/Sekunde) wurden sehr schnelle Phänomene aufgezeichnet. Die Kamera wurde von einem Kontrollrechner gesteuert. Die Datenübertragung erfolgte über ein Kabel in den sicheren Bereich des Aufenthaltsraums (Kap. 3.1.1.). So konnten sowohl Belichtungszeiten, Zwischenbildzeiten und Blenden für jedes Graphiksystem in Entfernung zur Kamera eingestellt werden.

Die Auslösung der Kamera erfolgte über eine Lichtschranke (Skizze 3.1.2.: Ls), die über eine Photodiode einen elektrischen Impuls auslöste, wenn ein Geschoss sie $(0,35$ $\mathrm{m}$ vor dem Zieleintritt) überquerte. Der, von einem Oszillographen verstärkte, elektrische Impuls löste schließlich die Kamera aus, welche über einen Eingangskanal verfügte. Als Photodiode wurde die Diode eines zuvor beschädigten Chronygraphen (Marke: Chrony M-2 Delta; Shooting Chrony Inc., 3269 Niagara Falls Blvd., North Tonawanda, NY 14120) ausgebaut und verwendet.

Die Spezifikationen der Kamera:

- Halterung für Nikon - Objektive 28-600 mm

- Belichtungszeit $10 \mathrm{~ns}$ bis zu $10 \mathrm{~ms}$ (frei wählbar in 10-ns-Schritten)

- Zwischenbildzeit $10 \mathrm{~ns}$ bis zu $1 \mathrm{~ms}$ (frei wählbar in 10-ns-Schritten)

- Tiefe 0,64 m, ausgenommen Objektiv

- Breite $0,325 \mathrm{~m}$

- Höhe 0,50 m, einschließlich des niedrigen Stativ-Tellers

- Gewicht $28 \mathrm{~kg}$.

Für die Beleuchtung des Zieles wurde eine Lampe mit einem 500-Watt-Leuchtmittel verwendet. Bei durchsichtigen Zielen wurden Sequenzen im Durchlicht mit 
Belichtungszeiten zwischen 1-5 $\mu$ s aufgezeichnet. Die Lampe stand dabei auf der kameraabgewandten Seite des Zieles.

Bei nicht durchsichtigen Zielen wurde mit Auflicht und $10 \mu$ selichtet. Die Lampe strahlte dabei von der Seite, auf der auch die Kamera stand, auf das Ziel.

Die Kamera war durch eine Kiste $(0,70 \times 0,35 \times 0,60 \mathrm{~m})$ aus 0,03 m starken Spanplatten vor Ziel- und Geschossfragmenten geschützt. Vor dem Kameraobjektiv war in die Holzkiste ein rundes Fenster (0,10 m Durchmesser) gefräst, welches von einer 0,002 m starken, klaren Plexiglasscheibe überdeckt wurde.

\subsubsection{Druckmessgerät}

Verwendet wurde das von dem 1. Physikalischen Institut der Universität Stuttgart ( www.rp-acoustics.de) entwickelte Glasfaserhydrophon FOPH 300. Das Gerät kann den Druck in Flüssigkeiten mit einer hohen zeitlichen Auflösung (AnsprechAnstiegszeit 6,5-7,5 ns) messen. Eine 300-Milliwatt-Laserdiode erzeugte einen

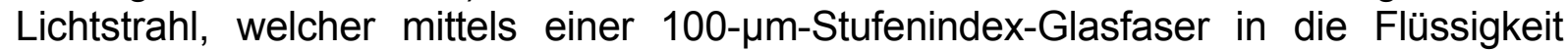
geleitet wurde. Die Intensität des Lichtes, welches am Faserende reflektiert wurde, wurde mit einer Photodiode gemessen.

Wie viel Licht reflektiert wurde, war abhängig von dem Unterschied zwischen dem Brechungsindex der Faser und dem der umgebenden Flüssigkeit. Der Brechungsindex der Flüssigkeit ist wiederum druckabhängig. Eine Druckänderung führte somit zu einer Änderung des Brechungsindex der Flüssigkeit mit Änderung der Intensität des reflektierten Lichts, welche gemessen wurde.

Die Spezifikationen des Hydrophons:

- Räumliche Auflösung:

- Ansprech-Anstiegszeit:

$100 \mu \mathrm{m}$

- schnelle Nachkalibrierung ohne Referenzmittel im Untersuchungsmaterial möglich

- Wiedergabe von positiven und negativen Druckamplituden.

\subsubsection{Ballistisches Pendel}

Zur Messung des Geschossimpulses nach Austritt aus dem Versuchsziel wurde $1,00 \mathrm{~m}$ hinter der vierten Blende der Versuchszielhalterung ein ballistisches Pendel (Photo 7) installiert. An einem Querbalken an der Decke des Schießganges wurde mittels Schraubenösen und Holzlatten eine Holzkiste reibungsarm gelagert. Die Kiste hatte eine Stirnfläche von $40 \times 40 \mathrm{~cm}$ und eine Tiefe von $60 \mathrm{~cm}$. Die Pendelkiste war mit schweren Papierlagen befüllt und an der Stirnseite mit einer Holzfaserplatte verschlossen. Auf der Holzfaserplatte wurde vor jedem Schuss ein Blatt Papier angebracht, um den Treffpunkt im Pendel nachvollziehen zu können. 
Die Rückseite der Pendelkiste wurde nach jedem Schuss kontrolliert und wurde während der gesamten Versuchsreihe nicht durchschlagen. Das Pendel wurde also nicht durchschossen (Kap 5.1.).

Der Pendelausschlag wurde folgendermaßen gemessen:

An dem Pendel war ein Nylonfaden verknotet. Das andere, freie Ende des Fadens wurde durch eine Öse an der Zielhalterung geführt. Direkt unter dieser Öse saß dem gespannten Faden eine Wäscheklammer als Fadenreiter lose auf.

Beim Ausschlag des Pendels - zunächst von der Zielhalterung weg - zog sich nur der Faden durch die Öse, die Klammer wurde von der Öse zurückgehalten.

Im Anschluss und nach Ausschwingen des Pendels wurde die Strecke zwischen Öse und verschobenem Fadenreiter ausgemessen. Diese Strecke entsprach dem maximalen Pendelausschlag.

Zur Pendelkalibrierung wurde Munition mit verschiedenen Ladungen verschossen. Das Pendelgewicht betrug bei Versuchsbeginn und bei Versuchsende $\sim 37,3 \mathrm{~kg}$. Das Gewicht der Geschosse, die von dem ballistischen Pendel aufgenommen wurden, kann man unbeachtet lassen.

\subsubsection{Sicherheitskugelfang}

Als Sicherheitskugelfang hinter dem ballistischen Pendel diente ein Raum, in dem in Verlängerung der Ziellinie eine Holzkiste $(0,80 \times 0,80 \times 3,50 \mathrm{~m})$ stand, welche mit Papierlagen und Reißwolle gefüllt war (Kap. 5.1.). Der Kellerraum endete an der Hinterseite mit einer Ziegelwand. Hinter der Ziegelwand begann das Erdreich.

\subsection{Munition}

\subsubsection{Kaliber .223 Rem}

Die Patrone mit randloser Hülse und Zentralfeuerzündung hat einen Stoßbodendurchmesser von 9,60 mm. Vor dem Ausziehring weist die Hülse einen Durchmesser von 9,58 mm auf, der sich bis zur Hülsenschulter auf 9,00 mm verjüngt. In der Hülsenschulter fällt der Durchmesser innerhalb 3,03 mm von 9,00 mm auf $6,43 \mathrm{~mm}$ und bleibt dann bis zum Hülsenmund konstant. Die Hülse misst in ihrer Gesamtlänge 44,70 mm.

Patronen sollten folgende geschossabhängige Gesamtlängen nicht überschreiten (DYNAMIT NOBEL 1998):

Voll-Mantel-Flach Geschoss (2,6 g): Patronenlänge 52,0 mm

Voll-Mantel-Spitz Geschoss (3,0 g): Patronenlänge 53,5 mm

Voll-Mantel-Spitz Geschoss (3,2 g): Patronenlänge 54,8 mm. 
Gemäß Anlage III der 3. Waffenverordnung zum Waffengesetz der BRD sind unter anderem vorgeschrieben:

Max. zulässiger Gebrauchsgasdruck: 3700 bar

Max. Verschlussabstand: 0,10 mm

Drall-Länge: 0,305 m

Min. Felddurchmesser: $5,56 \mathrm{~mm}$

Min. Zugdurchmesser: 5,69 mm

Geschossdurchmesser: $5,70 \mathrm{~mm}$.

\subsubsection{Kaliber .222 Rem}

Die Patrone mit randloser Hülse und Zentralfeuerzündung hat einen Stoßbodendurchmesser von 9,60 mm. Vor dem Ausziehring weist die Hülse einen Durchmesser von 9,59 mm auf, der sich bis zur Hülsenschulter auf 9,07 mm verjüngt. In der Hülsenschulter fällt der Durchmesser innerhalb 3,12 $\mathrm{mm}$ von 9,07 $\mathrm{mm}$ auf $6,43 \mathrm{~mm}$ und bleibt dann bis zum Hülsenmund konstant. Die Hülse misst in ihrer Gesamtlänge 43,18 mm.

Patronen sollten folgende geschossabhängige Gesamtlängen nicht überschreiten (DYNAMIT NOBEL 1998):

Voll-Mantel-Flach Geschoss (2,6 g): Patronenlänge 50,0 mm

Voll-Mantel-Spitz Geschoss (3,0 g): Patronenlänge 51,4 mm

Voll-Mantel-Spitz Geschoss (3,2 g): Patronenlänge 53,0 mm.

Gemäß Anlage III der 3. Waffenverordnung zum Waffengesetz der BRD sind unter anderem vorgeschrieben:

Max. zulässiger Gebrauchsgasdruck: 3200 bar

Max. Verschlussabstand: 0,15 mm

Drall-Länge: 0,356 m

Min. Felddurchmesser: $5,56 \mathrm{~mm}$

Min. Zugdurchmesser: 5,69 mm

Geschossdurchmesser: $5,70 \mathrm{~mm}$.

\subsubsection{Wiederladetechnik}

Für unsere Versuche wurden Munitionsreihen laboriert, die sich in ihrer Mündungsgeschwindigkeit stark unterschieden ( $115 \mathrm{~m} / \mathrm{s}$ bis $\sim 1575 \mathrm{~m} / \mathrm{s})$. Die Patronenhülsen können nach Gebrauch und nach Rekalibrierung wiederholt benutzt werden. Dafür wurden Pulver wieder neu verfüllt und Zündhütchen sowie Geschoss wieder neu verpresst. 
Wenn gebrauchte Hülsen verwendet wurden, mussten diese zunächst gereinigt werden. Mit einer Kalibriermatrize (Photo 8 li.) des entsprechenden Kalibers wurden die gefetteten Hülsen dann insbesondere im Bereich des aufgeweiteten Hülsenhalses auf ihr Idealmaß gepresst. Gleichzeitig stieß ein zentrierter Stift das verbrauchte Zündhütchen aus. Die so rekalibrierte Hülse wurde dann in ihrer Gesamtlänge kontrolliert und überschüssiges Material im Bereich des Hülsenmundes mit einem Hülsentrimmer abgedreht (Photo 9). Der Hülsenmund wurde entgratet, mit Graphit bestäubt und dann gebürstet, was das spätere Geschosssetzen erleichterte. Danach wurde ein neues Zündhütchen in die Zündglocke gesetzt. Dabei wurde zur Sicherheit eine Schutzbrille getragen. Eine mit einer Pulverwaage (Photo 10) auf $\pm 0,0065 \mathrm{Gramm}$ abgewogene Treibladung gewünschter Art und Menge wurde in die Hülse gefüllt. Nach dem Einsetzen des Geschosses in den Hülsenmund mittels einer Setzmatrize (Photo 8 re.) und der Ladepresse (Photo 11) wurde die Munition mit den relevanten Ladedaten beschriftet und sicher verwahrt (Photo 12).

\subsubsection{Laborierung der Munition}

Anhand überprüfter Ladedaten wurde eine „Anfangsladung“ errechnet, die bei offensiven Pulvern ca. $10 \%$ unter der Maximal-Ladung, bei progressiven ca. $5 \%$ unter der Maximal-Ladung liegt. Durch stufenweise Veränderung der Menge einer Treibladung haben wir uns an die jeweils erforderlichen Laborierungen herangearbeitet, wobei die Hülsen und Zündhütchen auf Zeichen des maximal zulässigen Gasdruckes kontrolliert wurden.

Die einzelnen Laborierungen wurden mit dem Programm QuickLOAD (Kap. 3.2.7) überprüft. Ein entsprechendes Datenblatt für die Laborierungen 223.5 (s.u.) ist im Anhang aufgeführt (Kap. 7.7.).

Die Munition des Kalibers .223 Rem wies folgende Merkmale auf:

Hülse: $\quad$.223 Remington, Hersteller PMP, Los.-Nr. LOT 143

Geschosse: $\quad$ 5,70 mm VMJ 3,0 g, Hersteller RWS, Los.-Nr. 82063;

5,70 mm Solid-B.T. 2,916 g, Barnes, 1853-1 Los-Nr. 00/12/00 ND;

Typ 1 (Sand, 0,324 g); Typ 2 (Messingspäne, 0,454 g); Typ 3 (Holzdübel, 0,259 g)

Zündhütchen: 4,45 mm Amboss Sinoxid, Hersteller RWS, Art.-Nr. 4033.

Die Munition des Kalibers .222 Rem wies folgende Merkmale auf:

Hülse: $\quad$.222 Remington, Hersteller PMP, Los.-Nr. LOT 013

Geschosse: $\quad 5,70$ mm Zoll Solid-B.T. 2,916 g, Barnes, 1853-1 Los-Nr. 00/12/00 ND; Typ 1 (Sand, 0,324 g)

Zündhütchen: $\quad 4,45$ mm Amboss Sinoxid, Hersteller RWS, Art.-Nr. 4033. 


\begin{tabular}{|c|c|c|c|c|}
\hline & $\begin{array}{l}\text { Geschosstyp } \\
\text { (Kap. 3.2.5.) }\end{array}$ & $\begin{array}{c}\text { Pulver } \\
\text { (Kap. 3.2.6.) }\end{array}$ & Pulvermasse [g] & $\begin{array}{l}\text { Patronenlänge } \\
\text { [mm] }\end{array}$ \\
\hline 223.1 & RWS VMJ $(3,0 \mathrm{~g})$ & N330 & 0,15 & 53,50 \\
\hline 223.2 & RWS VMJ $(3,0 \mathrm{~g})$ & N110 & 0,40 & 53,50 \\
\hline 223.3 & RWS VMJ $(3,0 \mathrm{~g})$ & N110 & 0,55 & 53,50 \\
\hline 223.4 & RWS VMJ $(3,0 \mathrm{~g})$ & N120 & 1,00 & 53,50 \\
\hline 223.5 & RWS VMJ $(3,0 \mathrm{~g})$ & N120 & 1,30 & 53,50 \\
\hline 223.6 & RWS VMJ $(3,0 \mathrm{~g})$ & N110 & 1,35 & 53,50 \\
\hline 223.7 & RWS VMJ $(3,0 \mathrm{~g})$ & N130 & 1,66 & 53,50 \\
\hline 223.solid & Barnes Solid-BT $(2,916 \mathrm{~g})$ & N130 & 1,555 & 53,50 \\
\hline 223.sand & Typ $1(0,324 \mathrm{~g})$ & N110 & 0,40 & 53,50 \\
\hline 223.mess & Typ $2(0,454 \mathrm{~g})$ & N110 & 0,40 & 53,50 \\
\hline 223.holz & Typ $3(0,259 \mathrm{~g})$ & N110 & 0,40 & 53,50 \\
\hline 222.solid & Barnes Solid-BT $(2,916 \mathrm{~g})$ & N120 & 20,00 & 54,10 \\
\hline 222.sand & Typ $1(0,324 \mathrm{~g})$ & N120 & 20,00 & 54,10 \\
\hline
\end{tabular}

Tab. 3.2.4.: Laborierung der Munition

Für die Schüsse s-64 bis s-67 wurde Munition der Firma PMC mit der Los-Nr. LOT 017 mit Vollmantelgeschoss $(3,56 \mathrm{~g})$ verschossen.

Die Munition des Kalibers .22 Ir (s-171 - s-190) wies folgende Merkmale auf:

„Swartklip High Velocity“ Patronen der Firma SABS mit der Los-Nr. 158541 und Bleigeschoss $(2,592 \mathrm{~g})$.

\subsubsection{Verwendete Geschosse}

Für die vorliegende Arbeit wurden sieben verschiedene Geschosse verwendet:

1) RWS-Vollmantelspitzgeschoss (Photo 13 I.), Bleikern $(3,0 \mathrm{~g})$

2) Barnes Solid (Photo 13 2.v.l.), massives Messinggeschoss (2,916 g)

3) Geklebtes Sandgeschoss (Photo $13 \mathrm{~m}$.), selbst hergestellt $(0,324 \mathrm{~g})$

4) Geklebtes Messinggeschoss (Photo 13 2.v.r.), selbst hergestellt $(0,454 \mathrm{~g})$

5) Holzdübel (Photo $13 \mathrm{r}$.) auf $5,70 \mathrm{~mm}$ gedreht, selbst hergestellt $(0,259 \mathrm{~g})$

6) SABS-Bleigeschoss $2,6 \mathrm{~g}(2,592 \mathrm{~g})$

7) PMC-Vollmantelspitzgeschoss, Bleikern (3,56 g).

Entfernt man in kühler Umgebung ein Fabrikgeschoss aus zuvor erstarrtem Paraffin, kann der Abdruck als Gießkokille für Zwei-Komponenten-Kleber (Pattex-Stabilit) und Zusatz dienen. 
Die geklebten Geschosse wurden aus Klebstoff und Sand (bzw. Klebstoff und Messingspänen) in solchen Wachsmatrizen (Photo 14) ausgehärtet. Die so passend kalibrierte Klebstoffmasse wird nach wenigen Minuten fest und kann durch erneutes Schmelzen des Paraffins leicht entnommen werden.

Geschosstyp 3 bestand aus „Pattex-Stabilit“ (Endfestigkeit bis $25 \mathrm{~N} / \mathrm{mm}^{2}$ und gesiebtem Sand im Volumenverhältnis 1:1.

Geschosstyp 4 bestand aus „Pattex-Stabilit“ und gemahlenen Messingspänen im Volumenverhältnis 1:1.

Geschosstyp 5 war ein auf den Durchmesser von 5,70 mm gedrehter $15 \mathrm{~mm}$ langer Holzdübel (ursprünglicher Durchmesser war zunächst $6 \mathrm{~mm}$ ).

\subsubsection{Treibmittel}

Als zulässige Obergrenzen (VIHTAVUORI 1998) der Ladedaten für die verwendeten Pulver gelten für das Kaliber .223 und ein 2,916 g Geschoss:

„N120: max.: 23.5 gr. ( 3463 fps)”

"Anfangsladung: 21.7 gr. ( 3187 fps)“

"N130: max.: 25.6 gr. ( 3511 fps)"

"Anfangsladung: 23.5 gr. ( 3235 fps)“ entspr. $1,523 \mathrm{~g}$ und $\sim 1055 \mathrm{~m} / \mathrm{s}$ entspr. $1,406 \mathrm{~g}$ und $\sim 971 \mathrm{~m} / \mathrm{s}$

entspr. $1,659 \mathrm{~g}$ und $\sim 1070 \mathrm{~m} / \mathrm{s}$ entspr. $1,523 \mathrm{~g}$ und $\sim 986 \mathrm{~m} / \mathrm{s}$.

Als zulässige Obergrenzen (VIHTAVUORI 1989) der Ladedaten für die verwendeten Pulver gelten für das Kaliber .222 und ein 2,916 g Geschoss:

„N110: max.: 15.4 gr. ( 3008 fps)”

„Anfangsladung: 13.6 gr. ( 2781 fps)“

„N120: max.: 20.7 gr. ( 3257 fps)”

"Anfangsladung: 19.3 gr. ( 3035 fps)“

"N130: max.: 23.2 gr. ( 3340 fps)"

"Anfangsladung: 21.8 gr. ( 3120 fps)“ entspr. 0,998 g und $\sim 917 \mathrm{~m} / \mathrm{s}$

entspr. $0,881 \mathrm{~g}$ und $\sim 848 \mathrm{~m} / \mathrm{s}$

entspr. $1,341 \mathrm{~g}$ und $\sim 993 \mathrm{~m} / \mathrm{s}$

entspr. $1,251 \mathrm{~g}$ und $\sim 925 \mathrm{~m} / \mathrm{s}$

entspr. $1,503 \mathrm{~g}$ und $\sim 1018 \mathrm{~m} / \mathrm{s}$

entspr. 1,413 g und $\sim 951 \mathrm{~m} / \mathrm{s}$.

Verwendet wurden Pulver der Firma Vihtavuori mit folgenden Los-Nummern:

N330: 325/99, 00165, 27.06.2000; N110: 520/01, 02742, 02.01.2002; N120: 304/99, 02034, 26.09.2001; N130: 515/01, 00924, 22.10.2001.

Die Treibladungspulver wurden entsprechend den Sicherheitsvorschriften (Kap. 5.1.) in einem unbewohnten Nebengebäude aufbewahrt.

\subsubsection{Computerprogramm QuickLOAD}

Die Ladedaten wurden mit dem Programm QuickLOAD überprüft. Das Programm eignet sich als Orientierungshilfe bei der Laborierungsentwicklung.

Das Programm war auf den Autor lizenziert und liegt in der Version 2.9 Build 108 (Jahr 2002) vor. Es wurde direkt von Dipl.-Ing. H. Brömel, Neubrücker Weg 15, 64832 
Babenhausen bezogen. Für die verwendete Laborierung 223.5 ist ein Datenblatt im Anhang (Kap. 7.7.) aufgeführt.

\subsection{Versuchswaffen}

\subsubsection{Repetierbüchse Savage 10 FP (.223 Rem)}

Eingesetzt wurde die Repetierbüchse (Photo 4) der Marke Savage, Modell Savage 10/110 FP Tactical des Kalibers .223 Rem mit der Waffennummer F945308. Das Gewehr wiegt $3,40 \mathrm{~kg}$, ist 1,15 m lang und hat einen Lauf von 0,61 m Länge bei einer Dralllänge von 0,305 m. Auf einer Weaver-Schiene wurde das Propoint PDP3 von Tasco flach über dem Lauf verschraubt (Kap. 3.1.4.). Alle Patronen des Kalibers .223 wurden mit dieser Versuchswaffe verschossen.

$\rightarrow$ www.savagearms.com (Savage Arms, Inc., Road, Westfield, MA 01085, USA).

\subsubsection{Kipplaufbüchse $C Z$ (.222 Rem)}

Eingesetzt wurde die Kipplaufbüchse (Photo 5) der Marke CZ (Česká Zabrojovka Brno A.S.), Modell Brünner ZBK des Kalibers .222 Rem mit der Waffennummer 010509 und offener Visierung. Das Gewehr wiegt 2,70 kg, ist 1,04 m lang und hat einen Lauf von $0,60 \mathrm{~m}$ Länge bei einer Drallänge von $0,356 \mathrm{~m}$. Aufgrund seines robusten Verschlusses (Laufhaken mit Keilverriegelung) und des niedrigen Anschaffungswertes wurde die Kipplaufbüchse im Bereich des zulässigen Maximaldruckwertes und der laufverschmierenden Geschosse eingesetzt. Alle Patronen des Kalibers .222 wurden mit dieser Versuchswaffe verschossen.

$\rightarrow$ www.czub.cz (Zabrojovka Brno A.S., Lazaretni 7, 65617 Brno, Czech Republic).

\subsubsection{Kleinkarabiner Krico (.22 Ir)}

Zur Verfügung stand eine Repetierbüchse (Photo 6) der Marke Kriegeskorte \& Co, Modell Krico des Kalibers 22 Ir mit der Waffennummer 334405 und offener Visierung. Das Gewehr wiegt 2,90 kg, ist 1,12 m lang und hat einen Lauf von 0,61 m Länge. Die Kalibrierung der Geschwindigkeitsmessgeräte (Kap. 3.5.1.) wurde mit ihr durchgeführt. Alle Patronen des Kalibers .22 Ir „Swartklip High Velocity“ der Firma SABS wurden mit dieser Versuchswaffe verschossen.

$\rightarrow$ (Krico Jagd- und Sportwaffen GmbH, Nürnberger Straße 6, D-90602 Pyrbaum). 


\subsection{Versuchsziele}

\subsubsection{Gelatineblöcke (Bloom 250, Typ A)}

Es wurde 10-prozentige Industrie-Gelatine (250 Bloom, Typ A-Schweinegelatine, Körnung 20/60) mit Zusatz von Thymol verwendet. Bezogen wurde die Gelatine von der Firma Hellmann ( $\rightarrow$ Hellmann $\mathrm{GmbH}$, Martinstrasse 5, 87700 Memmingen, Art.-Nr. 25002).

Bei der Herstellung wurde darauf geachtet, die Gelatine mit zunächst kaltem Wasser anzusetzen und das Gemisch einige Stunden quellen zu lassen. Nach mindestens 2 Stunden wurde der Ansatz in einem Wasserbad (nicht über $40^{\circ} \mathrm{C}$ ) bis zur vollständigen Lösung leicht erwärmt und wenig gerührt. Die Gelatinelösung wurde in Formen (30 x $40 \times 15 \mathrm{~cm}$ ) gegossen und bis zur Erstarrung bei $10^{\circ} \mathrm{C}$ gekühlt. Nach Entnahme aus der Form wurde die Gelatine in zwei gleiche Blöcke $(15 \times 40 \times 15 \mathrm{~cm})$ geschnitten und zum Schutz vor Austrocknung in Folie verpackt. Die Blöcke wurden bis zum Beschuss für mindestens $24 \mathrm{~h}$ bei $10^{\circ} \mathrm{C}$ weiter gekühlt (Kap. 4.1.6. u. Kap. 5.2.1.3.).

\subsubsection{Wassercontainer}

Für die vorliegende Arbeit wurden Container in den folgenden Maßen beschossen:

- Typ a $(0,085 \times 0,085 \times 0,055 \mathrm{m:} 0,4 \mathrm{I})$

- Typ b $(0,10 \times 0,086 \times 0,086 \mathrm{m:0} 0,74 \mathrm{I})$

- Typ c $(0,18 \times 0,09 \times 0,09 \mathrm{m:} 1,46 \mathrm{I})$

- Typ d (Flasche: $1,5 \mathrm{I})$

- Typ e $(0,15 \times 0,13 \times 0,10 \mathrm{m:} 1,95 \mathrm{I})$

- Typ $\mathrm{f}(0,17 \times 0,14 \times 0,10 \mathrm{~m}: 2,38 \mathrm{l})$

- Typh $(0,315 \times 0,22 \times 0,17 \mathrm{~m}: 11,78 \mathrm{I})$.

Die Wände von Typ a bis Typ c bestanden aus Polystyrol (PS) und waren < 0,001 m stark. Die Wände von Typ d bis Typ h bestanden aus Polyethylenterephthalat (PET).

Für die Schüsse s-131 bis s-170 wurden Plastikbeutel in Halterungen (Innenmaß 0,12 x 0,12 $\mathrm{m} \times$ variierende Tiefe) gespannt und befüllt. Die Halterungen bestanden aus $0,15 \times 0,15 \times 0,015 \mathrm{~m}$ Styroporplatten und Holzstäben. Die Container waren mit Leitungswasser $\left(20^{\circ} \mathrm{C}\right)$ gefüllt. 


\subsubsection{Stickstoffcontainer}

Container in den folgenden Maßen wurden beschossen:

- Typ b $(0,10 \times 0,086 \times 0,086 \mathrm{m:} 0,74 \mathrm{I})$

- Typ c $(0,18 \times 0,09 \times 0,09 \mathrm{m:} 1,46 \mathrm{I})$

- Typ e $(0,15 \times 0,13 \times 0,10 \mathrm{~m}: 1,95 \mathrm{I})$

- Typ g (Eimer: $5 \mathrm{I})$.

Die Wände von Typ b und Typ c bestanden aus Polystyrol (PS) und waren $<0,001 \mathrm{~m}$ stark. Die Wände von Typ e und Typ g bestanden aus Polyethylenterephthalat (PET).

Für die Schüsse s-131 bis s-170 wurden Plastikbeutel in Halterungen (Innenmaß 0,12 x 0,12 $\mathrm{m} \times$ variierende Tiefe) gespannt und befüllt. Die Halterungen bestanden aus 0,15 x 0,15 x 0,015 m Styroporplatten und Holzstäben. Die Container waren mit flüssigem Stickstoff $\left(-197^{\circ} \mathrm{C}\right)$ gefüllt.

\subsubsection{PVC-Hartschaumplatten und Rigips-Platten}

Als Versuchsziele kamen "Creativ-Hartschaumplatten“ aus PVC (Palight Dichte: 0,055 $\mathrm{g} / \mathrm{mm}^{3}$, Schlagzähigkeit bei $23^{\circ} \mathrm{C}: 34 \mathrm{~J}$, Fallgewicht $25 \mathrm{~mm}$ Stahlkugel: bei $0^{\circ} \mathrm{C} 20 \mathrm{~J}$, bei $-10^{\circ} \mathrm{C} 8 \mathrm{~J}$, Druckfestigkeit $9,4 \mathrm{MPa}$ ) in der Abmessung von $10 \times 10 \times 0,3 \mathrm{~cm}$ zum Einsatz. Jeweils zwei Platten wurden im Abstand von $0,7 \mathrm{~cm}$ parallel montiert und im $90^{\circ}$-Winkel orthograd beschossen.

Hinter den beiden Platten befand sich im Abstand von $0,7 \mathrm{~cm}$ ein Gelatineblock (10 $\mathrm{x}$ 10 x $10 \mathrm{~cm}$, Typ-A, 250 Bloom), der die Geschossfragmente aufnahm.

Außerdem wurden Rigips-Platten beschossen. Rigips-Platten bestehen aus einem Gipskern, welcher mit Karton ummantelt ist. Die Platten haben eine Nenndicke von $0,95 \mathrm{~cm}$ und Maßtoleranzen von $\pm 0,5 \mathrm{~mm}$. Der Hersteller gibt eine Rohdichte von ca. > $660 \mathrm{~kg} / \mathrm{m}^{3}$ und ein Flächengewicht von ca. $>6,3 \mathrm{~kg} / \mathrm{m}^{2}$ an.

\subsubsection{Schlachttierteile}

Es wurden zwei Schlachttierteile beschossen. Die längsgeteilten Schweineköpfe wurden in einer Fleischerei erworben. 


\subsubsection{Melonen (Cucumis melo)}

Es wurden Melonen (Cucumis melo) mit einer Temperatur von $21^{\circ} \mathrm{C}$ und unterschiedlichen Massen (0,87 - 1,20 kg) beschossen.

Die Schallgeschwindigkeit in Melonen wurde bestimmt, indem Laufzeitmessungen ausgewertet wurden. Verwendet wurden Ultraschallwandler der Firma Panametrics und ein Oszilloskop. Mit einem Pulsgenerator wurde ein Signal gesetzt und dann gemessen, wie lange es für die definierte Strecke durch eine Melonenscheibe benötigte. Der Puls schwächte sich durch Dämpfung stark ab und verbreitete sich durch Dispersion. Die gemessene Schallgeschwindigkeit lag zwischen 500 und 1000 $\mathrm{m} / \mathrm{s}$.

\subsection{Kalibrierung und Laborierung}

\subsubsection{Kalibrierung der Geschwindigkeitsmessgeräte}

Zur Kalibrierung und ersten Kontrolle der drei elektronischen Geschwindigkeitsmesser (Chrony A-B-C) wurden sie hintereinander in der Versuchszielhalterung positioniert und überschossen. Als Munition kam das kleinere Kaliber $.22 \mathrm{Ir}$ mit der entsprechenden Munition (.22Ir "Swartklip High Velocity“ Patronen der Firma SABS mit der Los-Nr. 158541) zum Einsatz.

Die Ergebnisse wurden nach jedem Schuss dokumentiert (Kap. 4.1.1.). Der Geschwindigkeitsmesser Chrony A, der in seinen Ergebnissen am meisten von den beiden anderen: Chrony $B$ und Chrony $C$, abwich, wurde nicht weiter verwendet.

Anschließend wurden Chrony 1 (zuvor B) und 2 (zuvor C) in der Zielhalterung mit Munition der Laborierung 223.1 (s-121 bis s-130) überschossen. Der Geschwindigkeitsverlust der Geschosse über eine Strecke von 1,40 m in Luft wurde gemessen (Kap. 4.1.2.).

\subsubsection{Laborierungsentwicklung}

Der Empfehlung aus der Dissertation von KLATT (1996) wurde gefolgt, indem für die Laborierung niedriger $v_{0}$ von der Standardlaborierung ausgehend absteigende Ladungsreihen erstellt wurden. Für hohe $v_{0}$ wurden unter Berücksichtigung des maximal zulässigen Gebrauchsgasdruck (Kap. 3.2.1. und 3.2.2.) aufsteigende Ladungsreihen erstellt.

Statt des von KLATT (1996) favorisierten Vollmantelspitzgeschosses (3,24 g) ohne Bootsheck wurde eines mit noch geringerer Masse verwendet (VMS 3,0 g, Hersteller RWS, Los.-Nr. 2145847), um problemlos eine noch höhere Geschwindigkeit zu bewirken. Die leere Versuchszielhalterung wurde zur Laborierungsentwicklung durchschossen. Mit dem Chrony 1 wurde die jeweilige Geschossgeschwindigkeit $\left(v_{a}\right)$ 
im Abstand 2,60 $\mathrm{m}$ von der Laufmündung ermittelt. Mit dem Chrony 2 wurde die jeweilige Geschossgeschwindigkeit $\left(v_{\text {rst }}\right)$ im Abstand 4,00 $\mathrm{m}$ von der Laufmündung ermittelt. Jeweils 3 Schuss der Laborierungen 223.1, 223.5, 223.6, 223.7 wurden abgegeben, die Geschwindigkeiten $v_{a}$ und $v_{r s t}$ gemessen und die Standardabweichung der unterschiedlichen Laborierungen ermittelt (Kap. 4.1.3.).

In den Blenden der Versuchszielhalterung waren kurzfaserige Schießscheibenkartons angebracht. Bei rundem Durchschuss wurde auf eine stabile Flugbahn des

Geschosses rückgeschlossen. Die Aufnahmen der Hochgeschwindigkeitskamera bestätigten später den stabilen Geschossflug.

\subsubsection{Kalibrierung des ballistischen Pendels}

Um es zu eichen, wurde das Pendel ohne Zwischenziel beschossen. Die Ergebnisse wurden nach jedem Schuss dokumentiert (Kap. 4.1.5.).

Verschossen wurde Munition in der Laborierung 223.1, 223.5, 223.6, 223.7.

Bei demselben Geschossgewicht von jeweils 3,0 g wurde der Pendelausschlag als Funktion der Geschossgeschwindigkeit gemessen.

\subsection{Schussversuche und Sicherheit}

Unter besonderer Berücksichtigung der unter Kap. 5.1. diskutierten Sicherheitsaspekte wurden Schussversuche nur durchgeführt, wenn sich mindestens zwei und maximal vier Personen im dann verschlossenen ballistischen Labor aufhielten. Der Schießgang wurde nur betreten, wenn der Kammerverschluss offen sichtbar neben der Versuchswaffe lag oder die Kipplaufbüchse mit abgeknicktem Lauf geöffnet war.

Innerhalb der Arbeitsgruppe waren die Abläufe vor Schussauslösung standardisiert und wurden von allen Beteiligten stets angekündigt und bestätigt:

Vor dem Laden der Waffe hielten sich alle Beteiligten im sicheren Bereich des Aufenthaltsraumes auf, wo auch die Munition gelagert war. Zum Laden trat nur eine Person mit jeweils nur einer Patrone an das Gewehr und kündigte das Laden der Waffe an. Dann wurde das Entsichern der Waffe angekündigt und durchgeführt. Die Person, welche das Gewehr geladen hatte, ging daraufhin zurück in den sicheren Bereich des Aufenthaltsraumes. Bei Schüssen mit Kamerakontrolle wurde zu diesem Zeitpunkt die Lichtschranke aktiviert und bestätigt. Im Anschluss wurde der Schuss nochmals angekündigt. Nach Bestätigung des Signals durch alle Anwesenden wurde der Schuss ausgelöst.

Im ballistischen Labor war sowohl ein Festnetztelefon installiert als auch ein Mobiltelefon zum Absetzen eines eventuellen Notrufes aktiviert. Ein Erste-Hilfe-Kasten stand bereit und bei Schussauslösung wurden Gehörschutzkapseln getragen. Zudem waren die Mitarbeiter des Institutes durch Aushang über die Versuchsdurchführung informiert worden.

Alle Schussversuche sind tabellarisch im Anhang (Kap. 7.1.) aufgelistet. 


\section{Ergebnisse eigener Untersuchungen}

\subsection{Ergebnisse der Kalibrierung und Laborierung}

\subsubsection{Kalibrierung Chrony A-C mit Laborierung $.22 \mathrm{Ir}$}

Abgegeben wurden 10 Schüsse (s-181 - s-190) mit "Swartklip High Velocity“ Patronen der Firma SABS (Los-Nr. 158541) des Kalibers .22 Ir. Die Geschwindigkeit wurde von jeweils drei Geschwindigkeitsmessern registriert. So wurde der Chrony ermittelt, dessen Messwerte am stärksten von den beiden anderen abwichen. (hier Chrony A mit Standardabweichung $\left.s_{x}=4,577\right)$. Folgende Messergebnisse wurden erhoben:

\begin{tabular}{|c|c|c|c|}
\hline & $\begin{array}{l}\text { Anzeige Chrony A } \\
{[\mathrm{m} / \mathrm{s}]}\end{array}$ & $\begin{array}{c}\text { Anzeige Chrony B (1) } \\
{[\mathrm{m} / \mathrm{s}]}\end{array}$ & $\begin{array}{c}\text { Anzeige Chrony C (2) } \\
{[\mathrm{m} / \mathrm{s}]}\end{array}$ \\
\hline s-181 & 335 & 333 & 329 \\
\hline$s-182$ & 337 & 335 & 332 \\
\hline$s-183$ & 339 & 337 & 333 \\
\hline s-184 & 342 & 343 & 339 \\
\hline s-185 & 331 & 339 & 336 \\
\hline$s-186$ & 341 & 336 & 338 \\
\hline$s-187$ & 347 & 341 & 338 \\
\hline$s-188$ & 338 & 333 & 339 \\
\hline$s-189$ & 341 & 338 & 337 \\
\hline$s-190$ & 344 & 337 & 340 \\
\hline $\bar{x}$ & 339,5 & 337,2 & 336,1 \\
\hline $\mathbf{x}_{\mathrm{m}}$ & 340 & 337 & 337,5 \\
\hline $\mathbf{s}_{\mathrm{x}}$ & 4,577 & 3,225 & 3,604 \\
\hline
\end{tabular}

Tab. 4.1.1.: Kalibrierung Chrony A-C mit Laborierung .22 Ir

$\bar{x}=$ Mittelwert, $\mathrm{x}_{\mathrm{m}}=$ Median, $\mathrm{s}_{\mathrm{x}}=$ Standardabweichung

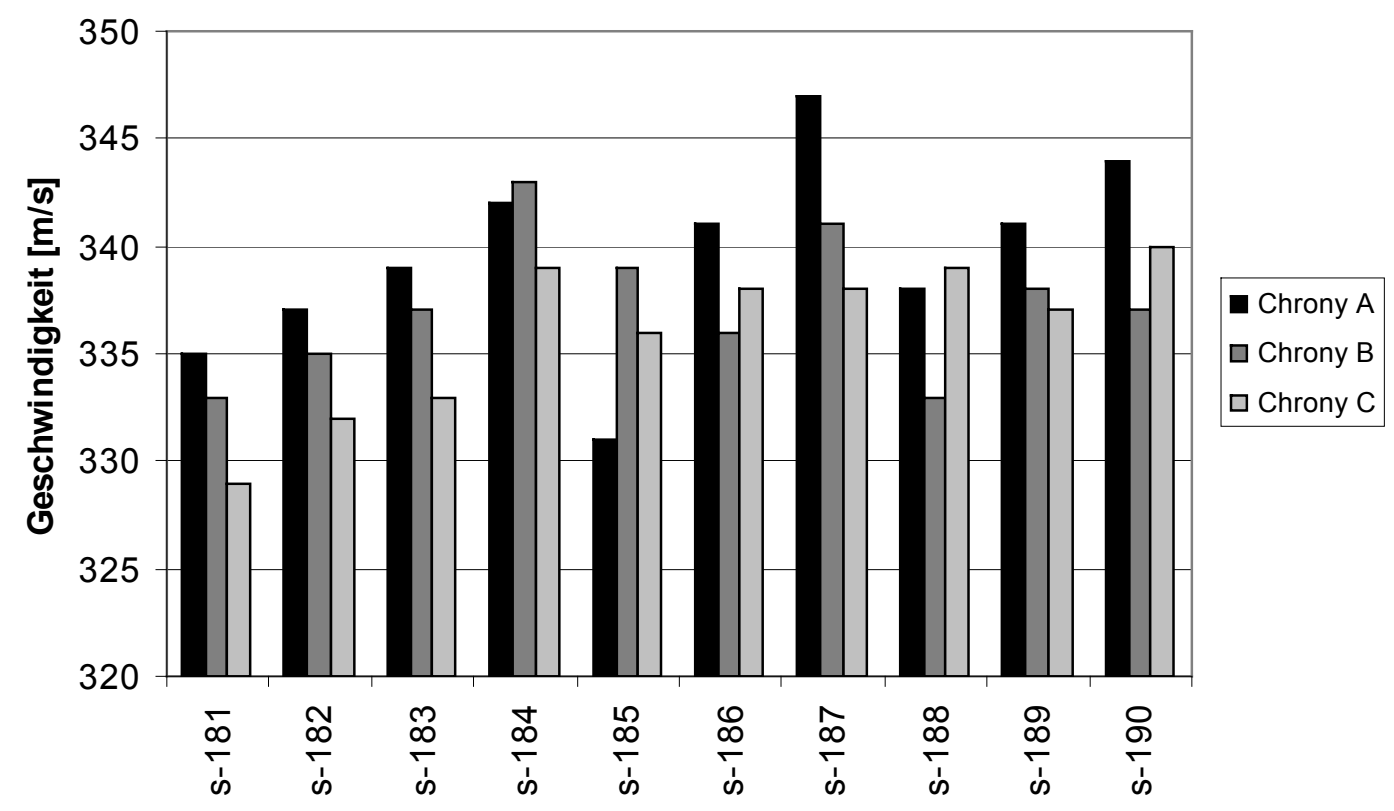

Graph 4.1.1.: Kalibrierung Chrony A-C mit Laborierung .22 Ir 
4.1.2. Kalibrierung Chrony 1 und 2 mit Laborierung 223.1

Über die in der Zielhalterung montierten Chronys 1 (B) und 2 (C) wurden je 10 Schüsse mit 223.1 abgegeben:

\begin{tabular}{|c|c|c|c|c|c|c|c|c|c|c|}
\cline { 2 - 9 } \multicolumn{1}{c|}{} & $\mathbf{s - 1 2 1}$ & $\mathbf{s - 1 2 2}$ & $\mathbf{s - 1 2 3}$ & $\mathbf{s - 1 2 4}$ & $\mathbf{s - 1 2 5}$ & $\mathbf{s}-126$ & $\mathbf{s}-127$ & $\mathbf{s}-128$ & $\mathbf{s}-129$ & $\mathbf{s}-130$ \\
\hline $\begin{array}{c}\text { Chrony 1 } \\
\mathbf{v}_{\mathbf{a}}\end{array}$ & $\begin{array}{c}128 \\
{[\mathrm{~m} / \mathrm{s}]}\end{array}$ & $\begin{array}{c}132 \\
{[\mathrm{~m} / \mathrm{s}]}\end{array}$ & $\begin{array}{c}128 \\
{[\mathrm{~m} / \mathrm{s}]}\end{array}$ & $\begin{array}{c}127 \\
{[\mathrm{~m} / \mathrm{s}]}\end{array}$ & $\begin{array}{c}132 \\
{[\mathrm{~m} / \mathrm{s}]}\end{array}$ & $\begin{array}{c}132 \\
{[\mathrm{~m} / \mathrm{s}]}\end{array}$ & $\begin{array}{c}130 \\
{[\mathrm{~m} / \mathrm{s}]}\end{array}$ & $\begin{array}{c}131 \\
{[\mathrm{~m} / \mathrm{s}]}\end{array}$ & $\begin{array}{c}128 \\
{[\mathrm{~m} / \mathrm{s}]}\end{array}$ & $\begin{array}{c}130 \\
{[\mathrm{~m} / \mathrm{s}]}\end{array}$ \\
\hline $\begin{array}{c}\text { Chrony 2 } \\
\mathbf{v}_{\mathbf{r s t}}\end{array}$ & $\begin{array}{c}126 \\
{[\mathrm{~m} / \mathrm{s}]}\end{array}$ & $\begin{array}{c}131 \\
{[\mathrm{~m} / \mathrm{s}]}\end{array}$ & $\begin{array}{c}127 \\
{[\mathrm{~m} / \mathrm{s}]}\end{array}$ & $\begin{array}{c}126 \\
{[\mathrm{~m} / \mathrm{s}]}\end{array}$ & $\begin{array}{c}132 \\
{[\mathrm{~m} / \mathrm{s}]}\end{array}$ & $\begin{array}{c}130 \\
{[\mathrm{~m} / \mathrm{s}]}\end{array}$ & $\begin{array}{c}129 \\
{[\mathrm{~m} / \mathrm{s}]}\end{array}$ & $\begin{array}{c}129 \\
{[\mathrm{~m} / \mathrm{s}]}\end{array}$ & $\begin{array}{c}126 \\
{[\mathrm{~m} / \mathrm{s}]}\end{array}$ & $\begin{array}{c}128 \\
{[\mathrm{~m} / \mathrm{s}]}\end{array}$ \\
\hline
\end{tabular}

Tab. 4.1.2.: Kalibrierung Chrony 1 und 2 mit Laborierung 223.1

$\bar{x}$ (Mittelwert) $=129,1 \mathrm{~m} / \mathrm{s}$,

$\mathrm{x}_{\mathrm{m}}($ Median $)=129 \mathrm{~m} / \mathrm{s}$

$\mathrm{s}_{\mathrm{x}}($ Standardabweichung $)=2,125 \mathrm{~m} / \mathrm{s}$

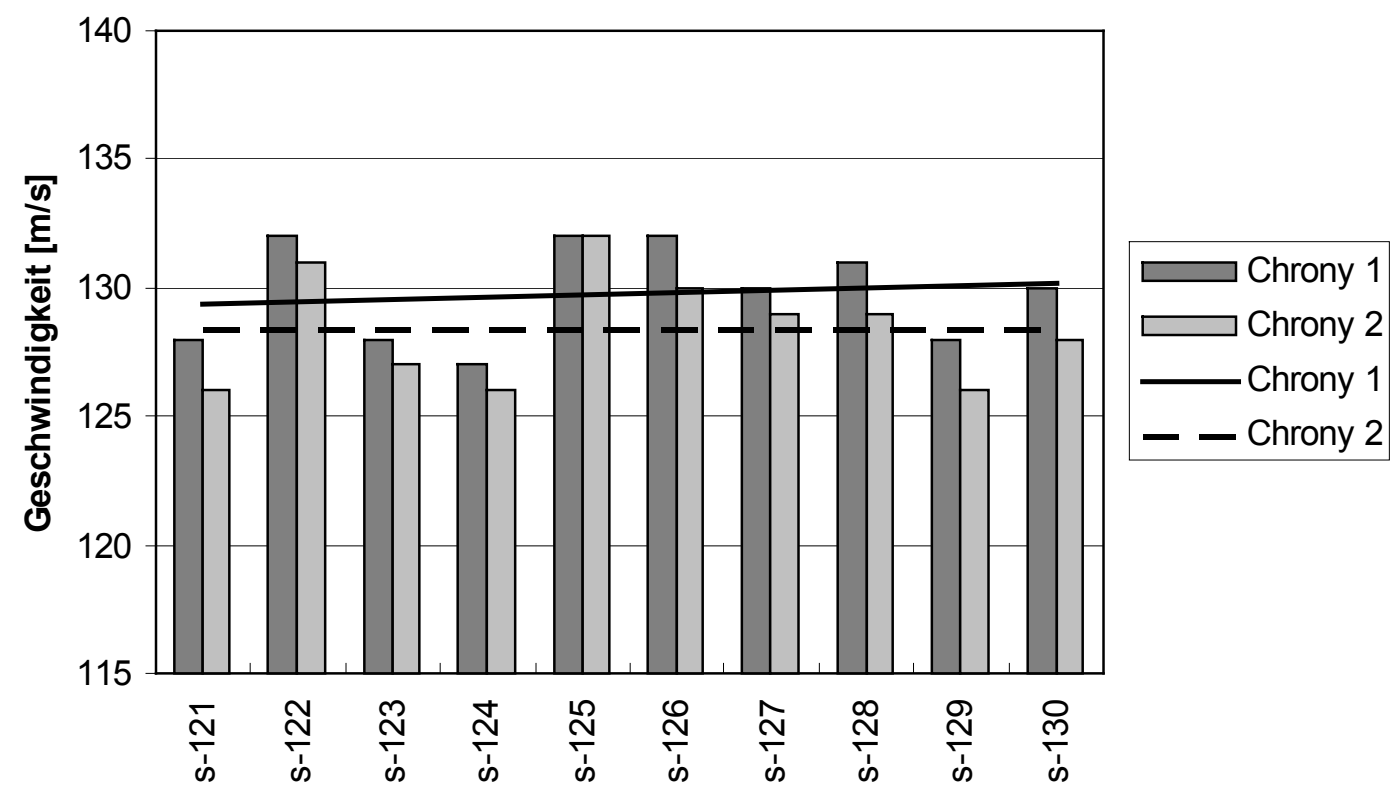

Graph 4.1.2.: Kalibrierung Chrony 1 und 2 mit Laborierung 223.1

Die Geschosse verloren während ihres Fluges an Geschwindigkeit. Der Geschwindigkeitsverlust innerhalb von 1,40 m wurde (Kap. 5.3.1.) berechnet. 1,40 m entspricht dem Abstand des Messpunktes der beiden baugleichen Chronygraphen 1 und 2. 
4.1.3. Kalibrierung der laborierten Munition

Es wurden Treibladungen 223.1 bis 223.7 mit zunehmender Geschossgeschwindigkeit laboriert. Jeweils drei Leerschüsse sind in der folgenden Tabelle zur Ermittlung der Standardabweichung der einzelnen Laborierungen zusammengefasst:

\begin{tabular}{|c|c|c|}
\cline { 2 - 3 } \multicolumn{1}{c|}{} & Chrony 1: $\mathbf{v}_{\mathbf{a}}[\mathbf{m} / \mathbf{s}]$ & Chrony 2: $\mathbf{v}_{\mathbf{r s t}}[\mathbf{m} / \mathbf{s}]$ \\
\hline \multirow{3}{*}{ Lab 223.1 } & 128 & 127 \\
\cline { 2 - 3 } & 127 & 126 \\
\cline { 2 - 3 } & 132 & 132 \\
\hline \multirow{3}{*}{ Lab 223.5 } & 932 & 927 \\
\cline { 2 - 3 } & 969 & 969 \\
\cline { 2 - 3 } & 926 & 922 \\
\hline \multirow{3}{*}{ Lab 223.6 } & 1077 & 1061 \\
\cline { 2 - 3 } & 1075 & 1080 \\
\cline { 2 - 3 } & 1080 & 1086 \\
\hline \multirow{3}{*}{ Lab 223.7 } & 1132 & 1144 \\
\cline { 2 - 3 } & 1107 & 1122 \\
\cline { 2 - 3 } & 1116 & 1119 \\
\hline
\end{tabular}

Tab. 4.1.3a.: Geschwindigkeit der laborierten Munition

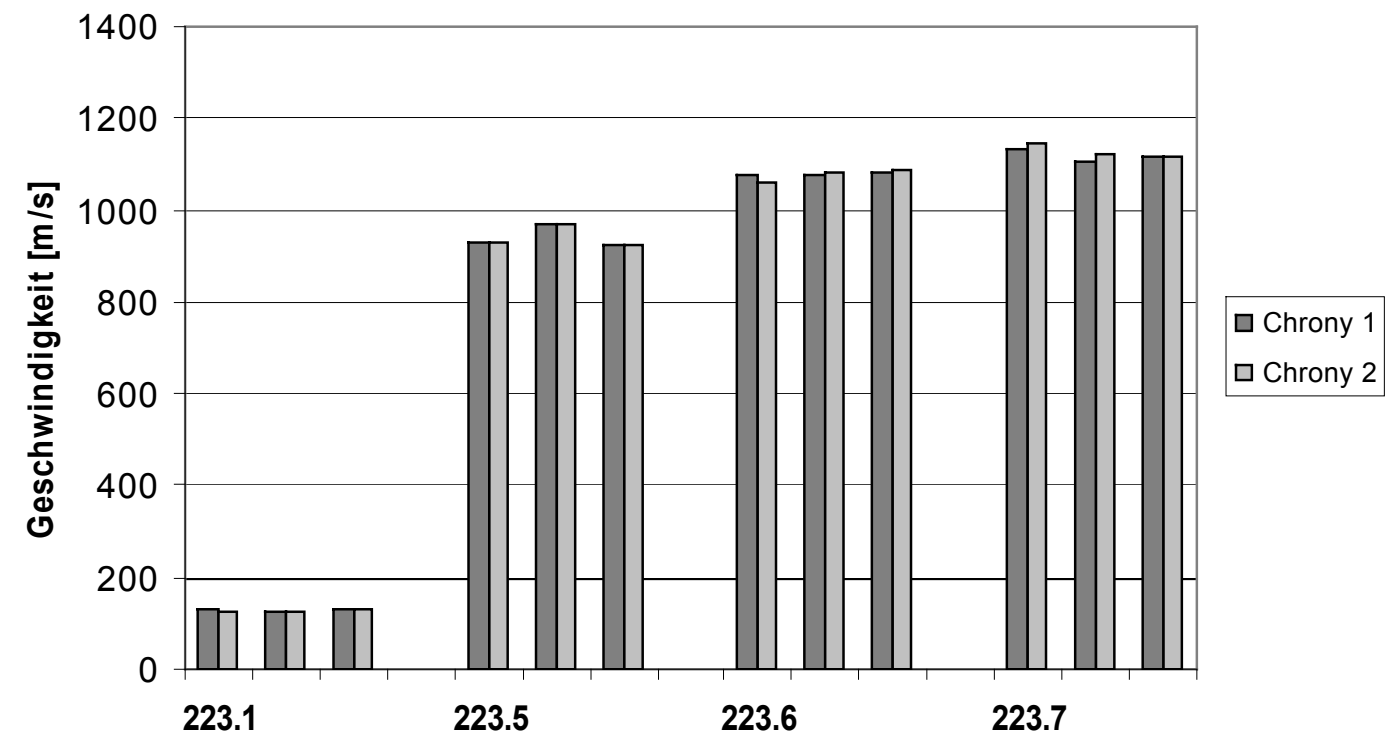

Graph 4.1.3.: Geschwindigkeit der laborierten Munition 
Die Standardabweichung der laborierten Munition 223.1, 223.5, 223.6, 223.7 wurde berechnet. Vergleichend wurde auch aus den Werten der Tab. 4.1.1. die Standardabweichung der Fabrikmunition ( $.22 \mathrm{Ir}$ ) berechnet.

\begin{tabular}{|c|c|c|c|c|c|}
\cline { 2 - 6 } \multicolumn{1}{c|}{} & $\mathbf{. 2 2} \mathbf{~ I r}$ & $\mathbf{2 2 3 . 1}$ & $\mathbf{2 2 3 . 5}$ & $\mathbf{2 2 3 . 6}$ & $\mathbf{2 2 3 . 7}$ \\
\hline $\mathrm{s}_{\mathrm{x}}$ & 3,376 & 2,658 & 22,049 & 8,456 & 12,987 \\
\hline $\bar{x}$ & $129,1[\mathrm{~m} / \mathrm{s}]$ & $128,7[\mathrm{~m} / \mathrm{s}]$ & $940,8[\mathrm{~m} / \mathrm{s}]$ & $1076,5[\mathrm{~m} / \mathrm{s}]$ & $1123,3[\mathrm{~m} / \mathrm{s}]$ \\
\hline $\mathrm{s}_{\mathrm{x}} / \bar{x}$ & 0,026 & 0,021 & 0,023 & 0,008 & 0,012 \\
\hline
\end{tabular}

Tab. 4.1.3b.: Standardabweichung der laborierten Munition 
4.1.4. Kalibrierung des elektrooptischen Systems
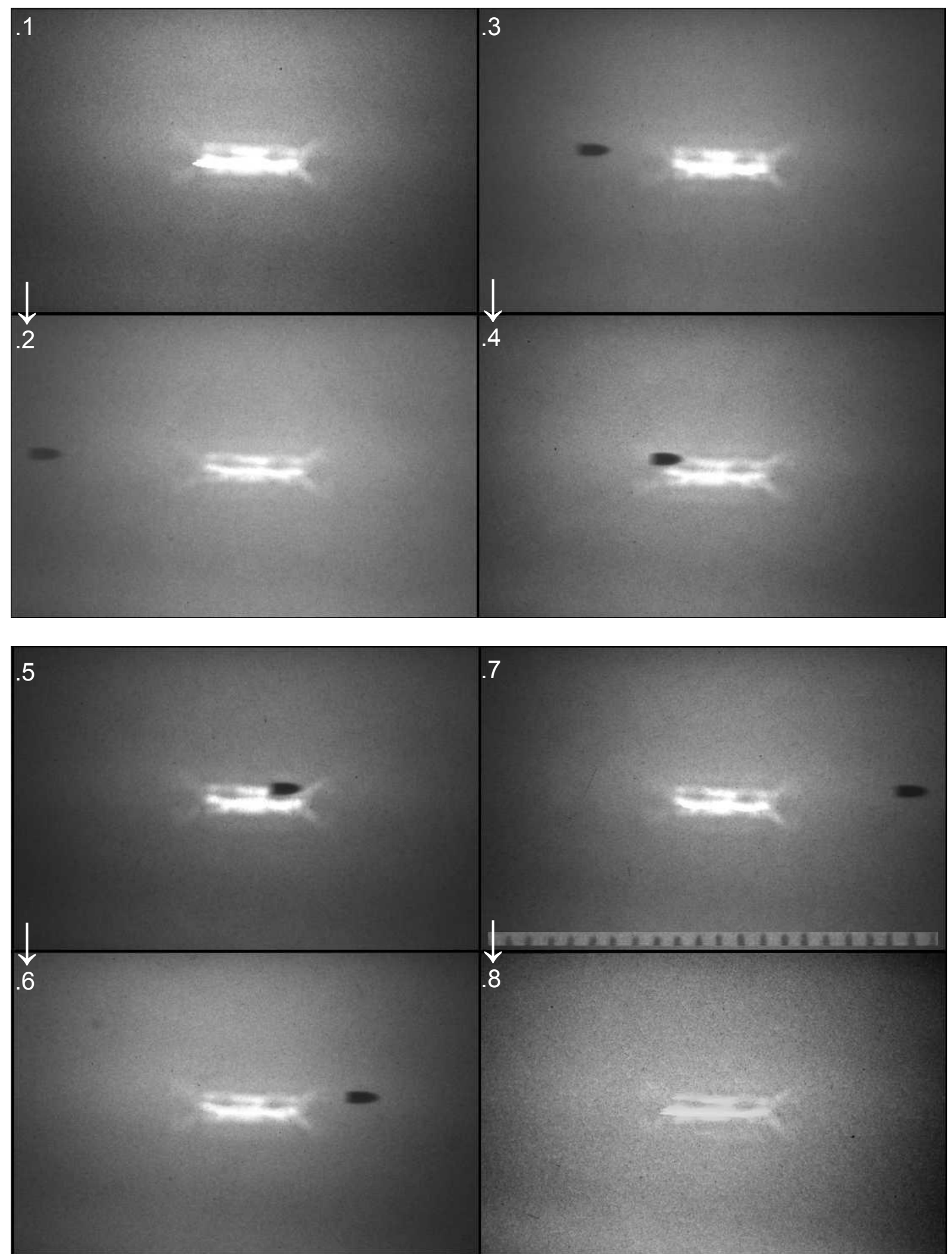

Photo s-01: Geschossdurchflug durch das Sichtfeld einer Hochgeschwindigkeitskamera. Im Hintergrund von Bild 1 bis Bild 8 die helle Wendel der 500 Watt Leuchte. 
zu Photo s-01: Geschoss: VMJ (3,0 g), Munition: 223.5, Ziel: Luft

$\begin{array}{lll}\text { Chrony 1: } & 932 & \mathrm{~m} / \mathrm{s} \\ \text { Chrony 2: } & 927 & \mathrm{~m} / \mathrm{s} \\ \text { Objektiv: } & 28 & \mathrm{~mm} \\ \text { Belichtungsdauer: } & 5 & \mu \mathrm{s} \\ \text { Zwischenbildzeit: } & 35 & \mu \mathrm{s}\end{array}$

$\begin{array}{lll}\text { Bild 1: } & 0 & \mu s \\ \text { Bild 2: } & 40 & \mu s \\ \text { Bild 3: } & 80 & \mu s \\ \text { Bild 4: } & 120 & \mu s \\ \text { Bild 5: } & 160 & \mu s \\ \text { Bild 6: } & 200 & \mu s \\ \text { Bild 7: } & 240 & \mu s \\ \text { Bild 8: } & 280 & \mu s\end{array}$

Alle Bildsequenzen sind mit der Schussnummer (hier s-01) und aufeinander folgend mit den einzelnen Bildnummern (hier s-01.1 bis s-01.8) markiert. In den unteren Teil von Bild 7 wurde nachträglich eine Maßskala eingefügt (Kap. 4.2.2.). Jeder Teilstrich steht für einen Zentimeter.

Beim Durchflug durch eine Lichtschranke wurde die Hochgeschwindigkeitskamera ausgelöst. Für die Bildsequenz wurden eine Belichtungszeit von $5 \mu$ und eine Zwischenbildzeit von $35 \mu$ s eingestellt. Das Geschoss des Kalibers .223 Rem ist auf Bild 2 bis Bild 7 zu sehen. Im Hintergrund von Bild 1 bis Bild 8 zeichnet sich die Wendel des 500 Watt Leuchtmittels hell ab (Kap. 3.1.6.).

Die Geschwindigkeitsmessgeräte Chrony 1 und Chrony 2 zeigten für s-01 eine Geschossgeschwindigkeit von $932 \mathrm{~m} / \mathrm{s}$ und $927 \mathrm{~m} / \mathrm{s}$. Aus den Laufstrecken der Bilder wurde hierzu in Folge vergleichend eine Geschossgeschwindigkeit (933 m/s) berechnet (Tab. 4.1.4.).

Die voneinander unabhängigen Messmethoden geben einen Eindruck davon, ob in einer Methode ein großer systematischer Fehler vorlag. Hierzu wurden 4 Schüsse auf die leere Zielhalterung abgegeben. Die Geschwindigkeitsberechnungen aus der elektrooptischen Aufzeichnung stimmen mit der Geschwindigkeitsmessung mittels der Chronygraphen 1 und 2 annähernd überein. Auch der Pendelausschlag ermöglicht es, eine Geschossgeschwindigkeit festzustellen (Kap. 4.1.5.):

\begin{tabular}{|c|c|c|c|}
\hline & Differenz [cm] & Zeitspanne [us] & $V_{3 \text { (Imacon) }[}[\mathrm{m} / \mathrm{s}]$ \\
\hline Bild s-01.2-3 & 3,70 & 40 & 925 \\
\hline Bild s-01.3-4 & 3,46 & 40 & 865 \\
\hline Bild s-01.4-5 & 4,06 & 40 & 1015 \\
\hline Bild s-01.5 -6 & 3,62 & 40 & 905 \\
\hline Bild s-01.6 - 7 & 3,86 & 40 & 965 \\
\hline$\sum$ Bild s-01.2-7 & 18,67 & 20 & 933 \\
\hline
\end{tabular}

Tab. 4.1.4a.: Geschossfront s-01

Chrony 1: $\quad 932 \mathrm{~m} / \mathrm{s}$

Chrony 2: $\quad 927 \mathrm{~m} / \mathrm{s}$

$\left(\mathrm{v}_{\mathrm{a}}+\mathrm{v}_{\text {rst }}\right) / 2: \quad 929,5 \mathrm{~m} / \mathrm{s}$

Pendelausschlag: $\quad 0,021 \mathrm{~m}$

entspricht $\mathrm{v}_{\mathrm{ab}}$ : $\quad 891 \mathrm{~m} / \mathrm{s}$ 


\begin{tabular}{|c|c|c|c|}
\hline & Differenz [cm] & Zeitspanne [ $\mu \mathrm{s}]$ & $\mathrm{V}_{3 \text { (Imacon) }}[\mathrm{m} / \mathrm{s}]$ \\
\hline Bild s-06.1-2 & 3,26 & 30 & 1087 \\
\hline Bild s-06.2-3 & 3,34 & 30 & 1113 \\
\hline Bild s-06.3-4 & 3,07 & 30 & 1023 \\
\hline Bild s-06.4-5 & 3,42 & 30 & 1140 \\
\hline Bild s-06.5-6 & 3,03 & 30 & 1010 \\
\hline$\sum$ Bild s-06.1-6 & 16,12 & 150 & 1075 \\
\hline
\end{tabular}

Tab. 4.1.4b.: Geschossfront s-06

Chrony 1:

Chrony 2:

$1066 \mathrm{~m} / \mathrm{s}$

$1058 \mathrm{~m} / \mathrm{s}$

$\left(v_{\mathrm{a}}+\mathrm{v}_{\text {rst }}\right) / 2$ :

$1062 \mathrm{~m} / \mathrm{s}$

Pendelausschlag: $\quad 0,024 \mathrm{~m}$

entspricht $\mathrm{V}_{\mathrm{ab}}$ : $\quad 909 \mathrm{~m} / \mathrm{s}$

\begin{tabular}{|c|c|c|c|}
\hline & Differenz [cm] & Zeitspanne [ $\mu \mathrm{s}]$ & $V_{3 \text { (Imacon) }[}[\mathrm{m} / \mathrm{s}]$ \\
\hline Bild s-07.1-2 & 3,82 & 35 & 1091 \\
\hline Bild s-07.2 -3 & 3,86 & 35 & 1103 \\
\hline Bild s-07.3 -4 & 3,62 & 35 & 1034 \\
\hline Bild s-07.4 - 5 & 3,98 & 35 & 1137 \\
\hline Bild s-07.5-6 & 3,54 & 35 & 1011 \\
\hline$\sum$ Bild s-07.1-6 & 18,83 & $1,75 \cdot 10^{-4}$ & 1076 \\
\hline
\end{tabular}

Tab. 4.1.4c.: Geschossfront s-07

Chrony 1: $\quad 1075 \mathrm{~m} / \mathrm{s}$

Chrony 2: $\quad 1080 \mathrm{~m} / \mathrm{s}$

$\left(\mathrm{v}_{\mathrm{a}}+\mathrm{v}_{\text {rst }}\right) / 2: \quad 1077,5 \mathrm{~m} / \mathrm{s}$

Pendelausschlag: $\quad 0,025 \mathrm{~m}$

entspricht $\mathrm{v}_{\mathrm{ab}}$ : $\quad 947 \mathrm{~m} / \mathrm{s}$

\begin{tabular}{|c|c|c|c|}
\hline & Differenz [cm] & 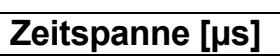 & $V_{3 \text { (Imacon) }[\mathrm{m} / \mathrm{s}]}$ \\
\hline Bild s-30.1-2 & 2,95 & 25 & 1180 \\
\hline Bild s-30.2 - 3 & 2,83 & 25 & 1132 \\
\hline Bild s-30.3-4 & 2,87 & 25 & 1148 \\
\hline Bild s-30.4-5 & 3,10 & 25 & 1240 \\
\hline Bild s-30.5-6 & 2,75 & 25 & 1100 \\
\hline$\sum$ Bild s-30.2-7 & 14,49 & 125 & 1159 \\
\hline
\end{tabular}

Tab. 4.1.4d.: Geschossfront s-30

Chrony 1: $\quad 1107 \mathrm{~m} / \mathrm{s}$

Chrony 2: $\quad 1122 \mathrm{~m} / \mathrm{s}$

$\left(\mathrm{v}_{\mathrm{a}}+\mathrm{v}_{\mathrm{rst}}\right) / 2: \quad 1114,5 \mathrm{~m} / \mathrm{s}$

Pendelausschlag: $\quad 0,028 \mathrm{~m}$

entspricht $\mathrm{v}_{\mathrm{ab}}$ : $\quad 1060 \mathrm{~m} / \mathrm{s}$ 
Für die Abweichungen zwischen der durch die Chronys $\left(\left[\mathrm{v}_{\mathrm{a}}+\mathrm{v}_{\mathrm{rst}}\right] / 2\right)$ gemittelten Geschwindigkeit und der elektrooptisch ermittelten Geschwindigkeit ( $v_{3}$ [Imacon]) ergeben sich folgende Werte:

\begin{tabular}{|c|c|c|c|c|}
\cline { 2 - 5 } \multicolumn{1}{c|}{} & Schuss s-01 & Schuss s-06 & Schuss s-07 & Schuss s-30 \\
\hline $\begin{array}{c}\text { Abweichung } \\
\text { [m/s] }\end{array}$ & 3,5 & 13 & 1,5 & 44,5 \\
\hline $\begin{array}{c}\text { relative } \\
\text { Abweichung [\%] }\end{array}$ & 0,38 & 1,21 & 0,14 & 3,84 \\
\hline
\end{tabular}

Tab. 4.1.4e.: Abweichungen der Chronygraphen

Ein Beispiel: Bei s-01 ist $v_{3}=933$ und $\left(v_{a}+v_{r s t}\right) / 2=929,5 \mathrm{~m} / \mathrm{s}$. Die Abweichung beträgt $3,5 \mathrm{~m} / \mathrm{s}$ und entspricht $0,38 \%$ von $\mathrm{v}_{3}$.

Der Vergleich der voneinander unabhängigen Geschwindigkeitsmessungen zeigt eine gute Übereinstimmung mit einer relativen Abweichung bis 3,84 \% (Schuss s-30).

\subsubsection{Kalibrierung des ballistischen Pendels}

Durch Beschuss des Pendels in unterschiedlichen Geschwindigkeitsbereichen wurde unter Aufzeichnung des Pendelausschlages eine Geschwindigkeitsmessung der einschlagenden Geschosse vorgenommen (Kap. 7.4.). Die aus dem Pendelausschlag berechnete Geschwindigkeit wird in folgender Tabelle mit den elektrooptischen Messungen verglichen.

\begin{tabular}{|c|c|c|c|c|}
\cline { 2 - 5 } \multicolumn{1}{c|}{} & $\begin{array}{c}\left(\mathbf{v}_{\mathbf{a}}+\mathbf{v}_{\mathbf{r s t}}\right) / \mathbf{2} \\
{[\mathbf{m} / \mathbf{s}]}\end{array}$ & $\begin{array}{c}\mathbf{b}_{\boldsymbol{\alpha}} \\
{[\mathbf{m}]}\end{array}$ & $\begin{array}{c}\mathbf{V}_{\text {ber }} \\
{[\mathbf{m} / \mathbf{s}]}\end{array}$ & $\begin{array}{c}\mathbf{v}_{\text {ab }} \\
{[\mathbf{m} / \mathbf{s}]}\end{array}$ \\
\hline $\mathbf{1}(\mathbf{s}-27)$ & 1138 & 0,030 & 831,3 & 1235 \\
\hline $\mathbf{2}(\mathbf{s}-32)$ & 1117,5 & 0,028 & 775,9 & 1156 \\
\hline $\mathbf{3}(\mathbf{s}-24)$ & 1083 & 0,025 & 692,8 & 1042 \\
\hline $\mathbf{4}(\mathbf{s}-\mathbf{0 7})$ & 1077,5 & 0,025 & 692,8 & 1042 \\
\hline $\mathbf{5}(\mathbf{s}-\mathbf{- 0 2})$ & 1069 & 0,024 & 665,1 & 1004 \\
\hline $\mathbf{6}(\mathbf{s}-16)$ & 1066 & 0,026 & 720,5 & 1080 \\
\hline $\mathbf{7}(\mathbf{s}-35)$ & 969 & 0,022 & 609,6 & 929 \\
\hline $\mathbf{8}(\mathbf{s}-14)$ & 810 & 0,019 & 526,5 & 815 \\
\hline $\mathbf{9}(\mathbf{s}-15)$ & 703 & 0,016 & 443,4 & 701 \\
\hline $\mathbf{1 0}(\mathbf{s}-125)$ & 132 & 0,001 & 27,7 & 133 \\
\hline $\mathbf{1 1}(\mathbf{s}-123)$ & 127,5 & 0,0015 & 41,6 & 152 \\
\hline $\mathbf{1 2}(\mathbf{s}-124)$ & 126,5 & 0,001 & 27,7 & 133 \\
\hline
\end{tabular}

Tab. 4.1.5.: Kalibrierung des ballistischen Pendels

$\left(v_{a}+v_{r s t}\right) / 2=$ Mittelwert gemessener Geschwindigkeiten $v_{a}$ und $v_{r s t}$ $\mathrm{b}_{\alpha}=$ gemessener Pendelausschlag

$\mathrm{V}_{\text {ber }}=$ berechnete Geschwindigkeit (Kap. 7.4. Formel (10))

$=\left((37,30298 / 0,00298) \times(2 \pi / 1,93) \times\left(0,68 \times b_{\alpha}[\mathrm{m}]\right)\right) /[\mathrm{s}] \approx 27711 \times \mathrm{b}_{\alpha}[\mathrm{m} / \mathrm{s}]$

$\mathrm{V}_{\mathrm{ab}}=$ abgelesene Geschwindigkeit (aus Graph 4.1.5.)

$=\left(\left(37872 \times b_{\alpha}[\mathrm{m}]\right)+95,327\right) /[\mathrm{s}]$ 
Die Ausschläge des ballistischen Pendels wurden gegen die elektrooptischen Messungen aufgetragen. Die Intervalle zwischen den zwölf Messpunkten wurden durch lineare Regressionsanalyse approximiert.

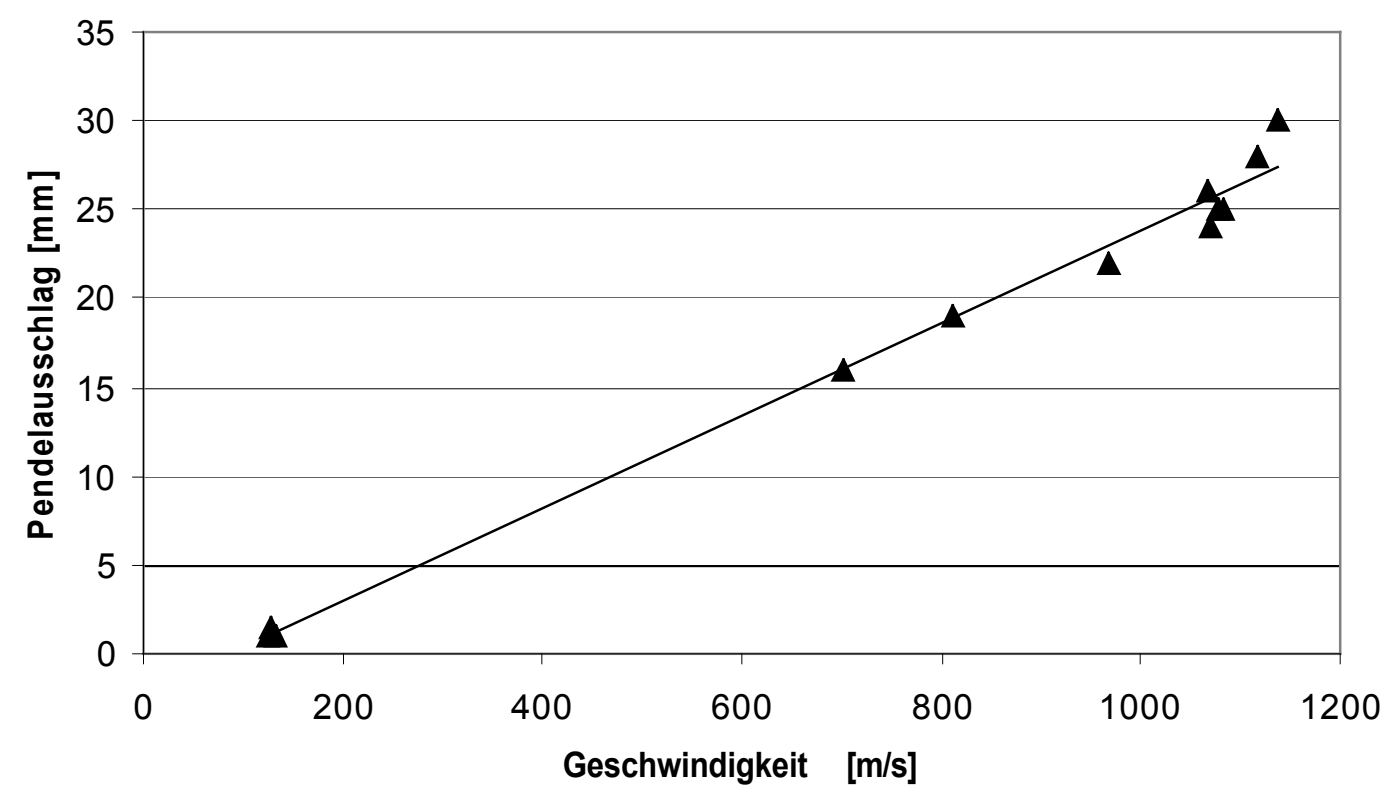

Graph 4.1.5.: Kalibrierung des ballistischen Pendels

So konnte anhand der Graphik die Geschwindigkeit $\mathrm{V}_{\mathrm{ab}} \mathrm{m} / \mathrm{s}$ der Geschosse abgelesen werden. 
4.1.6. Temperatur der Gelatineblöcke im zeitlichen Verlauf

Die verwendeten Gelatineblöcke $(15 \times 40 \times 15 \mathrm{~cm}, 9$ I) wurden mindestens 24 Stunden bei $10^{\circ} \mathrm{C}$ gekühlt. Bei $21^{\circ} \mathrm{C}$ Raumtemperatur stieg ihre Temperatur ohne Beschuss innerhalb von 7,5 Stunden um $3,5^{\circ}$ auf $13,5^{\circ} \mathrm{C}$ an. Die Temperatur wurde mit einem Infrarot-Thermometer gemessen. Laut SELLIER und KNEUBUEHL (2001, S. 230) sind „übliche Beschusstemperaturen z.B. $4^{\circ} \mathrm{C}$ (Fackler), $10^{\circ} \mathrm{C}$ (NATO) oder $15^{\circ} \mathrm{C}$ (Dynamit Nobel AG, Fürth)“.

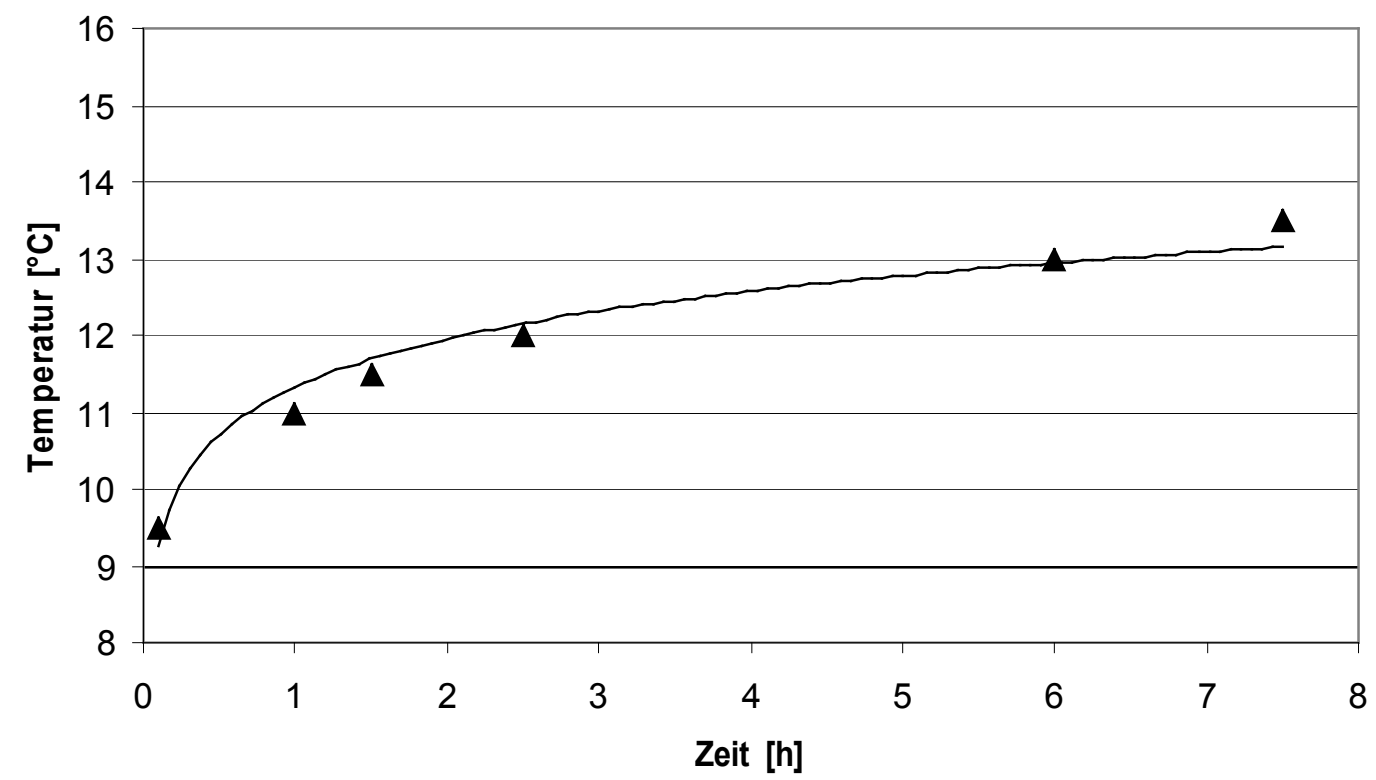

Graph 4.1.6.: Temperatur der Gelatineblöcke im zeitlichen Verlauf

\subsection{Ergebnisse der Schussversuche}

4.2.1. Schusstrichter von Zerlegungsgeschossen an technischen Materialien

Zerlegungsgeschosse wurden auf jeweils zwei Hartschaumplatten geschossen, hinter denen ein Gelatineblock die Geschoss- und Zieltrümmer aufnahm.

Für s-91 bis s-100 wurden Sand und Klebstoff als Geschoss (Typ1),

für s-101 bis s-110 wurden Messingspäne und Klebstoff als Geschoss (Typ2)

und für s-111 bis s-120 wurden Holzdübel als Geschoss (Typ3) geladen. Vergleichend wurde Fabrikmunition mit Vollbleigeschossen des Kalibers .22 Ir verschossen (s-181 s-190).

Das folgende Photo 15 zeigt sind die Geschossfragmente von s-100. Die Fragmente eines aus Sand geklebten Projektils liegen auf der Rückseite der beschossenen PVCHartschaumplatte. Insgesamt hatte es zwei, jeweils $3 \mathrm{~mm}$ dicke, Hartschaumplatten mit $402 \mathrm{~m} / \mathrm{s}$ durchschlagen. Gut zu sehen ist (der mit einem Pfeil markierte) Schusstrichter, welcher hier von der Rückseite, also der Seite des Ausschusses photographiert wurde. 
Die Platte liegt auf Millimeterpapier, welches unter dem Schusstrichter zu sehen ist. Auf der Abbildung sind zum direkten Vergleich zwei noch nicht verladene Geschosse, VMJ (RWS 3,0 g) und Typ 3, zu sehen.

Für diese Untersuchung wurden 20 geklebte Geschosse und 10 Holzdübel hergestellt und verschossen. Anders als VMJ (Kap. 5.3.2.2.) zerlegten sich die geklebten Geschosse auch schon bei Geschwindigkeiten um $290 \mathrm{~m} / \mathrm{s}$ und erzeugen trotzdem typische Einschüsse. Die Projektile trafen häufiger unterstabilisiert auf, erzeugten dann „Keyhole“-Einschüsse (Kap. 5.3.2.1.) und fragmentierten sich im Ziel mitunter vollständig.

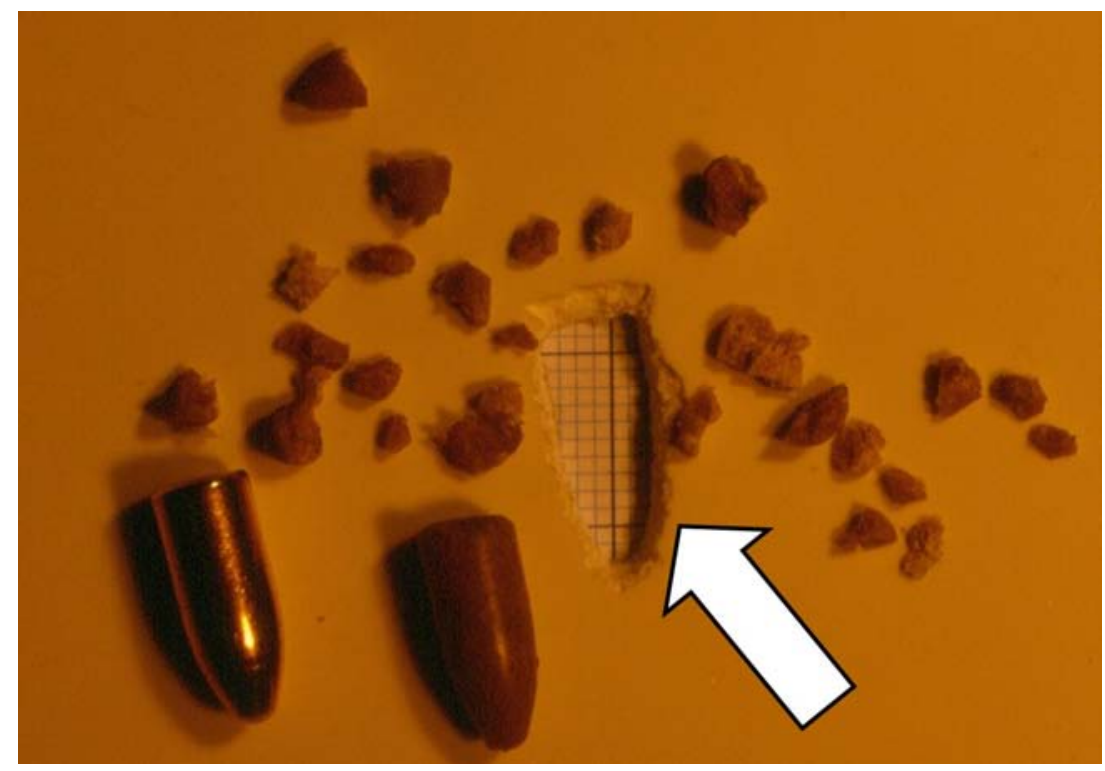

Vergrößerung von Photo 15 (Kap. 7.3.): Geschossfragmente (s-100) sowie Durchschuss des Geschosses durch die PVC-Hartschaumplatte (ausschussseitig)

Das Geschossmaterial wurde in weiten Grenzen variiert und sein Einfluss auf die Schusstrichter untersucht. Der Vergleich unterschiedlicher Laborierungen (223.sand, 223.messing und 223.holz) lässt Aussagen über den Einfluss des Geschossmaterials auf die Zielballistik erwarten, wenn die übrigen Versuchsbedingungen gleich bleiben.

Nach dem Schuss wurden die Schusstrichter in der ersten Hartschaumplatte und der zweiten Hartschaumplatte mit einer Schieblehre ausgemessen. Der jeweils kleinste Durchmesser auf Ein- und Ausschussseite (A und B) in Ziel eins (erste Platte) und der jeweils kleinste Durchmesser auf Ein- und Ausschussseite ( $C$ und $D)$ in Ziel zwei (zweite Platte) wurden in folgender Tabelle zusammengestellt: 


\begin{tabular}{|c|c|c|c|c|c|c|c|c|}
\hline & & $\mathrm{A}[\mathrm{m}]$ & $\mathrm{B}$ [m] & $\mathrm{C}[\mathrm{m}]$ & $\mathrm{D}[\mathrm{m}]$ & $\mathrm{B} / \mathrm{A}$ & $\mathrm{D} / \mathrm{C}$ & $V_{a}[\mathrm{~m} / \mathrm{s}]$ \\
\hline \multirow{10}{*}{$\begin{array}{l}\text { Dू } \\
\text { लొ }\end{array}$} & $s-91$ & $5,92 \times 10^{-3}$ & $8,29 \times 10^{-3}$ & $14,23 \times 10^{-3}$ & $20,50 \times 10^{-3}$ & 1,400 & 1,441 & 461 \\
\hline & $s-92$ & $6,31 \times 10^{-3}$ & $9,98 \times 10^{-3}$ & $10,22 \times 10^{-3}$ & $15,84 \times 10^{-3}$ & 1,582 & 1,550 & 377 \\
\hline & $s-93$ & $5,85 \times 10^{-3}$ & $9,32 \times 10^{-3}$ & $6,14 \times 10^{-3}$ & $8,53 \times 10^{-3}$ & 1,593 & 1,389 & - \\
\hline & $s-94$ & $6,21 \times 10^{-3}$ & $9,17 \times 10^{-3}$ & $5,66 \times 10^{-3}$ & $9,24 \times 10^{-3}$ & 1,477 & 1,633 & - \\
\hline & s-95 & $6,59 \times 10^{-3}$ & $9,86 \times 10^{-3}$ & $6,22 \times 10^{-3}$ & $11,97 \times 10^{-3}$ & 1,496 & 1,924 & 417 \\
\hline & $s-96$ & $5,95 \times 10^{-3}$ & $9,39 \times 10^{-3}$ & $8,86 \times 10^{-3}$ & $16,71 \times 10^{-3}$ & 1,578 & 1,886 & 422 \\
\hline & s-97 & $7,15 \times 10^{-3}$ & $10,59 \times 10^{-3}$ & $6,27 \times 10^{-3}$ & $11,10 \times 10^{-3}$ & 1,481 & 1,770 & 363 \\
\hline & $s-98$ & $6,13 \times 10^{-3}$ & $9,62 \times 10^{-3}$ & $7,02 \times 10^{-3}$ & $14,22 \times 10^{-3}$ & 1,569 & 2,026 & - \\
\hline & $s-99$ & $6,11 \times 10^{-3}$ & $9,55 \times 10^{-3}$ & $5,74 \times 10^{-3}$ & $9,10 \times 10^{-3}$ & 1,563 & 1,622 & 446 \\
\hline & $s-100$ & $6,62 \times 10^{-3}$ & $10,31 \times 10^{-3}$ & $5,85 \times 10^{-3}$ & $9,72 \times 10^{-3}$ & 1,557 & 1,662 & 402 \\
\hline \multirow{10}{*}{ 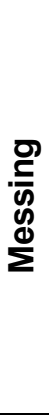 } & $s-101$ & $5,79 \times 10^{-3}$ & $10,12 \times 10^{-3}$ & $8,36 \times 10^{-3}$ & $12,56 \times 10^{-3}$ & 1,748 & 1,502 & - \\
\hline & $s-102$ & $6,20 \times 10^{-3}$ & $10,07 \times 10^{-3}$ & $7,09 \times 10^{-3}$ & $10,86 \times 10^{-3}$ & 1,624 & 1,532 & 478 \\
\hline & $s-103$ & $6,27 \times 10^{-3}$ & $10,50 \times 10^{-3}$ & $6,22 \times 10^{-3}$ & $11,08 \times 10^{-3}$ & 1,675 & 1,781 & 490 \\
\hline & $s-104$ & $6,48 \times 10^{-3}$ & $9,19 \times 10^{-3}$ & $5,76 \times 10^{-3}$ & $8,86 \times 10^{-3}$ & 1,418 & 1,538 & 501 \\
\hline & s-105 & $6,30 \times 10^{-3}$ & $10,37 \times 10^{-3}$ & $6,88 \times 10^{-3}$ & $10,09 \times 10^{-3}$ & 1,646 & 1,467 & 458 \\
\hline & $s-106$ & $6,05 \times 10^{-3}$ & $9,01 \times 10^{-3}$ & $6,68 \times 10^{-3}$ & $12,53 \times 10^{-3}$ & 1,489 & 1,876 & 498 \\
\hline & s-107 & $5,95 \times 10^{-3}$ & $9,97 \times 10^{-3}$ & $12,29 \times 10^{-3}$ & $16,73 \times 10^{-3}$ & 1,676 & 1,361 & 452 \\
\hline & $s-108$ & $6,06 \times 10^{-3}$ & $10,58 \times 10^{-3}$ & $5,87 \times 10^{-3}$ & $12,01 \times 10^{-3}$ & 1,746 & 2,046 & 506 \\
\hline & $s-109$ & $6,81 \times 10^{-3}$ & $9,04 \times 10^{-3}$ & $11,68 \times 10^{-3}$ & $17,78 \times 10^{-3}$ & 1,328 & 1,522 & 479 \\
\hline & $s-110$ & $5,98 \times 10^{-3}$ & $9,21 \times 10^{-3}$ & $7,03 \times 10^{-3}$ & $8,30 \times 10^{-3}$ & 1,540 & 1,181 & 475 \\
\hline \multirow{10}{*}{$\begin{array}{l}\frac{N}{0} \\
\text { ㅇ }\end{array}$} & $s-111$ & $6,27 \times 10^{-3}$ & $10,05 \times 10^{-3}$ & $12,31 \times 10^{-3}$ & $17,66 \times 10^{-3}$ & 1,603 & 1,435 & 395 \\
\hline & $s-112$ & $5,80 \times 10^{-3}$ & $10,76 \times 10^{-3}$ & $7,56 \times 10^{-3}$ & $11,86 \times 10^{-3}$ & 1,855 & 1,569 & 228 \\
\hline & $s-113$ & $6,77 \times 10^{-3}$ & $9,13 \times 10^{-3}$ & $12,35 \times 10^{-3}$ & $18,28 \times 10^{-3}$ & 1,349 & 1,480 & 389 \\
\hline & $s-114$ & $6,24 \times 10^{-3}$ & $9,40 \times 10^{-3}$ & $10,89 \times 10^{-3}$ & $14,59 \times 10^{-3}$ & 1,506 & 1,340 & 437 \\
\hline & $s-115$ & $6,58 \times 10^{-3}$ & $9,66 \times 10^{-3}$ & - & - & 1,468 & - & 163 \\
\hline & $s-116$ & $5,49 \times 10^{-3}$ & $12,86 \times 10^{-3}$ & - & - & 2,342 & - & 115 \\
\hline & $s-117$ & $6,78 \times 10^{-3}$ & $10,67 \times 10^{-3}$ & - & - & 1,574 & - & 129 \\
\hline & $s-118$ & $5,70 \times 10^{-3}$ & $8,22 \times 10^{-3}$ & $6,45 \times 10^{-3}$ & $9,98 \times 10^{-3}$ & 1,442 & 1,547 & 255 \\
\hline & s-119 & $5,59 \times 10^{-3}$ & $8,92 \times 10^{-3}$ & $6,50 \times 10^{-3}$ & $10,32 \times 10^{-3}$ & 1,596 & 1,588 & 226 \\
\hline & $s-120$ & $6,16 \times 10^{-3}$ & $10,33 \times 10^{-3}$ & $8,73 \times 10^{-3}$ & $16,32 \times 10^{-3}$ & 1,677 & 1,869 & 428 \\
\hline \multirow{10}{*}{$\frac{\overline{\mathbf{\omega}}}{\mathbf{0}}$} & $s-171$ & $5,74 \times 10^{-3}$ & $8,9 \times 10^{-3}$ & $6,97 \times 10^{-3}$ & $9,84 \times 10^{-3}$ & 1,551 & 1,412 & 331 \\
\hline & $s-172$ & $6,00 \times 10^{-3}$ & $8,67 \times 10^{-3}$ & $6,63 \times 10^{-3}$ & $10,31 \times 10^{-3}$ & 1,445 & 1,555 & 336 \\
\hline & $s-173$ & $6,13 \times 10^{-3}$ & $8,84 \times 10^{-3}$ & $6,32 \times 10^{-3}$ & $11,42 \times 10^{-3}$ & 1,442 & 1,807 & 335 \\
\hline & $s-174$ & $6,24 \times 10^{-3}$ & $8,9 \times 10^{-3}$ & $5,98 \times 10^{-3}$ & $10,6 \times 10^{-3}$ & 1,426 & 1,773 & 338 \\
\hline & s-175 & $6,08 \times 10^{-3}$ & $8,95 \times 10^{-3}$ & $6,21 \times 10^{-3}$ & $9,36 \times 10^{-3}$ & 1,472 & 1,507 & 330 \\
\hline & s-176 & $5,81 \times 10^{-3}$ & $8,52 \times 10^{-3}$ & $6,24 \times 10^{-3}$ & $9,02 \times 10^{-3}$ & 1,466 & 1,446 & 329 \\
\hline & $s-177$ & $6,17 \times 10^{-3}$ & $8,22 \times 10^{-3}$ & $6,03 \times 10^{-3}$ & $9,34 \times 10^{-3}$ & 1,332 & 1,549 & 331 \\
\hline & $s-178$ & $6,27 \times 10^{-3}$ & $7,45 \times 10^{-3}$ & $5,63 \times 10^{-3}$ & $8,65 \times 10^{-3}$ & 1,188 & 1,536 & 332 \\
\hline & $s-179$ & $5,81 \times 10^{-3}$ & $8,12 \times 10^{-3}$ & $6,53 \times 10^{-3}$ & $8,07 \times 10^{-3}$ & 1,398 & 1,236 & 336 \\
\hline & $s-180$ & $6,27 \times 10^{-3}$ & $8,51 \times 10^{-3}$ & $6,74 \times 10^{-3}$ & $9,83 \times 10^{-3}$ & 1,357 & 1,458 & 332 \\
\hline
\end{tabular}

Tab 4.2.1a.: Schusstrichtergröße auf PVC-Hartschaumplatten von

Zerlegungsgeschossen (Sand-, Messing-, Holz- und Bleigeschoss) 
Wir konnten zeigen (Graph 4.2.1.), dass die Variation des Geschossmaterials Auswirkung auf die Streuung des Quotienten B/A hat. Dieser Quotient setzt den Durchmesser der Schusslücke auf der Ausschussseite (B) zu dem Durchmesser der Schusslücke auf der Einschussseite (A) in Beziehung. Der Quotient B/A für die Schüsse s-91 bis s-120 und s-171 bis s-180 lässt sich auch gegen die jeweils gemessene Geschwindigkeit graphisch darstellen und wird im Kap 5.3.2.1. diskutiert:

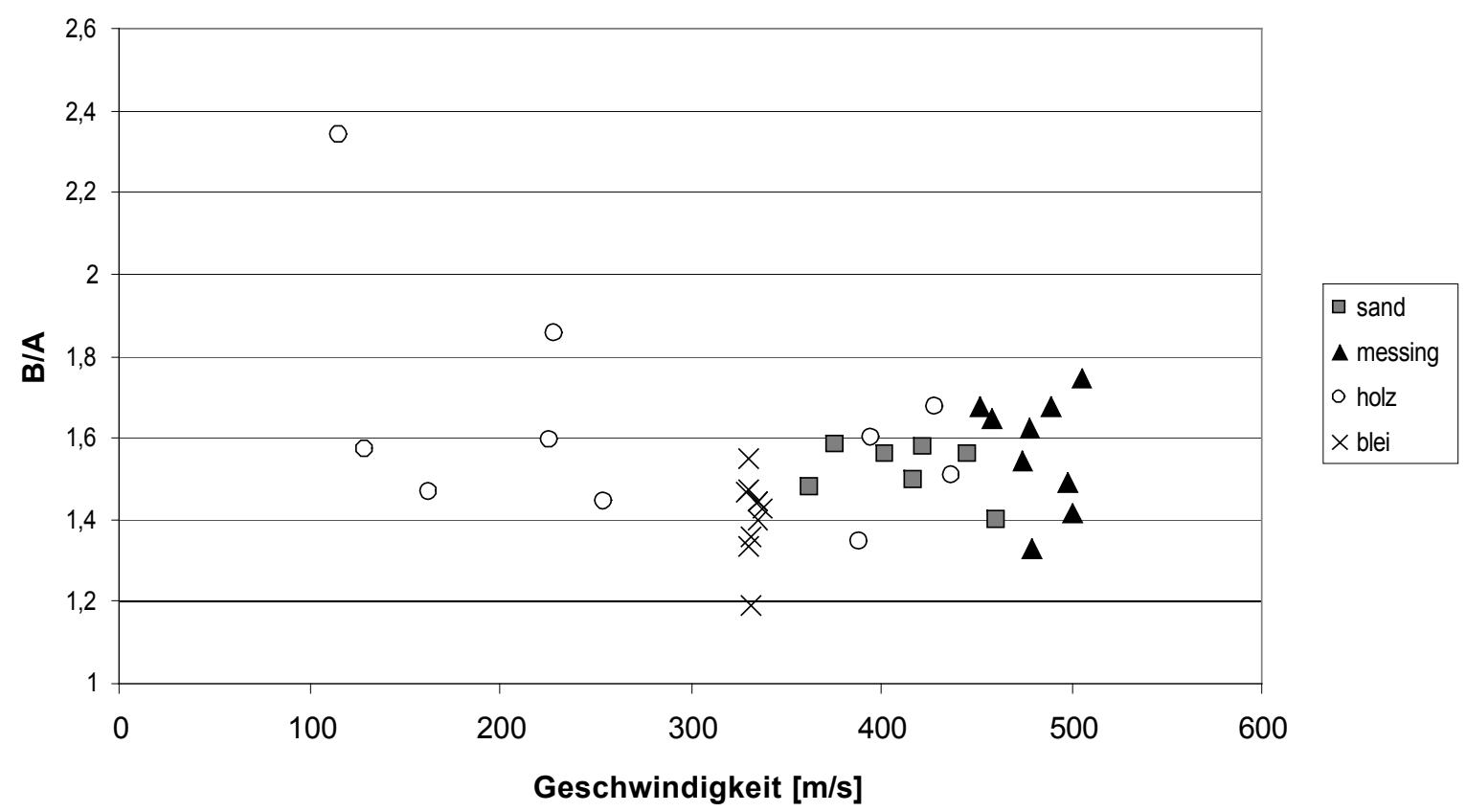

Graph 4.2.1a.: Schusstrichter von Zerlegungsgeschossen auf PVC (Schusstrichter-Verhältnis ausschussseitig/einschussseitig von verschiedenen Zerlegungsgeschossen auf PVC-Hartschaumplatten)

Auch Rigips-Platten $(0,95 \mathrm{~cm})$ wurden mit den Zerlegungsgeschossen und Vollblei orthograd beschossen.

Für die Untersuchung mit Schüssen auf Rigips-Platten wurden 20 weitere geklebte Geschosse hergestellt. Anders als beim Beschuss auf Hartschaumplatten wurde der Ziel-Mündungs-Abstand auf $60 \mathrm{~cm}$ verkürzt. Die Geschosse trafen ohne Drehung um die quere Achse auf und erzeugten kreisrunde Einschüsse.

Für s-191 bis s-200 wurden Sand und Klebstoff als Geschoss (Typ1) und für s-201 bis s-210 wurden Messingspäne und Klebstoff als Geschoss (Typ2) geladen.

Vergleichend wurde wieder Fabrikmunition mit Vollbleigeschossen des Kalibers .22 Ir verschossen (s-211 - s-220). 
Im Folgenden sind die Einschusstrichter von s-206 und s-207 abgebildet. Gut zu sehen sind die beiden Schusstrichter, beide von der Rückseite, also der Seite des Ausschusses, photographiert. Auf den Platten liegt ein Messstab (mm).

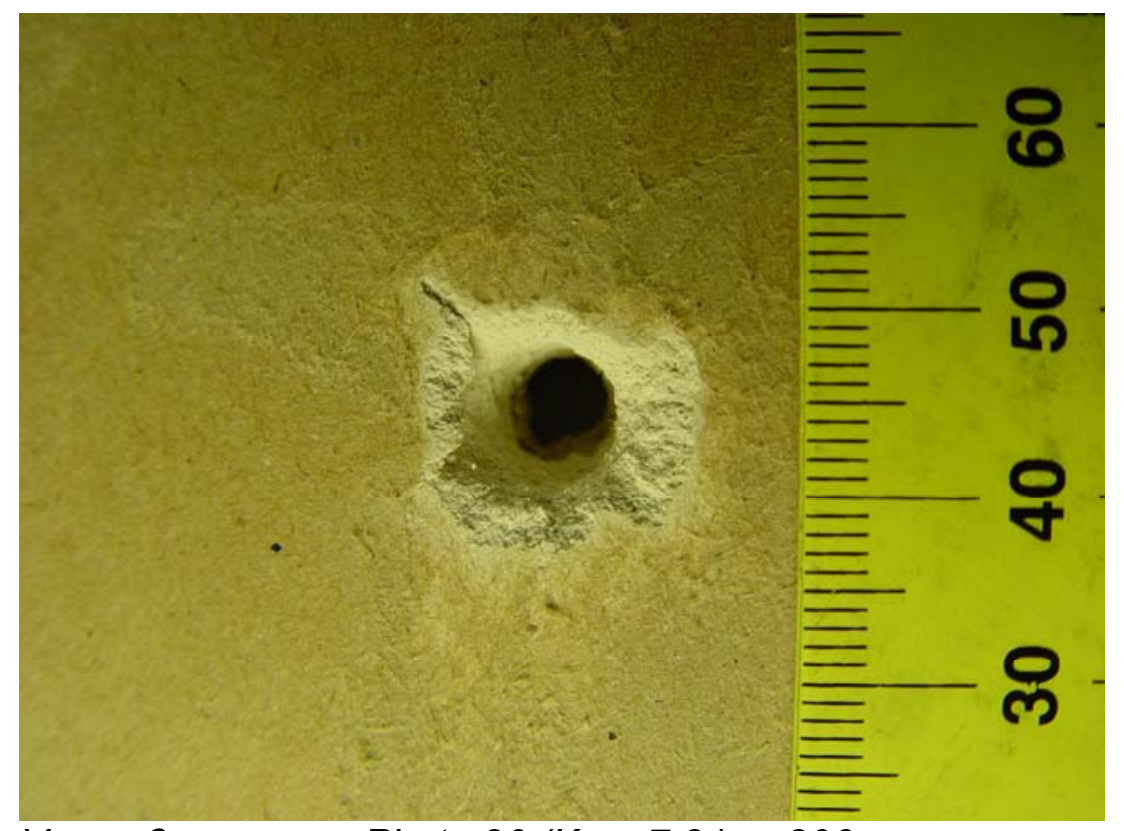

Vergrößerung von Photo 20 (Kap. 7.3.): s-206

(Rigips-Platte ausschussseitig nach Beschuss mit Zerlegungsgeschoss)

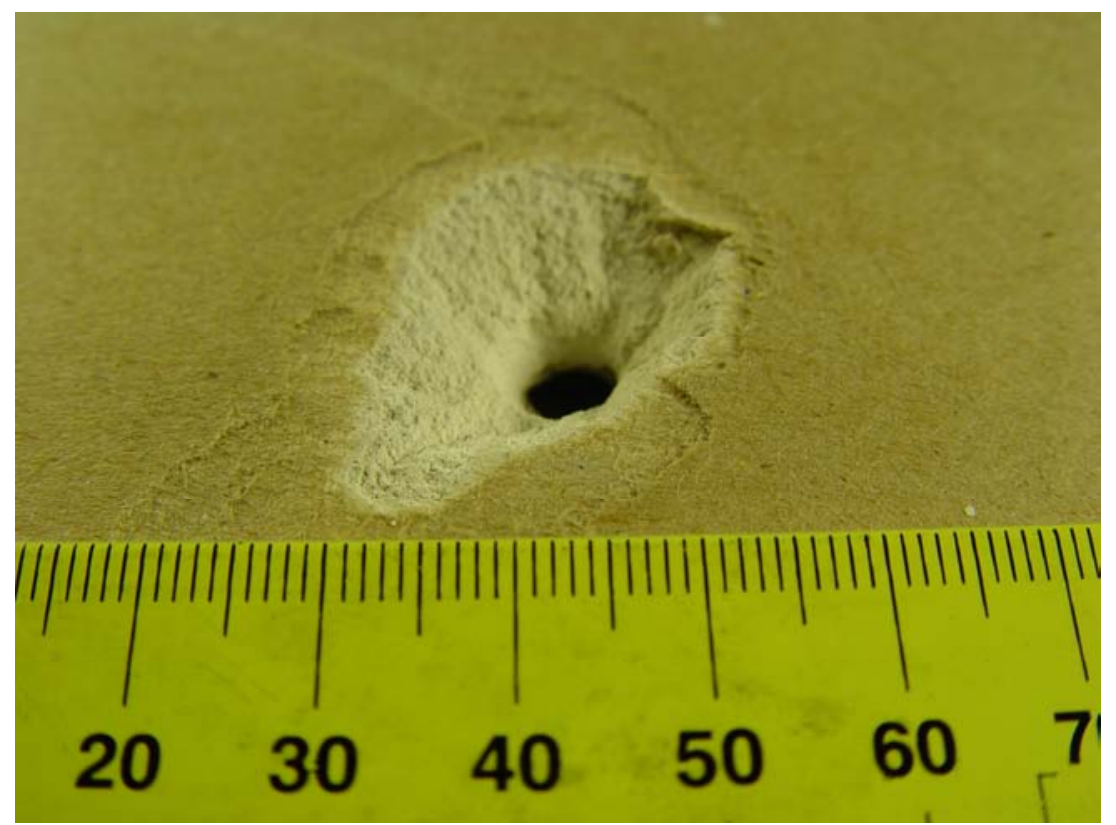

Vergrößerung von Photo 21 (Kap. 7.3.): s-207

(Rigips-Platte ausschussseitig nach Beschuss mit Zerlegungsgeschoss) 
Der Vergleich der unterschiedlichen Laborierungen (223.sand, 223.messing und .22 Ir) lässt wieder Aussagen über den Einfluss des Geschossmaterials auf die Zielballistik erwarten, wenn die übrigen Versuchsbedingungen gleich bleiben.

Nach jedem Schuss wurde der Schusstrichter der Rigips-Platte mit einer Schieblehre gemessen. Der jeweils kleinste Durchmesser auf Ein- und Ausschussseite (A und B) wurde in folgender Tabelle zusammengestellt:

\begin{tabular}{|c|c|c|c|c|c|}
\hline & & $A[\mathrm{~m}]$ & B [m] & B/A & $\mathbf{V}_{\mathrm{a}}[\mathrm{m} / \mathrm{s}]$ \\
\hline \multirow{10}{*}{$\begin{array}{l}\text { Dू } \\
\text { ஸू }\end{array}$} & $s-191$ & $6,38 \times 10^{-3}$ & $11,04 \times 10^{-3}$ & 1,73 & 456 \\
\hline & $s-192$ & $6,47 \times 10^{-3}$ & $12,43 \times 10^{-3}$ & 1,92 & 422 \\
\hline & s-193 & $5,98 \times 10^{-3}$ & $12,95 \times 10^{-3}$ & 2,17 & 397 \\
\hline & $s-194$ & $6,17 \times 10^{-3}$ & $12,67 \times 10^{-3}$ & 2,05 & - \\
\hline & $s-195$ & $6,21 \times 10^{-3}$ & $10,86 \times 10^{-3}$ & 1,75 & 405 \\
\hline & s-196 & $6,15 \times 10^{-3}$ & $11,05 \times 10^{-3}$ & 1,80 & 387 \\
\hline & s-197 & $6,42 \times 10^{-3}$ & $12,27 \times 10^{-3}$ & 1,91 & 489 \\
\hline & $s-198$ & $6,02 \times 10^{-3}$ & $11,82 \times 10^{-3}$ & 1,96 & 423 \\
\hline & s-199 & $6,40 \times 10^{-3}$ & $11,54 \times 10^{-3}$ & 1,80 & 419 \\
\hline & $s-200$ & $6,08 \times 10^{-3}$ & $12,21 \times 10^{-3}$ & 2,01 & 397 \\
\hline \multirow{10}{*}{ 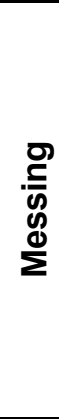 } & $s-201$ & $6,70 \times 10^{-3}$ & $10,63 \times 10^{-3}$ & 1,59 & 512 \\
\hline & $s-202$ & $7,05 \times 10^{-3}$ & $12,39 \times 10^{-3}$ & 1,76 & 492 \\
\hline & s-203 & $6,00 \times 10^{-3}$ & - & - & 498 \\
\hline & s-204 & $6,74 \times 10^{-3}$ & $22,10 \times 10^{-3}$ & 3,28 & 516 \\
\hline & s-205 & $6,91 \times 10^{-3}$ & $14,55 \times 10^{-3}$ & 2,11 & 493 \\
\hline & s-206 & $6,88 \times 10^{-3}$ & $13,74 \times 10^{-3}$ & 2,00 & 524 \\
\hline & s-207 & $6,84 \times 10^{-3}$ & $17,23 \times 10^{-3}$ & 2,51 & 472 \\
\hline & $s-208$ & $7,03 \times 10^{-3}$ & $13,04 \times 10^{-3}$ & 1,85 & 447 \\
\hline & s-209 & $6,94 \times 10^{-3}$ & $14,73 \times 10^{-3}$ & 2,12 & 521 \\
\hline & $s-210$ & $6,82 \times 10^{-3}$ & $13,81 \times 10^{-3}$ & 2,03 & 504 \\
\hline \multirow{10}{*}{$\frac{\bar{\alpha}}{\overline{0}}$} & $s-211$ & $6,18 \times 10^{-3}$ & $11,01 \times 10^{-3}$ & 1,78 & 335 \\
\hline & $s-212$ & $6,58 \times 10^{-3}$ & $12,31 \times 10^{-3}$ & 1,87 & 327 \\
\hline & $s-213$ & $6,40 \times 10^{-3}$ & $11,68 \times 10^{-3}$ & 1,83 & 341 \\
\hline & $s-214$ & $6,32 \times 10^{-3}$ & $12,92 \times 10^{-3}$ & 2,04 & 336 \\
\hline & $s-215$ & $6,61 \times 10^{-3}$ & $11,23 \times 10^{-3}$ & 1,70 & 324 \\
\hline & $s-216$ & $6,47 \times 10^{-3}$ & $11,69 \times 10^{-3}$ & 1,81 & 331 \\
\hline & s-217 & $7,00 \times 10^{-3}$ & $12,96 \times 10^{-3}$ & 1,85 & 379 \\
\hline & $s-218$ & $6,37 \times 10^{-3}$ & $10,39 \times 10^{-3}$ & 1,63 & 338 \\
\hline & $s-219$ & $6,90 \times 10^{-3}$ & $12,12 \times 10^{-3}$ & 1,76 & 338 \\
\hline & $s-220$ & $6,57 \times 10^{-3}$ & $13,33 \times 10^{-3}$ & 2,02 & 332 \\
\hline
\end{tabular}

Tab 4.2.1b.: Schusstrichtergröße auf Rigips-Platten von Zerlegungsgeschossen (Sand-, Messing- und Bleigeschoss) 
Wir konnten zeigen (Graph 4.2.1b.), dass die Variation des Geschossmaterials wieder Auswirkung auf die Streuung des Quotienten B/A hat. Dieser Quotient setzt den Durchmesser der Schusslücke auf der Ausschussseite (B) zu dem Durchmesser der Schusslücke auf der Einschussseite $(A)$ in Beziehung. Der Quotient B/A für die Schüsse s-191 bis s-220 lässt sich auch gegen die jeweils gemessene Geschwindigkeit graphisch darstellen und wird im Kap 5.3.2.1. diskutiert:

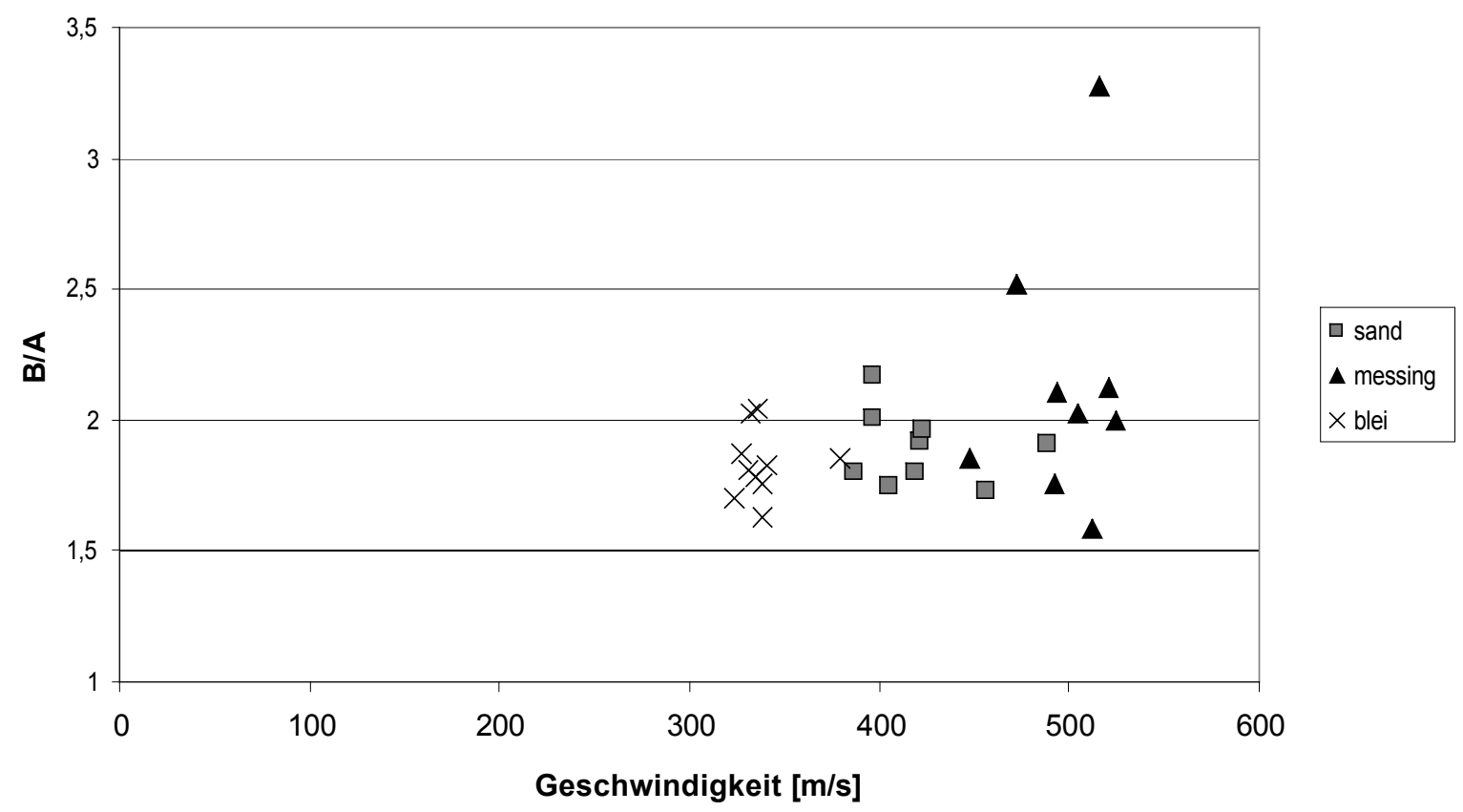

Graph 4.2.1b.: Schusstrichter von Zerlegungsgeschossen auf Rigips (Schusstrichter-Verhältnis ausschussseitig/einschussseitig von verschiedenen Zerlegungsgeschossen auf Rigips-Platten) 


\subsubsection{Eindringtiefe und Energieverlust von VMJ in Gelatine}

Die Geschossgeschwindigkeit wurde in weiten Grenzen $(132 \mathrm{~m} / \mathrm{s}-1083 \mathrm{~m} / \mathrm{s})$ variiert. Vollmantelgeschosse wurden unter konstanten Untersuchungsbedingungen mit zunehmender Geschwindigkeit in Gelatineblöcke geschossen.

Die Eindringtiefe und der Energieverlust von VMJ (RWS 3,0 g) in ballistischer Gelatine wurden bei unterschiedlichen Geschossgeschwindigkeiten ermittelt:

\begin{tabular}{|c|c|c|c|}
\cline { 2 - 4 } \multicolumn{1}{c|}{} & $\begin{array}{c}\text { Anzeige Chrony 1 } \\
{[\mathbf{m} / \mathbf{s}]}\end{array}$ & $\begin{array}{c}\text { Eindringtiefe in Gelatine } \\
{[\mathbf{m}]}\end{array}$ & $\begin{array}{c}\text { Energieverlust } \\
{[\mathbf{J} / \mathbf{c m}]}\end{array}$ \\
\hline Schuss s-03 & 1083 & 0,14 & 125,64 \\
\hline Schuss s-04 & 1077 & 0,16 & 108,75 \\
\hline Schuss s-17 & 1069 & 0,155 & 110,58 \\
\hline Schuss s-05 & 1061 & 0,15 & 112,60 \\
\hline Schuss s-73 & 925 & 0,33 & 38,88 \\
\hline Schuss s-86 & 924 & 0,34 & 37,68 \\
\hline Schuss s-72 & 785 & 0,51 & 18,12 \\
\hline Schuss s-71 & 547 & 0,58 & 7,74 \\
\hline Schuss s-70 & 476 & 0,52 & 6,54 \\
\hline Schuss s-74 & 247 & 0,425 & 2,17 \\
\hline Schuss s-68 & 132 & 0,22 & 1,18 \\
\hline
\end{tabular}

Tab. 4.2.2a.: Eindringtiefe von VMJ in Gelatine

(und Energieverlust bei unterschiedlichen Geschossgeschwindigkeiten)

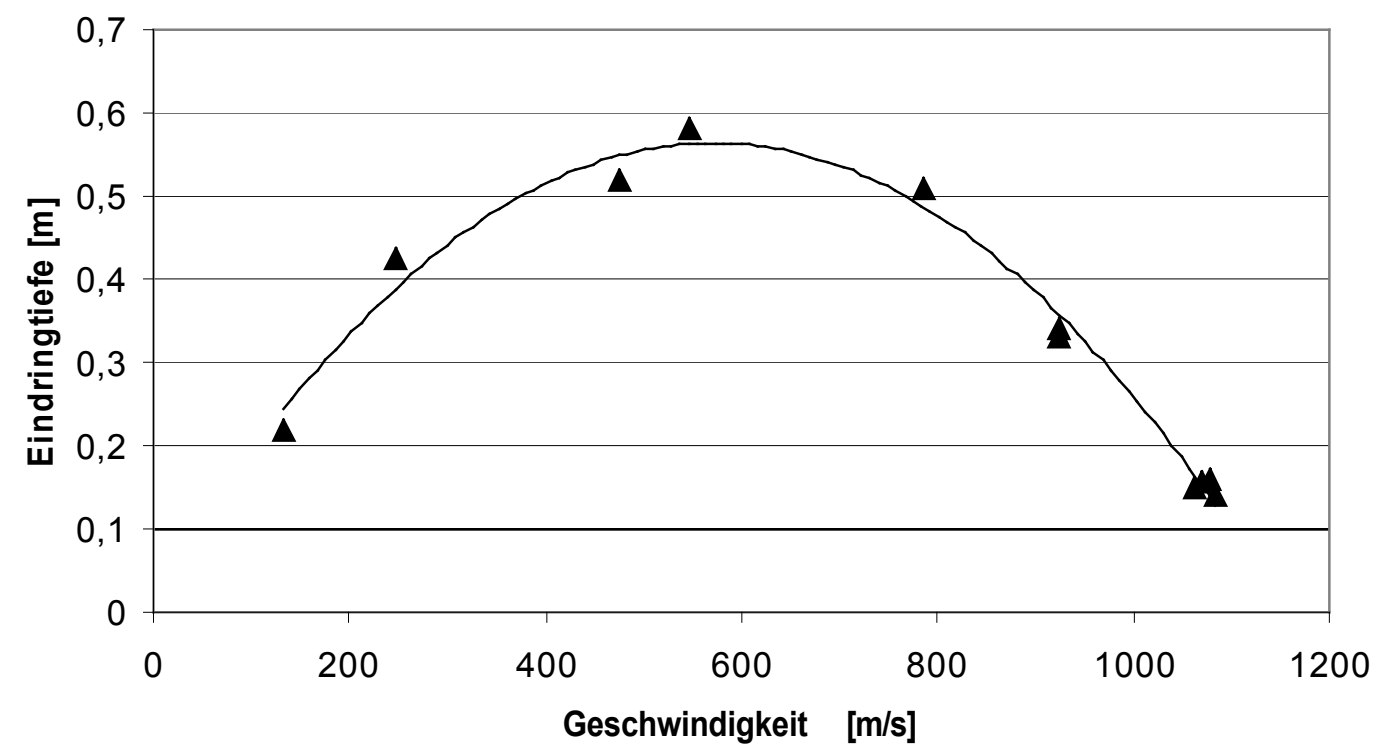

Graph 4.2.2a.: Eindringtiefe von VMJ in Gelatine 
Die Energie [J] eines Geschosses berechnet sich: $\mathrm{E}[\mathrm{J}]=0,5 \times$ Geschossmasse $[\mathrm{kg}] \mathrm{x}$ Geschossgeschwindigkeit $\mathrm{m} / \mathrm{s}^{2}$. Der Energieverlust pro $\mathrm{cm}$ im Ziel wurde errechnet und gegen die Geschwindigkeit aufgetragen (Graph 4.2.2b.):

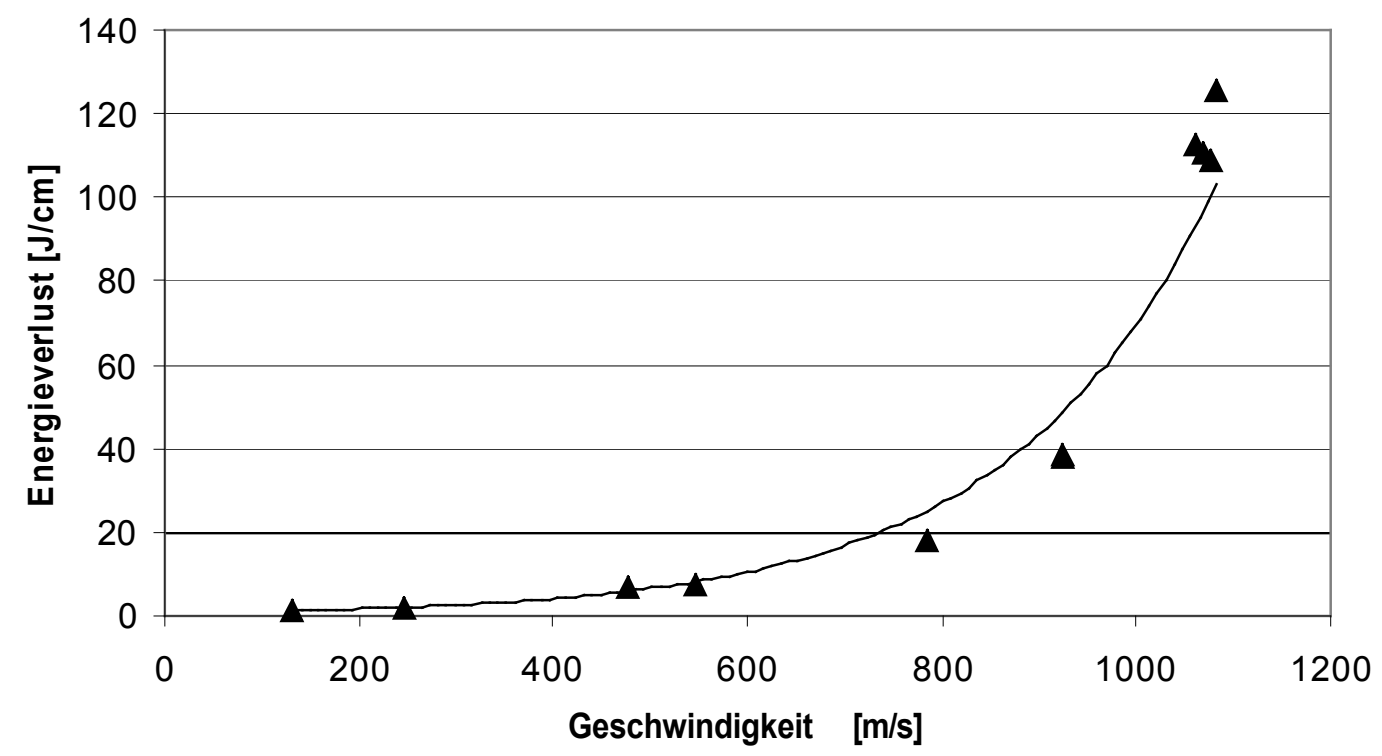

Graph 4.2.2b.: Energieverlust von VMJ in Gelatine 
Außerdem haben wir den relativen Energieverlust von 21 weiteren Schüssen gemessen. Mit unterschiedlicher Geschwindigkeit $(961-1086 \mathrm{~m} / \mathrm{s})$ wurde auf Wasser und Stickstoff geschossen. Die Schichtdicken der Ziele variierten zwischen 4 und 17 $\mathrm{cm}$. Zunächst wurde mit drei Stellen hinter dem Komma gerechnet und die Ergebnisse dann für die folgenden Tabellen auf- oder abgerundet.

\begin{tabular}{|c|c|c|c|c|c|c|c|}
\hline & $\mathbf{V}_{\mathbf{a}}[\mathbf{m} / \mathbf{s}]$ & $\mathbf{V}_{\text {rst }}[\mathbf{m} / \mathbf{s}] \mathbf{]}$ & $\begin{array}{c}\text { Schichtdicke } \\
\mathbf{N}_{\mathbf{2}}[\mathbf{c m}]\end{array}$ & $\mathbf{E ~ V ~}_{\mathbf{a}}[\mathbf{J}]$ & $\mathbf{E ~ V}_{\text {rst }}[\mathbf{J}]$ & $\Delta \mathbf{E}$ & $\begin{array}{c}\text { rel. E- } \\
\text { Verl [\%] }\end{array}$ \\
\hline $\mathrm{s}-41$ & 1086 & 20 & 0,15 & 1769,1 & 0,6 & 1768,5 & 100,0 \\
\hline $\mathrm{s}-42$ & 1075 & 228 & 0,15 & 1733,4 & 78,0 & 1655,5 & 96,0 \\
\hline $\mathrm{s}-43$ & 1065 & 455 & 0,09 & 1701,3 & 311,0 & 1390,8 & 81,8 \\
\hline $\mathrm{s}-44$ & 1063 & 439 & 0,09 & 1695,0 & 289,1 & 1405,9 & 83,0 \\
\hline $\mathrm{s}-45$ & 1061 & 301 & 0,09 & 1688,6 & 135,9 & 1552,7 & 92,0 \\
\hline $\mathrm{s}-46$ & 1063 & 301 & 0,09 & 1695,0 & 135,9 & 1559,1 & 92,0 \\
\hline $\mathrm{s}-140$ & 998 & 689 & 0,08 & 1494,0 & 712,1 & 781,9 & 52,3 \\
\hline $\mathrm{s}-141$ & 988 & 218 & 0,12 & 1464,2 & 71,3 & 1392,9 & 95,1 \\
\hline $\mathrm{s}-143$ & 991 & 949 & 0,04 & 1473,1 & 1350,9 & 122,2 & 8,3 \\
\hline $\mathrm{s}-144$ & 988 & 960 & 0,04 & 1464,2 & 1382,4 & 81,8 & 5,6 \\
\hline $\mathrm{s}-145$ & 989 & 945 & 0,06 & 1467,2 & 1339,5 & 127,6 & 8,7 \\
\hline $\mathrm{s}-146$ & 967 & 827 & 0,07 & 1402,6 & 1025,9 & 376,7 & 26,9 \\
\hline $\mathrm{s}-147$ & 961 & 640 & 0,08 & 1385,3 & 614,4 & 770,9 & 55,6 \\
\hline $\mathrm{s}-148$ & 984 & 619 & 0,08 & 1452,4 & 574,8 & 877,6 & 60,4 \\
\hline $\mathrm{s}-149$ & 991 & 467 & 0,10 & 1473,1 & 327,1 & 1146,0 & 77,8 \\
\hline $\mathrm{s}-150$ & 986 & 653 & 0,09 & 1458,3 & 639,6 & 818,7 & 56,1 \\
\hline
\end{tabular}

Tab. 4.2.2b.: Energieverlust von VMJ (961 - $1086 \mathrm{~m} / \mathrm{s})$ in Stickstoff

\begin{tabular}{|c|c|c|c|c|c|c|c|}
\hline & $\mathbf{V}_{\mathbf{a}}[\mathbf{m} / \mathbf{s}]$ & $\mathbf{V}_{\text {rst }}[\mathbf{m} / \mathbf{s}]$ & $\begin{array}{c}\text { Schichtdicke } \\
\mathbf{H}_{\mathbf{2}} \mathbf{O}[\mathbf{c m}]\end{array}$ & $\mathbf{E ~ V ~}_{\mathbf{a}}[\mathbf{J}]$ & $\mathbf{E ~ V}_{\text {rst }}[\mathbf{J}]$ & $\Delta \mathbf{E}$ & $\begin{array}{c}\text { rel.E-Verl } \\
{[\%]}\end{array}$ \\
\hline $\mathrm{s}-25$ & 1080 & 13 & 0,17 & 1749,6 & 0,3 & 1749,4 & 100,0 \\
\hline $\mathrm{s}-155$ & 974 & 925 & 0,09 & 1423,0 & 1283,4 & 139,6 & 9,8 \\
\hline $\mathrm{s}-156$ & 965 & 63 & 0,12 & 1396,8 & 6,0 & 1390,9 & 99,6 \\
\hline $\mathrm{s}-157$ & 969 & 53 & 0,12 & 1408,4 & 4,2 & 1404,2 & 99,7 \\
\hline $\mathrm{s}-158$ & 965 & 71 & 0,12 & 1396,8 & 7,6 & 1389,3 & 99,5 \\
\hline
\end{tabular}

Tab. 4.2.2c.: Energieverlust von VMJ (965-1080 m/s) in Wasser 
Als wir die Geschossgeschwindigkeit bei weiteren 20 Schüssen noch steigerten $(1101-1157 \mathrm{~m} / \mathrm{s})$, ergaben sich folgende Werte aus den Messungen:

\begin{tabular}{|c|c|c|c|c|c|c|c|}
\hline & $\mathbf{V}_{\mathbf{a}}[\mathbf{m} / \mathbf{s}]$ & $\mathbf{V}_{\text {rst }}[\mathbf{m} / \mathbf{s}] \mathbf{]}$ & $\begin{array}{c}\text { Schichtdicke } \\
\mathbf{N}_{\mathbf{2}}[\mathbf{c m}]\end{array}$ & $\mathbf{E ~ V ~}_{\mathbf{a}}[\mathbf{J}]$ & $\mathbf{E ~ V}_{\text {rst }}[\mathbf{J}]$ & $\Delta \mathbf{E}$ & $\begin{array}{c}\text { rel.E-Verl } \\
{[\%]}\end{array}$ \\
\hline $\mathrm{s}-76$ & 1157 & 6 & 0,18 & 2008,0 & 0,1 & 2007,9 & 100,0 \\
\hline $\mathrm{s}-131$ & 1101 & 1075 & 0,01 & 1818,3 & 1733,4 & 84,9 & 4,7 \\
\hline $\mathrm{s}-132$ & 1125 & 510 & 0,04 & 1898,4 & 390,2 & 1508,3 & 79,5 \\
\hline $\mathrm{s}-133$ & 1125 & 570 & 0,08 & 1898,4 & 487,4 & 1411,1 & 74,3 \\
\hline $\mathrm{s}-134$ & 1125 & 30 & 0,12 & 1898,4 & 1,4 & 1897,1 & 99,9 \\
\hline $\mathrm{s}-135$ & 1116 & 7 & 0,16 & 1868,2 & 0,1 & 1868,1 & 100,0 \\
\hline $\mathrm{s}-136$ & 1122 & 501 & 0,04 & 1888,3 & 376,5 & 1511,8 & 80,1 \\
\hline $\mathrm{s}-137$ & 1114 & 501 & 0,08 & 1861,5 & 376,5 & 1485,0 & 79,8 \\
\hline $\mathrm{s}-138$ & 1121 & 0 & 0,12 & 1885,0 & 0 & 1885,0 & 100,0 \\
\hline
\end{tabular}

Tab. 4.2.2d.: Energieverlust von VMJ (1101 - $1157 \mathrm{~m} / \mathrm{s})$ in Stickstoff

\begin{tabular}{|c|c|c|c|c|c|c|c|}
\hline & $\mathbf{V}_{\mathbf{a}}[\mathbf{m} / \mathbf{s}]$ & $\mathbf{V}_{\text {rst }}[\mathbf{m} / \mathbf{s}] \mathbf{]}$ & $\begin{array}{c}\text { Schichtdicke } \\
\mathbf{H}_{\mathbf{2}} \mathbf{O}[\mathbf{c m}]\end{array}$ & $\mathbf{E ~ V ~}_{\mathbf{a}}[\mathbf{J}]$ & $\mathbf{E ~ V ~}_{\text {rst }}[\mathbf{J}]$ & $\Delta \mathbf{E}$ & $\begin{array}{c}\text { rel.E-Verl } \\
{[\%]}\end{array}$ \\
\hline $\mathrm{s}-28$ & 1132 & 14 & 0,17 & 1922,1 & 0,3 & 1921,8 & 100,0 \\
\hline $\mathrm{s}-31$ & 1135 & 0 & 0,18 & 1932,3 & 0 & 1932,3 & 100,0 \\
\hline $\mathrm{s}-33$ & 1125 & 0 & 0,18 & 1898,4 & 0 & 1898,4 & 100,0 \\
\hline $\mathrm{s}-50$ & 1125 & 43 & 0,15 & 1898,4 & 2,8 & 1895,7 & 99,9 \\
\hline $\mathrm{s}-51$ & 1113 & 16 & 0,15 & 1858,2 & 0,4 & 1857,8 & 99,9 \\
\hline $\mathrm{s}-54$ & 1132 & 11 & 0,18 & 1922,1 & 0,2 & 1922,0 & 100,0 \\
\hline $\mathrm{s}-55$ & 1125 & 8 & 0,18 & 1898,4 & 0,1 & 1898,3 & 100,0 \\
\hline $\mathrm{s}-62$ & 1110 & 0 & 0,32 & 1848,2 & 0 & 1848,2 & 100,0 \\
\hline $\mathrm{s}-63$ & 1110 & 0 & 0,32 & 1848,2 & 0 & 1848,2 & 100,0 \\
\hline $\mathrm{s}-153$ & 1122 & 403 & 0,08 & 1888,3 & 243,6 & 1644,7 & 87,1 \\
\hline $\mathrm{s}-154$ & 1144 & 1066 & 0,02 & 1963,1 & 1704,5 & 258,6 & 13,2 \\
\hline
\end{tabular}

Tab. 4.2.2e.: Energieverlust von VMJ (1110 - $1144 \mathrm{~m} / \mathrm{s})$ in Wasser

Aus den Werten wurden Graphiken erstellt und diskutiert (Kap. 5.3.2.2.). 
4.2.3. Zielmaterial an der Ausschussseite von Cucumis melo
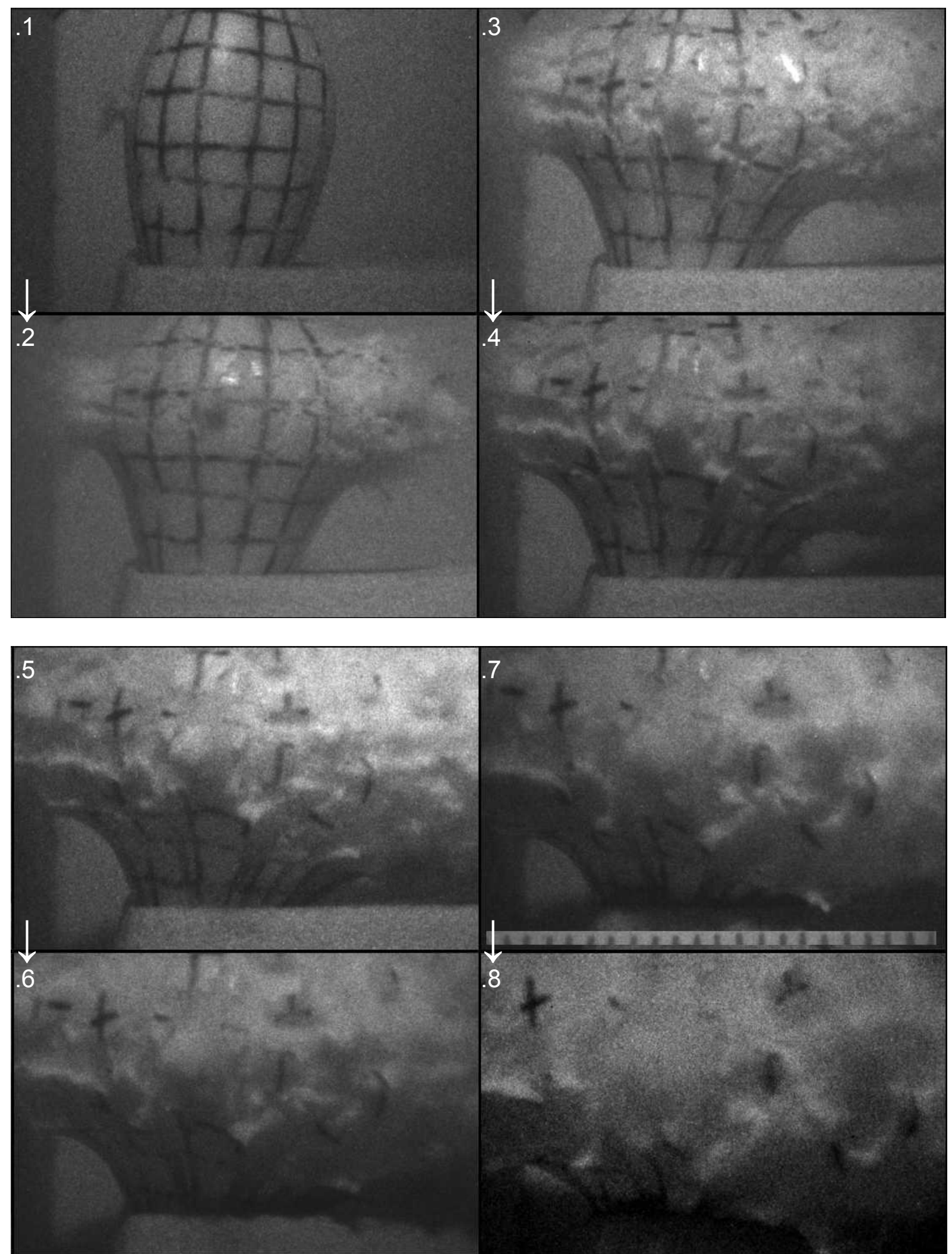

Photo s-13: Durchschuss durch eine Melone, deren Schale mit Linien markiert ist. In der Bildfolge zahlreiche Einrisse bis zur vollständigen Zerlegung der Melone. 
zu Photo s-13: Geschoss: VMJ (3,0 g), Munition: 223.6 Ziel: Cucumis melo, 1,2 kg

Chrony 1:

Chrony 2 :

Objektiv:

Belichtungsdauer:

Zwischenbildzeit:

$1063 \mathrm{~m} / \mathrm{s}$

$28 \mathrm{~mm}$

$10 \mu s$

Bild 1: $\quad 0 \quad \mu s$

Bild 2: $\quad 300 \quad \mu s$

Bild 3: $\quad 500 \quad \mu s$

Bild 4: $\quad 700 \quad \mu s$

Bild 5: $\quad 900 \quad \mu s$

Bild 6: $\quad 1100 \mu s$

Bild 7: $\quad 1300 \mu s$

Bild 8: $\quad 1700 \mu s$

Beschossen wurde Cucumis melo mit einer Masse von 1,2 kg. Die Schale der Frucht war mit Markierungslinien gekennzeichnet. Anhand dieser Linien können einzelne Reste von Cucumis melo bis zum Bild 8 messend verfolgt werden.

Auf Bild 1 ist das Geschoss bereits in das Ziel eingedrungen. An der Ausschussseite konnte die Mindestgeschwindigkeit der beschleunigten Zielmasse zwischen Bild 1 und Bild 2 berechnet werden.

\begin{tabular}{|c|c|c|c|}
\cline { 2 - 4 } \multicolumn{1}{c|}{} & Differenz [cm] & Zeitspanne [ $\boldsymbol{\mu s}]$ & $\mathbf{V}_{\mathbf{3} \text { (Imacon) }}[\mathbf{m} / \mathbf{s}]$ \\
\hline$\sum$ Bild s-13.1 -2 & 6,09 & $<300$ & $>203$ \\
\hline
\end{tabular}

Tab. 4.2.3.: Material an der Ausschussseite s-13

Chrony 1: $\quad 1063 \mathrm{~m} / \mathrm{s}$

Gut zu sehen sind die zahlreichen Einrisse in der Schale von Cucumis melo, bevor sich das Ziel nahezu vollständig zerlegt.

Um die Geschwindigkeit des Zielmaterials an der Ein- und Ausschussseite genauer berechnen zu können, wurde später das Beobachtungs-Zeitfenster bei Beschuss von Cucumis melo verringert (Kap. 4.2.4.).

Die gemessene Schallgeschwindigkeit in Melonen wurde gemessen und betrug zwischen 500 und $1000 \mathrm{~m} / \mathrm{s}$ (Kap. 3.4.6.). Sie liegt unter der Schallgeschwindigkeit von Wasser. Außerdem wird Schall in Melonen durch deren Feinstruktur stärker gedämpft als z.B. in Wasser. 
4.2.4. Zielmaterial an der Ein- und Ausschussseite von Cucumis melo
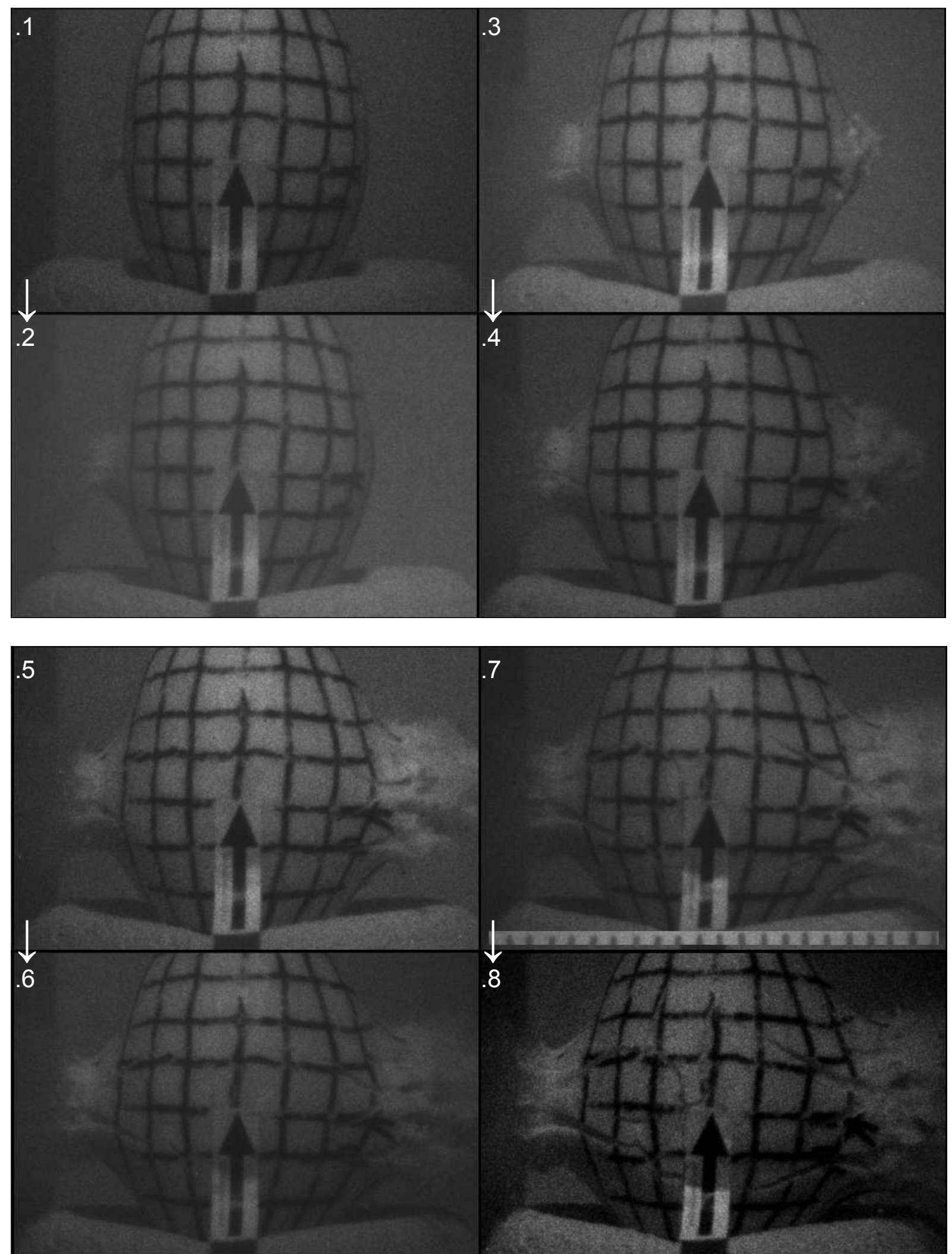

Photo s-11: Durchschuss durch eine Melone mit höherer Zeitauflösung zur Ermittlung der Geschwindigkeit des Zielmaterials am Ein- und Ausschuss. Messpfeil $=6 \mathrm{~cm}$. 
zu Photo s-11: Geschoss: VMJ (3,0 g), Munition: 223.6, Ziel: Cucumis melo, 1,11 kg

Chrony 1:

Chrony 2:

Objektiv:

Belichtungsdauer:

Zwischenbildzeit:

$1066 \mathrm{~m} / \mathrm{s}$

$28 \mathrm{~mm}$

$10 \mu s$

Bild 1: $\quad 0 \quad \mu s$

Bild 2: $\quad 160 \quad \mu s$

Bild 3: $\quad 240 \quad \mu s$

Bild 4: $\quad 320 \quad \mu s$

Bild 5: $\quad 400 \quad \mu s$

Bild 6: $\quad 480 \quad \mu s$

Bild 7: $\quad 560 \quad \mu s$

Bild 8: $\quad 640 \quad \mu s$

Beim Beschuss von Cucumis melo $(1,11 \mathrm{~kg})$ wurden die Zwischenbildzeiten so gewählt, dass die Geschwindigkeiten von beschleunigtem Zielmaterial am Ein- und Ausschuss ermittelt werden konnten. Im Vergleich zu der vorherigen Bildsequenz (Kap. 4.2.3.) wurden die ersten $640 \mu$ s also in höherer Zeitauflösung dargestellt.

Die Geschwindigkeit des Zielmaterials wurde nun auch mit der Hochgeschwindigkeitskamera ermittelt:

\begin{tabular}{|c|c|c|c|}
\hline & Differenz [cm] & Zeitspanne [us] & $\mathbf{V}_{3 \text { (Imacon) }}[\mathrm{m} / \mathrm{s}]$ \\
\hline Bild s-11.1-2 & 2,07 & 160 & 129 \\
\hline Bild s-11.2-3 & 1,63 & 160 & 68 \\
\hline$\sum$ Bild s-11.1-3 & 3,70 & 320 & 116 \\
\hline
\end{tabular}

Tab. 4.2.4a.: Material an der Einschussseite s-11

\begin{tabular}{|c|c|c|c|}
\cline { 2 - 4 } \multicolumn{1}{c|}{} & Differenz $[\mathrm{cm}]$ & Zeitspanne $[\mu \mathrm{s}]$ & $\mathbf{V}_{\mathbf{3}}$ (Imacon) $[\mathrm{m} / \mathrm{s}]$ \\
\hline$\sum$ Bild s-11.3-4 & 2,15 & 160 & 134 \\
\hline
\end{tabular}

Tab. 4.2.4b.: Material an der Ausschussseite s-11

Chrony 1: $\quad 1066 \mathrm{~m} / \mathrm{s}$

Als Messstab war vor Schussabgabe ein Papier mit Pfeil (entspricht sechs Zentimeter) angebracht worden. Auf Bild 8 sind zahlreiche Risse in der Schale der Frucht zu sehen. 
4.2.5. Geschwindigkeit einer Höhlenfront in Gelatine (bis $154 \mu \mathrm{s})$
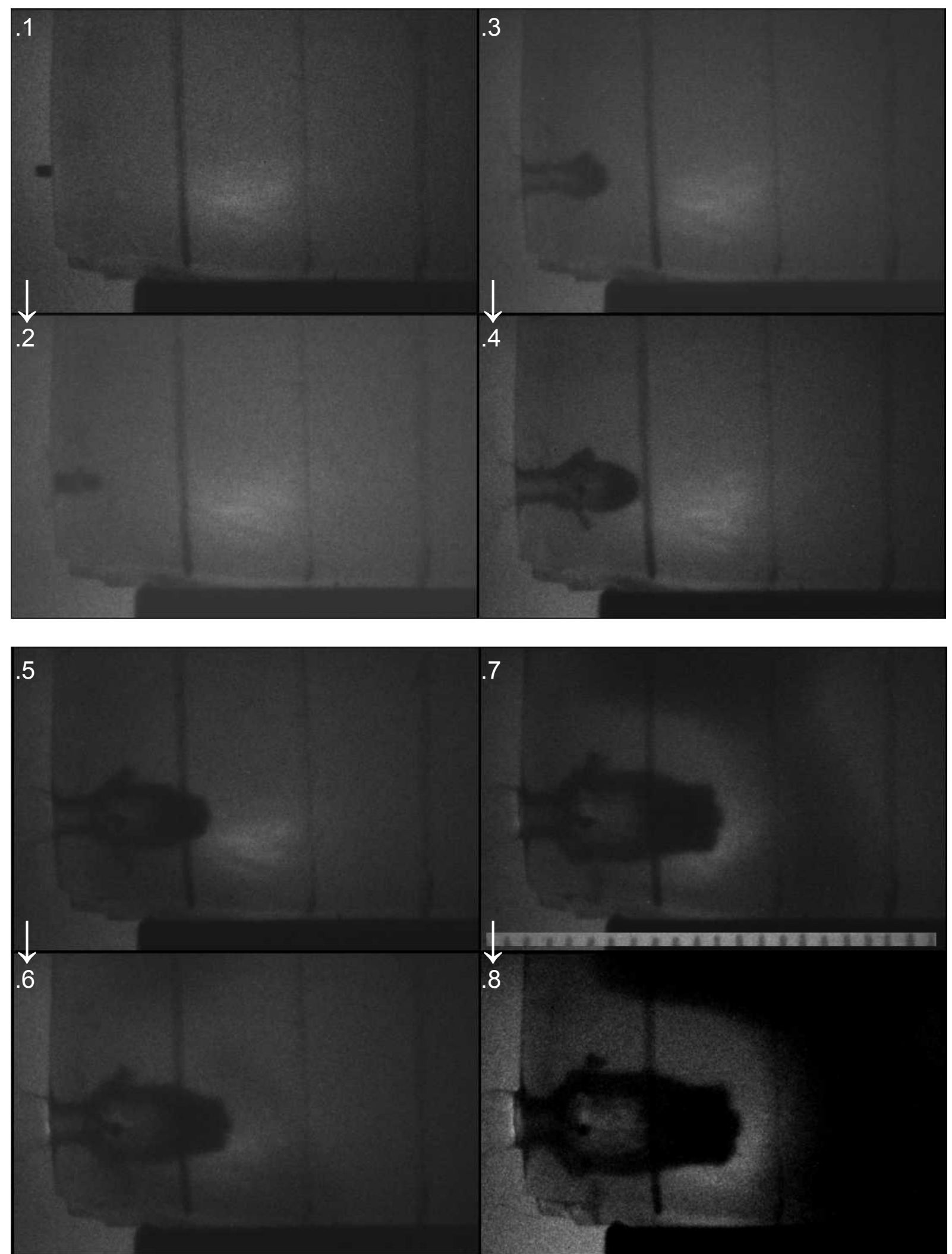

Photo s-03: Wie sich eine temporäre Höhle in Gelatine ausbreitet. Auf Bild 3 ist das Geschoss bereits fragmentiert. Vertikale Markierung: Abstände $5 \mathrm{~cm}$. Messstabmarken auf Bild 7: Abstände $1 \mathrm{~cm}$. 
zu Photo s-03: Geschoss: VMJ (3,0 g), Munition: 223.6, Ziel: Gelatine, $10^{\circ} \mathrm{C}$

Chrony 1:

Chrony 2:

Schusskanal:

Objektiv:

$1083 \mathrm{~m} / \mathrm{s}$

$28 \quad \mathrm{~mm}$

Belichtungsdauer: $\quad 2 \quad \mu s$

Zwischenbildzeit: $\quad 20 \quad \mu s$

Bild 1: $\quad 0 \quad \mu s$

Bild 2: $\quad 22 \quad \mu s$

Bild 3: $\quad 44 \quad \mu s$

Bild 4: $\quad 66 \quad \mu s$

Bild 5: $\quad 88 \quad \mu s$

Bild 6: $\quad 110 \quad \mu s$

Bild 7: $\quad 132 \quad \mu s$

Bild 8: $\quad 154 \quad \mu s$

Auf Bild 2 bis Bild 8 ist zu sehen, wie sich eine temporäre Höhle in Gelatine ausbreitet. Als temporäre Höhle bezeichnet SELLIER (1969, S. 122) die während und kurze Zeit nach Geschoßdurchgang vorhandene Höhle, deren „Ausdehnung offenbar von den elastischen Eigenschaften des durchdrungenen Gewebes abhängt". Auf Bild 3 ist das Vollmantelgeschoss bereits fragmentiert. Vor der Fragmentation ist keinerlei Geschossdrehung um die quere Achse abgebildet. (Auf den Originalphotos ist das besser zu sehen als hier auf den Kopien.)

Auf den folgenden Bildern übertragen größere Fragmente (insbesondere des Messingmantels) mehr Energie als kleinere Fragmente des Bleikerns und bleiben zurück. Die kleineren Fragmente des Bleikerns wandern mit der sich ausbreitenden temporären Höhlenfront.

Zwischen den vertikalen Markierungen auf dem Gelatineblock liegen 5 Zentimeter. In den unteren Teil von Bild 7 wurde nachträglich eine Maßskala eingefügt. Der Abstand zwischen zwei Teilstrichen entspricht einem Zentimeter (Kap. 5.2.2.).

Aus der Bildsequenz wurden der Geschwindigkeitsverlust und der Energieverlust des Geschosses innerhalb der ersten $154 \mu$ s errechnet. Dafür wurde zunächst die Geschwindigkeit, mit der sich die Höhlenfront in Schussrichtung ausbreitet, ermittelt:

\begin{tabular}{|c|c|c|c|}
\cline { 2 - 4 } \multicolumn{1}{c|}{} & Differenz [cm] & Zeitspanne $[\boldsymbol{\mu s}]$ & $\mathbf{v}_{\mathbf{3}}$ (Imacon) $[\mathbf{m} / \mathbf{s}]$ \\
\hline Bild s-03.1-2 & 2,43 & 22 & 1104 \\
\hline Bild s-03.2-3 & 1,87 & 22 & 850 \\
\hline Bild s-03.3-4 & 1,51 & 22 & 686 \\
\hline Bild s-03.4-5 & 1,59 & 22 & 723 \\
\hline Bild s-03.5-6 & 1,27 & 22 & 577 \\
\hline Bild s-03.6-7 & 0,80 & 22 & 364 \\
\hline Bild s-03.7-8 & 0,72 & 22 & 326 \\
\hline
\end{tabular}

\begin{tabular}{c|c|r}
$\sum$ Bild s-03.1-8 & 10,19 & 154
\end{tabular}

Tab. 4.2.5a.: Geschwindigkeit der Höhlenfront s-03 (bis $154 \mu \mathrm{s})$

Chrony 1: $1083 \mathrm{~m} / \mathrm{s}$

Es fällt auf, dass das Geschoss im Ziel innerhalb von $44 \mu \mathrm{s}$ von $1104 \mathrm{~m} / \mathrm{s}$ auf $686 \mathrm{~m} / \mathrm{s}$ abgebremst wird und sich fragmentiert. Innerhalb der folgenden $22 \mu \mathrm{s}$ breitet sich die temporäre Höhle mit ungefähr $723 \mathrm{~m} / \mathrm{s}$ aus. 
Wenn man zur Berechnung der Geschossenergie von einer konstanten Geschossmasse von 0,3 g ausgeht, kann aus den Geschossgeschwindigkeiten auch die Geschossenergie und der Energieverlust errechnet werden.

Zur Berechnung des Energieverlustes kann die Geschossenergie zweimal (aus insgesamt je drei Bildern) ermittelt und voneinander subtrahiert werden. Auswertefehler (Kap. 4.2.) gehen dabei in die Berechnung ein:

\begin{tabular}{|c|c|c|c|}
\hline & $\Delta E[J]$ & Differenz [cm] & Energieverlust [J/cm] \\
\hline Bild s-03.1 - 3 & 744,474 & 4,30 & 173,13 \\
\hline Bild s-03.2-4 & 377,856 & 3,38 & 111,79 \\
\hline Bild s-03.3-5 & $-78,200$ & 3,10 & $-25,23$ \\
\hline Bild s-03.4-6 & 284,7 & 2,86 & 99,55 \\
\hline Bild s-03.5-7 & 300,65 & 2,07 & 145,24 \\
\hline Bild s-03.6-8 & 39,33 & 1,52 & 25,87 \\
\hline Bild s-03.1 - 8 & 1668,81 & 10,19 & 163,77 \\
\hline
\end{tabular}

Tab. 4.2.5b.: Energieverlust $s-03$ (bis $154 \mu s)$

Chrony 1:

$1083 \mathrm{~m} / \mathrm{s}$ 
4.2.6. Geschwindigkeit einer Höhlenfront in Gelatine (bis $700 \mu \mathrm{s})$
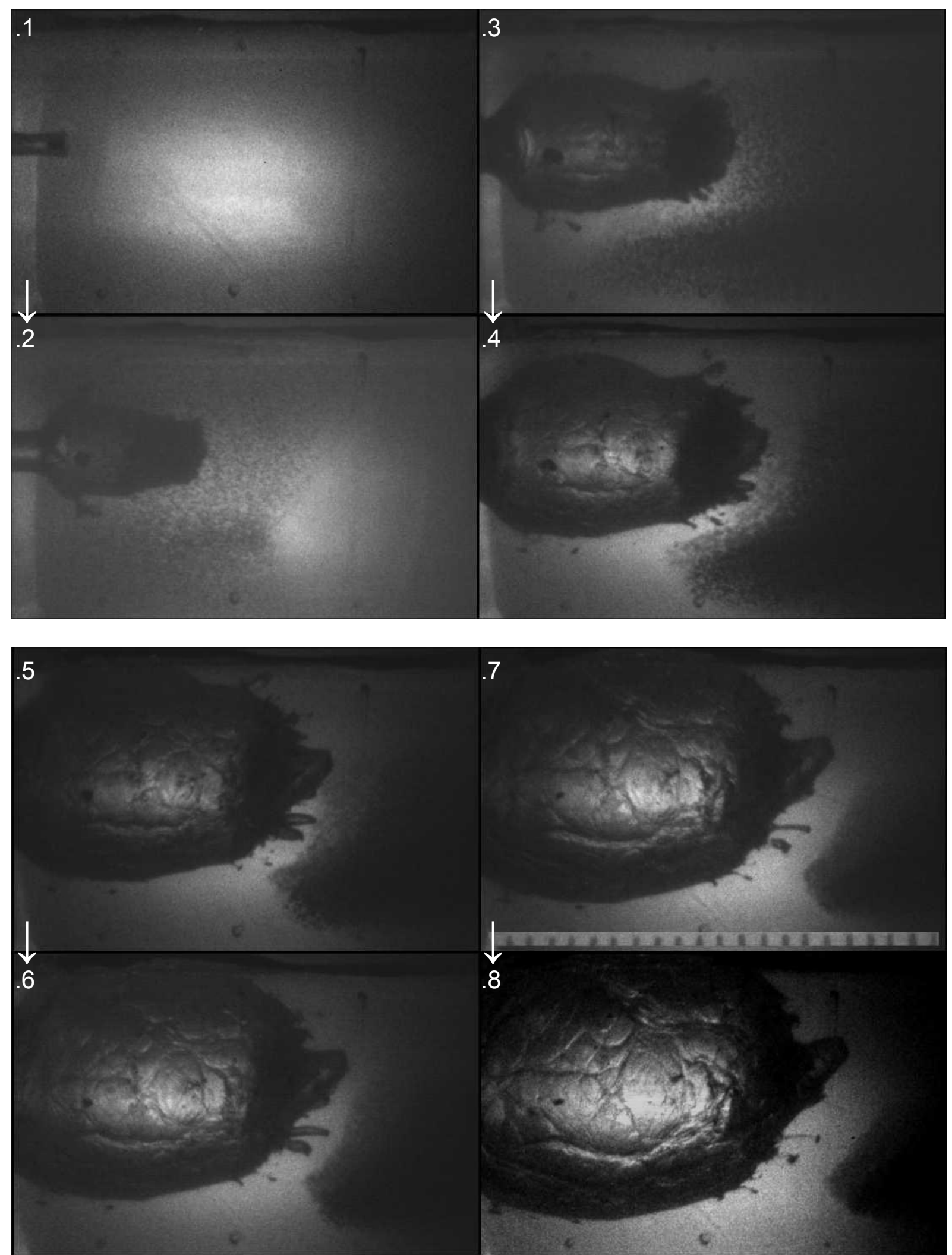

Photo s-17: Ausbreitung einer temporären Höhle. Auf Bild 2 ist das Geschoss bereits fragmentiert. Auf Bild 6 haben einzelne Fragmente eigene kleine temporäre Höhlen erzeugt. 
zu Photo s-17: Geschoss: VMJ (3,0 g), Munition: 223.6, Ziel: Gelatine, $10^{\circ} \mathrm{C}$

Chrony 1:

Chrony 2:

Schusskanal:

Objektiv:

$1069 \mathrm{~m} / \mathrm{s}$

$28 \mathrm{~mm}$

Belichtungsdauer: $2 \quad \mu s$

Zwischenbildzeit: $\quad 98 \quad \mu s$

Bild 1: $\quad 0 \quad \mu s$

Bild 2: $\quad 100 \quad \mu s$

Bild 3: $\quad 200 \quad \mu s$

Bild 4: $\quad 300 \quad \mu s$

Bild 5: $\quad 400 \quad \mu s$

Bild 6: $\quad 500 \quad \mu s$

Bild 7: $\quad 600 \quad \mu s$

Bild 8: $\quad 700 \quad \mu s$

Auf Bild 1 bis Bild 8 ist zu sehen, wie sich die temporäre Höhle in Gelatine ausbreitet. Auf Bild 2 ist das Vollmantelgeschoss bereits fragmentiert. Die Fragmentation erfolgt ohne vorherige Geschossdrehung um die quere Achse. (Auf den Originalphotos sieht man das besser.)

Die Zwischenbildzeiten wurden so gewählt, dass anhand der Aufnahmen der Geschwindigkeitsverlust und der Energieverlust des Geschosses innerhalb der ersten $700 \mu$ s errechnet werden konnten.

$\mathrm{Zu}$ sehen ist auch, wie einzelne Geschossfragmente (z.B. auf Bild 6 im Bereich der temporären Höhlenfront) eigene kleine temporäre Höhlen erzeugen. Solche Höhlen schließen sich im weiteren Verlauf, wenn sich die nachfolgende große temporäre Höhle des Restgeschosses weiter ausbreitet.

Abseits der Höhle sind Bereiche des Gelatineblocks verschattet. Die dunklen Bereiche sind am ehesten durch Lichtbrechung an Gasblasen zu erklären. In Folge werden diese dunklen Bereiche als Gasblasenschwärme bezeichnet.

Auf gleiche Weise, wie im Kap. 4.2.6. beschrieben, wurde die Geschwindigkeit der Höhlenfront (bis $700 \mu \mathrm{s}$ ) ermittelt.

\begin{tabular}{|c|c|c|c|}
\hline & Differenz [cm] & Zeitspanne [us] & $\mathbf{V}_{3 \text { (Imacon) }[\mathrm{m} / \mathrm{s}]}$ \\
\hline Bild s-17.1 - 2 & 6,57 & 100 & 657 \\
\hline Bild s-17.2 - 3 & 2,79 & 100 & 279 \\
\hline Bild s-17.3-4 & 1,63 & 100 & 163 \\
\hline Bild s-17.4-5 & 1,35 & 100 & 135 \\
\hline Bild s-17.5-6 & 0,84 & 100 & 84 \\
\hline Bild s-17.6-7 & 0,88 & 100 & 68 \\
\hline Bild s-17.7 -8 & 0,68 & 100 & 68 \\
\hline$\sum$ Bild s-17.1 - 8 & 14,73 & 700 & 210 \\
\hline
\end{tabular}

Tab. 4.2.6a.: Geschwindigkeit der Höhlenfront s-17 (bis $700 \mu s$ )

Chrony 1 :

$1169 \mathrm{~m} / \mathrm{s}$ 


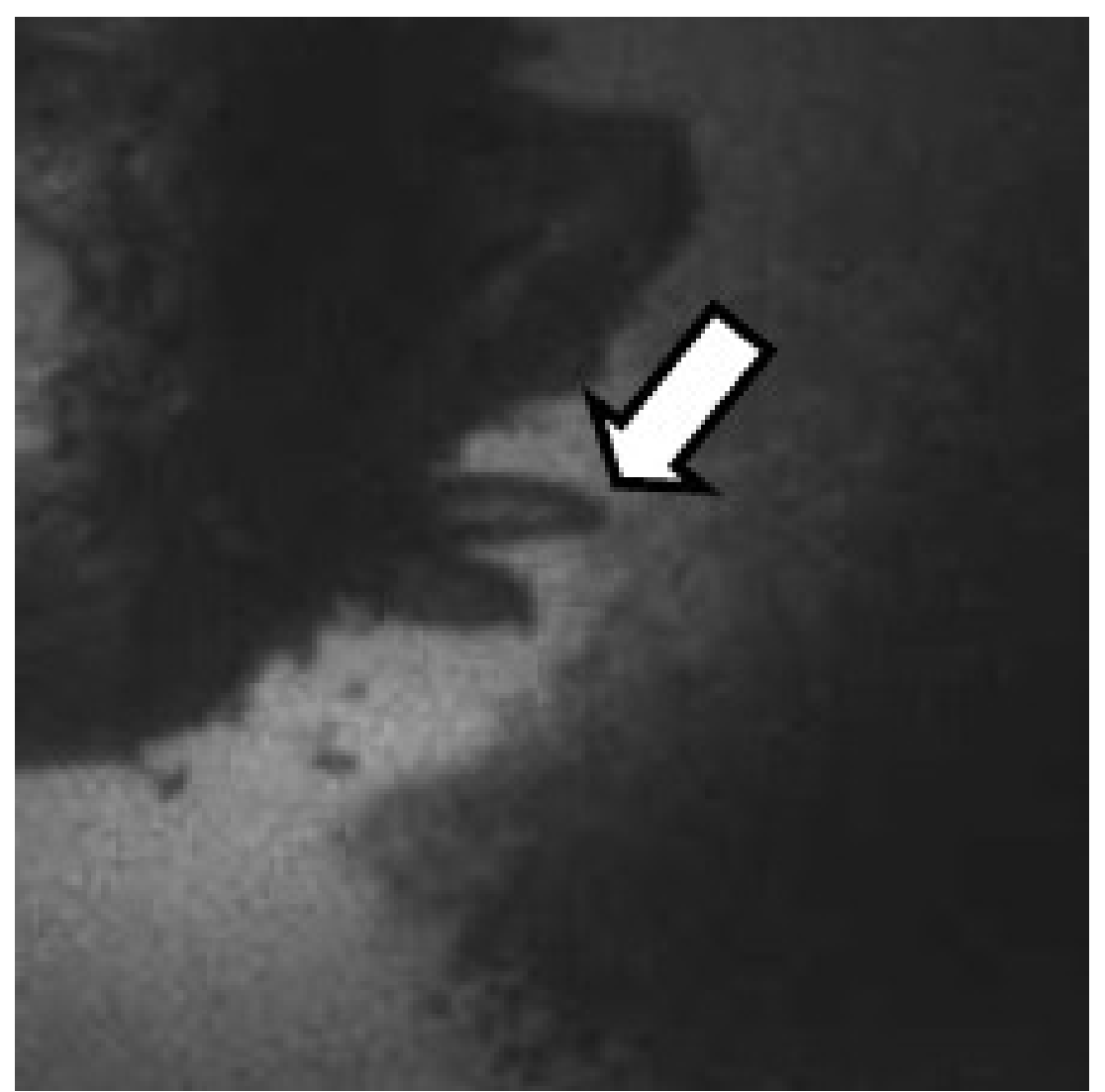

Vergrößerung von Photo s-17.5 (siehe Anfang des Kapitels)

Außerdem wurde die Geschwindigkeit eines Geschossfragmentes ermittelt, welches auf der Vergrößerung s-17.5 mit einem Pfeil markiert ist.

\begin{tabular}{|c|c|c|c|}
\cline { 2 - 4 } \multicolumn{1}{c|}{} & Differenz [cm] & Zeitspanne [ $\mathbf{\mu s}]$ & $\mathbf{V}_{\mathbf{3}}$ (Imacon) \\
\hline Bild s-17.1 -2 & 6,57 & 100 & 657 \\
\hline Bild s-17.2-3 & 2,35 & 100 & 235 \\
\hline Bild s-17.3-4 & 1,67 & 100 & 167 \\
\hline Bild s-17.4-5 & 1,00 & 100 & 100 \\
\hline Bild s-17.5-6 & 0,60 & 100 & 60 \\
\hline Bild s-17.6-7 & 0,40 & 100 & 40 \\
\hline Bild s-17.7-8 & 0,40 & 100 & 40 \\
\hline
\end{tabular}

\begin{tabular}{|c|c|c|c|}
\hline$\sum$ Bild s-17.1-8 & $\mathbf{1 2 , 9 9}$ & 700 & 186 \\
\hline
\end{tabular}

Tab.4.2.6b.: Geschwindigkeit der Fragmentfront s-17 (bis $700 \mu s$ )

Chrony 1:

$1169 \mathrm{~m} / \mathrm{s}$ 
Auch für s-17 wurde der Energieverlust des Geschosses berechnet und später ausgewertet (Kap. 5.3.2.6.):

\begin{tabular}{|c|c|c|c|}
\cline { 2 - 4 } \multicolumn{1}{c|}{} & $\boldsymbol{\Delta E}[\mathrm{J}]$ & Differenz $[\mathbf{c m}]$ & Energieverlust [J/cm] \\
\hline Bild s-17.1-3 & 564,63 & 8,92 & 63,30 \\
\hline Bild s-17.2-4 & 41,01 & 4,02 & 10,20 \\
\hline Bild s-17.3-5 & 26,83 & 2,67 & 10,05 \\
\hline Bild s-17.4-6 & 9,6 & 1,60 & 6 \\
\hline Bild s-17.5-7 & 3 & 1,00 & 3 \\
\hline Bild s-17.7-8 & 0 & 0,80 & 0 \\
\hline
\end{tabular}

\begin{tabular}{|c|c|c|c|}
\hline$\sum$ Bild s-17.1-8 & 645,07 & 12,99 & 33,93 \\
\hline
\end{tabular}

Tab. 4.3.2.6c.: Energieverlust s-17 (bis $700 \mu s$ )

Chrony 1:

$1169 \mathrm{~m} / \mathrm{s}$ 
4.2.7. Geschwindigkeit einer Höhlenfront in (einem Container, gefüllt mit flüssigem) Stickstoff
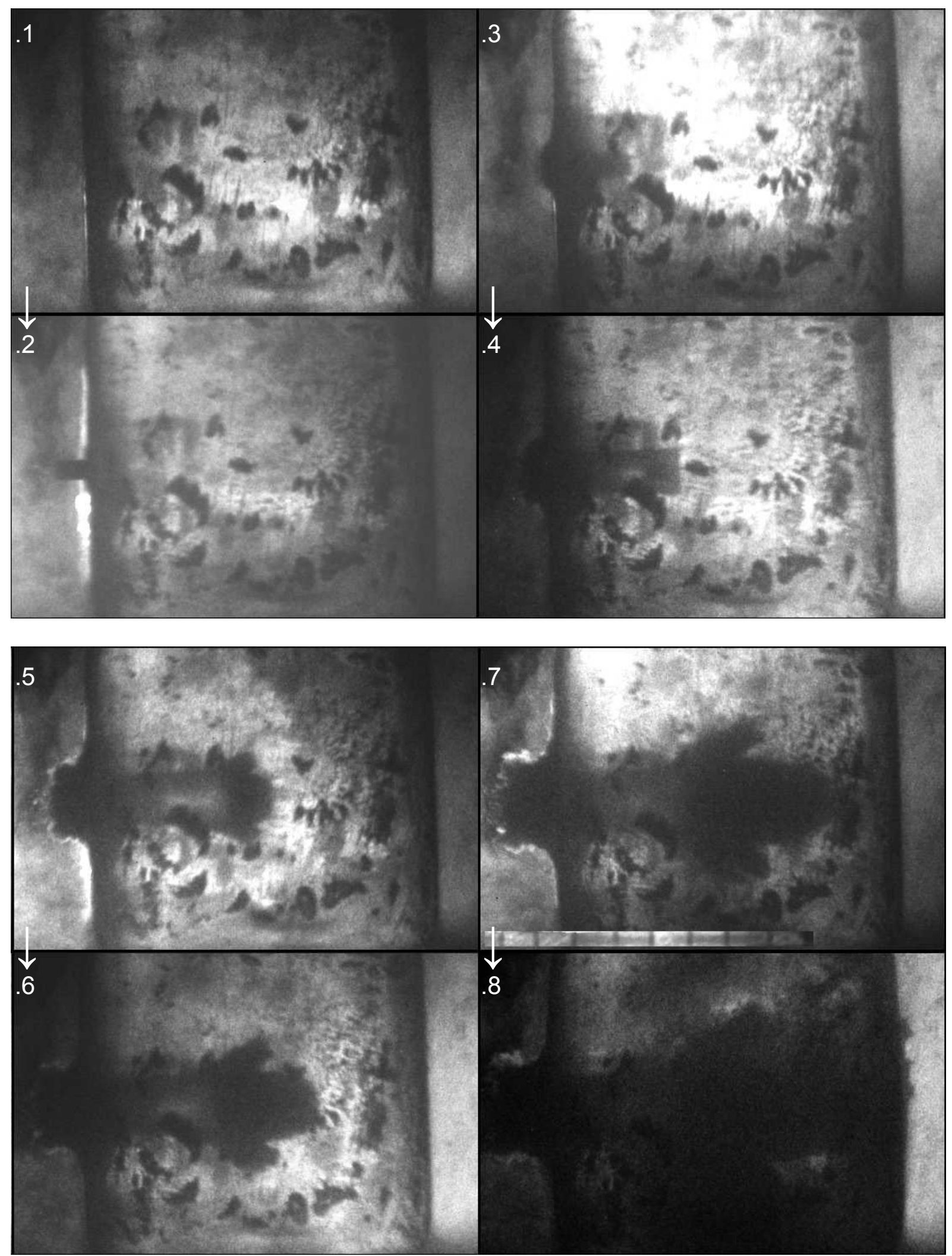

Photo s-43: Abgebildet ist die Zielhöhle in flüssigem Stickstoff. Durch Kondensation hat sich an der Außenseite des Containers eine Eisschicht gebildet, welche die Darstellung der Zielhöhle stört. Auf Bild 4 ist das Geschoss bereits fragmentiert. 
zu Photo s-43: Geschoss: VMJ (3,0 g), Munition: 223.7, Ziel: $\mathbf{N}_{2}$

$\begin{array}{lll}\text { Chrony 1: } & 1065 & \mathrm{~m} / \mathrm{s} \\ \text { Chrony 2: } & 455 & \mathrm{~m} / \mathrm{s} \\ \text { Objektiv: } & 50 & \mathrm{~mm} \\ \text { Belichtungsdauer: } & 2 & \mu \mathrm{s} \\ \text { Zwischenbildzeit: } & 15 & \mu \mathrm{s}\end{array}$

Bild 1: $\quad 0 \quad \mu s$

Bild 2: $\quad 17 \quad \mu s$

Bild 3: $\quad 34 \quad \mu s$

Bild 4: $\quad 51 \quad \mu s$

Bild 5: $\quad 68 \quad \mu s$

Bild 6: $\quad 85 \quad \mu s$

Bild 7: $\quad 102 \quad \mu s$

Bild 8: $\quad 119 \quad \mu s$

Stickstoff siedet bei $-197^{\circ} \mathrm{C}$. Im Container steigen Gasblasen auf und brechen das Durchlicht. An der Außenwand des Containers hat sich bereits eine Eisschicht aus Kondenswasser gebildet, welche die Auswertung der Bilder erschwert.

Die temporäre Höhle breitet sich in Stickstoff ähnlich aus wie in Gelatine. Das Geschoss ist auf Bild 4 bereits fragmentiert. Auf den folgenden Bildern 5 bis 8 sind einzelne Geschossfragmente gut abgrenzbar.

Die Geschwindigkeit wurde berechnet, mit welcher sich die temporäre Höhle in Stickstoff ausbreitet:

\begin{tabular}{|c|c|c|c|}
\hline & Differenz [cm] & Zeitspanne [ $\mu s]$ & $\mathbf{V}_{3 \text { (Imacon) }[\mathrm{m} / \mathrm{s}]}$ \\
\hline Bild s-43.3-4 & 1,30 & 17 & 765 \\
\hline Bild s-43.4-5 & 1,57 & 17 & 924 \\
\hline Bild s-43.5-6 & 1,20 & 17 & 706 \\
\hline Bild s-43.6 - 7 & 1,26 & 17 & 741 \\
\hline$\sum$ Bild s-43.3 - 7 & 5,33 & 68 & 784 \\
\hline
\end{tabular}

Tab. 4.2.7.: Geschwindigkeit der Höhlenfront in Stickstoff s-43

Chrony 1:

Chrony 2:

$1065 \mathrm{~m} / \mathrm{s}$

$455 \mathrm{~m} / \mathrm{s}$

Das Geschoss hat sich innerhalb 34 us von 1065 m/s auf 765 m/s verzögert. 


\subsubsection{Maximaler Durchmesser einer temporären Höhle}
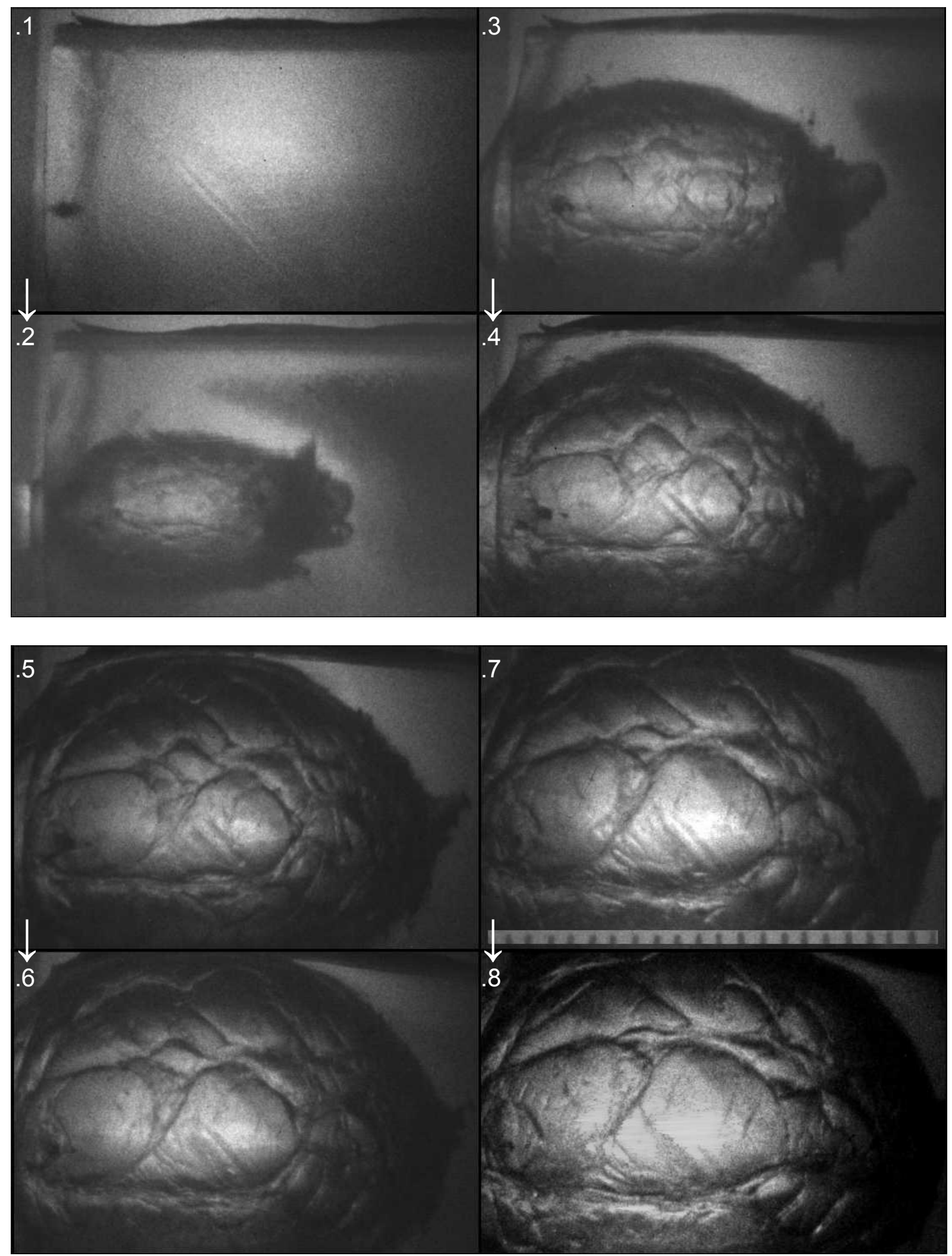

Photo s-18: Ausbreitung einer temporären Höhle. Auf Bild 8: Maximale Größe der Höhle. Auf Bild 2: Geschoss bereits fragmentiert. 
zu Photo s-18: Geschoss: VMJ (3,0 g) Munition: 223.6, Ziel: Gelatine, $10^{\circ} \mathrm{C}$

Chrony 1:

Chrony 2:

Schusskanal:

Objektiv: $1069 \mathrm{~m} / \mathrm{s}$

$0,155 \mathrm{~cm}$

Belichtungsdauer: $\quad 2$

Zwischenbildzeit: $\quad 298 \quad \mu s$

$\begin{array}{lll}\text { Bild 1: } & 0 & \mu s \\ \text { Bild 2: } & 300 & \mu s \\ \text { Bild 3: } & 600 & \mu s \\ \text { Bild 4: } & 900 & \mu s \\ \text { Bild 5: } & 1200 & \mu s \\ \text { Bild 6: } & 1500 & \mu s \\ \text { Bild 7: } & 1800 & \mu s \\ \text { Bild 8: } & 2100 & \mu s\end{array}$

$\mathrm{Ab}$ dem Bild 2 ist zu sehen, wie sich eine temporäre Höhle in Gelatine ausbreitet. Auf Bild 2 ist das Vollmantelgeschoss bereits fragmentiert.

Die Zwischenbildzeiten wurden so gewählt, dass die Ausbreitung der temporären Höhle fast bis zur Ausbildung des Maximaldurchmessers verfolgt werden kann. Für den Durchmesser haben wir folgende Werte ausgemessen.

\begin{tabular}{|c|c|}
\cline { 2 - 2 } \multicolumn{1}{c|}{} & Durchmesser [cm] \\
\hline Bild s-18.1 & - \\
\hline Bild s-18.2 & 8,2 \\
\hline Bild s-18.3 & 11,5 \\
\hline Bild s-18.4 & 13,9 \\
\hline Bild s-18.5 & 15,3 \\
\hline Bild s-18.6 & 16,7 \\
\hline Bild s-18.7 & 17,4 \\
\hline
\end{tabular}

Tab. 4.2.8.: maximaler Durchmesser der temporären Höhle s-18

Chrony 1: $1027 \mathrm{~m} / \mathrm{s}$ 
Zur besseren Übersicht lassen sich die Werte auch graphisch darstellen:

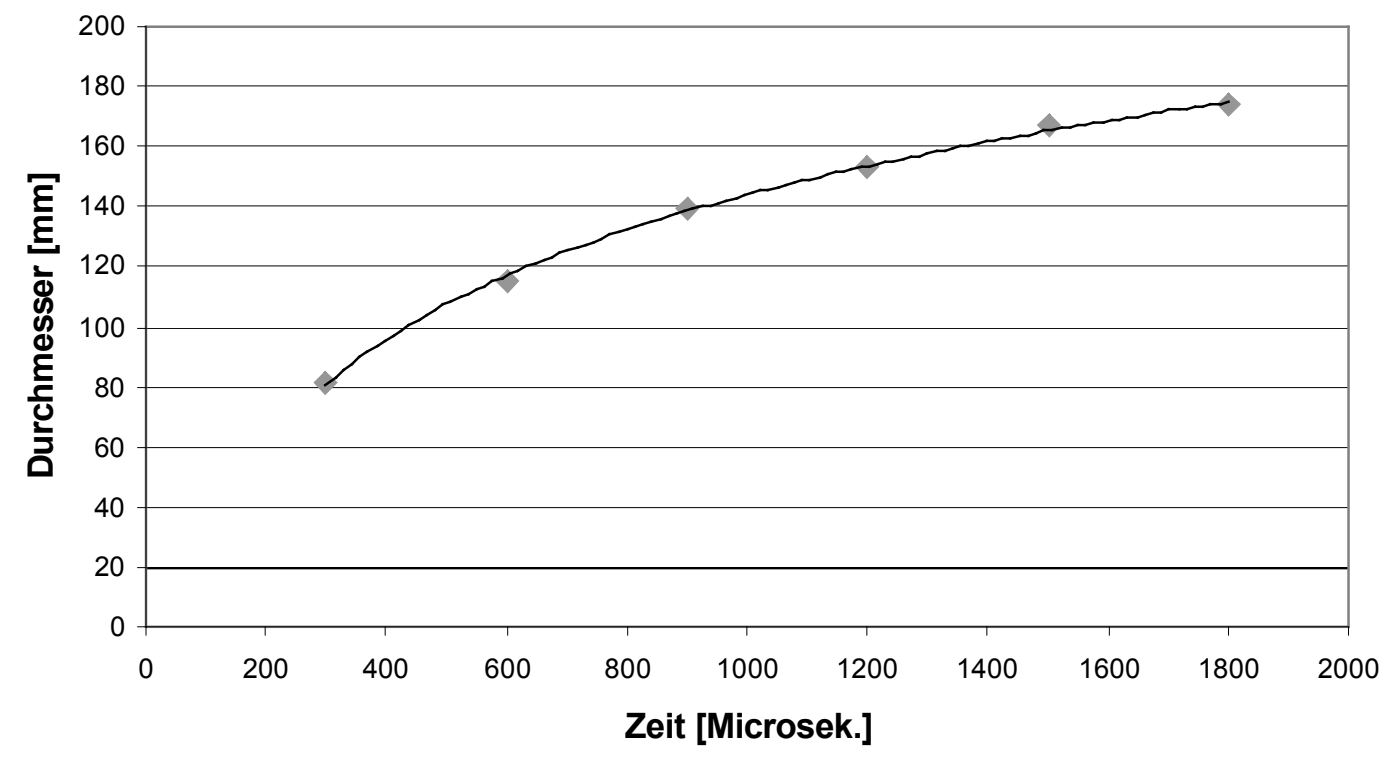

Graph 4.2.8.: Entwicklung des maximalen Durchmessers der temporären Höhle s-18 (in Abhängigkeit von der Zeit)

Aus Sicht der Kamera betrachtet erscheint die temporäre Höhle zunächst eher oval. Erst später bildet sie sich zunehmend rund ab. Die Größe der maximalen Ausbreitung der temporären Höhle erreicht dann fast $18 \mathrm{~cm}$. Das $1027 \mathrm{~m} / \mathrm{s}$ schnelle VMJ s-18 hat eine temporäre Höhle erzeugt, die in ihrer maximalen Ausdehnung ca. 32 mal dem Geschossdurchmesser entspricht.

Andere Autoren hatten andere Werte genannt (s. Kap. Diskussion: 5.3.2.9.). 
4.2.9. Gasballonkollaps in Wasser abseits vom Schusskanal
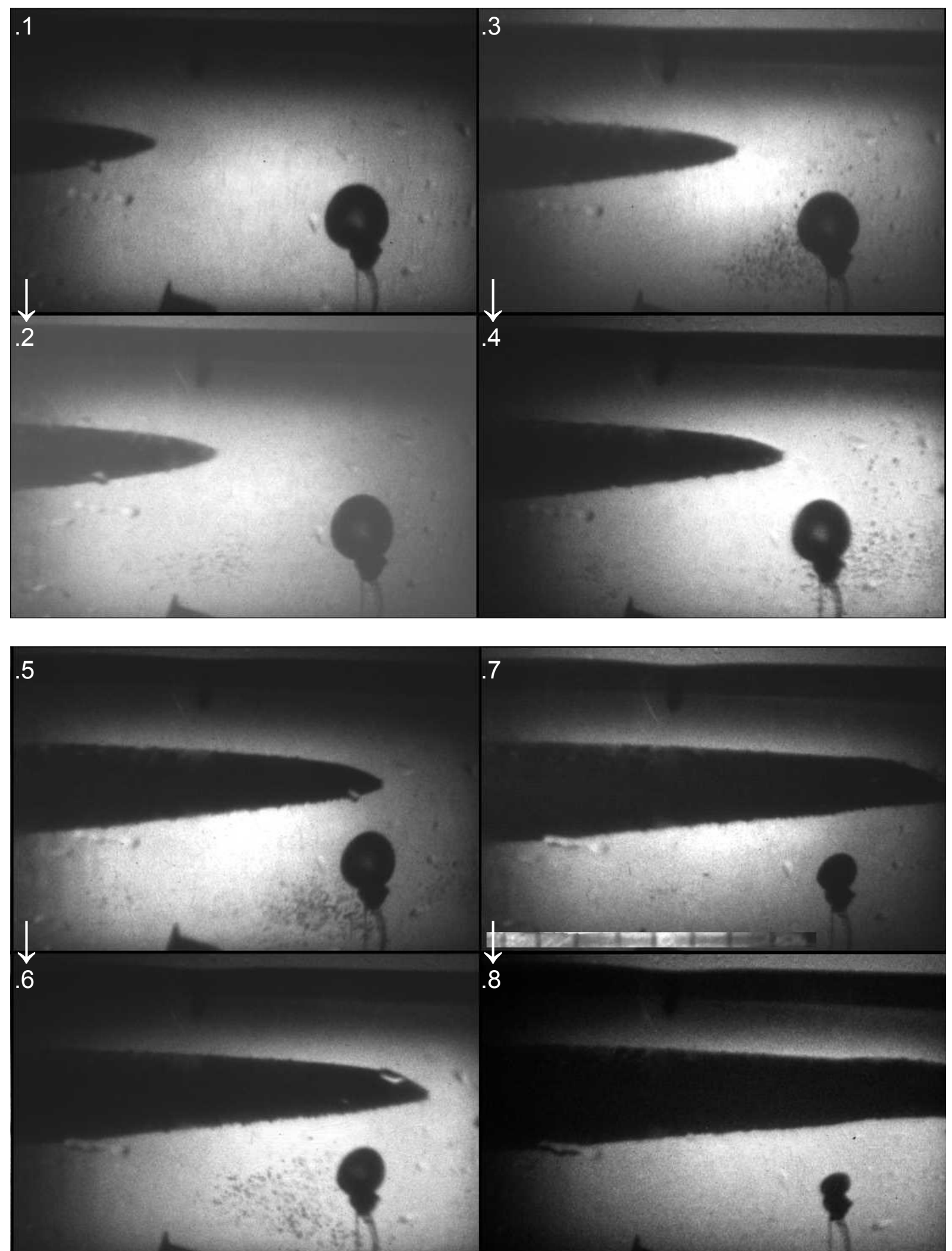

Photo s-66: Schuss auf eine mit Wasser gefüllte Plastikflasche. Ein mit Luft gefüllter, an einem Faden fixierter Ballon verkleinert seinen Durchmesser beim Überschießen von 17,3 mm (Bild 1) auf 7,6 mm (Bild 8). 
zu Photo s-66: Geschoss: VMJ (3,56 g), Munition: PMC, Ziel: Wasser mit Gasballon

Chrony 1:

Chrony 2:

Objektiv:

Belichtungsdauer:

Zwischenbildzeit:

$$
889 \mathrm{~m} / \mathrm{s}
$$

$50 \mathrm{~mm}$

$1,5 \mu s$

$14,5 \mu s$

Bild 1: $\quad 0 \quad \mu s$

Bild 2: $\quad 15 \quad \mu s$

Bild 3: $\quad 30 \quad \mu s$

Bild 4: $\quad 45 \quad \mu s$

Bild 5: $\quad 60 \quad \mu s$

Bild 6: $\quad 75 \quad \mu s$

Bild 7: $\quad 90 \quad \mu s$

Bild 8: $\quad 105 \mu \mathrm{s}$

Im letzten Kapitel (Kap. 4.2.8.) wurde eine expandierende temporäre Höhle abgebildet. Hier nun wird ein Blasenkollaps abseits der expandierenden temporären Höhle dargestellt. Zu diesem Zweck wurde eine mit 1,5 Liter Wasser gefüllte Plastikflasche beschossen. Der Einschuss befand sich am Boden der liegenden Flasche. Im Sichtfeld der Kamera wurde direkt unterhalb des Schusskanals ein luftgefüllter Ballon in der Flüssigkeit mittels eines Fadens fixiert.

Der luftgefüllte Gasballon hatte einen Ausgangsdurchmesser von 17,3 mm. Dieser verkleinerte sich beim Überschuss innerhalb von $105 \mu \mathrm{s}$ auf 7,6 mm.

\begin{tabular}{|c|c|c|}
\cline { 2 - 3 } \multicolumn{1}{c|}{} & Durchmesser [mm] & Volumen [ $\mathbf{m m}^{3}$ ] \\
\hline Bild s-60.1 & 17,3 & 2711 \\
\hline Bild s-60.2 & 16,4 & 2310 \\
\hline Bild s-60.3 & 16,2 & 2226 \\
\hline Bild s-60.4 & 15,3 & 1875 \\
\hline Bild s-60.5 & 14,5 & 1596 \\
\hline Bild s-60.6 & 12,0 & 905 \\
\hline Bild s-60.7 & 10,0 & 524 \\
\hline Bild s-60.7 & 07,6 & 230 \\
\hline
\end{tabular}

Tab. 4.2.9.: Gasballonkollaps in Wasser

Chrony 1:

$889 \mathrm{~m} / \mathrm{s}$ 
Der zunächst ziemlich große Durchmesser der Luftblase verringert sich bereits, bevor das Geschoss auf Höhe derselben ist. Die Zeit, innerhalb der eine Gasblase kollabiert, lässt Rückschlüsse auf den Umgebungsdruck zu (Kap. 5.3.2.9.). Zu sehen ist weiter, wie in einem Bereich vor dem Gasballon zwischenzeitlich kleine Verschattungen entstehen:

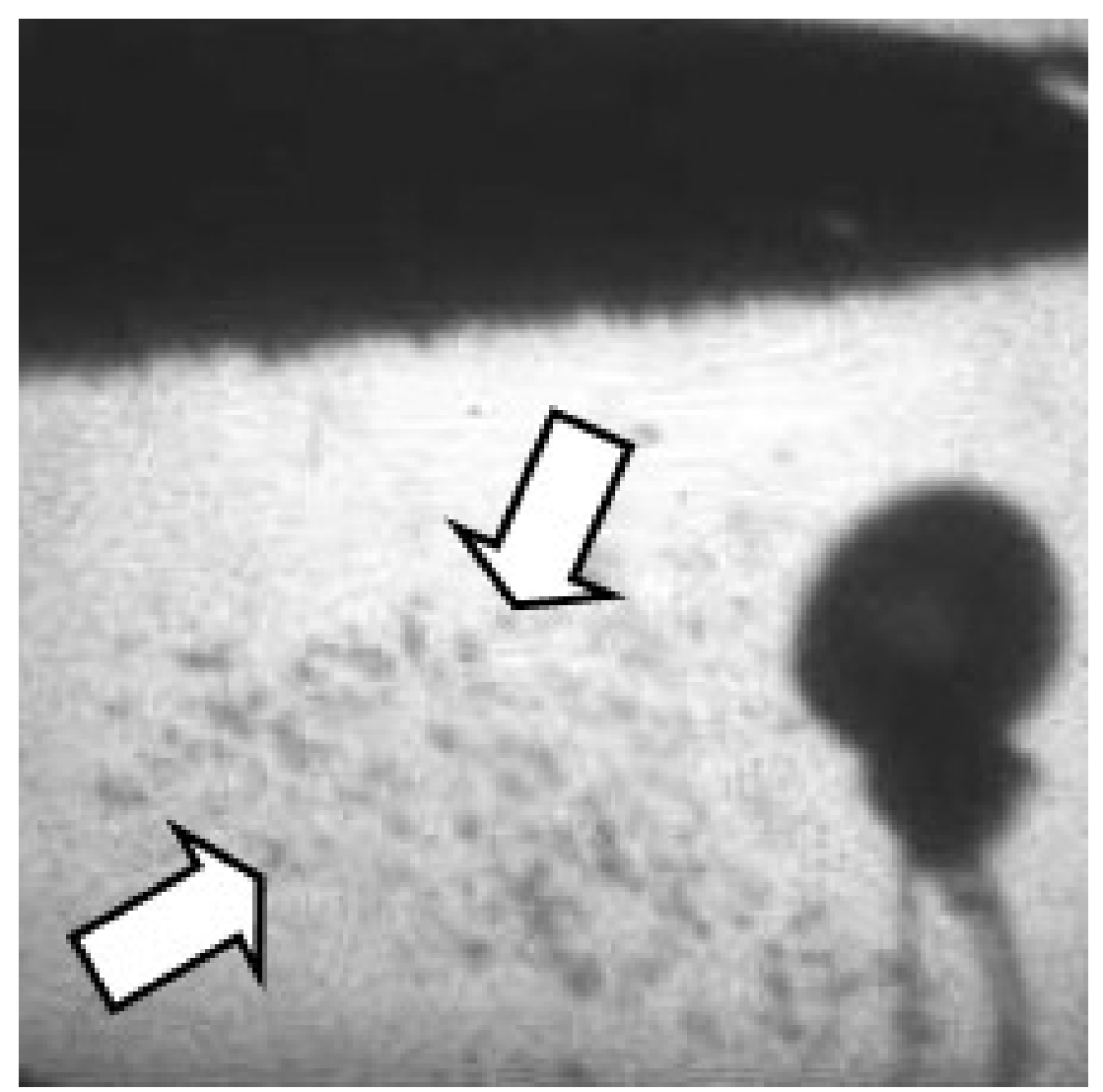

Vergrößerung von Photo s-66.6 (siehe Anfang des Kapitels)

Diese Verschattungen sind auf vier Bildern hintereinander abgebildet. Bereits auf Bild 7 sind sie nicht mehr sichtbar. Die Verschattungen werden ab Kapitel 4.2.11. weiter beschrieben.

Es fällt auf, dass das $889 \mathrm{~m} / \mathrm{s}$ schnelle und massive Messinggeschoss sich nicht in Wasser zerlegt. Bis zum Bild 7 steilt es sich leicht um seine Querachse auf.

Im folgenden Kapitel (Kap. 4.2.10.) dreht sich ein weiteres massives Geschoss sogar weit mehr um seine quere Achse als hier s-66. 
4.2.10. Zielprofil eines massiven Messinggeschosses in Gelatine
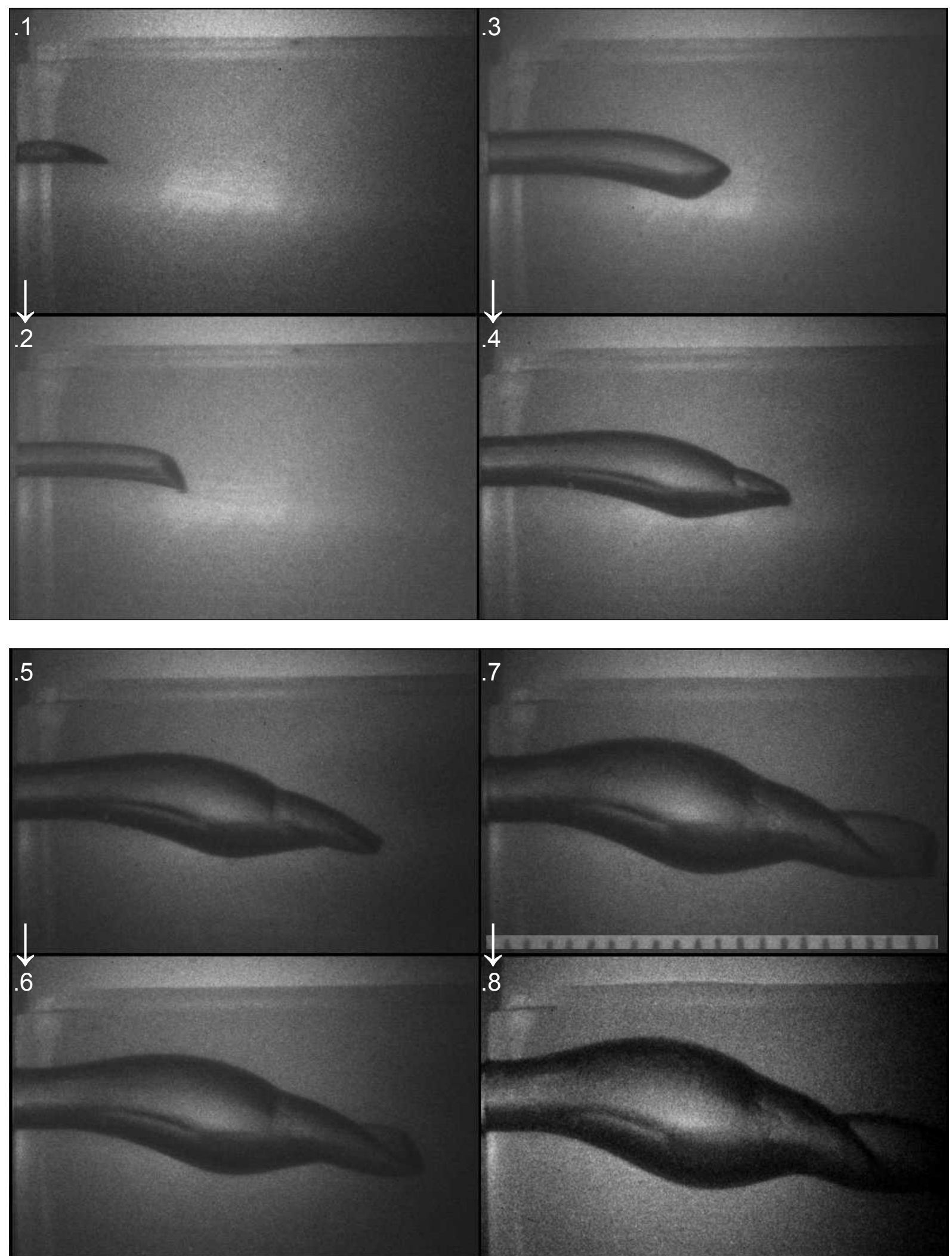

Photo s-23: Das Geschoss dreht sich um seine Querachse (auf Bild 2 bereits um $53^{\circ}$ ). 
zu Photo s-23: Geschoss: Solid (3,0 g), Munition: 223.solid, Ziel: Gelatine, $10^{\circ} \mathrm{C}$

$\begin{array}{lll}\text { Chrony 1: } & 1027 & \mathrm{~m} / \mathrm{s} \\ \text { Chrony 2: } & - & \\ \text { Objektiv: } & 28 & \mathrm{~mm} \\ \text { Belichtungsdauer: } & 2 & \mu \mathrm{s} \\ \text { Zwischenbildzeit: } & 40 & \mu \mathrm{s}\end{array}$

Bild 1: $\quad 0 \quad \mu s$

Bild 2: $\quad 42 \quad \mu s$

Bild 3: $\quad 84 \quad \mu s$

Bild 4: $\quad 126 \quad \mu s$

Bild 5: $\quad 168 \quad \mu s$

Bild 6: $\quad 210 \quad \mu s$

Bild 7: $\quad 252 \quad \mu s$

Bild 8: $\quad 294 \quad \mu s$

Dieses Geschoss also dreht sich weit mehr um seine quere Achse. Auf Bild 2 beträgt der gemessene Drehwinkel $53^{\circ}$. In der Vergrößerung ist das Geschoss als Verlängerung des Pfeils in dem Schusskanal abgebildet. Die schwarze Linie markiert die ursprüngliche (horizontale) Schussrichtung des Messinggeschosses, die weiße Linie markiert dessen Abweichung um seine quere Achse. Der Drehwinkel beträgt zu diesem Zeitpunkt $53^{\circ}$.

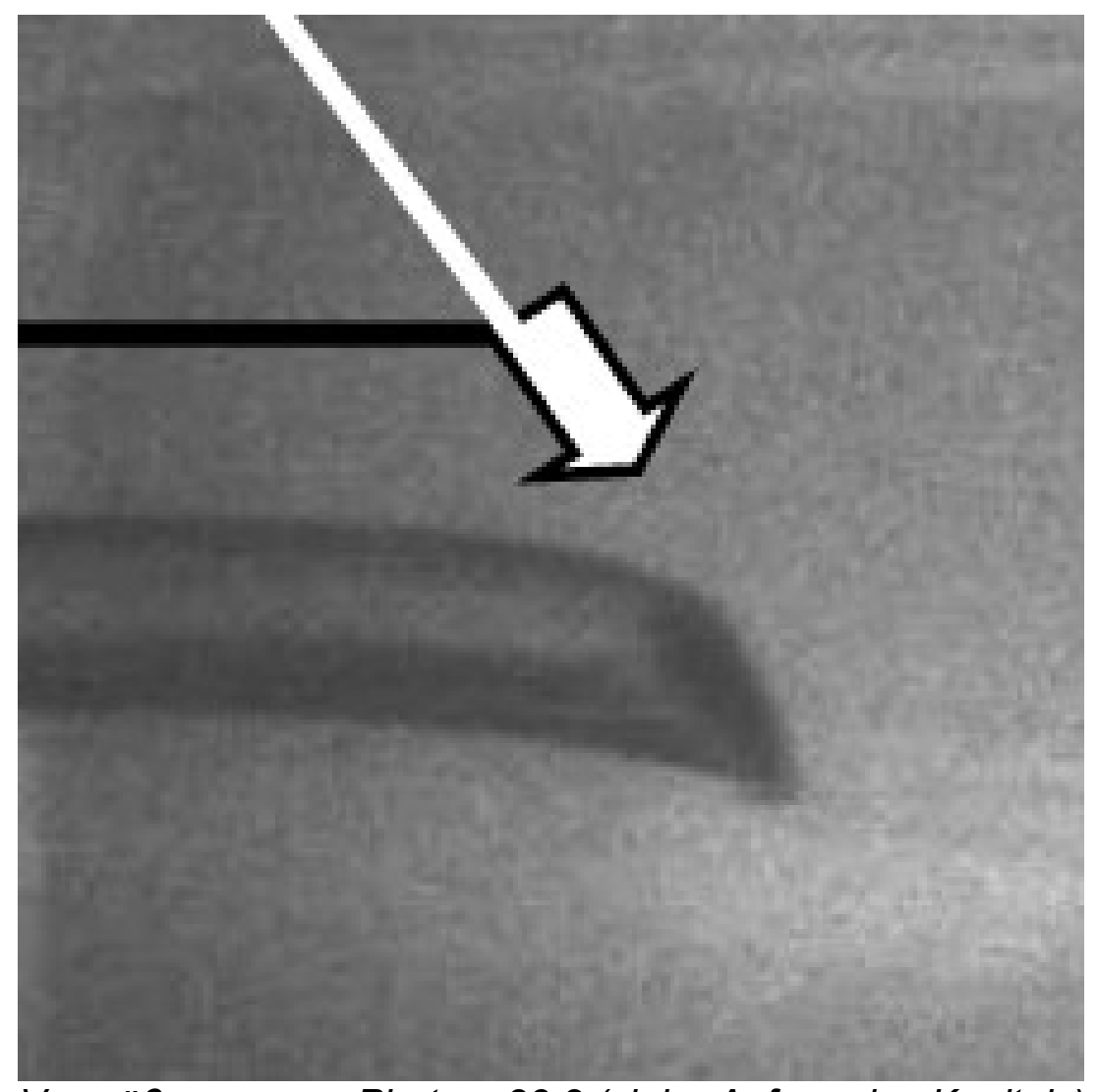

Vergrößerung von Photo s-23.2 (siehe Anfang des Kapitels) 
Auf Bild 3 beträgt der Drehwinkel dann $137^{\circ}$. Bis zum Bild 7 hat sich das Geschoss um $283^{\circ}$ gedreht und es ist davon auszugehen, dass sich das Geschoss im weiteren Verlauf auch weiter drehen wird.

Auf der Bildsequenz von s-23 ist auch abgebildet, wie sich die temporäre Höhle nach dem Geschossdurchtritt weiter ausbreitet. Der Durchmesser der temporären Höhle ist dort am größten, wo das Geschoss quer zur Schussrichtung stand.

In der Tabelle sind die ausgemessenen Drehwinkel um die quere Achse zusammengefasst.

\begin{tabular}{|c|c|}
\cline { 2 - 2 } \multicolumn{1}{c|}{} & Drehwinkel [ $\left.{ }^{\circ}{ }^{\circ}\right]$ \\
\hline Bild s-23.1 & 10 \\
\hline Bild s-23.2 & 53 \\
\hline Bild s-23.3 & 137 \\
\hline Bild s-23.4 & 187 \\
\hline Bild s-23.5 & 210 \\
\hline Bild s-23.6 & 251 \\
\hline Bild s-23.7 & 283 \\
\hline
\end{tabular}

$\sum$ Bild s-23.1-7

$>280$

Tab. 4.2.10a.: Drehwinkel des Messinggeschosses in Gelatine

Graphische Darstellung des Drehwinkels gegen die Strecke im Ziel:

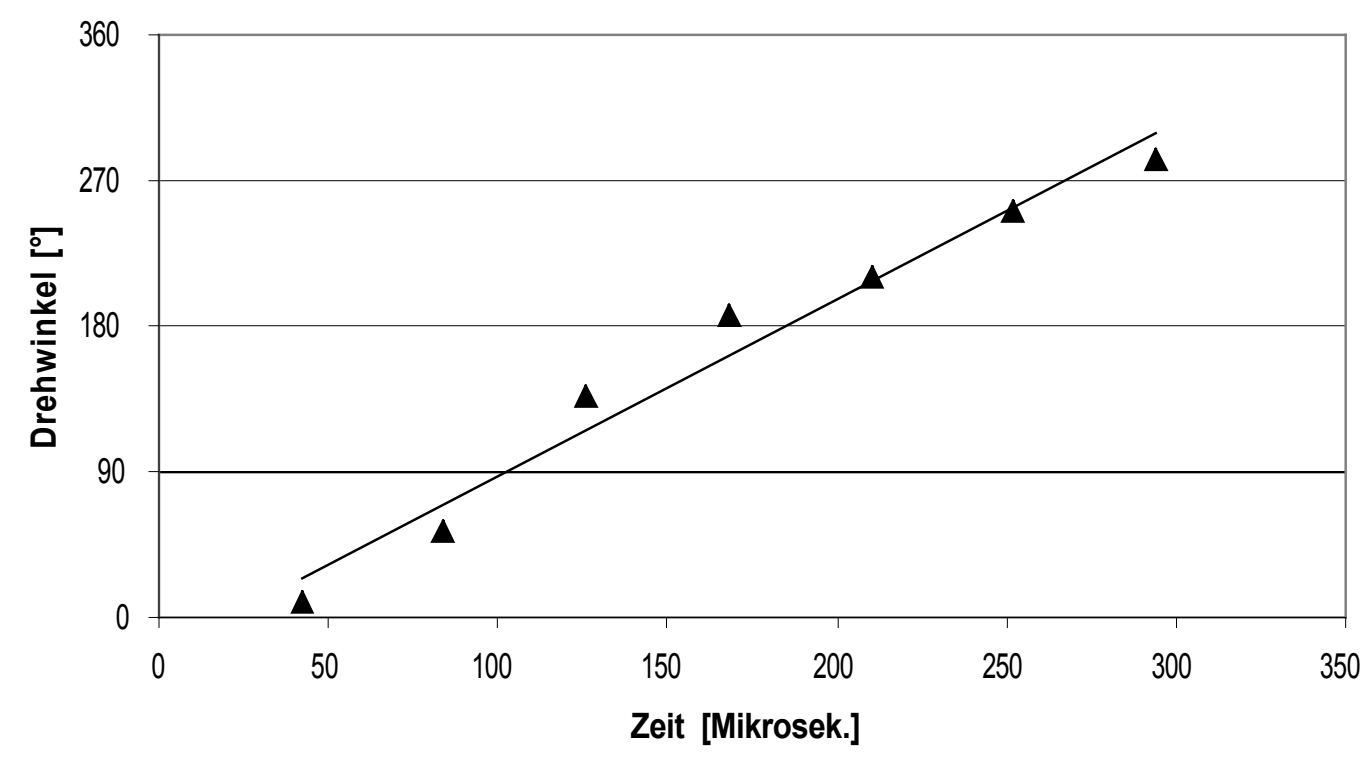

Graph 4.2.10a.: Drehwinkel des Messinggeschosses in Gelatine (s-23 in ballistischer Gelatine) 
Das Projektil dreht sich (von $10^{\circ}$ auf Bild 1) innerhalb von $252 \mu \mathrm{s}$ um $273^{\circ}$ (auf $283^{\circ}$ auf Bild 7). Die Drehwinkelgeschwindigkeit beträgt $\sim 1,09 \times 10^{6}\left[{ }^{\circ} / \mathrm{s}\right]$. Das entspricht $\sim 3,03 \times 10^{3}[\mathrm{U} / \mathrm{s}]$ Umdrehungen um die Querachse pro Sekunde.

Durch Messen der vom Geschoss in jeweils $42 \mu$ s zurückgelegten Wegstrecken erhält man folgende Geschwindigkeiten:

\begin{tabular}{|c|c|c|c|}
\hline & Differenz [cm] & Zeitspanne [us] & $V_{3 \text { (Imacon) }[\mathrm{m} / \mathrm{s}]}$ \\
\hline Bild s-23.1-2 & 3,66 & 42 & 871 \\
\hline Bild s-23.2-3 & 3,46 & 42 & 824 \\
\hline Bild s-23.3-4 & 2,79 & 42 & 664 \\
\hline Bild s-23.4 - 5 & 2,61 & 42 & 621 \\
\hline Bild s-23.5 -6 & 2,39 & 42 & 569 \\
\hline Bild s-23.6-7 & 1,87 & 42 & 445 \\
\hline$\sum$ Bild s-23.1 - 7 & 16,84 & 252 & 668 \\
\hline
\end{tabular}

Tab. 4.2.10b.: Geschwindigkeit des Messinggeschosses in Gelatine

Chrony 1: $\quad 1027 \mathrm{~m} / \mathrm{s}$

Graphische Darstellung der Geschwindigkeit gegen die Zeit:

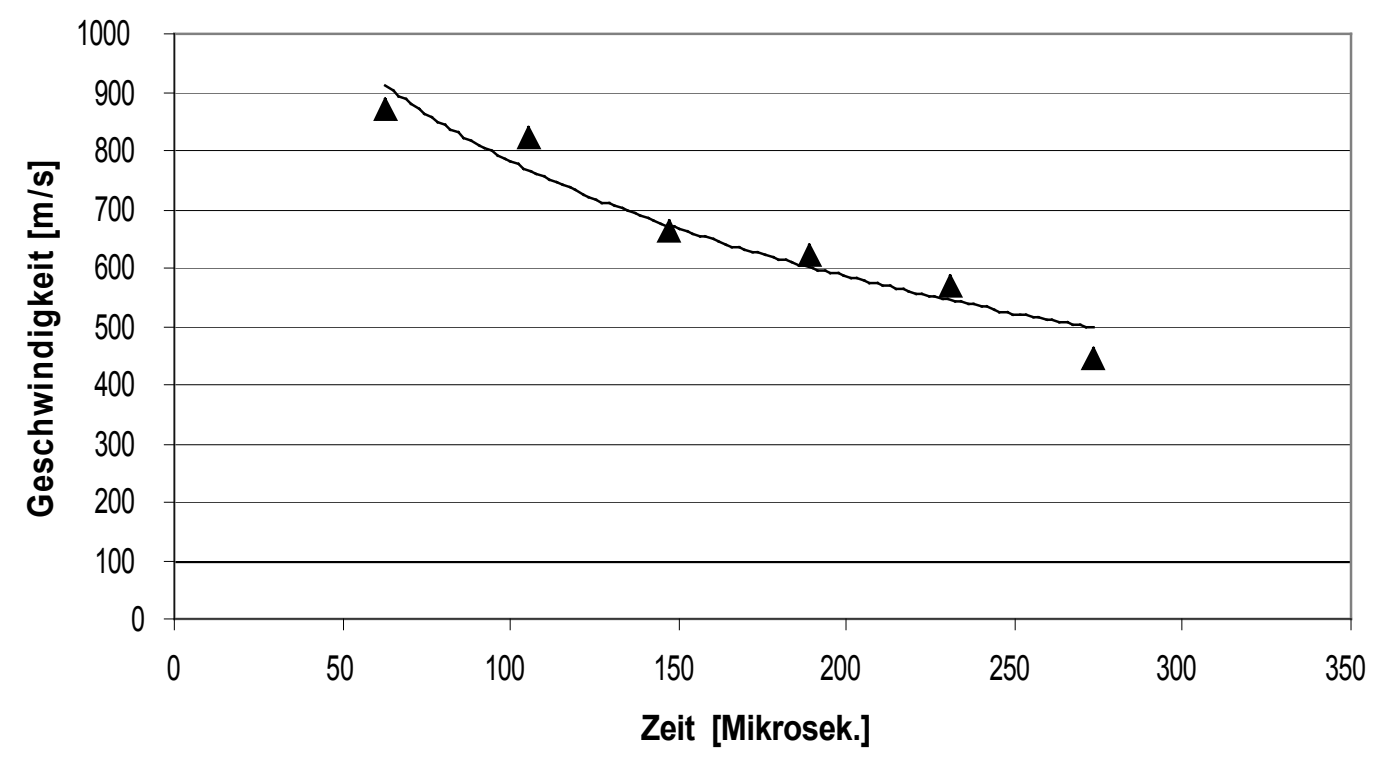

Graph 4.2.10b.: Geschwindigkeit des Messinggeschosses in Gelatine (s-23 in ballistischer Gelatine) 
Das Geschoss gibt, trotz vergleichbarer Masse und Form, weniger Energie ab als ein sich fragmentierendes VMJ (z.B. Kap. 4.2.5., s-03: 163,77 J/cm):

\begin{tabular}{|c|c|c|c|}
\cline { 2 - 4 } \multicolumn{1}{c|}{} & $\boldsymbol{\Delta E}[\mathbf{J}]$ & Differenz [cm] & Energieverlust [J/cm] \\
\hline Bild s-23.1-3 & 115 & 7,12 & 16,15 \\
\hline Bild s-23.2-4 & 346 & 6,25 & 55,36 \\
\hline Bild s-23.3-5 & 83 & 5,40 & 15,35 \\
\hline Bild s-23.4-6 & 93 & 5,00 & 18,56 \\
\hline Bild s-23.5-7 & 189 & 4,26 & 44,27 \\
\hline & & & \\
\hline
\end{tabular}

\begin{tabular}{|c|c|c|c|}
\hline$\sum$ Bild s-23.1 - 7 & 841 & 16,84 & 49,94 \\
\hline
\end{tabular}

Tab. 4.2.10c.: Energieverlust des Messinggeschosses in Gelatine Chrony 1: $1027 \mathrm{~m} / \mathrm{s}$

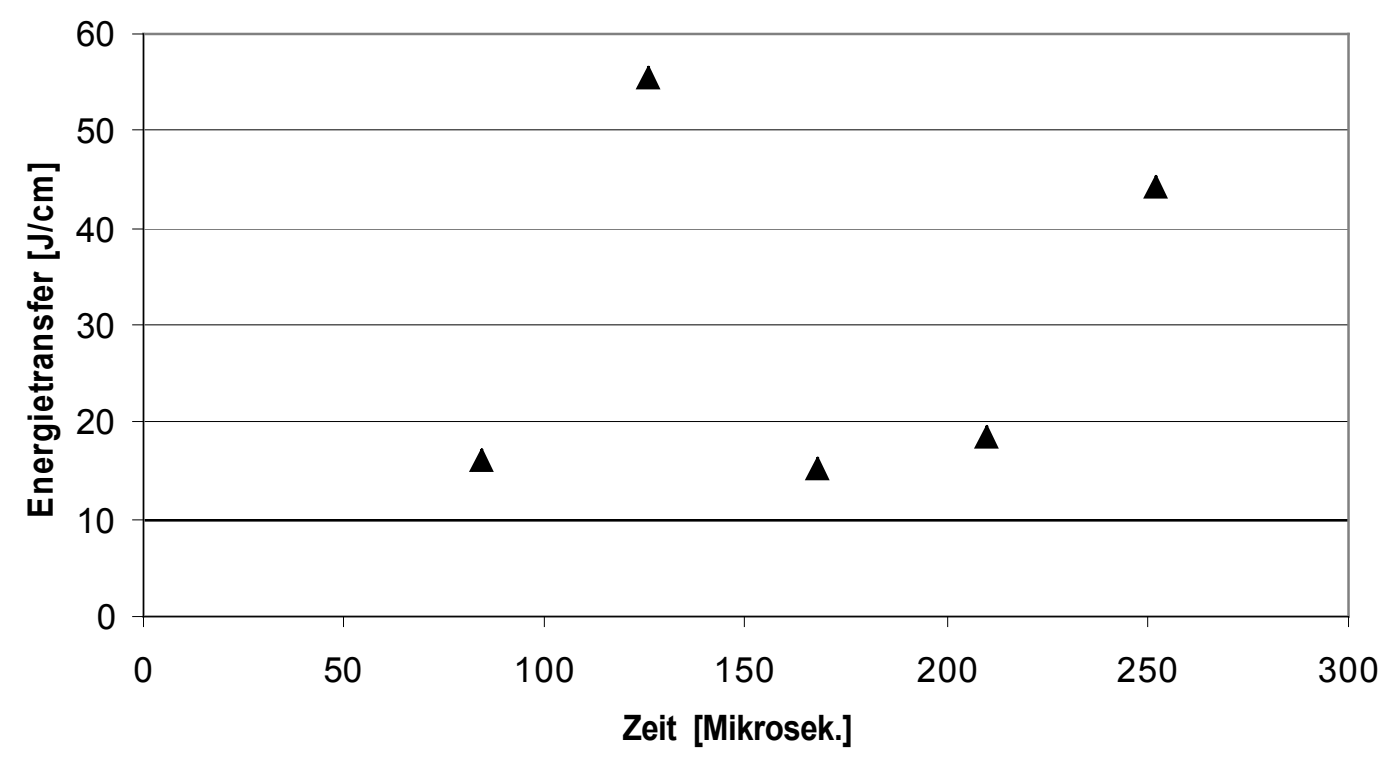

Graph 4.2.10c.: Energieverlust des Messinggeschosses in Gelatine (s-23 in ballistischer Gelatine)

Der Energieverlust und der Drehwinkel werden im Kapitel 5.3.2.10. weiter diskutiert. 


\subsubsection{Schwärme von Gasblasen abseits der temporären Höhle}
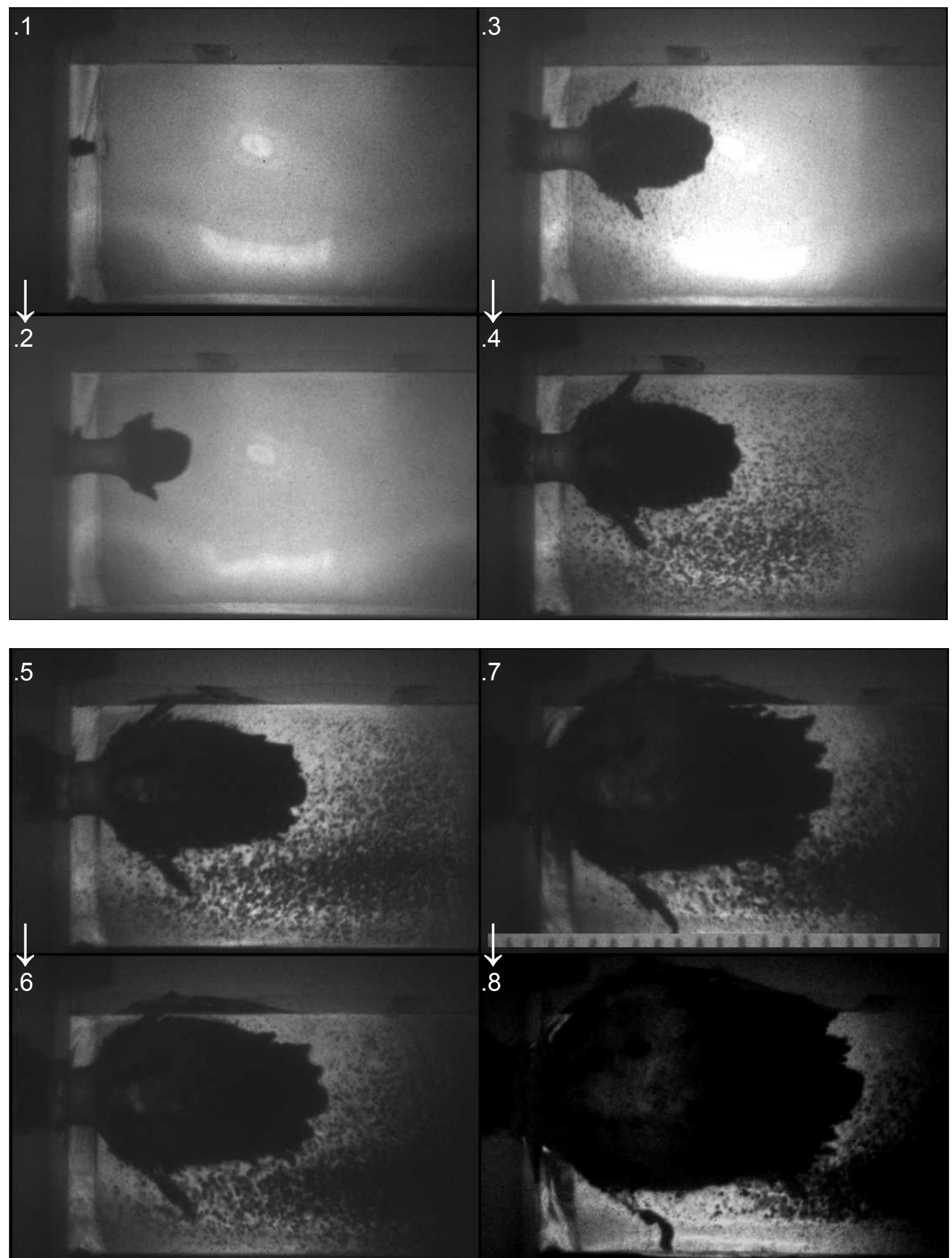

Photo s-25: Schuss auf einen rechteckigen und mit Wasser gefüllten Container. Verschattete Bereiche neben der temporären Höhle und an der Unterseite des Containers durch Lichtbrechung an kleinen Gasblasen. 
zu Photo s-25: Geschoss: VMJ (3,0 g), Munition: 223.6, Ziel: Wasser

$\begin{array}{lll}\text { Chrony 1: } & 1080 \mathrm{~m} / \mathrm{s} \\ \text { Chrony 2: } & 13 & \mathrm{~m} / \mathrm{s} \\ \text { Ziel: } & \text { Wasser } \\ \text { Objektiv: } & 28 & \mathrm{~mm} \\ \text { Belichtungsdauer: } & 2 & \mu \mathrm{s} \\ \text { Zwischenbildzeit: } & 30-60 \mathrm{ss}\end{array}$

$\begin{array}{lll}\text { Bild 1: } & 0 & \mu s \\ \text { Bild 2: } & 32 & \mu s \\ \text { Bild 3: } & 64 & \mu s \\ \text { Bild 4: } & 96 & \mu s \\ \text { Bild 5: } & 128 & \mu s \\ \text { Bild 6: } & 160 & \mu s \\ \text { Bild 7: } & 222 & \mu s \\ \text { Bild 8: } & 284 & \mu s\end{array}$

Der mit Wasser gefüllte Container war rechteckig und nicht rotationssymmetrisch. An seiner oben offenen Seite grenzte Wasser an freie Umgebungsluft. An den Seitenwänden (PET) grenzte der Container ebenfalls an freie Luft. Mit seiner Unterseite stand der Container auf einem Massivholzbrett.

Auch auf dieser Bilderfolge (s-25) sind ähnlich wie auf oben schon beschriebenen (s-17, s-43, s-18, s-66) verschattete Bereiche neben der temporären Höhle eines sich fragmentierenden Vollmantelgeschosses in Wasser abgebildet.

Besonders dunkel erscheint ein Bereich zwischen Schusskanal und der Unterseite des Containers. Die Verschattungen lassen sich durch Lichtbrechung (s. Kap. 7.6.) an kleinen Gasblasen erklären.

Die Gasblasen schwingen abseits der temporären Höhle auf. 
4.2.12. Fokus von Gasblasen im rotationssymmetrischen Ziel
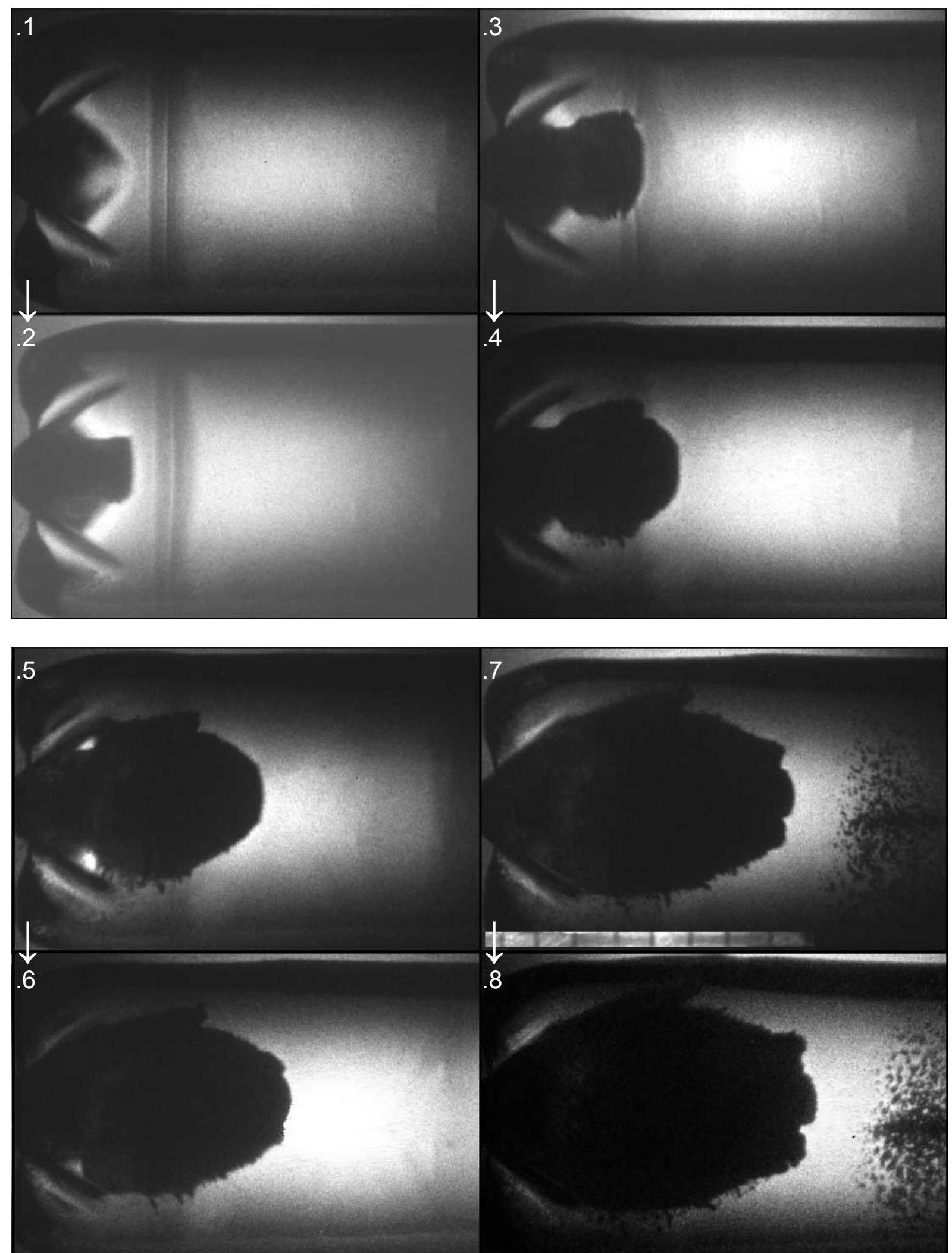

Photo s-58: Schuss auf eine liegende und mit Wasser gefüllte Plastikflasche. Vor der temporären Höhle des sich fragmentierenden Geschosses schwingen Gasblasen auf. 
zu Photo s-58: Geschoss: VMJ (3,0 g), Munition: 223.7, Ziel: Wasser in Plastikflasche

$\begin{array}{lll}\text { Chrony 1: } & 1104 & \mathrm{~m} / \mathrm{s} \\ \text { Chrony 2: } & 36 & \mathrm{~m} / \mathrm{s} \\ \text { Objektiv: } & 50 & \mathrm{~mm} \\ \text { Belichtungsdauer: } & 2 & \mu \mathrm{s} \\ \text { Zwischenbildzeit: } & 12 & \mu \mathrm{s}\end{array}$

Bild 1: $\quad 0 \quad \mu s$

Bild 2: $\quad 14 \quad \mu s$

Bild 3: $\quad 28 \quad \mu s$

Bild 4: $\quad 42 \quad \mu s$

Bild 5: $\quad 56 \quad \mu s$

Bild 6: $\quad 70 \quad \mu s$

Bild 7: $\quad 84 \quad \mu s$

Bild 8: $\quad 98 \quad \mu s$

Hier war eine wassergefüllte, rotationssymmetrische Plastikflasche das ballistische Ziel. Der Einschuss erfolgte am Boden der liegenden Flasche.

Die Flasche war von freier Luft umgeben und lag mit kleiner Aufliegefläche auf einem Massivholzbrett.

Vor der temporären Höhle eines sich fragmentierenden Vollmantelgeschosses in Wasser sind Bereiche mit aufschwingenden Gasblasen abgebildet. Besonders dunkel erscheint ein Bereich vor der temporären Höhle direkt in Schussrichtung. Es scheint, als sei nach Durchlauf einer Überdruckwelle ein Unterdruckfokus (Pfeile) mit Gasblasenbildung entstanden:

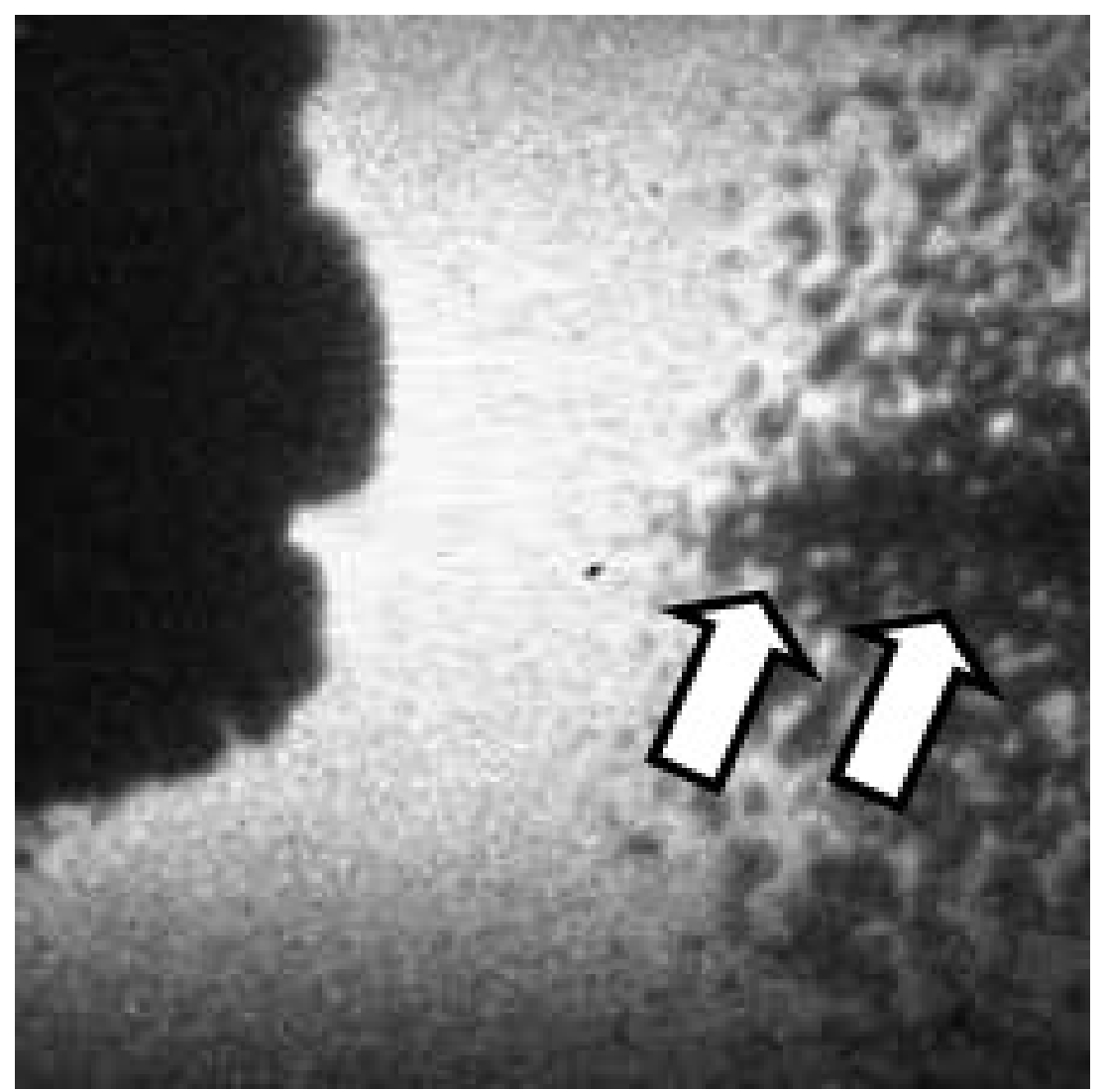

Vergrößerung von Photo s-58.8 (siehe Anfang des Kapitels) 
4.2.13. Wellenfront und Schwärme von Gasblasen
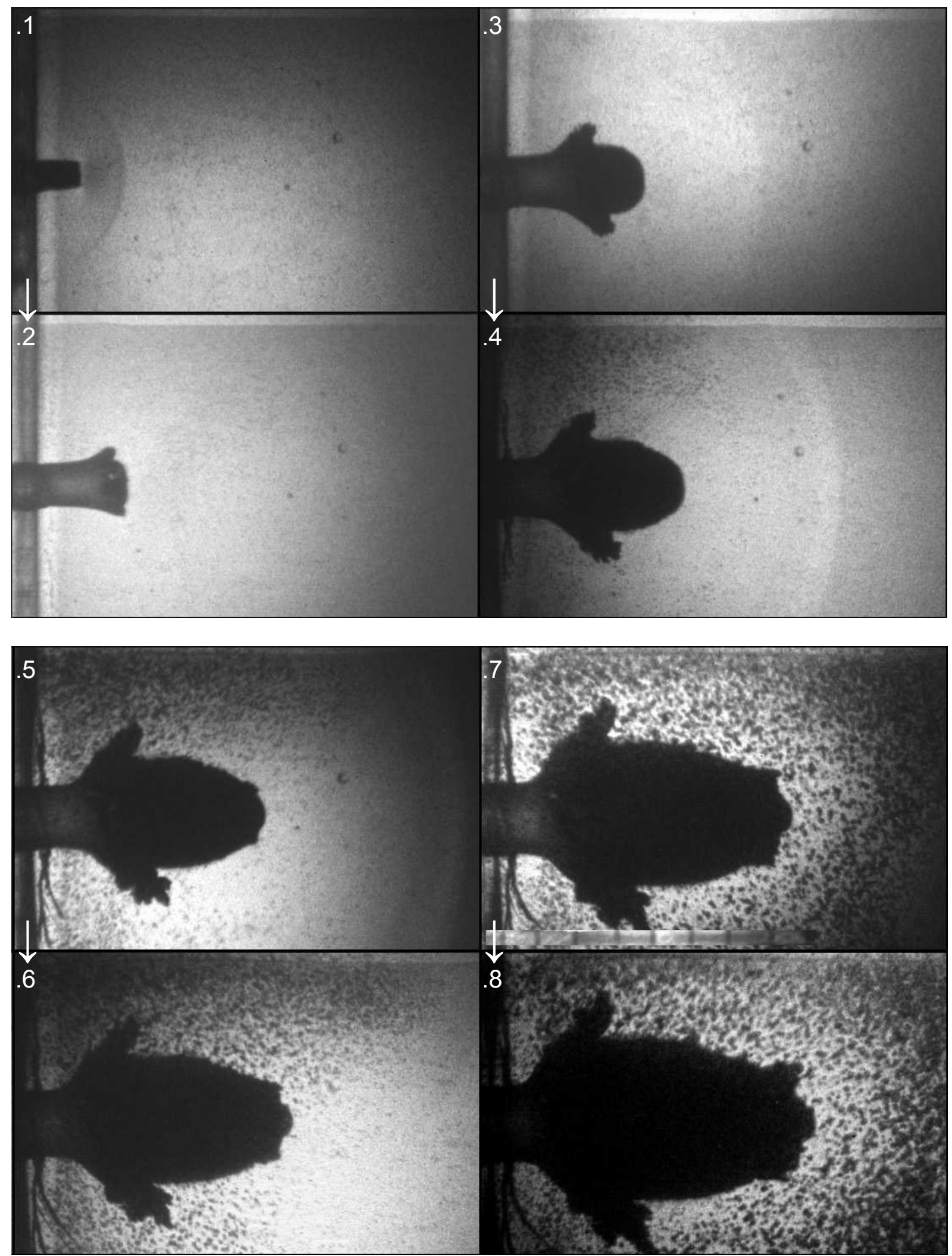

Photo s-53: Ein sich in Wasser fragmentierendes Vollmantelgeschoss. Bild 5 - 8: Gasblasen abseits der temporären Höhle streuen das Durchlicht. 
zu Photo s-53: Geschoss: VMJ (3,0 g), Munition: 223.7, Ziel: Wasser

$\begin{array}{lll}\text { Chrony 1: } & 1113 & \mathrm{~m} / \mathrm{s} \\ \text { Chrony 2: } & - & \\ \text { Objektiv: } & 50 & \mathrm{~mm} \\ \text { Belichtungsdauer: } & 1 & \mu \mathrm{s} \\ \text { Zwischenbildzeit: } & 14 & \mu \mathrm{s}\end{array}$

Bild 1: $\quad 0 \quad \mu s$

Bild 2: $\quad 15 \quad \mu s$

Bild 3: $\quad 30 \quad \mu s$

Bild 4: $\quad 45 \quad \mu s$

Bild 5: $\quad 60 \quad \mu s$

Bild 6: $\quad 75 \quad \mu s$

Bild 7: $\quad 90 \quad \mu s$

Bild 8: $\quad 105 \quad \mu s$

Ein Vollmantelgeschoss fragmentiert sich in Wasser. Auf Bild 5 bis Bild 8 streuen Gasblasen abseits der temporären Höhle das Durchlicht.

Auf Bild 1 bis Bild 5 sehen wir eine gekrümmte Wellenfront, die sich ausbreitet. Anhand ihres Radius konnten wir ihren Ursprung am Einschuss bestimmen (Kap. 5.3.2.13.). Die Geschwindigkeit der Verdichtungswelle wurde aus den Aufnahmen berechnet. Sie war größer als die Geschwindigkeit, mit der sich die temporäre Höhle ausbreitete.

In Wasser führt eine Druckänderung auch zur Änderung des Brechungsindex. Eine starke Verdichtungswelle lässt sich deshalb im Durchlicht elektrooptisch aufzeichnen.

In Kap. 4.2.16. wird dann eine ähnliche Zustandsänderung zu sehen sein und durch zeitgleiche Druckmessung näher beschrieben werden. 


\subsubsection{Wellenfront mit Reflexion}
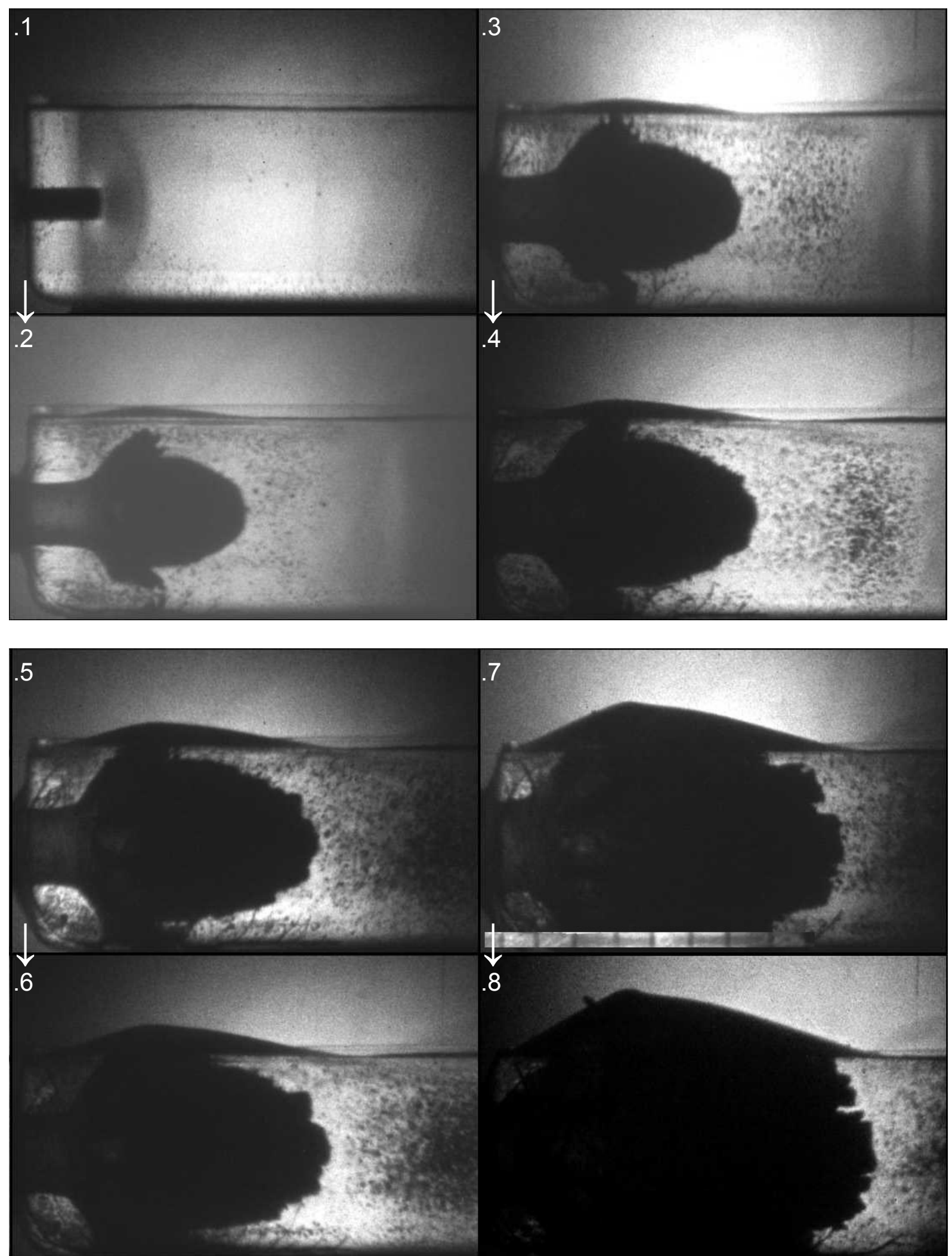

Photo s-54: Ein Vollmantelgeschoss fragmentiert sich in mit Wasser gefülltem Container. Kugelförmig sich ausbreitende Wellenfront (Bild 1 - 3), Reflexion an den Grenzflächen (Bild 2 - 3). 
zu Photo s-54: Geschoss: VMJ (3,0 g), Munition: 223.7, Ziel: Wasser

$\begin{array}{lll}\text { Chrony 1: } & 1132 & \mathrm{~m} / \mathrm{s} \\ \text { Chrony 2: } & 11 & \mathrm{~m} / \mathrm{s} \\ \text { Objektiv: } & 50 & \mathrm{~mm} \\ \text { Belichtungsdauer: } & 2 & \mu \mathrm{s} \\ \text { Zwischenbildzeit: } & 8-43 & \mu \mathrm{s}\end{array}$

Bild 1: $\quad 0 \quad \mu s$

Bild 2: $\quad 45 \quad \mu s$

Bild 3: $\quad 55 \quad \mu s$

Bild 4: $\quad 65 \quad \mu s$

Bild 5: $\quad 75 \quad \mu s$

Bild 6: $\quad 85 \quad \mu s$

Bild 7: $\quad 110 \quad \mu s$

Bild 8: $\quad 135 \quad \mu s$

Ein Vollmantelgeschoss fragmentiert sich in Wasser. Der Wassercontainer stand auf einem Massivholzbrett. Auf Bild 1 bis Bild 3 ist eine Wellenfront abgebildet, die sich kugelförmig ausbreitet. Anhand ihres Radius konnten wir ihren Ursprung am Einschuss bestimmen. Nach Durchlauf der Wellenfront folgt die an den Grenzflächen reflektierte Zustandsänderung. Diese Reflexion ist auf der Ausschnittsvergrößerung aus Bild 3 abgebildet und mit Pfeilen gekennzeichnet. Es ist davon auszugehen, dass es sich hierbei um Unterdruckwellen (Zugwellen) handelt. Im Bereich hinter den Unterdruckwellen schwingen Gasblasen auf.

An der Aufliegefläche, der Grenzfläche zum Massivholzblock, wird die Wellenfront weniger stark reflektiert.

Ca. $10 \mathrm{~cm}$ vom Einschuss entfernt ist die Glasfasersonde des Hydrophons von oben in den Wassercontainer integriert.

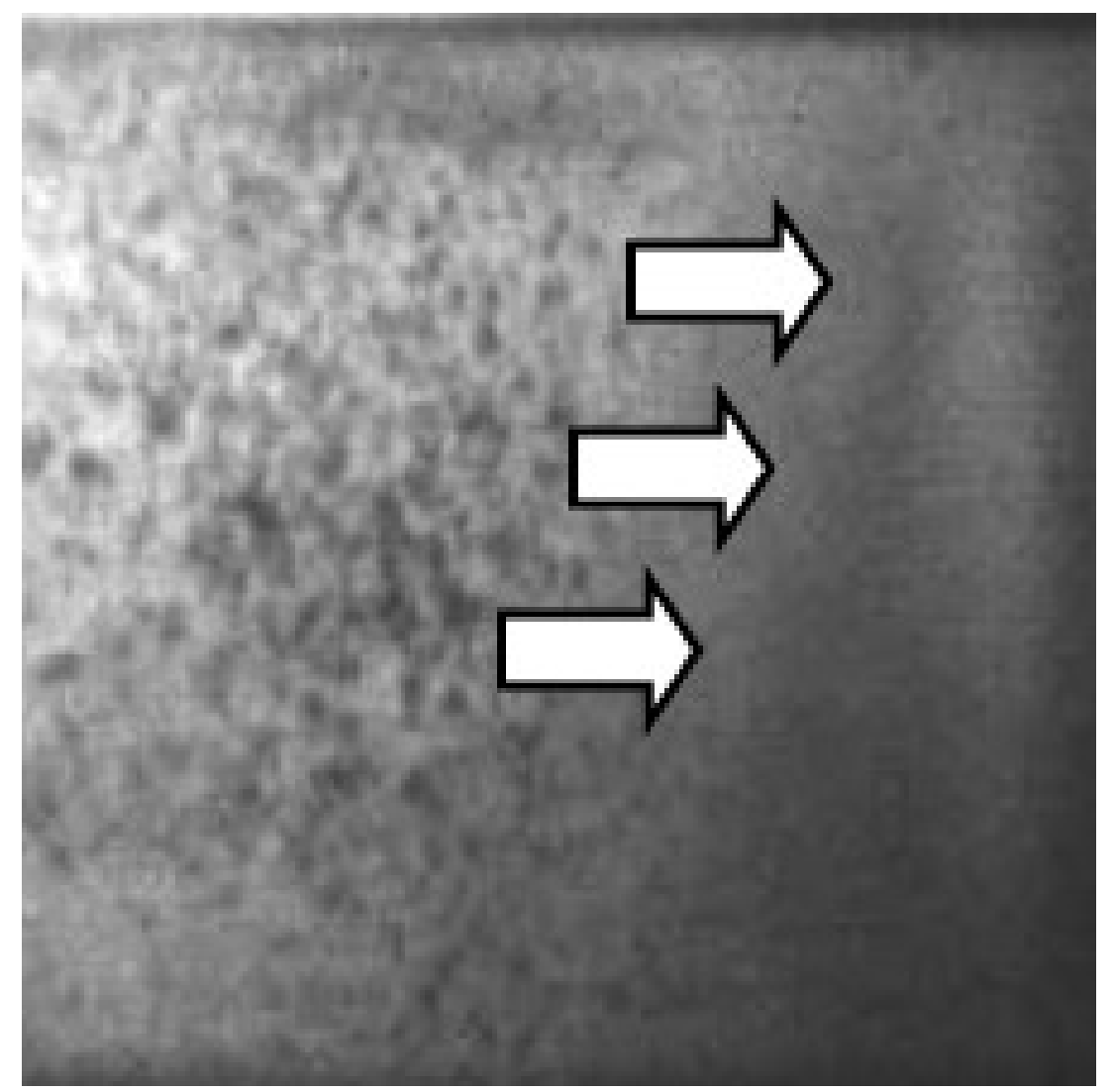

Vergrößerung von Photo s-54.3 (siehe Anfang des Kapitels) 
Die Geschwindigkeit der Wellenfront in Wasser lässt sich mit der Hochgeschwindigkeitskamera messen:

\begin{tabular}{|c|c|c|c|}
\cline { 2 - 4 } \multicolumn{1}{c|}{} & Differenz $[\mathrm{cm}]$ & Zeitspanne $[\mu \mathrm{s}]$ & $\mathrm{V}_{3 \text { (Imacon) }}[\mathrm{m} / \mathrm{s}]$ \\
\hline$\sum$ Bild s-54.1-2 & $\mathbf{6 , 5 8}$ & $\mathbf{4 5}$ & 1462 \\
\hline
\end{tabular}

Tab. 4.2.14.: Geschwindigkeit der Wellenfront in Wasser s-54

Chrony 1:

Chrony 2:

$1132 \mathrm{~m} / \mathrm{s}$

$11 \mathrm{~m} / \mathrm{s}$ 


\subsubsection{Wellenfront und einseitige Reflexion}
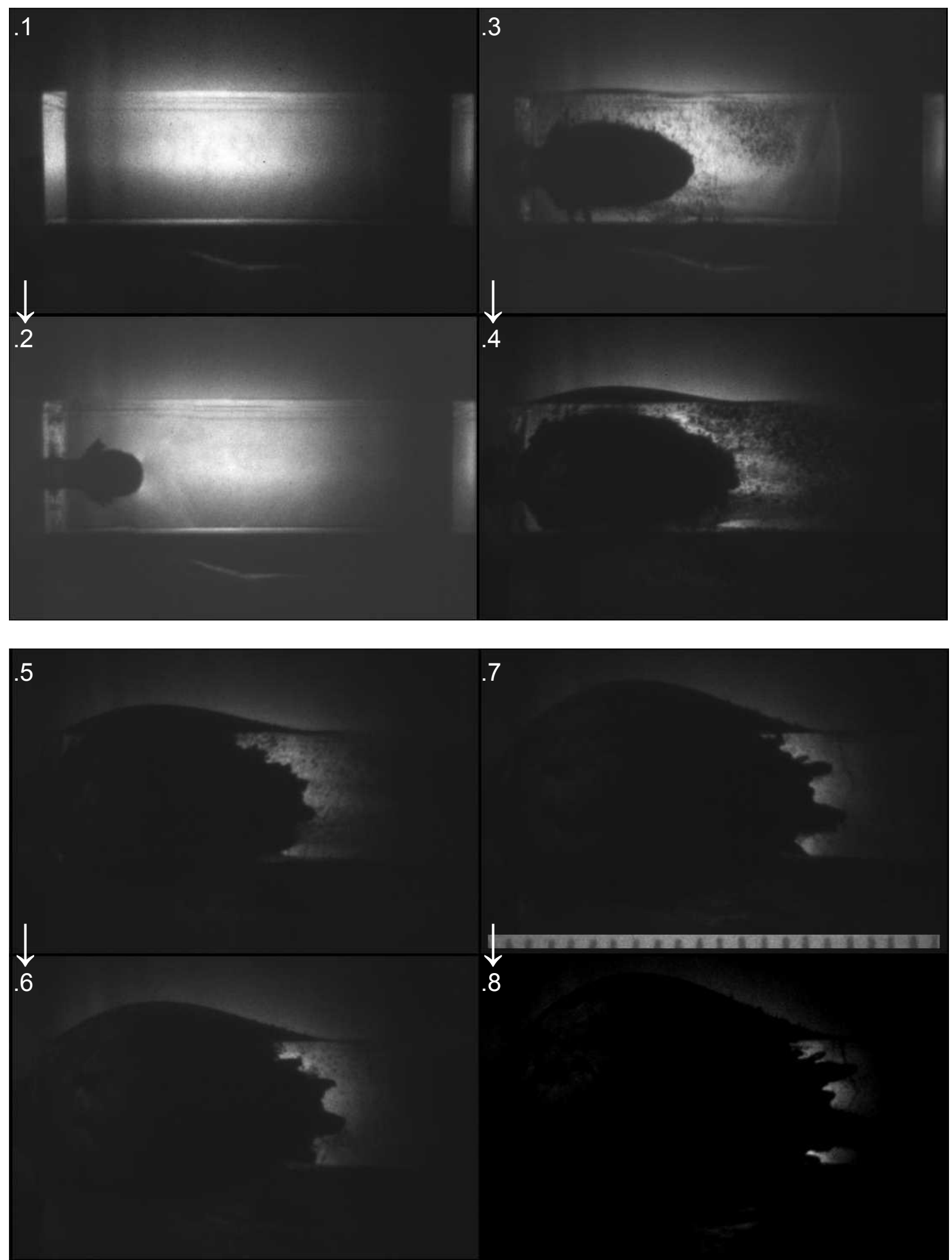

Photo s-33: Ein Vollmantelgeschoss fragmentiert sich in Wasser. Kugelförmig sich ausbreitende Verdichtungswelle (Bild 3). An der Grenzfläche reflektierte zweite Welle. 
zu Photo s-33: Geschoss: VMJ (3,0 g), Munition: 223.7, Ziel: Wasser (auf Gelatine)

$\begin{array}{lll}\text { Chrony 1: } & 1125 & \mathrm{~m} / \mathrm{s} \\ \text { Chrony 2: } & - & \\ \text { Objektiv: } & 28 & \mathrm{~mm} \\ \text { Belichtungsdauer: } & 1 & \mu \mathrm{s} \\ \text { Zwischenbildzeit: } & 44 & \mu \mathrm{s}\end{array}$

Bild 1: $\quad 0 \quad \mu s$

Bild 2: $\quad 45 \quad \mu s$

Bild 3: $\quad 90 \quad \mu s$

Bild 4: $\quad 135 \quad \mu s$

Bild 5: $\quad 180 \quad \mu s$

Bild 6: $\quad 225 \quad \mu s$

Bild 7: $\quad 270 \quad \mu s$

Bild 8: $\quad 315 \quad \mu s$

Der Wassercontainer steht auf einem Gelatineblock, welcher Schall ähnlich schnell transportiert wie Wasser. Die oben offene Fläche bzw. die Seitenwände des Containers grenzen an die freie Umgebungsluft.

Ein Vollmantelgeschoss fragmentiert sich in Wasser.

Auf Bild 3 ist eine Verdichtungswelle (Pfeil 1) abgebildet, die sich kugelförmig ausbreitet. Anhand ihres Radius lässt sich ihr Ursprung am Einschuss bestimmen. Nach ihrem Durchlauf folgt eine an der Grenzfläche zur freien Luft reflektierte zweite Welle (Pfeil 2). Es ist davon auszugehen, dass es sich hierbei um eine Unterdruckwelle (Zugwelle) handelt. Im Bereich hinter der Unterdruckwelle schwingen Gasblasen auf.

An der Aufliegefläche, der Grenzfläche zum Gelatineblock, erfolgt kaum eine Reflexion (Pfeil 3). Hier bilden sich auch kaum Gasblasen.

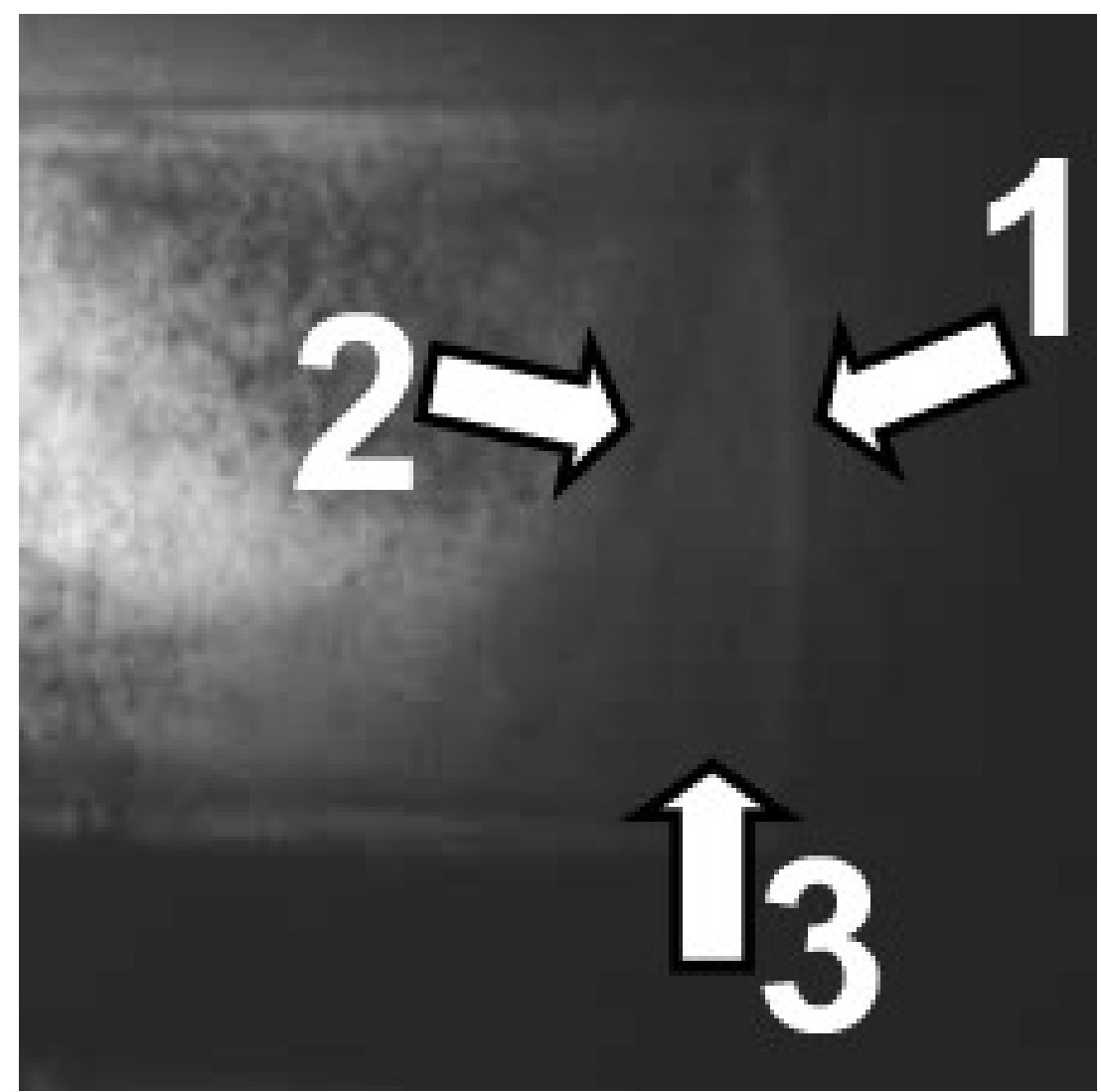

Vergrößerung von Photo s-33.3 (siehe Anfang des Kapitels) 
Verwendet man einen speziellen Filter des Graphikprogramms, kann die Wellenfront mit einseitiger Reflexion noch besser sichtbar gemacht werden:

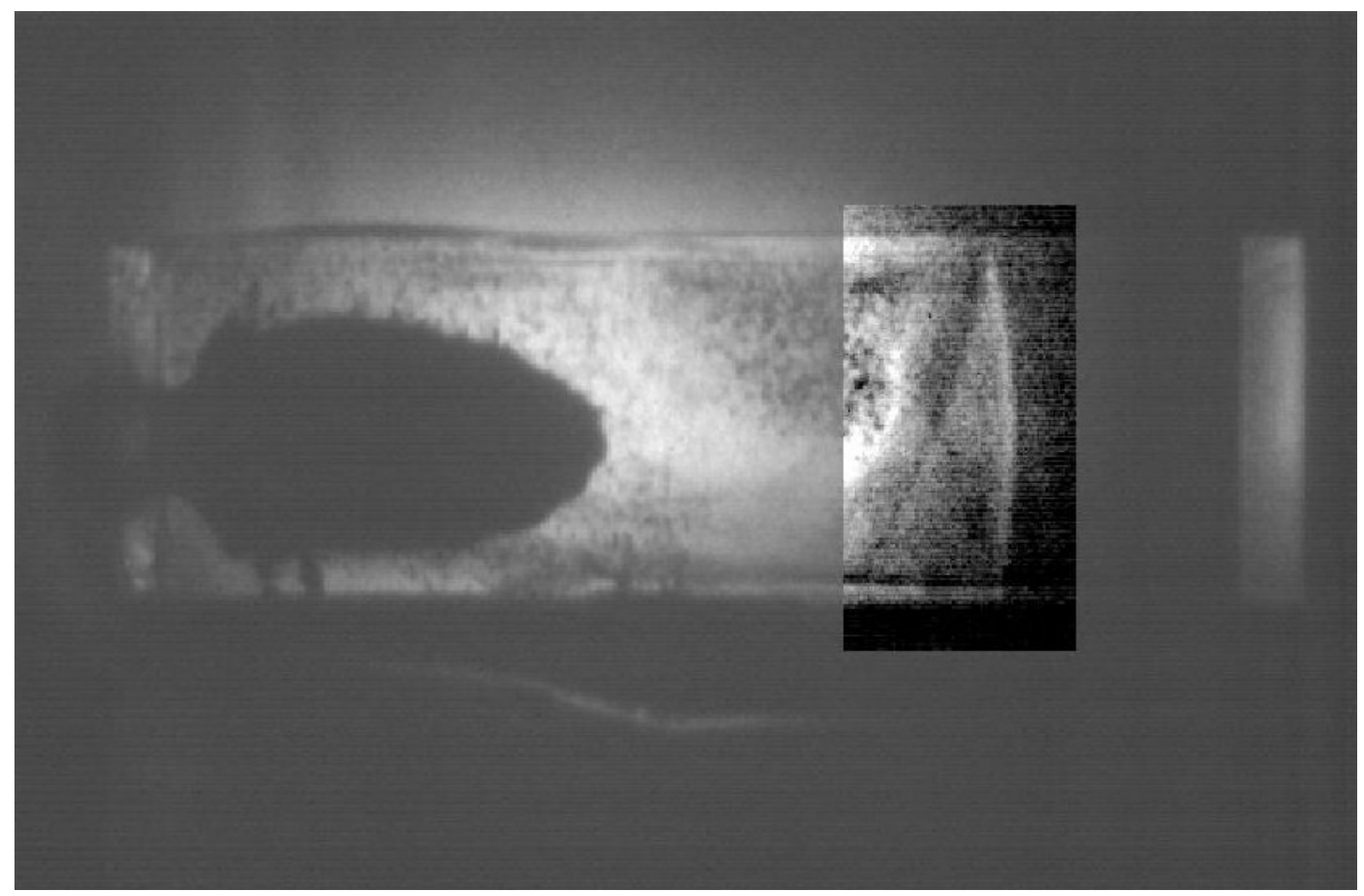

Vergrößerung von Photo 19 (Kap. 7.3.), entspricht Photo s-33.3 mit Graphikfilter 
4.2.16. Druckmessung einer Wellenfront
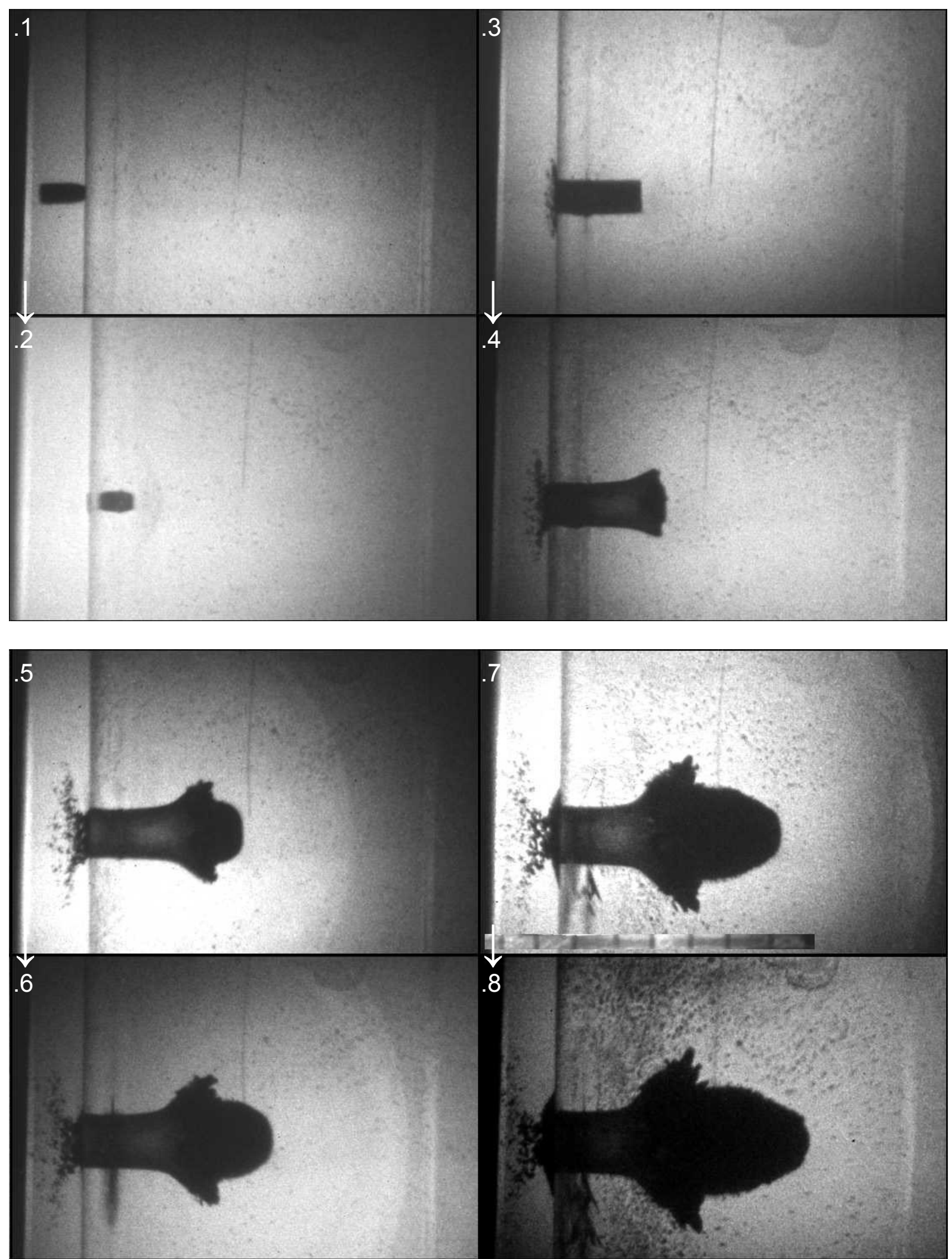

Photo s-51: Vollmantelgeschoss in Wasser erzeugt eine Wellenfront. Von der Mitte oben hängt die Glasfasersonde des Hydrophons und misst die Veränderung des Druckes. 
zu Photo s-51: Geschoss: VMJ (3,0 g), Munition: 223.7, Ziel: Wasser

$\begin{array}{lll}\text { Chrony 1: } & 1113 & \mathrm{~m} / \mathrm{s} \\ \text { Chrony 2: } & 16 & \mathrm{~m} / \mathrm{s} \\ \text { Objektiv: } & 50 & \mathrm{~mm} \\ \text { Belichtungsdauer: } & 1 & \mu \mathrm{s} \\ \text { Zwischenbildzeit: } & 10 & \mu \mathrm{s}\end{array}$

Bild 1: $\quad 0 \quad \mu s$

Bild 2: $\quad 11 \mu s$

Bild 3: $\quad 22 \quad \mu s$

Bild 4: $\quad 33 \quad \mu s$

Bild 5: $\quad 44 \quad \mu s$

Bild 6: $\quad 55 \quad \mu s$

Bild 7: $\quad 66 \quad \mu s$

Bild 8: $\quad 77 \mu s$

Ein Vollmantelgeschoss erzeugt in Wasser eine Wellenfront, die sich schneller als die temporäre Höhle ausbreitet. Vier Zentimeter vom Einschuss entfernt hängt die Glasfasersonde (Pfeil) des Hydrophons vor dem Schusskanal und stell die Zustandsänderung als Überdruckwelle fest.

Die Überdruckwelle breitet sich kugelförmig aus. Ihre Laufgeschwindigkeit kann für die ersten Zentimeter im Ziel aus Bild 2 bis Bild 7 berechnet werden. Druckmessungen mit dem Hydrophon wurden bei mehreren Schüssen durchgeführt. Für den Schuss s-51 betrug die Entfernung zwischen Einschuss und Glasfaser vier Zentimeter. Bei Schuss s-50 (Kap. 5.3.2.16.) waren es $16,5 \mathrm{~cm}$.

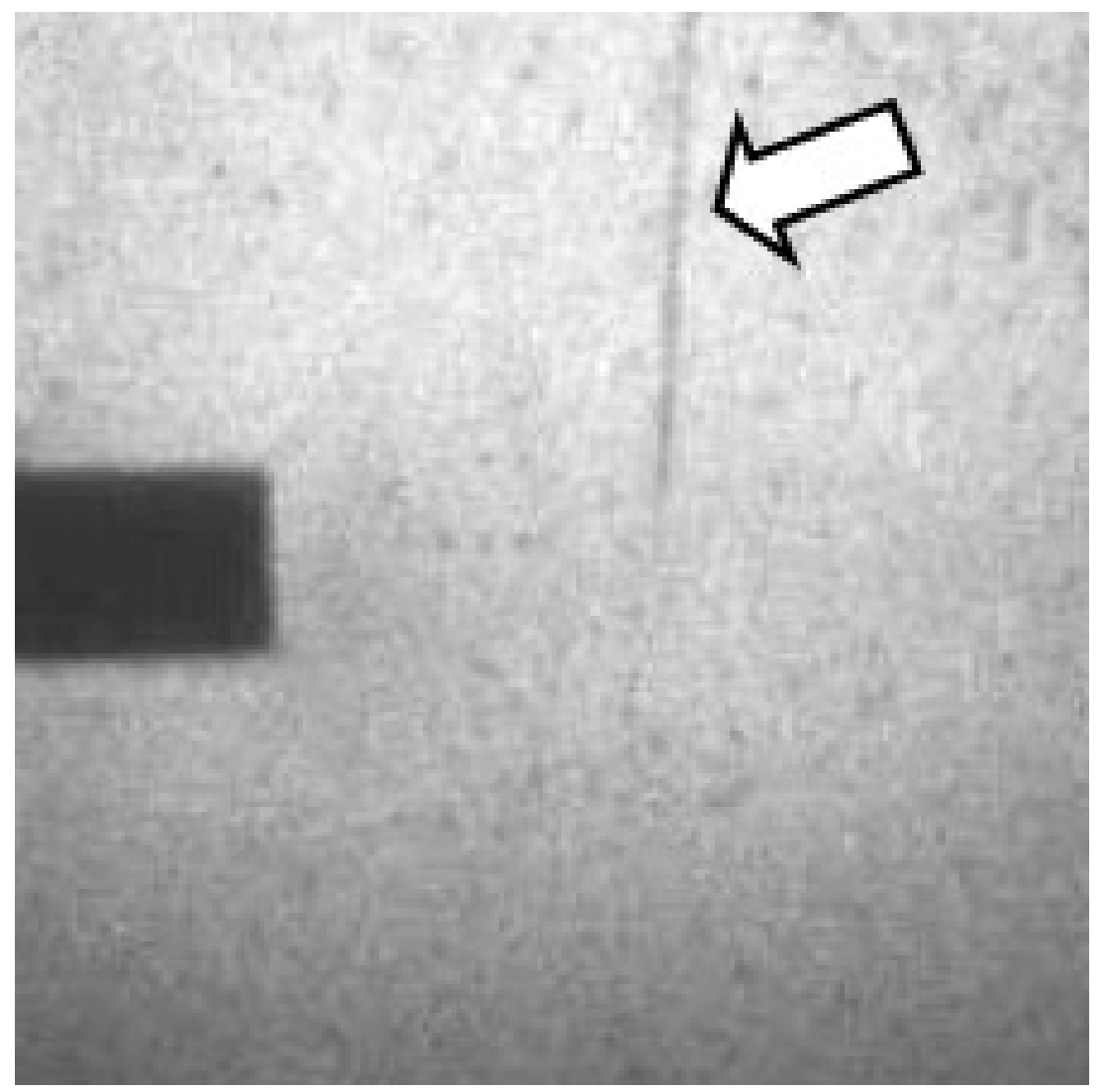

Vergrößerung von Photo s-51.3 (siehe Anfang des Kapitels) 
Die Ausbreitungsgeschwindigkeiten der Wellenfront, der temporären Höhle und einzelner Fragmente (des Geschosses) wurden berechnet:

\begin{tabular}{|c|c|c|c|}
\cline { 2 - 4 } \multicolumn{1}{c|}{} & Differenz [cm] & Zeitspanne $[\boldsymbol{\mu s}]$ & $\mathbf{V}_{\mathbf{3}}$ (Imacon) $[\mathbf{m} / \mathbf{s}]$ \\
\hline Bild s-51.1-2 & 1,81 & 11 & 1648 \\
\hline Bild s-51.2-3 & 1,72 & 11 & 1567 \\
\hline Bild s-51.3 -4 & 1,70 & 11 & 1547 \\
\hline Bild s-51.4-5 & 1,68 & 11 & 1527 \\
\hline Bild s-51.5-6 & 1,46 & 11 & 1326 \\
\hline Bild s-51.6-7 & 1,41 & 11 & 1286 \\
\hline \multicolumn{3}{|c|}{} \\
\hline Bild s-51.1-7 & $\mathbf{9 , 7 9}$ & $\mathbf{6 6}$ & $\mathbf{1 4 8 3}$ \\
\hline
\end{tabular}

Tab. 4.2.16a.: Geschwindigkeit der Wellenfront in Wasser s-51

Chrony 1:

Chrony 2:

$1113 \mathrm{~m} / \mathrm{s}$

$16 \mathrm{~m} / \mathrm{s}$

\begin{tabular}{|c|c|c|c|}
\hline & Differenz [cm] & Zeitspanne [ $\mu \mathrm{s}$ ] & $V_{3 \text { (Imacon) }[\mathrm{m} / \mathrm{s}]}$ \\
\hline Bild s-51.1-2 & 1,15 & 11 & 1045 \\
\hline Bild s-51.2-3 & 1,06 & 11 & 964 \\
\hline Bild s-51.3-4 & 0,64 & 11 & 583 \\
\hline Bild s-51.4-5 & 1,13 & 11 & 1025 \\
\hline Bild s-51.5 -6 & 0,84 & 11 & 764 \\
\hline Bild s-51.6-7 & 0,95 & 11 & 864 \\
\hline Bild s-51.7 - 8 & 0,71 & 11 & 643 \\
\hline Bild s-51.1-8 & 6,48 & 77 & 842 \\
\hline
\end{tabular}

Tab. 4.2.16b.: Geschwindigkeit der Höhlenfront in Wasser s-51

\begin{tabular}{|c|c|c|c|}
\hline & Differenz [cm] & 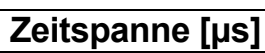 & $\mathbf{V}_{3 \text { (Imacon) }[\mathrm{m} / \mathrm{s}]}$ \\
\hline Bild s-51.1-2 & 1,15 & 11 & 1045 \\
\hline Bild s-51.2-3 & 1,06 & 11 & 964 \\
\hline Bild s-51.3-4 & 0,42 & 11 & 382 \\
\hline Bild s-51.4-5 & 0,44 & 11 & 402 \\
\hline Bild s-51.5-6 & 0,27 & 11 & 241 \\
\hline Bild s-51.6-7 & 0,29 & 11 & 261 \\
\hline Bild s-51.7 - 8 & 0,11 & 11 & 100 \\
\hline Bild s-51.1 - 8 & 3,74 & 77 & 485,05 \\
\hline
\end{tabular}

Tab. 4.2.16c.: Geschwindigkeit der Geschossfragmente in Wasser (s-51) 


\subsubsection{Durch Gasblasenkollaps beschleunigtes Zielmaterial}
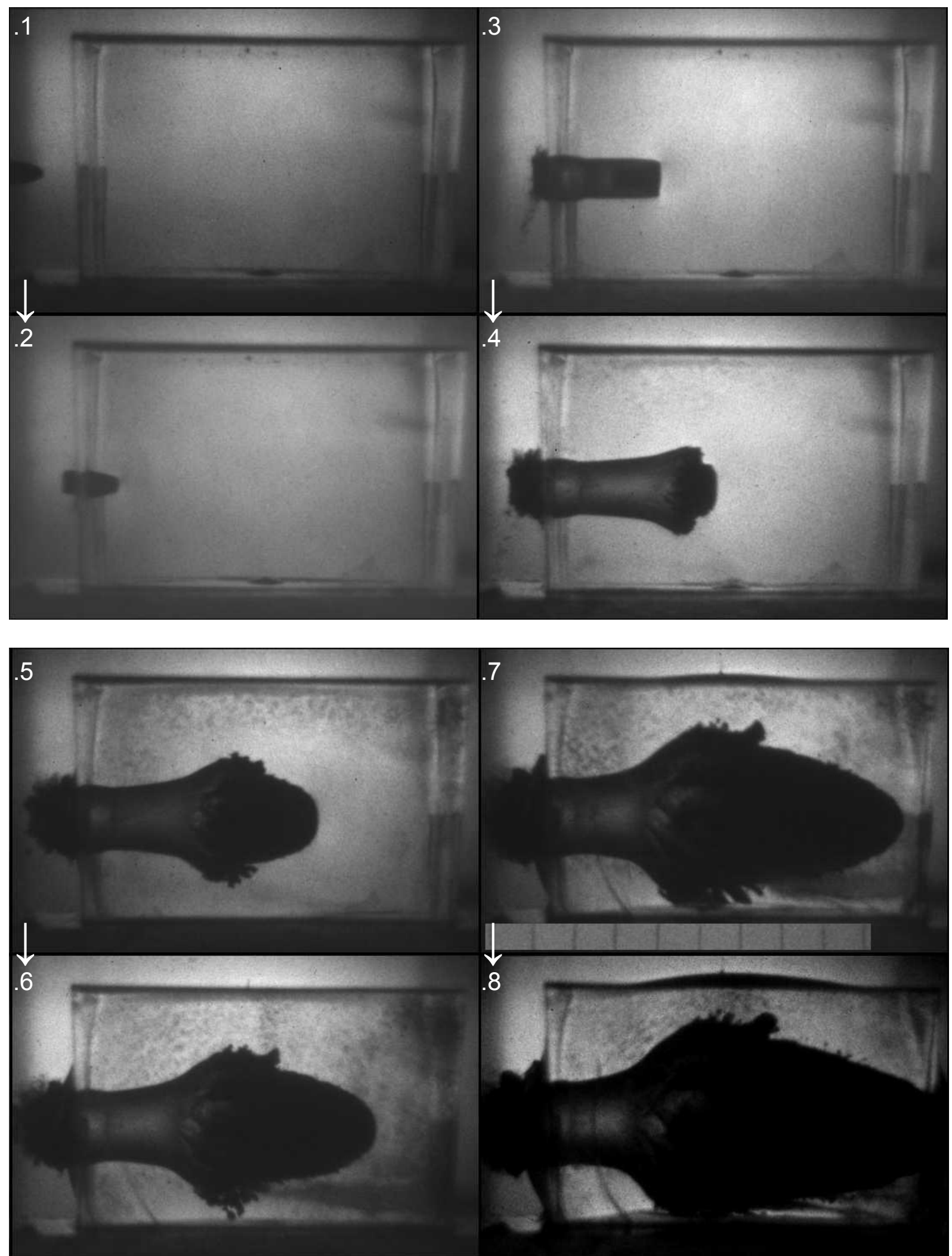

Photo s-36: Vollmantelgeschoss dringt in einen mit Wasser gefüllten Container ein. In der Mitte unter der Wasseroberfläche kollabiert eine zuvor eingebrachte Gasblase und erzeugt einen Wasserstrahl (Bild 6-8). 
zu Photo s-36: Geschoss: VMJ (3,0 g), Munition: 223.5, Ziel: Wasser mit Gasblase

$\begin{array}{lll}\text { Chrony 1: } & 932 & \mathrm{~m} / \mathrm{s} \\ \text { Chrony 2: } & 480 & \mathrm{~m} / \mathrm{s} \\ \text { Objektiv: } & 50 & \mathrm{~mm} \\ \text { Belichtungsdauer: } & 1 & \mu \mathrm{s} \\ \text { Zwischenbildzeit: } & 19 & \mu \mathrm{s}\end{array}$

Bild 1: $\quad 0 \quad \mu s$

Bild 2: $\quad 20 \quad \mu s$

Bild 3: $\quad 40 \quad \mu s$

Bild 4: $\quad 60 \quad \mu s$

Bild 5: $\quad 80 \quad \mu s$

Bild 6: $\quad 100 \quad \mu s$

Bild 7: $\quad 120 \quad \mu s$

Bild 8: $\quad 140 \quad \mu s$

Zu sehen ist eine Sequenz, in der ein Vollmantelgeschoss mit $932 \mathrm{~m} / \mathrm{s}$ in einen Wassercontainer eindringt. In der Versuchsreihe wurde Wasser beschossen, in das wir Gasblasen eingebracht hatten.

Eine Gasblase befindet sich unter der Wasseroberfläche in der Mitte des Containers. Die Gasblase kollabiert und an derselben Stelle wird $40 \mu$ später ein Wasserstrahl (Pfeil, Vergrößerung s-36.7) sichtbar. Die Geschwindigkeit, mit der hier Wasser transportiert wurde, wird im Kap. 5.3.2.17. berechnet.

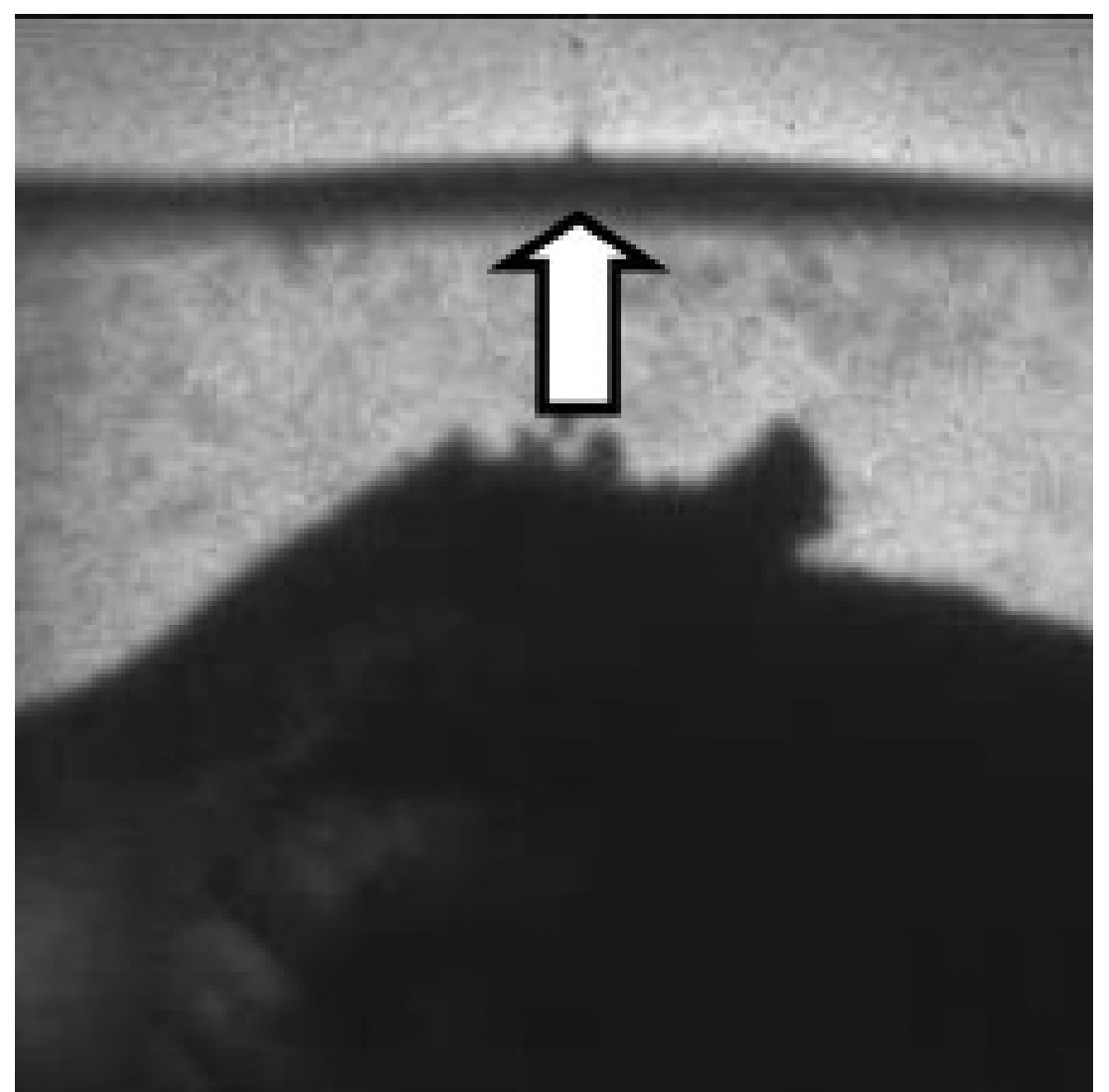

Vergrößerung von Photo s-36.7 (siehe Anfang des Kapitels) 


\subsubsection{Wellenfront in Stickstoff}
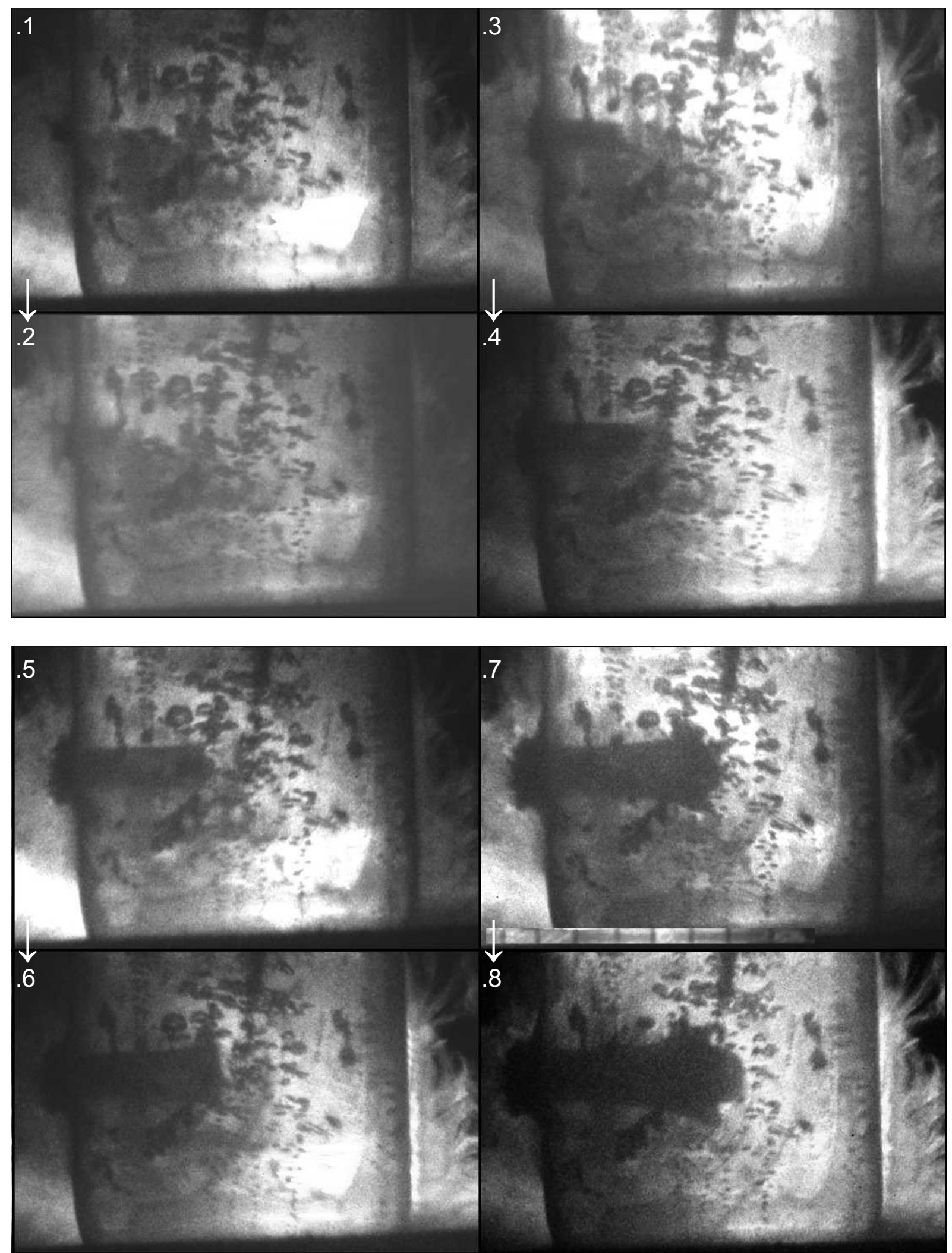

Photo s-46: Stickstoffcontainer unter Beschuss und ein sich fragmentierendes Geschoss. Die temporäre Höhle und eine schnelle Wellenfront breiten sich aus. 
zu Photo s-46: Geschoss: VMJ (3,0 g), Munition: 223.7, Ziel: $\mathbf{N}_{2}$

$\begin{array}{lll}\text { Chrony 1: } & 1069 & \mathrm{~m} / \mathrm{s} \\ \text { Chrony 2: } & 301 & \mathrm{~m} / \mathrm{s} \\ \text { Objektiv: } & 50 & \mathrm{~mm} \\ \text { Belichtungsdauer: } & 2 & \mu \mathrm{s} \\ \text { Zwischenbildzeit: } & 6 & \mu \mathrm{s}\end{array}$

Bild 1: $\quad 0 \quad \mu s$

Bild 2: $\quad 8 \quad \mu s$

Bild 3: $\quad 16 \quad \mu s$

Bild 4: $\quad 24 \quad \mu s$

Bild 5: $\quad 32 \quad \mu s$

Bild 6: $\quad 40 \quad \mu s$

Bild 7: $\quad 48 \quad \mu s$

Bild 8: $\quad 56 \quad \mu s$

Hier ist ein Stickstoffcontainer unter Beschuss abgebildet. Schon vor Beschuss steigen zahlreiche Gasblasen in der bei $-197^{\circ} \mathrm{C}$ siedenden Flüssigkeit auf. Außerdem gefriert Kondenswasser an der Außenseite des Containers, was die Auswertung und Interpretation der Darstellung erschwert. Trotzdem lassen sich ein sich fragmentierendes Geschoss, eine sich ausbreitende temporäre Höhle und eine schnelle Wellenfront voneinander abgrenzen. Diese Wellenfront breitet sich mit Schallgeschwindigkeit in flüssigem Stickstoff aus. Sie ist auf folgender Vergrößerung mit drei Pfeilen markiert und inre Geschwindigkeit in der Tabelle 4.2.18a. errechnet:

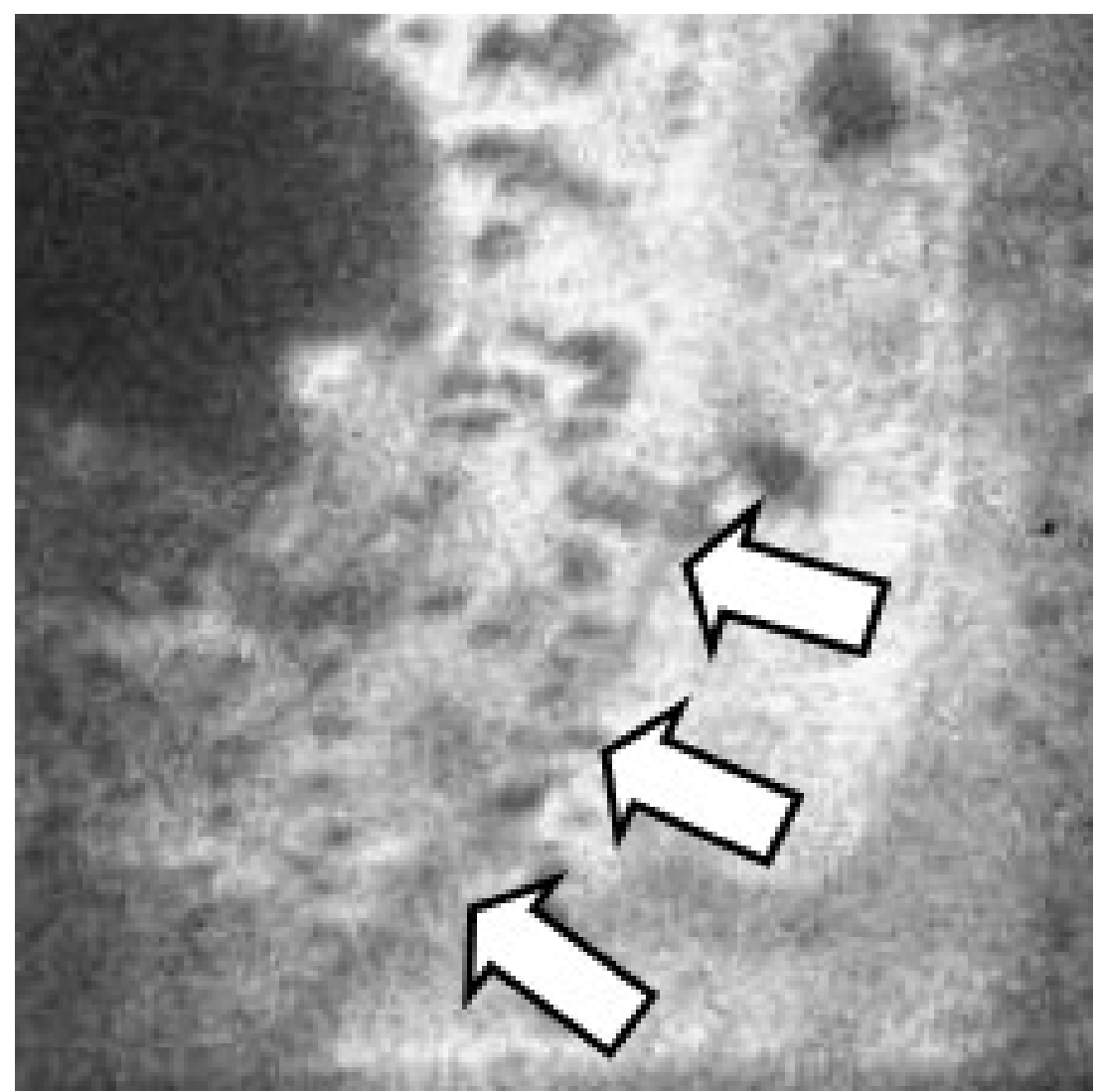

Vergrößerung von Photo s-46.7 (siehe Anfang des Kapitels) 


\begin{tabular}{|c|c|c|c|}
\hline & Differenz [cm] & Zeitspanne [us] & Wellenfront [m/s] \\
\hline Bild s-46.6-7 & 1,50 & 18 & 835 \\
\hline Bild s-46.7 - 8 & 1,35 & 18 & 749 \\
\hline$\sum$ Bild s-46.6-8 & 2,85 & 36 & 792 \\
\hline
\end{tabular}

Tab.4.2.18a.: Wellenfront in Stickstoff s-46

Chrony 1:

Chrony 2:

$1063 \mathrm{~m} / \mathrm{s}$

$301 \mathrm{~m} / \mathrm{s}$

Zudem wurden die Geschwindigkeiten des Projektils zu verschiedenen Zeiten und seine sich daraus ergebenden Energieverluste errechnet:

\begin{tabular}{|c|c|c|c|}
\hline & Differenz [cm] & Zeitspanne [s] & Geschwindigkeit [m/s] \\
\hline Bild s-46.3 - 4 & 0,71 & 18 & 394 \\
\hline Bild s-46.4-5 & 0,73 & 18 & 406 \\
\hline Bild s-46.5-6 & 0,51 & 18 & 283 \\
\hline Bild s-46.6 - 7 & 0,69 & 18 & 383 \\
\hline Bild s-46.7 - 8 & 0,55 & 18 & 306 \\
\hline
\end{tabular}

Tab. 4.2.18b.: Geschossgeschwindigkeit in Stickstoff s-46

\begin{tabular}{|c|c|c|c|}
\cline { 2 - 4 } \multicolumn{1}{c|}{} & $\boldsymbol{\Delta E}[\mathrm{J}]$ & Differenz [cm] & Energieverlust [J/cm] \\
\hline Bild s-46.3-5 & $-14,4$ & 1,44 & -10 \\
\hline Bild s-46.4-6 & 127,12 & 1,24 & 102,52 \\
\hline Bild s-46.5-7 & $-100,5$ & 1,20 & $-83,75$ \\
\hline Bild s-46.6-8 & 80,18 & 1,24 & 64,66 \\
\hline \multicolumn{4}{|c|}{} \\
\hline L Bild s-46.4-7 & $\mathbf{1 4 2 , 4}$ & $\mathbf{3 , 1 8}$ & $\mathbf{4 4 , 7 8}$ \\
\hline
\end{tabular}

Tab. 4.2.18c.: Energieverlust in Stickstoff s-46 


\section{Diskussion}

\subsection{Sicherheit und bauliche Bedingungen}

Die Sicherheit stand bei allen Versuchen im Vordergrund. Menschliche Fehler oder Fehleinschätzungen wurden durch standardisierte Aufgabenzuteilung und gegenseitige Kontrolle minimiert. Der Schießgang wurde nur betreten, wenn die Waffe entladen war und der Kammerverschluss offen sichtbar neben der Waffe lag.

Sämtliche Munition wurde im Aufenthaltsraum gelagert und nur einzeln vor dem jeweiligen Schuss zur Waffe transportiert. Bei Schussauslösung waren mindestens zwei Personen anwesend und befanden sich im sicheren Bereich des Aufenthaltsraumes (Kap. 3.1.1.). Ein Festnetztelefon zum Absetzen eines Notrufes war installiert. Während der Versuche war der Zugang zum ballistischen Labor verschlossen.

Für den Fall, dass ein Geschoss das ballistische Pendel durchschlagen hätte, diente ein weiterer Raum hinter dem Pendel als Sicherheits-Kugelfang. Der Raum endet an der Rückseite mit einer Ziegelwand und nachfolgendem Erdreich. In der Mitte des Raumes stand eine papiergefüllte Holzkiste (Kap. 3.1.9.), um Geschossenergie zusätzlich zu absorbieren. Das ballistische Pendel wurde allerdings von keinem Geschoss durchschlagen.

Der Autor ist im Umgang mit Langwaffen ausgebildet und Jagdscheininhaber. Die Waffen sind auf seine Waffenbesitzkarte eingetragen. Für den Erwerb, den Transport, den Umgang mit und die Lagerung von Treibladungspulvern hatte der Autor eine Erlaubnis nach $\S 27$ des Sprengstoffgesetzes erhalten.

Maximal zulässige Obergrenzen der Ladedaten wurden beachtet (Kap. 3.2.6.). Nicht verbrauchte Treibladungsmittel wurden in einem unbewohnten Nebengebäude aufbewahrt. Die Waffen wurden an den Versuchstagen im Waffenschrank des Institutes für Rechtsmedizin gelagert. Vor Schussauslösung wurde die Waffe in einer stabilen Waffenhalterung fixiert und justiert. Nach Sichtkontrolle des Laufes vor jedem Schuss wurde die Lauflinie der auf $3 \mathrm{~m}$ eingeschossenen Repetierbüchse mit Laserlicht kontrolliert. Die Auslösung des Abzuges erfolgte immer aus sicherem Abstand über einen dehnungsarmen Faden.

Alle am Versuch beteiligten Personen trugen Gehörschutzkapseln (Peltor Twin Cup $\mathrm{H} 10 \mathrm{~A}$ ). Eine leistungsstarke Lüftungsanlage war in Betrieb. Regelmäßiges Auskehren der Treibladungsreste verhinderte deren Anreicherung.

Besondere Aufmerksamkeit galt dem Befüllen der Hülsen mit Treibladungspulver. Konzentriertes Arbeiten und die Trennung der einzelnen Arbeitsmaterialien und Arbeitsschritte haben gefährliche Doppelladungen unterbunden. Beim Setzen der Zündhütchen in die Hülse wurde eine Schutzbrille getragen. Die Empfehlungen von DEVA (1995), DYNAMIT NOBEL (1998) und HODGDON (1996) wurden beachtet. Für stark reduzierte Gebrauchsladungen wurde kein progressives Pulver verwendet. Um in diesem Bereich einen gleichmäßigen Abbrand zu erreichen, wurde offensives Pulver eingesetzt. Bei ausgesprochenen Schwachladungen wurde der Lauf nach jedem Schuss kontrolliert. 


\subsection{Diskussion im Vorfeld der Untersuchung}

\subsubsection{Material und Methodik}

\subsubsection{Spezialgeschosse}

Zur Wirkweise selbst hergestellter oder industriell gefertigter, geklebter (MULLINS 2001) Geschosse gibt es kaum Literatur. Für die vorliegende Untersuchung wurden Geschosse selbst hergestellt (Kap. 3.2.5.). Es wurde gezeigt, dass sich Geschosse herstellen und verschießen lassen, welche sich im Zielmaterial zerlegen und (z.B. mit Röntgentechnik) nur schwer nachzuweisen sind.

Geschosse aus Holz können zudem auch verrotten. Es sind bereits Fälle dokumentiert, in denen Holzdübel als Projektil manipulierter Schreckschusswaffen eingesetzt wurden (PADOSCH et al. 2002).

Wir haben eine Untersuchung mit 40 Schuss auf Hartschaumplatten und 30 Schuss auf Rigips-Platten durchgeführt und Unterschiede in den Schusstrichtern und häufige „key-hohle-Einschüsse“ der unterstabilisierten Projektile nachgewiesen (Kap. 5.3.2.1.). Bei einem verkürztem Mündungsabstand zum Ziel $(0,60 \mathrm{~m})$ traten die selbst hergestellten Geschosse orthograd ins Ziel ein.

\subsubsection{Versuchswaffen}

Die Verbreitung kleinkalibriger Langwaffen nahm stetig zu (HAUCK 1990, SCHMECHTA 1990). Mit kleinen Kalibern werden hohe Geschossgeschwindigkeiten erreicht. Durch Verwendung selbst laborierter Munition wurde ein großer Geschwindigkeitsbereich abgedeckt. Für die Arbeit wählten wir eine Waffe des aktuellen NATO-Kalibers, eine zweite Waffe des Kalibers .222 Rem (mit gleichem Geschossdurchmesser) und eine dritte Waffe des weit verbreiteten Kleinkalibers .22 Ir um eine gute Vergleichbarkeit mit anderen Veröffentlichungen zu gewährleisten.

So ist beispielsweise durch die Verwendung des Militär-Kalibers .223 Rem (5,56 x 45 $\mathrm{mm}$ NATO) ein Vergleich der eigenen Ergebnisse mit den Ergebnissen anderer Autoren gut möglich (AEBI et al. 1977, ALBRETH et al. 1979, AMATO et al.1974, BERLIN et al. 1982, 1988 a, 1988 b, CHARTERS AC III und CHARTERS AC 1976, CLEMEDSON et al. 1973, DEVETH 1982, JANZON und SEEMAN 1985, JANZON et al. 1988, KNUDSEN und SORENSEN 1994, KNUDSEN und SVENDER 1994, MISSLIWETZ und WIESER 1989, NORDSTRAND et al. 1979, O'CONNELL et al. 1988, RICH 1980, RYBECK und JANZON 1976, RYBECK et al. 1975 a, 1975 b, SCEPANOVIC und ALBREHT 1982, SCEPANOVIC et al. 1982, 1988, SELLIER 1979, SWAN et al. 1983, TIKKA et al. 1982 a, 1982 c, WANG et al. 1982, 1988 und ZHANG et al. 1988). 


\subsubsection{Versuchsziele}

Einige Autoren berichteten über die Unzulänglichkeit herkömmlicher Zielsimulanzien (JANZON 1982 b, SCHANTZ 1979, TIKKA et al. 1982 b). Aus diesem Grund wurden für die verschiedenen Schussversuche unterschiedliche Zielmaterialien ausgewählt. Lebende Tiere und menschliches Gewebe wurden nicht beschossen.

Es wurde entsprechend den Empfehlungen zu Vor- und Nachteilen verschiedener Simulationsmedien von SELLIER und KNEUBUEHL (2001) 10-prozentige IndustrieGelatine (250 Bloom, Typ A-Schweinegelatine, Körnung 20/60) verwendet. Gelatine findet in der Erforschung der Zielballistik breite Verwendung und wurde auch von anderen Autoren (BERG SO 1973, FACKLER und MALINOWSKI 1988 a, JAIN et al. 2003, JUSSILA 2004, JUSSILA et al. 2005 b, SCHYMA C und SCHYMA P 1999, RAGSDALE und JOSSELSON 1988 a) benutzt.

Der Gelatinebeschuss sagt jedoch wenig über das unterschiedliche Verhalten von Geschossen in verschiedenen Organsystemen des Körpers aus (AMATO et al. 1974). Insbesondere der Wassergehalt des Zielmediums wirkt sich stark auf die Interaktion mit dem Projektil aus; das wusste HORSLEY (1894) bereits vor über 100 Jahren und wies ausdrücklich auf diesen Umstand hin.

THALI et al. (2001, 2002 a, 2002 c) entwickelten neue ballistische Modelle, indem sie Gelatine in Verbindung mit Hartholzstäben als Finger-Modell und Gelatine mit Silikon und Polyurethan als „Skin-skull-brain model“ in Gebrauch nahmen.

Ergebnisse vom Gelatinebeschuss eignen sich, unter Beachtung einiger Regeln (Kap. 3.4.1.), gut für internationale Vergleiche. FACKLER und MALINOWSKI (1988 b) hatten fehlerhafte Ergebnisse bei Beschüssen auf Gelatine auf zu hohe Wassertemperaturen bei der Herstellung zurückgeführt. Weil sich die physikalischen Eigenschaften der Gelatine je nach Temperatur verändern, wurden bei unserer Arbeit die Blöcke vor Beschuss für mindestens 24 Stunden auf die vorgesehene Beschusstemperatur von $10^{\circ} \mathrm{C}$ gekühlt.

Außerdem wurden mit Wasser gefüllte Container beschossen. Bereits HARVEY et al. (1962) hatten eine ausführliche Arbeit zur Entstehung von temporären Höhlen in Wasser und wasserreichen Medien veröffentlicht. LIU et al. (1988 b, 1988 c, S. 13) führten die Beschreibung der temporären Höhlen beim Beschuss von Wasser sehr anschaulich (,,at the very beginning the cavity looked like a snail with its antennae streched out") fort.

KIJEWSKI (1974 a, 1974 b) hatte Beschädigungen an technischen Materialien durch direkte Schusseinwirkungen beurteilt. KLAGES und WEITHOENER (1973) nutzten Hartfaserplatten, konnten nach Beschuss mit Kleinkalibermunition aber nur große Schwankungsbreiten in der Perforationsgröße feststellen. Der Durchschuss durch ein festes Primärziel mit Geschosszerlegung wurde für die vorliegende Arbeit reproduzierbar simuliert (Kap. 5.3.2.1.). Hinter zwei Hartschaumplatten befand sich im Abstand von $7 \mathrm{~mm}$ ein Gelatineblock $\left(0,10 \times 0,10 \times 0,10 \mathrm{~m}\right.$, Typ-A, 250 Bloom, $\left.10^{\circ} \mathrm{C}\right)$, der die Geschossfragmente aufnahm.

2 Schüsse (s-89, s-90) wurden auf Schweinekopfhälften abgegeben. Es wurde dokumentiert, dass geklebte Geschosse die Schädelkalotte eines Schlachttieres durchschlagen können. Damit ist es sehr wahrscheinlich, dass auch beim Menschen tödliche Verletzungen durch solche Projektile möglich sind. 
Kopfschüsse kommen häufig vor und verursachen oft lebensbedrohliche Verletzungen. Ungefähr $20 \%$ aller Schussverletzungen im militärischen Ernstfall sind Kopfschüsse (CAREY et al. 2000), obwohl der Kopf nur 9 \% der Körperoberfläche ausmacht.

Vorzugsweise Schweine wurden in der Vergangenheit als Versuchsziel benutzt (GUSTAFSSON et al. 1997, HASSELGREN et al. 1982, HOLMSTRÖM et al. 1979, JANZON 1982 b, JOHANNSON et al. 1982, JUSSILA et al. 2005 a, LARSSON et al. 1979, LARSSON et al. 1982, LENNQUIST et al. 1979, LEWIS et al. 1979, ÖBERG et al. 1979, POST und LEWIS 1979). Dabei ist es trotz des hohen Aufwandes nur begrenzt möglich, die Erkenntnisse auf Schusswunden am Menschen zu übertragen (SCHANTZ 1979). Auch andere Tiere wie Ratten (WILLIAMS et al. 2005), Katzen (PUCKETT et al. 1946) und Hunde (HEIDEMAN und GELIN 1979, MA et al. 1988, REMINGTON et al. 1950, RYBECK et al. 1975 a, 1975 b, WANG et al. 1982, 1988, ZIERVOGEL 1979) wurden für verschiedene Arbeiten beschossen, um Erkenntnisse über Schusswunden zu gewinnen. So hatten ebenfalls LIU et al. (1982) einhundertsechsundfünfzig anästhesierte Hunde beschossen und versucht, einen Zusammenhang von Geschossgeschwindigkeit und Geschossform auf die Energieabsorption zu beschreiben.

Achtmal haben wir auf Früchte von Cucumis melo geschossen. Sie eignen sich aufgrund des hohen Wassergehaltes als Ziel (KLATT 1996). Wir suchten nach reproduzierbaren Prinzipien der Ballistik in wasserreichen und inhomogenen Körpern.

\subsubsection{Fehlerquellen und Fehlerberechnung}

Bereits vor den Experimenten wurden Fehlerquellen diskutiert und die Messmethoden entsprechend angepasst. Weglängen [m] wurden mit einem geeichten Metermaß auf 3 Stellen hinter dem Komma bestimmt. Die Pendelausschläge und die Durchmesser der Schusstrichter wurden mit einer Schieblehre genauer bestimmt.

Drei voneinander unabhängige Messmethoden wurden bei der Geschwindigkeitsmessung eingesetzt:

a. die Geschwindigkeitsmessung mithilfe der Chronygraphen

b. die Geschwindigkeitsmessung mithilfe des Pendelausschlages (berechnet und abgelesen)

c. die Geschwindigkeitsmessung mithilfe der Hochgeschwindigkeitskamera.

Gerade durch den Vergleich dieser drei voneinander unabhängigen Messungen lassen sich systematische Fehler erkennen. 


\section{Zu a.:}

Die Blenden der Zielhalterung hielten Pulverschmauch und Geschoss- und Zielfragmente auf, um die Geschwindigkeitsmessung nicht zu verfälschen. Das parallele Überfliegen des Geschosses zur Längsachse des Chronys war hingegen nicht mit Sicherheit zu erreichen:

Ein Chrony misst die Geschwindigkeit eines Geschosses unter der Annahme, dass das Projektil zwischen den Impulsen zur Zeitmessung eine Wegstrecke von genau $0,305 \mathrm{~m}$ zurücklegt (Kap. 3.1.5.). Es ist aber durchaus möglich, dass diese Wegstrecke länger ist, wenn die Flugbahnachse nicht parallel zur Längsachse des Chronys ist. Innerhalb der gemessenen Zeit legt das Geschoss also möglicherweise eine längere Wegstrecke zurück. Dadurch ist die Geschwindigkeit größer als der angezeigte Wert.

Es wäre für Geschosse aufgrund der Maße der Zielhalterung nur dann möglich gewesen, die Blende 3 (Durchmesser 0,15 m) zu durchschlagen, wenn sie innerhalb von $0,70 \mathrm{~m}$ (Treffpunkt - Blende 3) um < als 0,075 $\mathrm{m}$ von der ursprünglich vorgesehenen Flugbahn abweichen würden. Ihre Flugbahn würde sich dabei maximal um 4,01 mm auf 70,401 cm, die Wegstrecke sich maximal um 0,57 \% verlängern.

Weil die Geschosse nach Zieldurchtritt nicht weiter abgelenkt werden, verlängert sich die Wegstrecke zwischen den Impulsen zur Zeitmessung von 0,305 m ebenfalls um maximal 0,57 \%. Da die Wegstrecke direkt in die Berechnung der Geschwindigkeit $\mathrm{m} / \mathrm{s}$ eingeht, entspricht der relative Fehler auch hier 0,57 \%. Die Messung der Geschwindigkeit mit Chrony 2 führte also zu einem Messwert, der der tatsächlichen Geschossgeschwindigkeit entsprach oder bis zu 0,57 \% geringer war.

Bei Chrony 1 ist der relative Fehler aufgrund der längeren Flugbahn (Mündung Blende1: 2,3 m) deutlich geringer.

Aufgrund der Maße der Zielhalterung war es für Geschosse nur dann möglich, die Blende 1 (Durchmesser 0,15 m) zu durchschlagen, wenn sie innerhalb von 2,30 m (Mündung - Blende 1) um < als $0,075 \mathrm{~m}$ im rechten Winkel von der ursprünglich vorgesehenen Flugbahn abwichen. Ihre Flugbahn verlängert sich dabei maximal um $1,22 \mathrm{~mm}$ auf 2,301 $\mathrm{m}$. Das entspricht einem relativen Fehler von 0,053 \% bei der Messung der Geschwindigkeit mit Chrony 1. Die Geschwindigkeitsmessung mit Chrony 1 führte also zu Messwerten, die der tatsächlichen Geschossgeschwindigkeit entsprach oder bis zu 0,053\% geringer war. 


\section{Zu b.:}

Ein "ballistisches Pendel“ wurde auch von anderen Autoren zur Geschwindigkeitsmessung eines Geschosses genutzt (JANZON et al. 1979) und empfohlen (KNUDSEN und SVENDER 1994).

Die Geschwindigkeit eines Geschosses lässt sich über den Pendelausschlag (KLATT 1996) anhand der im Anhang dargestellten Beziehung (Kap. 6.5.) berechnen:

$v_{1}=\frac{\mathrm{m}_{1}+\mathrm{m}_{2}}{\mathrm{~m}_{1}} \times \frac{2 \cdot \pi}{T} \times \bar{x}$

In Betracht kommen folgende Fehler bei der rechnerischen Geschossgeschwindigkeitsbestimmung:

$\mathrm{m}_{1}=$ Geschossmasse $=0,00298 \mathrm{~kg} \pm 0,00001 \mathrm{~kg}(0,34 \%)$

$\mathrm{m}_{2}=$ Pendelmasse $=37,3 \mathrm{~kg} \pm 0,1 \mathrm{~kg}(0,27 \%)$

$T=$ Schwingungsdauer $=1,93 \mathrm{~s} \pm 0,02 \mathrm{~s}(1,04 \%)$

$\bar{x} \approx$ Pendelausschlag $=b_{\alpha} \mathrm{m} \pm 0,0005 \mathrm{~m}(\min 1,67 \%-\max 50 \%)$

Geschossmasse, Pendelmasse und Schwingungsdauer sind als konstant zu betrachten, der Pendelausschlag hingegen variierte von Schuss zu Schuss.

Deshalb hat der Pendelausschlag den größten Anteil am relativen Fehler insgesamt. Wenn das Pendel nur $1 \mathrm{~mm}$ ausschlägt, macht sich eine Messungenauigkeit von $\pm 0,5$ $\mathrm{mm}$ stark bemerkbar (relativer Fehler 50 \%).

Den „Fehler im ungünstigsten Fall“ berechnet man, indem man alle Fehlereinflüsse mit positivem Vorzeichen annimmt und addiert:

$\Delta f=\left|\Delta^{a} f\right|+\left|\Delta^{b} f\right|+\ldots$

Die voneinander unabhängigen Fehler heben sich, statistisch gesehen, gegenseitig teilweise auf, das Gauß'sche Fehlerfortpflanzungsgesetz ist anzuwenden:

$\Delta f=\sqrt{\left(\Delta^{a} f\right)^{2}+\left(\Delta^{b} f\right)^{2}+\ldots}$. 
Wenn man aus den vier (voneinander unabhängigen) Fehlergrößen unter Beachtung des Gauß'schen Fehlerfortpflanzungsgesetzes den relativen Fehler ermittelt, ergeben sich für die Schussserie zur Pendelkalibrierung folgende Werte:

\begin{tabular}{|c|c|c|c|c|c|}
\hline$b_{\alpha}[\mathrm{m}]$ & $\mathbf{v}_{\mathrm{ber}}[\mathrm{m} / \mathrm{s}]$ & $\begin{array}{l}\text { relativer Fehler } \\
\text { (Pendel- } \\
\text { ausschlag) [\%] }\end{array}$ & $\begin{array}{l}\text { relativer Fehler } \\
\text { (insgesamt) [\%] }\end{array}$ & $\begin{array}{c}\text { I relativer Fehler } \\
\text { im } \\
\text { ungünstigsten } \\
\text { Fall [\%] }\end{array}$ & $\begin{array}{c} \pm \text { absoluter } \\
\text { Fehler } \\
\text { (insgesamt) } \\
\text { [m/s] } \\
\end{array}$ \\
\hline 0,030 & 831,3 & 1,67 & 2,02 & 3,32 & 16,79 \\
\hline 0,028 & 775,9 & 1,79 & 2,12 & 3,44 & 16,45 \\
\hline 0,025 & 692,8 & 2,00 & 2,30 & 3,65 & 15,93 \\
\hline 0,025 & 692,8 & 2,00 & 2,30 & 3,65 & 15,93 \\
\hline 0,024 & 665,1 & 2,08 & 2,37 & 3,73 & 15,76 \\
\hline 0,026 & 720,5 & 1,92 & 2,23 & 3,57 & 16,07 \\
\hline 0,022 & 609,6 & 2,27 & 2,53 & 3,92 & 15,42 \\
\hline 0,019 & 526,5 & 2,64 & 2,87 & 4,29 & 15,11 \\
\hline 0,016 & 443,4 & 3,13 & 3,33 & 4,78 & 14,77 \\
\hline 0,001 & 27,7 & 50,00 & 50,02 & 51,65 & 13,86 \\
\hline 0,0015 & 41,6 & 33,33 & 33,35 & 34,98 & 13,87 \\
\hline 0,001 & 27,7 & 50,00 & 50,02 & 51,65 & 13,86 \\
\hline
\end{tabular}

Tab. 5.2.2a.: Fehlerabschätzung der berechneten Geschwindigkeit $\mathrm{b}_{\mathrm{a}}=$ gemessener Pendelausschlag

$v_{\text {ber }}=$ berechnete Geschwindigkeit (Kap. 7.4. Formel (10))

Legt man eine Messungenauigkeit von $\pm 5 \cdot 10^{-4}$ zugrunde, ist die Geschwindigkeitsmessung mittels eines Pendels (wie es von uns verwendet wurde) erst bei einem Pendelausschlag von $>16 \mathrm{~mm}$ sinnvoll. Der relative Fehler insgesamt liegt dann bei $<3,33 \%$. 
Die Geschwindigkeitsbestimmung sollte über das Messen des Pendelausschlages anhand einer approximierten Kalibrationskurve (Graph 4.1.5. im Kap. 4.1.5.) erfolgen. Für unser ballistisches Pendel galt: $\mathrm{v}_{\mathrm{ab}}=\left(\left(37872 \times \mathrm{b}_{\alpha}[\mathrm{m}]\right)+95,327\right) /[\mathrm{s}]$.

Der resultierende absolute und relative Fehler ist in den folgenden Tabellen dargestellt:

\begin{tabular}{|c|c|c|c|c|c|c|c|}
\hline $\begin{array}{c}\left(\mathbf{v}_{\mathbf{a}}+\mathbf{v}_{\mathbf{r s t}}\right) / \mathbf{2} \\
{[\mathbf{m} / \mathbf{s}]}\end{array}$ & $\begin{array}{c}\mathbf{b}_{\mathbf{\alpha}} \mathbf{m i n} / \mathbf{b}_{\mathbf{\alpha}} \mathbf{m a x} \\
{[\mathbf{m}]}\end{array}$ & $\begin{array}{c}\mathbf{v}_{\mathbf{a b} \min } \\
{[\mathbf{m} / \mathbf{s}]}\end{array}$ & $\begin{array}{c}\mathbf{v}_{\mathbf{a b} \max } \\
{[\mathbf{m} / \mathbf{s}]}\end{array}$ & $\begin{array}{c}\mathbf{\Delta}_{\min } \\
{[\mathbf{m} / \mathbf{s}]}\end{array}$ & $\begin{array}{c}\mathbf{\Delta}_{\max } \\
{[\mathbf{m} / \mathbf{s}]}\end{array}$ & $\begin{array}{c}\text { relativer } \\
\text { Fehler }_{\text {min }}\end{array}$ & $\begin{array}{c}\text { relativer } \\
\text { Fehler }_{\text {max }}\end{array}$ \\
\hline 1138 & $0,0295 / 0,0305$ & 1213 & 1250 & 75 & 112 & 6,59 & 9,84 \\
\hline 1117,5 & $0,0275 / 0,0285$ & 1137 & 1175 & 19,5 & 57,5 & 1,75 & 5,15 \\
\hline 1083 & $0,0245 / 0,0255$ & 1023 & 1061 & 60 & 22 & 5,54 & 2,03 \\
\hline 1077,5 & $0,0245 / 0,0255$ & 1023 & 1061 & 54,5 & 16,5 & 5,06 & 1,53 \\
\hline 1069 & $0,0235 / 0,0245$ & 985 & 1023 & 84 & 46 & 7,86 & 4,30 \\
\hline 1066 & $0,0255 / 0,0265$ & 1061 & 1099 & 5 & 33 & 0,47 & 3,10 \\
\hline 969 & $0,0215 / 0,0225$ & 910 & 947 & 59 & 22 & 6,09 & 2,27 \\
\hline 810 & $0,0185 / 0,0195$ & 796 & 834 & 41 & 24 & 5,06 & 2,96 \\
\hline 703 & $0,0155 / 0,0165$ & 682 & 720 & 21 & 17 & 2,99 & 2,42 \\
\hline 132 & $0,0005 / 0,0015$ & 114 & 152 & 18 & 20 & 13,64 & 15,15 \\
\hline 127,5 & $0,0010 / 0,0020$ & 133 & 171 & 55 & 43,5 & 43,14 & 34,12 \\
\hline 126,5 & $0,0005 / 0,0015$ & 114 & 152 & 12,5 & 25,5 & 9,88 & 20,16 \\
\hline
\end{tabular}

Tab. 5.2.2b.: Fehlerabschätzung der abgelesenen Geschwindigkeit

$\left(v_{\mathrm{a}}+\mathrm{v}_{\mathrm{rst}}\right) / 2=$ Mittelwert gemessener Geschwindigkeiten $\mathrm{v}_{\mathrm{a}}$ und $\mathrm{v}_{\mathrm{rst}}$

$b_{a} \min =$ gemessener Pendelausschlag $[\mathrm{m}]-0,0005 \mathrm{~m}$

$b_{a} \max =$ gemessener Pendelausschlag $[\mathrm{m}]+0,0005 \mathrm{~m}$

$v_{\text {ab min }}=$ auf Grundlage von $b_{a}$ min abgelesene Geschwindigkeit (Kap. 3.1.4.)

$v_{a b \max }=$ auf Grundlage von $b_{a}$ max abgelesene Geschwindigkeit (Kap. 3.1.4.)

$\left.\Delta_{\text {min }}=\mid v_{\text {ab min }}-\left(\mathrm{v}_{\mathrm{a}}+\mathrm{v}_{\text {rst }}\right) / 2\right) \mid$

$\left.\Delta_{\max }=\mid \mathrm{v}_{\text {ab max }}-\left(\mathrm{v}_{\mathrm{a}}+\mathrm{v}_{\text {rst }}\right) / 2\right) \mid$

relativer Fehler $r_{\min }=\left(\Delta_{\min } \times 100\right) /\left(\left(v_{\mathrm{a}}+\mathrm{v}_{\text {rst }}\right) / 2\right)$

relativer Fehler $r_{\max }=\left(\Delta_{\max } \times 100\right) /\left(\left(\mathrm{v}_{\mathrm{a}}+\mathrm{v}_{\mathrm{rst}}\right) / 2\right)$

Im unteren Geschwindigkeitsbereich hat der angenommene Fehler von $\pm 0,5 \mathrm{~mm}$ einen größeren relativen Einfluss auf den Pendelausschlag als im hohen Geschwindigkeitsbereich.

Der relative Fehler für Geschwindigkeiten $\geq 703 \mathrm{~m} / \mathrm{s}$ liegt jedoch immer unter $\pm 10 \%$. 
Zu c.:

Bei der Geschwindigkeitsmessung mittels einer Hochgeschwindigkeitskamera können wir den Fehler der Zeitmessung vernachlässigen (z.B. $280 \mu \mathrm{s} \pm 1$ ns: entspricht etwa $0,00036 \%)$.

Einen größeren Einfluss bei der Geschwindigkeitsmessung mittels Hochgeschwindigkeitskamera hat die Genauigkeit bei der Ermittlung der Wegstrecke. Für die erstellten Mess-Skalen wurde eine Messungenauigkeit von $\pm 0,5 \mathrm{~mm}$ angenommen. Für die Auswertung der elektrooptischen Aufzeichnungen wurde eine Messungenauigkeit von \pm 1 Pixel angenommen.

In Graphik-Programmen lassen sich die digitalen Bildsequenzen der Hochgeschwindigkeitskamera ausmessen. Zum Vergleich ist wichtig, dass die Bildsequenzen immer mit derselben Anzahl an Bildpunkten (Pixel) elektronisch erfasst wurden. Ein Graphik-Programm kann die Zahl der Bildpunkte auszählen, die innerhalb einer definierten Wegstrecke liegen. Aus der Anzahl der Pixel kann dann berechnet werden, wie lang die Wegstrecke [m] ist.

Die mit dem 28-mm-Objektiv (s-1 bis s-34) photographierte Mess-Skala 0,20 m $( \pm 0,5 \mathrm{~mm})$ entsprach bei Auswertung 502 Pixel ( \pm 1 Pixel). Also entsprach bei Auswertung 1 Pixel $=3,98 \times 10^{-4} \mathrm{~m}$. Unter oben genannter Annahme und nach dem Gauß'sche Fehlerfortpflanzungsgesetz wurde der relative Fehler $( \pm 0,325 \%)$ und der Fehler im ungünstigsten Fall $( \pm 0,45 \%)$ berechnet.

Die mit dem 50-mm-Objektiv (s-35, s-36 und s-37) photographierte Mess-Skala 0,09 m $( \pm 0,5 \mathrm{~mm})$ entsprach bei Auswertung 440 Pixel $( \pm 1$ Pixel). Also entsprach bei Auswertung1 Pixel $=2,05 \times 10^{-4} \mathrm{~m}$. Der relative Fehler $( \pm 0,61 \%)$ und der Fehler im ungünstigsten Fall $( \pm 0,79 \%)$ wurde für s-35 bis s-37 berechnet.

Die mit dem 50-mm-Objektiv (s-38 bis s-67) photographierte Mess-Skala 0,08 m $( \pm 0,5$ $\mathrm{mm}$ ) entsprach bei Auswertung 362 Pixel ( \pm 1 Pixel). Also war hier 1 Pixel mit 2,21 $\mathrm{x}$ $10^{-4}$ Meter gleichzusetzten. Der relative Fehler $( \pm 0,68 \%)$ und der Fehler im ungünstigsten Fall $( \pm 0,90 \%)$ wurde für s-38 bis s-67 berechnet.

Mit der Kamera wurde nach Objektivwechsel (nach s-34) und nach Neupositionierung der Zielhalterung (nach s-37) ein Zentimetermaß im Zielbereich photographiert. Diese Aufnahmen dienten später als Maßstab zur Bildauswertung (s.o.).

Für eine bessere Übersicht wurden in die Bildsequenzen zusätzlich die jeweils passenden Maßstäbe eingefügt (jeweils im Bild 7 unten). Hierzu wurde ein Teil einer Photodatei ausgeschnitten und nachträglich in eine andere Photodatei eingefügt. Wenn beide Photodateien mit derselben Kameraeinstellung und demselben Objektiv aufgenommen wurden, ist davon auszugehen, dass der Maßstab im Verhältnis 1:1 übertragen werden kann. In diesem Fall sollte es zu keiner Maßstabsverfälschung kommen. Zudem dient der eingefügte Maßstab der besseren Orientierung des Betrachters. Als Maßstab kann auch der definierte Geschossdurchmesser vor Zieleintritt verwendet werden.

Theoretisch wäre die Temperaturänderung (Kap.4.1.6.) der Gelatineblöcke eine weitere Fehlerquelle. Andere Autoren (JANZON 1982 a) schätzen den Einfluss der Temperatur-Erhöhung um $0,5-1{ }^{\circ} \mathrm{C}$ aber als sehr gering ein. 


\subsection{Diskussion der Ergebnisse eigener Untersuchungen}

\subsubsection{Diskussion der Kalibrierung und Laborierung}

Wegen der starken Variation der Geschossgeschwindigkeit bei Verwendung derselben Geschosse sollte ihr Einfluss auf die Wirkungsänderung (AMATO et al. 1971 a, DEMUTH 1966, DEMUTH 1969) im Ziel untersucht werden. Andere Autoren hatten für ihre Versuche entweder nur langsame Munition, welche für die forensische Arbeit einen hohen Stellenwert besitzt (MARKAKIS et al. 1992, ZIEGLER 1990), oder sehr schnelle Munition verwendet (FACKLER et al. 1986, 1988 a, LI B et al. 2001, TAN et al. 2002). Wir haben zur Abdeckung eines großen Geschwindigkeitsbereiches entsprechende Munition selbst hergestellt.

Die Standardabweichungen der von Chrony 1 und Chrony 2 gemessenen Geschwindigkeiten von Fabrikmunition $(.22 \mathrm{Ir}$ ) lagen bei $3,23 \mathrm{~m} / \mathrm{s}$ und $3,60 \mathrm{~m} / \mathrm{s}$. Es ist davon auszugehen, dass bei selbst laborierter Munition die Standardabweichungen geringer waren, weil die Pulvermengen nicht über das Volumen, sondern über die Masse bestimmt wurden. Außerdem hatte der Zündsatz einen nicht zu vernachlässigenden Einfluss auf die Geschossgeschwindigkeit. Bei Hülsen mit Zentralfeuerzündung (.222 Rem, .223 Rem) kann die Zündhütchenladung herstellungsbedingt gleichmäßiger eingebracht werden als bei Randfeuerhülsen (.22 Ir).

Die Verzögerung (durch Luftreibung) der Laborierung $223.1(129,1 \mathrm{~m} / \mathrm{s})$ wurde berechnet. Die Messung von Chrony 1 und Chrony 2 erfolgte in einem Abstand von 1,40 m. Das Geschoss verlor innerhalb dieser Strecke (und innerhalb von 0,01084 s) durchschnittlich $1,4 \mathrm{~m} / \mathrm{s}$ an Geschwindigkeit (Tab. 4.1.2.). Die Verzögerung betrug $129,15\left[\mathrm{~m} / \mathrm{s}^{2}\right]$. Bei einer Geschwindigkeit von 129,1 m/s verlor das Geschoss innerhalb von $1,40 \mathrm{~m} \mathrm{1,08} \%$ seiner Geschwindigkeit.

Die Verzögerung der Laborierung $223.5(940,8 \mathrm{~m} / \mathrm{s})$ wurde im Vergleich berechnet. Das Geschoss verlor innerhalb $1,40 \mathrm{~m}$ (und innerhalb von 0,00151 s) durchschnittlich $3 \mathrm{~m} / \mathrm{s}$ an Geschwindigkeit (Tab. 4.1.3a.). Die Verzögerung betrug 1986,75 [m/ $\left.\mathrm{s}^{2}\right]$. Bei $940,8 \mathrm{~m} / \mathrm{s}$ entsprach der relative Geschwindigkeitsverlust innerhalb von $1,40 \mathrm{~m} \mathrm{0,32 \%}$.

Für unseren Versuchsaufbau galt, dass der von der Ausgangsgeschwindigkeit abhängige Geschwindigkeitsverlust durch Luftreibung innerhalb der gemessenen Distanz $<1,08 \%$ war. Innerhalb von 1,40 m zwischen den beiden Chronygraphen kam es durch Luftreibung zu Geschwindigkeits- und Energieverlust der Geschosse auch ohne Zieldurchtritt, z.B. bei Schüssen zur Erstellung einer Eichkurve.

Die relative Standardabweichung (Tab. 4.1.3b.) der Geschwindigkeit von Fabrikmunition war $2,61 \%$. Für die selbst laborierte Munition lag die relative Standardabweichung der Geschwindigkeit stets darunter.

Die Werte für die verwendeten Laborierungen zeigen, dass die die Geschossgeschwindigkeit beeinflussenden Faktoren in einem engen Bereich streuen. Solche Einflussfaktoren sind Treibladungsmassen, Abmessung der Hülsen, Zündhütchen, Geschossgewicht und Auszugskraft der Geschosse (Setztiefe).

Die einzelnen Schüsse einer Laborierung sind demnach gut vergleichbar. 


\subsubsection{Diskussion der Schussversuche}

\subsubsection{Schusstrichter von Zerlegungsgeschossen an technischen Materialien}

In der Rechtsmedizinischen Literatur werden immer wieder unklare Auffindesituationen, wie gemeinschaftlicher Suizid (FALLER-MARQUARDT und POLLAK 2000), "hunting-related firearm accidents“ (BAKER et al. 2001, S. 287) oder mehrfache Schussverletzungen des Schädels (MADEA et al. 1986), beschrieben, die sich erst durch die anschließende Autopsie klären. Nicht immer lassen sich Projektile auffinden.

Wir haben (Kap. 4.2.1.) gezeigt, wie mit selbst hergestellten Geschossen typische Einschüsse an Hartschaumplatten und Rigips-Platten erzeugt werden können. Je nach Beschaffenheit der Geschosse könnten sich solche Projektile in der rechtsmedizinischen Praxis bei Durchtritt durch eine Schädelkalotte zerlegen. Intrakraniell wären später z.B. nur Spuren von Sand und Klebstoff oder Holz vorhanden. Diese könnten leicht übersehen werden. Bei längeren Liegezeiten wären dann die Fragmente des Projektils eventuell gar nicht mehr aufzufinden. Wahrscheinlich können die Geschosse vom Typ 3 und Typ 5 aufgrund ihrer Materialeigenschaften auch nicht sicher im Röntgenbild als Geschossfragmente erkannt werden.

Bei den Versuchen fiel auf, dass die selbst hergestellten Projektile häufiger unterstabilisiert auftrafen und dann "Keyhole“-Einschüsse erzeugten. „Keyhole“Einschüsse (STONE und PETTY 1991) entstehen, wenn Geschosse nicht senkrecht auftreffen: Die Geschosssilhouette bleibt als unrunder Einschuss sichtbar. BERLIN et al. (1976), DEVETH (1982) und LIU et al. (1988 b) hatten sich mit der Problematik unterstabilisierter Vollmantelgeschosse beschäftigt. Auch KAMPMANN und KIJEWSKI (1986) untersuchten den Einfluss der Stoßnutation auf die Geschosswirkung.

Als wir den Mündungsabstand zum Ziel (Rigips-Platten) später bei 30 weiteren Schüssen reduzierten $(0,60 \mathrm{~m})$, traten alle Geschosse orthograd ins Ziel ein und erzeugten kreisrunde Einschüsse (Kap. 4.2.1.). 
Es war zu erwarten, dass die Durchschlagskraft eines geklebten Geschosses sehr gering ist. Immerhin sind mit geklebten Geschossen die Maxilla und die Kalotte eines Schlachttierkopfes (Photo 16) perforiert worden.

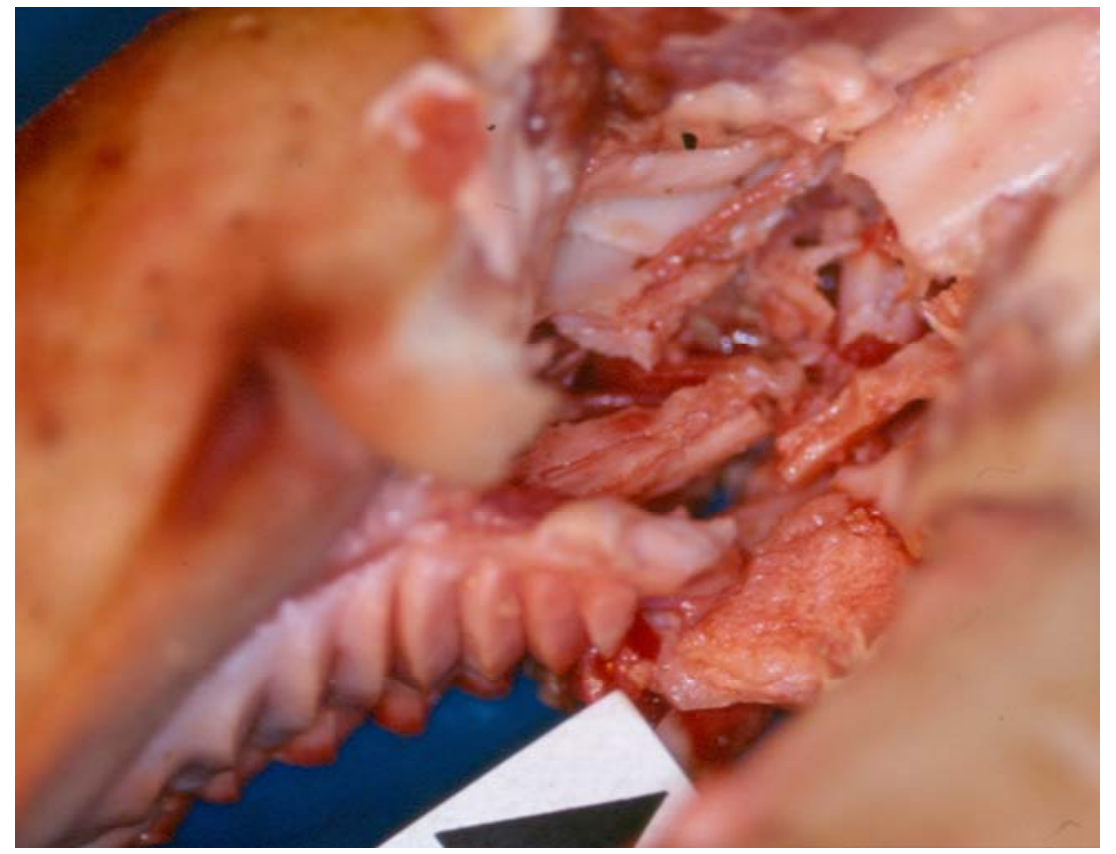

Vergrößerung von Photo 16 (Kap. 7.3.)

KIJEWSKI und KAMPMANN (1986) hatten ebenfalls Schlachttierteile beschossen und atypische Ausschüsse reproduziert. Laut BARTLETT et al. (2000) liegt die zur Hautpenetration benötigte Geschossgeschwindigkeit des Kalibers .223 REM bereits bei $45-52 \mathrm{~m} / \mathrm{s}$.

KIJEWSKI (1979) und KIJEWSKI et al. (1980) hatten auch Untersuchungen zu Schusstrichtern durchgeführt. In unserer Untersuchung wurde das Geschossmaterial in weiten Grenzen variiert und der Einfluss auf die Schusstrichter untersucht (Kap. 4.2.1.). Wir konnten zeigen, dass die Variation des Geschossmaterials Auswirkung auf die Streuung des Quotienten B/A hat.

Wir sehen in der Graphik 4.2.1., dass die Geschosse mit der größten Masse (Blei und geklebte Messingspäne) am geringsten in der Geschwindigkeit streuen. In dem Quotienten aus den Durchmessern der Aus- und Einschussseite streuen hingegen die spröden Sandgeschosse am wenigsten und die flexiblen Holzdübel (kaum Zerlegung) am weitesten.

Die geklebten Geschosse zerlegten sich schon ab einer Geschwindigkeit $>290 \mathrm{~m} / \mathrm{s}$. Die Holzdübel zerlegten sich erst ab einer Geschwindigkeit $>437 \mathrm{~m} / \mathrm{s}$. Einfluss auf die Geschosszerlegung haben Geschossmaterial und Geschossgeschwindigkeit.

Die Verwendung selbst hergestellter Projektile ist selten. Es wurde von PADOSCH et al. (2002) berichtet, dass "hölzerne Tandem-Projektile mittels zweier Schüsse aus einem manipulierten Schreckschussrevolver" verschossen worden waren.

Uns sind keine Studien bekannt, welche sich systematisch mit selbst hergestellten Projektilen befassen. 
Die unterschiedliche Wirkweise anderer Spezialgeschosse wurde hingegen in der Literatur bereits beschrieben (DEMUTH et al. 1976, DREYE und SCHUSTER 1953, EISENMENGER et al. 1989, GRAHAM et al. 1966, HARREL 1979, JOSSELSON et al. 1985, KLUPS 1998, KNEUBUEHL 1998, KNIGHT 1982, MENZIES und ANDERSON 1980, SELLIER 1969, 1977, SELLIER und KNEUBUEHL 2001, SYKES et al. 1988, SMIALEK und SPITZ 1976, VERHOFF und KARGER 2003).

SELLIER hat sich bereits 1976 mit „Abprallern an Beton“ beschäftigt und seine Befunde über "Rikochettieren von Büchsengeschossen verschiedener Bauart" veröffentlicht.

„Zerbrechliche Trainings Munition“ (FTA: Frangible Training Ammunition) gewinnt im amerikanischen Raum zunehmend an Bedeutung (MULLINS 2001). Wenn das Geschoss beim Auftreffen auf das Ziel vollständig zerbirst, ist die Gefahr geringer, verletzt zu werden, als wenn das Geschoss als Ganzes abprallt. In Deutschland darf solche Munition nicht verkauft werden. Rückschlüsse auf die verwendete Waffe anhand solcher Projektile sind nicht möglich.

Auch die Bundeswehr verwendet FTA derzeit nicht (WEIS 2002), weil sie sich „nach dem Eindringen in eine Vielzahl von Fragmenten zerlegt“. WEIS (2002) führt weiter aus, dass „beim täglichen Übungsbetrieb Personenschäden mit Übungsmunition nicht auszuschließen sind“ und "die Frangible-Munition eine nicht akzeptable Gefährdung für den Soldaten darstellt".

Die deutsche Polizei hat Frangible-Munition „ausgiebig durch ein Polizeipräsidium in Hessen erprobt“ (DAMM 2002). Weil ihre Verwendung an komplexe Umrüstung der Schießstände gebunden ist, kann dies, je nach Gegebenheiten des Schießstandes, „durchaus zu verschiedenen Entscheidungen bezüglich der Übungsmunition führen“. 


\subsubsection{Eindringtiefe und Energieverlust von VMJ in Gelatine}

Die Eindringtiefe von VMJ wurde untersucht, um Rückschlüsse auf die Eigenschaften (z.B. Geschwindigkeit) von Projektilen ziehen zu können. OTTOSON (1964) hatte eine solche Untersuchung für die Wundballistik gefordert. BERG S und KIJEWSKI (1982) veröffentlichten bereits 1982, dass die Geschossgeschwindigkeit ein wesentlicher Faktor für die Entstehung verschiedener Schusswunden ist.

Für die vorliegende Arbeit wurde die Geschossgeschwindigkeit in weiten Grenzen (132 $\mathrm{m} / \mathrm{s}-1083 \mathrm{~m} / \mathrm{s}$ ) variiert (Kap. 4.2.2.). Die Eindringtiefe in wasserreichen Zielmedien nahm zunächst in direkter Abhängigkeit zur Geschossgeschwindigkeit zu. Das ist nichts Neues oder Ungewöhnliches und steht im Einklang mit anderen Veröffentlichungen zur Wundballistik (MacPHERSON 1994).

Ab Geschwindigkeiten von 600-800 m/s nimmt die Eindringtiefe der 3,0 g schweren Vollmantelgeschosse dann aber wieder ab:

Im Kap. 4.2.2. ist die Eindringtiefe als Funktion der Geschwindigkeit dargestellt (Graph 4.2.2a.). Ein VMJ des Kalibers .223 Rem mit einer $v_{a}$ von $132 \mathrm{~m} / \mathrm{s}$ dringt $0,22 \mathrm{~m}$ in ballistische Gelatine ein. Das gleiche Geschoss dringt aber bei einer $v_{a}$ von $1083 \mathrm{~m} / \mathrm{s}$ nur noch 0,14 $\mathrm{m}$ (Photo 17) in das gleiche Material ein:

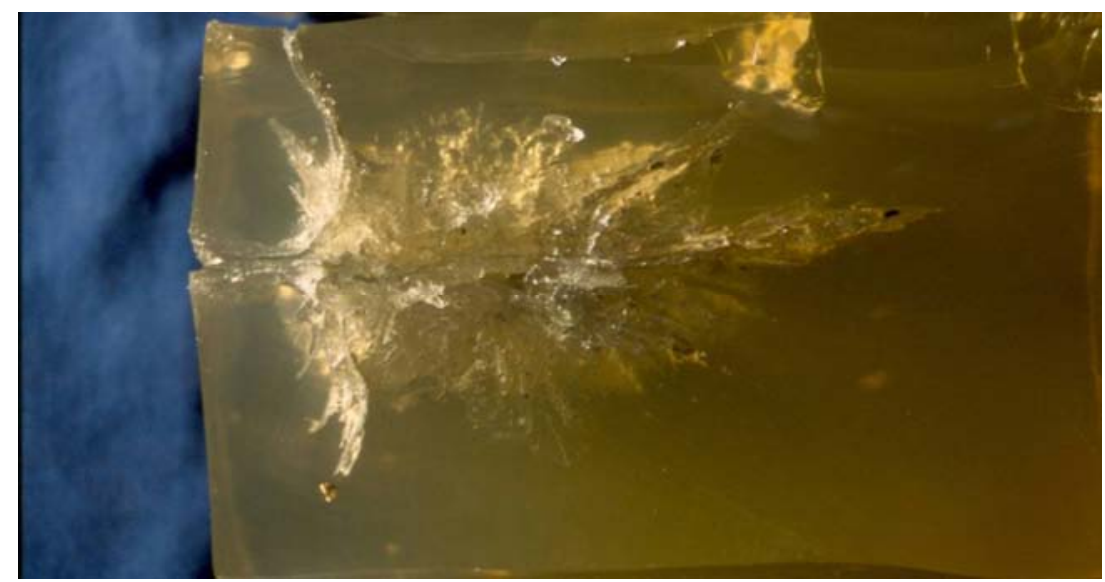

Vergrößerung von Photo 17 (Kap. 7.3.)

Der Scheitelpunkt der maximalen Eindringtiefe liegt in dem Bereich, in dem das Geschoss beginnt, sich zu fragmentieren. Geschosse mit Geschwindigkeiten > 800 $\mathrm{m} / \mathrm{s}$ dringen weniger tief als langsamere Geschosse in wasserreiche Medien ein, wobei deutlich mehr Energie pro $\mathrm{cm}$ im Ziel absorbiert wird (Graph 4.2.2b.).

BARACH et al. (1986 b) sahen als wesentlichen Faktor für die Energieabgabe das Geschossgewicht an. In unserer Versuchsreihe war die Geschossmasse konstant und der Einfluss von Geschossgeschwindigkeit und Zielmaterial wurde untersucht. FACKLER et al. (1984 a) hatten bereits den Zusammenhang von Deformation und Fragmentation der Geschosse mit der Auftreffgeschwindigkeit herausgearbeitet. Sie waren der Meinung, dass sich Geschosse allenfalls nach $90^{\circ}$ Drehung um die quere Achse fragmentieren. Fackler hatte auch einzelne Geschossfragmente geborgen und photographiert. 
Anders als Fackler haben wir viele hundert Geschossfragmente abgebildet (Photo 18), nachdem sie aus beschossener Gelatine geborgen worden waren. Die Gelatine wurde aufgelöst und die Fragmente wurden komplett geborgen. Die Fragmente ergaben zusammen das Geschossausgangsgewicht von 3,0 g.

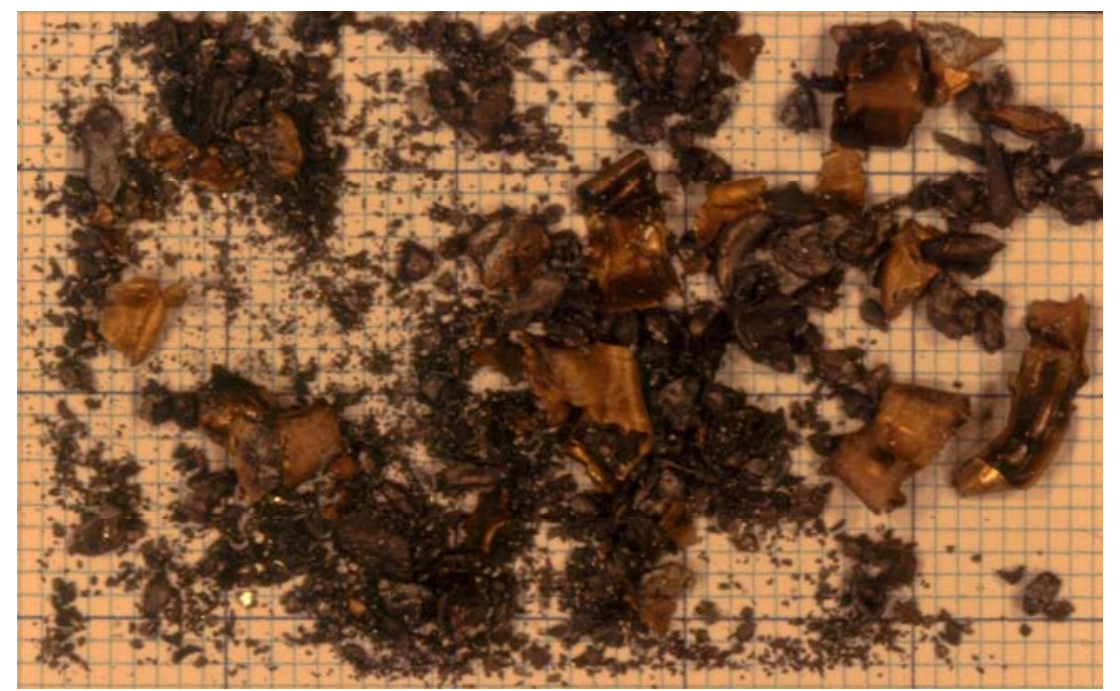

Vergrößerung von Photo 18 (Kap. 7.3.)

Zudem fand die Zerlegung in der vorliegenden Untersuchung in wasserreichen Zielen bereits vor der Geschossdrehung um die quere Achse statt, die das Ende des sogenannten "narrow-channel“ und den „point of maximum energy deposit" (COUPLAND et al. 2000, S. 6) definiert. Auch KNEUBUEHL und THALI (2003, S. 48) haben veröffentlicht, dass "the break-up of the bullet always happened at the movement of maximal lateral position". Wir haben in unserer Untersuchung jedoch die Zerlegung von VMJ im Geschwindigkeitsbereich > $800 \mathrm{~m} / \mathrm{s}$ mit 10 Schüssen dokumentiert (s-03, s-08, s-17, s-25, s-26, s-28, s-31, s-33, s-36 und s-37), obwohl sich die Geschosse nicht querstellten. Auch in flüssigem Stickstoff zerlegt sich das Geschoss bereits vor Drehung um die quere Achse (s-43, s-46).

Gerade bei hoher Geschossgeschwindigkeit steigt der Einfluss der Zielfeuchte (Gelatine in dieser Arbeit: $90 \%$ ) auf das Geschoss und die Geschosswirkung (PANKRATZ und FISCHER 1985, SCHYMA 1996).

Einen guten Eindruck der Fragmentation eines VMJ innerhalb von $20 \mu$ s gewinnt man auf Bild 3 und Bild 4 (Kap. 4.2.17.) des Schusses s-36.

Das verwendete Geschoss besitzt die kleinste Masse (3,0 g) der Vollmantelgeschosse mit Durchmesser 5,56 mm, die heute in Deutschland zu erwerben sind. Entsprechend der kleinen Geschossmasse ist der Mantel dünner als bei anderen Geschossen. Die Manteldicke der verwendeten 3,0 g VMJ (RWS) lag zwischen 0,15 und 0,16 mm, die Manteldicke der verwendeten 3,56 g VMJ (PMC) zwischen 0.24 und $0,25 \mathrm{~mm}$ (Photo 22).

Weil der Mantel das Geschossblei im Ziel zusammenhält, fragmentieren sich VMJ mit dickerem Mantel evtl. erst mit höherer Geschwindigkeit. Geschosse mit Hartmetallkern oder massive Messinggeschosse zeigen ein anderes Verhalten bei Fragmentation und fragmentieren sich erst bei höherer Geschwindigkeit (Kap. 5.3.2.10.). 
Dass die Geschossgeschwindigkeit wesentlichen Einfluss auf die Zielballistik hat, steht außer Frage. Viele Autoren haben Untersuchungen zu diesem Thema veröffentlicht (BERLIN 1979, BERLIN et al. 1976, 1977, 1979, CHENG et al. 1988, DIMOND und RICH 1967, FENG et al. 1988, HUELKE et al. 1967, KIJEWSKI 1992, LI M et al. 1988, LIU et al. 1988 a, 1988 b, 1988 c, MANDRACCHIA et al. 1999, OEHMICHEN 1992, ORLOWSKI et al. 1982 a, 1982 b, ROSE et al. 1988, SCEPANOVIC 1979, SELLIER 1967, 1977 und WATKINS et al. 1982).

Die Geschossenergie ist proportional zur Masse und dem Quadrat der Geschwindigkeit. Damit ergibt sich z.B. für ein $985 \mathrm{~m} / \mathrm{s}$ schnelles Geschoss mit $2.98 \mathrm{~g}$ des Kalibers .223 Remington eine Energie von rund 1450 Joule. Für schnellere Geschosse liegt die Energie entsprechend höher.

Wir haben den relativen Energieverlust von zunächst 21 Schüssen gemessen (Kap. 4.2.2.). Mit unterschiedlicher Geschwindigkeit $(961-1086 \mathrm{~m} / \mathrm{s})$ wurde auf Wasser und Stickstoff geschossen. Die Schichtdicken der Ziele variierten zwischen $4 \mathrm{~cm}$ und 17 $\mathrm{cm}$.

Graphisch lassen sich die Befunde wie folgt darstellen:

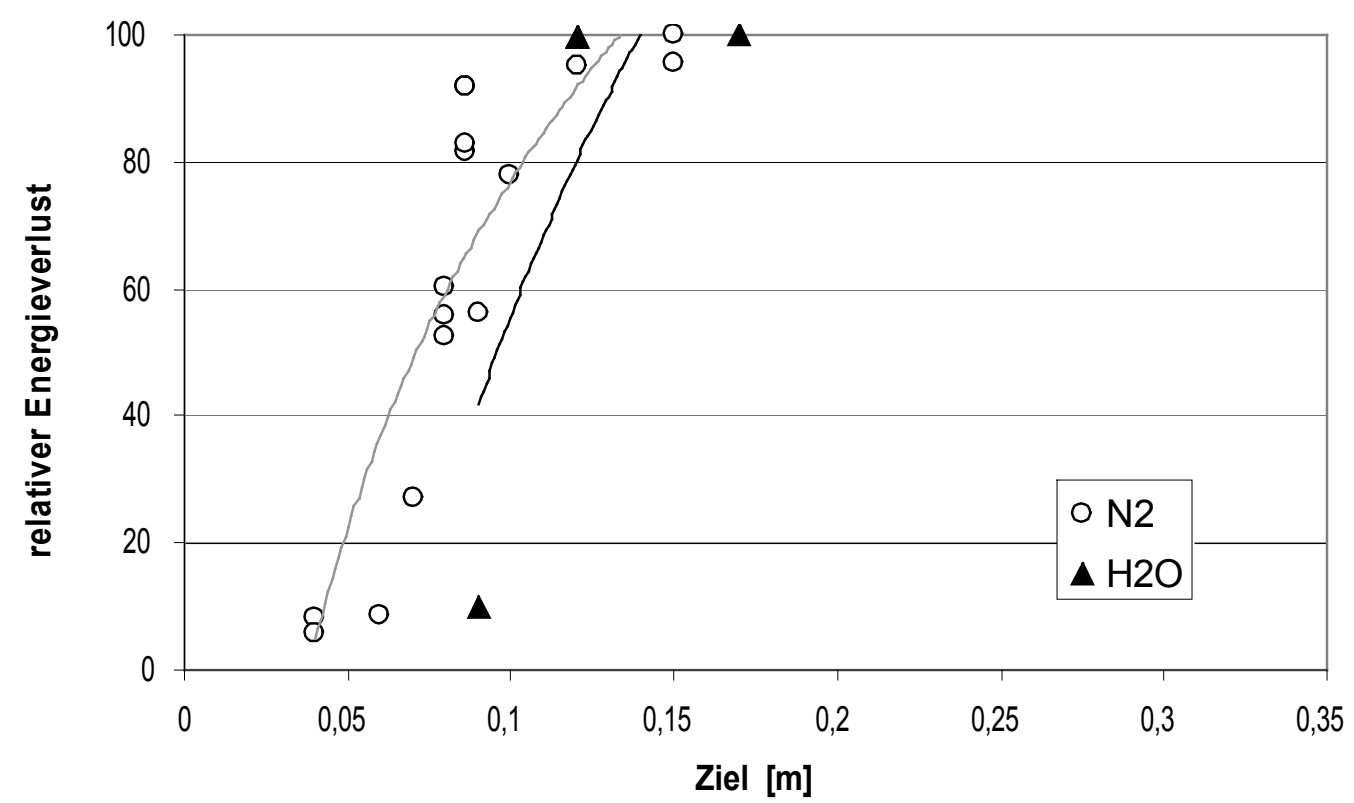

Graph 5.3.2.2a.: relativer Energieverlust von VMJ $(961$ - $1086 \mathrm{~m} / \mathrm{s})$ (in Stickstoff und Wasser)

Der Energieverlust war in unserer Untersuchung in flüssigem Stickstoff größer als in Wasser.

Und das obwohl die Schichtdicke von Stickstoff von uns zu hoch angesetzt, weil nicht zu vermeiden war, dass zahlreiche Gasblasen in der siedenden Flüssigkeit aufstiegen. 
Wenn wir die Geschossgeschwindigkeit bei weiteren 20 Schüssen steigerten (1101 $1157 \mathrm{~m} / \mathrm{s}$ ), ergab sich folgendes Bild:

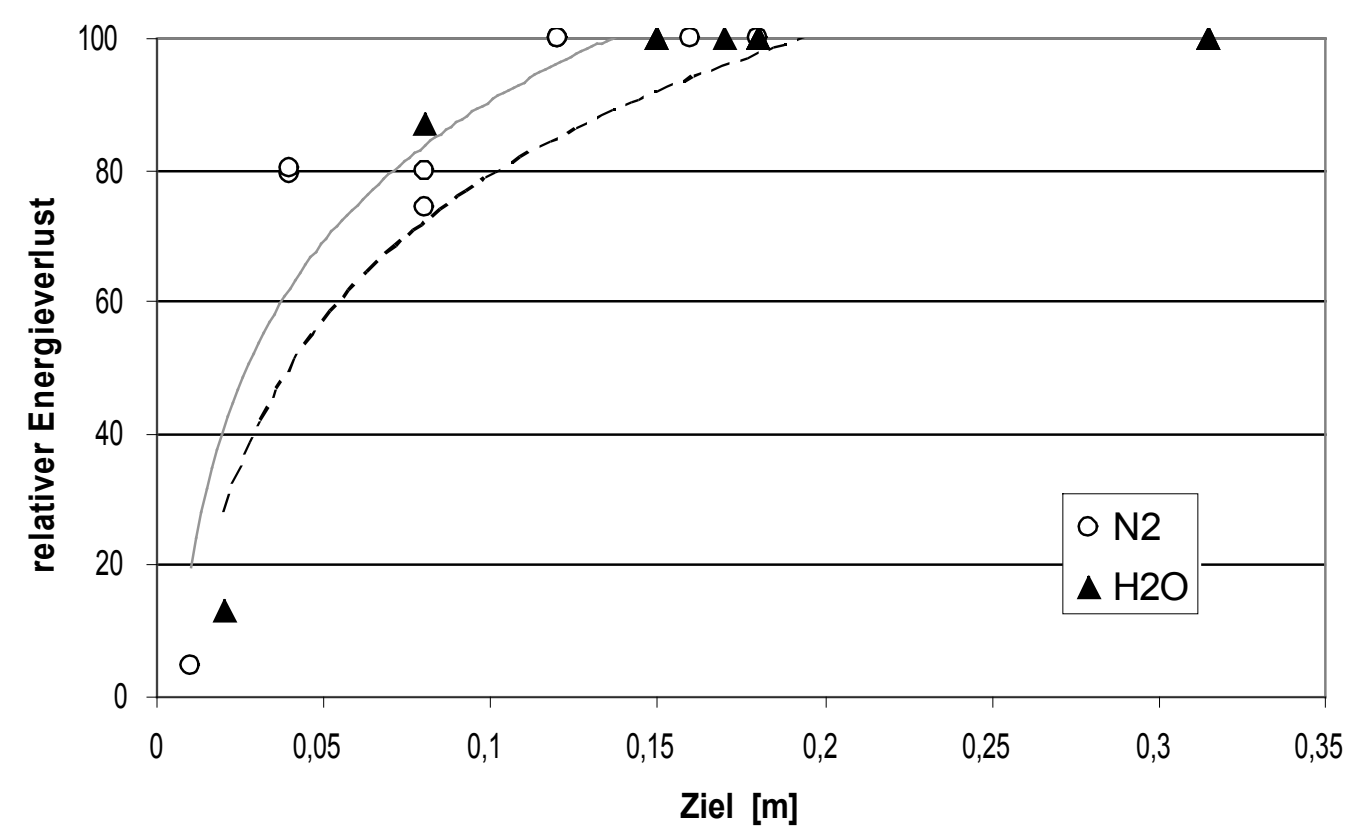

Graph 5.3.2.2b.: relativer Energieverlust von VMJ $(1101-1157 \mathrm{~m} / \mathrm{s})$

(in Stickstoff und Wasser)

Ein größerer Energieverlust fand also in einer noch früheren Phase im Ziel statt, wenn die Geschossgeschwindigkeit stieg. In flüssigem Stickstoff wurde mehr Energie abgegeben als in Wasser. Diesen Effekt erklären wir damit, dass die Schallgeschwindigkeit in Stickstoff niedriger als in Wasser und auch niedriger als die Geschwindigkeit der Geschosse ist.

\subsubsection{Zielmaterial an der Ausschussseite von Cucumis melo}

Wir haben Cucumis melo mit einer Masse von $1,2 \mathrm{~kg}$ beschossen. Die Geschwindigkeit von beschleunigtem Zielmaterial an der Ausschussseite konnte auf eine Mindestgeschwindigkeit von > $203 \mathrm{~m} / \mathrm{s}$ berechnet werden.

Das Geschoss wurde innerhalb von $3 \cdot 10^{-4}$ Sekunden von $1063 \mathrm{~m} / \mathrm{s}$ auf $>203 \mathrm{~m} / \mathrm{s}$ verzögert. Das Geschoss zerlegte sich innerhalb des Zieles, ein hoher relativer Energieverlust in wasserreichen Zielen war bereits von KLATT (1996) festgestellt und auch von KEGEL et al. (2000) diskutiert worden.

Die Schallgeschwindigkeit in Cucumis melo wurde gemessen. Bei der Messung der Schallgeschwindigkeit wird der Messpuls durch Dämpfung stark verbreitert. Die Schallgeschwindigkeit lag bei uns in einem Bereich zwischen 500-1000 m/s. Damit liegt die Schallgeschwindigkeit in Cucumis melo zum Teil deutlich unter der Geschwindigkeit einzelner Geschosse (z.B. s-13, 1063 m/s). Mit Cucumis melo lassen 
sich eindrucksvoll die Sprengschüsse des Schädels mit massiver Hirnschädigung simulieren. Seltener als Sprengschüsse (RISSE und WEILER 1988) sind die von Krönlein beschriebenen Kopfschüsse „mit Exenteration des oft kompletten Gehirns“ (REINHARD und MATTERN 1999, S. 383). Im Vergleich zu Schädelschüssen kann es auch beim Beschuss der menschlichen Lunge aufgrund ihrer unterschiedlichen Alveolargröße und erheblichen Druckdifferenzen zu eigentümlichen Verletzungskriterien kommen. GRIMAL et al. (2002, S. 1088) diskutieren „the pressure differential between two alveoli [...] as a possible injury criterion". Modellvorstellungen zur Energieabgabe von Geschossen in homogenen Materialien wurden von BERLIN et al. (1976, 1977), von JANZON et al. (1979) und von SELLIER (1969) veröffentlicht.

Mit der Problematik der Unterscheidung von Ein- und Ausschüssen an Durchschüssen haben sich KAMPMANN und KIJEWSKI (1986), KIJEWSKI (1992), POLLAK und ROTHSCHILD (2004), STONE und PETTY (1991) und andere Autoren beschäftigt. So hatten RESCHELEIT et al. (2001, S. 215) erkannt, dass bei „beschossenen Opfern, bei denen der Ausschussbereich einer festen, flächigen [...] Unterlage aufliegt, in einem hohen Prozentsatz mit Textilfasern in der Ausschusslücke zu rechnen ist". Sie erklärten das Phänomen mit dem Aufprall des Geschosses, welcher die nachgewiesenen Fasern zurücktreibe. Außerdem berichten sie von der Reflexion einer Kugelwelle an einem Widerlager, z.B. bei Auflage auf fester Unterlage.

\subsubsection{Zielmaterial an der Ein- und Ausschussseite von Cucumis melo}

Auch am Einschuss wird Zielmaterial entgegen der Schussrichtung beschleunigt. Unter den bei unserer Untersuchung gegebenen Bedingungen erreichte die Geschwindigkeit des Zielmateriales an der Einschussseite $(129 \mathrm{~m} / \mathrm{s})$ annähernd die Geschwindigkeit des Zielmateriales an der Ausschussseite (134 m/s). Die Beschleunigung von Zielmaterial am Einschuss läuft der Beschleunigung am Ausschuss und damit der Schussrichtung entgegen. Die Untersuchung ließ aufgrund der angewandten Methodik nur Aussagen über Zielmaterialbeschleunigung in zwei Richtungen zu. Die Analyse von Zielmaterialbeschleunigung innerhalb und außerhalb komplexer Ziele unter Beachtung der dritten Dimension (Spiegel oder zweite Kamera) wurde bereits von WIND et al. (1988) gefordert.

POLLAK (1980, 1982) hatte über das „retrograde Abspritzen von Gewebeteilen“ und den Abstreifring von Einschüssen „im Palmar- und Plantarbereich“ berichtet. GROSSE PERDEKAMP et al. (2005, S. 218) berichten in ihrer Untersuchung über Gewebedefekte am Einschuss von „backspatter of tissue particles up to $1 \mathrm{~mm}$. BARTLETT et al. (2000) haben über die notwendige Geschossgeschwindigkeit zur Hautpenetration mit "tail splash“ oder „splash back“ veröffentlicht. FENG et al. (1988) beschrieben sogar, dass bei Geschossgeschwindigkeiten über $1200 \mathrm{~m} / \mathrm{s}$ der Materialtransport am Einschuss meist größer als am Ausschuss sei. METTER und SCHULZ (1983) beschrieben die einem absoluten Nahschuss ähnelnden mehrstrahligen Gewebsverletzungen an parenchymatösen, wasserreichen (!) Bauchorganen an der Ein- und Ausschussseite. Atypische Einschüsse durch Hochgeschwindigkeitsmunition an wasserreichen Zielen haben KLATT (1996), SIEGMUND et al. (2002) und KEGEL (2003) und beschrieben. Im Übrigen haben THALI et al. (2002 b) eine Studie zur Morphologie des Materialtransportes an Einschüssen veröffentlicht, ebenfalls unter Verwendung der Hochgeschwindigkeitskamera Imacon 468. Bereits SELLIER (1969) war zu ähnlichen 
Ergebnissen gekommen und hat diese in einem eigenen Kapitel als die „Durch das Geschoß bedingten Veränderungen am Einschuß" veröffentlicht.

\subsubsection{Geschwindigkeit einer Höhlenfront in Gelatine (bis $154 \mu \mathrm{s}$ )}

Bereits HORSLEY (1894) hatte die destruierende Wirkung von Geschossen mit kleinem Durchmesser und hoher Geschwindigkeit beschrieben. Die Geschwindigkeit des Zielmateriales innerhalb eines Zieles kann jetzt, 111 Jahre später, mit der Hochgeschwindigkeitskamera ermittelt werden, wenn das Ziel lichtdurchlässig ist. Als „temporäre Höhle“ bezeichnete SELLIER (1969, S. 122) die „während und kurze Zeit nach Geschossdurchgang vorhandene“ Höhle, deren „Ausdehnung offenbar von den elastischen Eigenschaften des durchdrungenen Gewebes abhängt“. Von SELLIER und KNEUBUEHL (2001, S. 158) wurde der Begriff „temporäre Höhle“ benutzt, weil er „umfassender als jener der temporären Wundhöhle [...] auch die Höhlen in den Simulanzien einschließt". Die Geschwindigkeit, mit der sich die Höhlenfront in Schussrichtung (in Gelatine) ausbreitete, wurde von uns ermittelt (Kap. 4.2.5.).

Dabei fiel auf, dass das Geschoss im Ziel innerhalb von $44 \mu \mathrm{s}$ von $1104 \mathrm{~m} / \mathrm{s}$ auf 686 $\mathrm{m} / \mathrm{s}$ abgebremst wurde und sich fragmentierte. Innerhalb der folgenden $22 \mu \mathrm{s}$ breitete sich die temporäre Höhle noch mit ungefähr $723 \mathrm{~m} / \mathrm{s}$ aus.

Es ist anzunehmen, dass die Geschossgeschwindigkeit im Ziel weiter abnimmt. Die Front der temporären Höhle aber breitet sich nach Geschossfragmentation mit zunehmender Geschwindigkeit aus. Das Geschoss bleibt zumindest teilweise in Fragmenten zurück. Später fällt die Geschwindigkeit, mit der sich die Höhle ausbreitet, wieder ab. Man kann davon auszugehen, dass das sich fragmentierende Projektil (innerhalb $66 \mu \mathrm{s}$ ) einen Impuls auf das Gewebe überträgt (siehe unten).

Die Messwerte aus Tab. 4.2.5a. lassen sich graphisch darstellen:

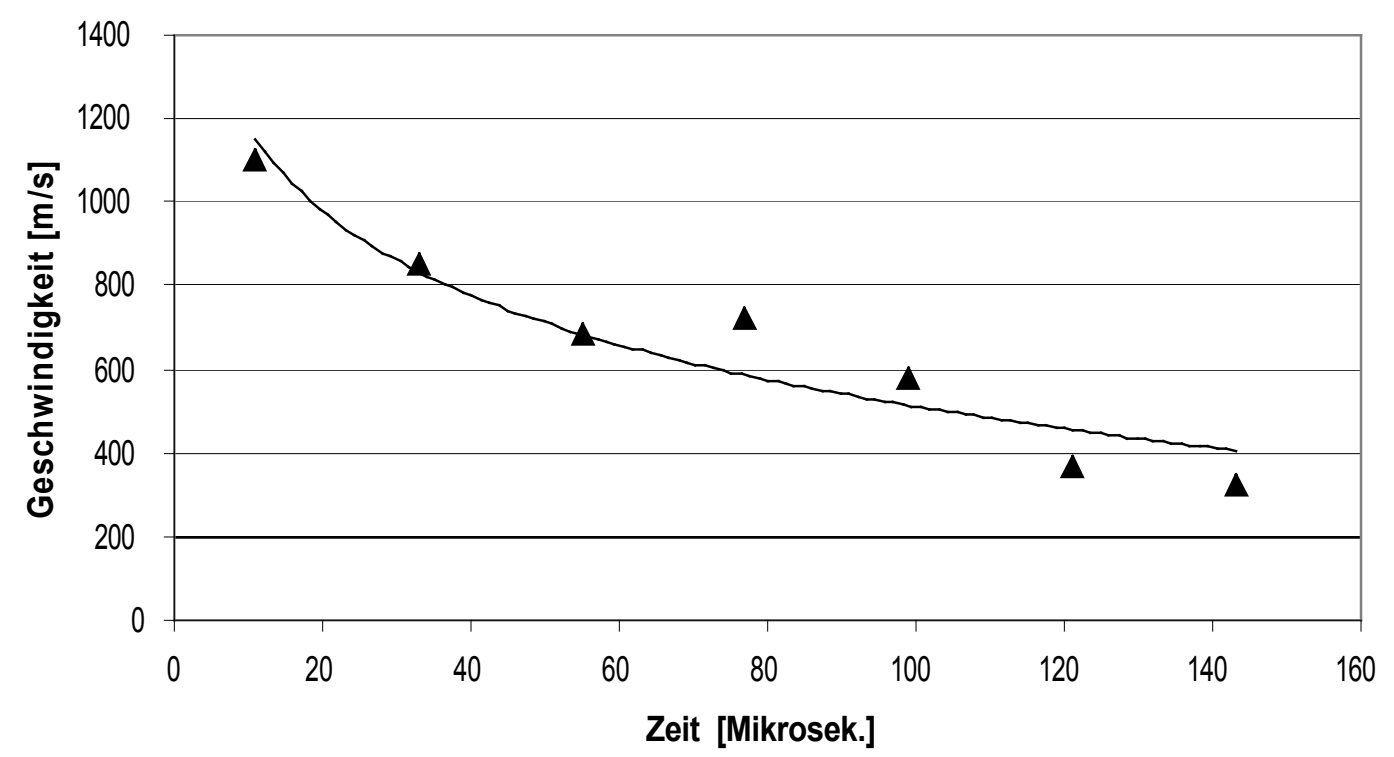

Graph 5.3.2.5a.: Geschwindigkeit der Höhlenfront s-03 (bis $154 \mu \mathrm{s})$

(nach Beschuss von ballistischer Gelatine mit VMJ) 
Wenn, wie hier abgebildet, die Geschwindigkeit der Höhlenfront gegen die Zeit aufgetragen wird, ergeben sich weitere Fragen: Welche Mechanismen wirken in den ersten Mikrosekunden innerhalb des Geschoss-Ziel-Systems? Welcher Druck entsteht auf das Projektil bei seinem Eintritt (Kap. 5.3.2.16.)? Ist die Ausbreitungsgeschwindigkeit der temporären Höhle verantwortlich für unterschiedliche Mechanismen benachbarter (AMATO und RICH 1972) und intraabdomineller (COLLINS et al. 1988) Gefäßschädigungen?

Das Ausmessen der temporären Höhle im zeitlichen Verlauf der Geschoss-ZielWechselwirkung liefert mehr Informationen als das einfache Messen der Zielprofile nach Beruhigung des Systems. So konnte auch der Energieverlust [J/cm] vom Schuss s-03 errechnet werden (Tab. 4.2.5b) und wird hier graphisch dargestellt:

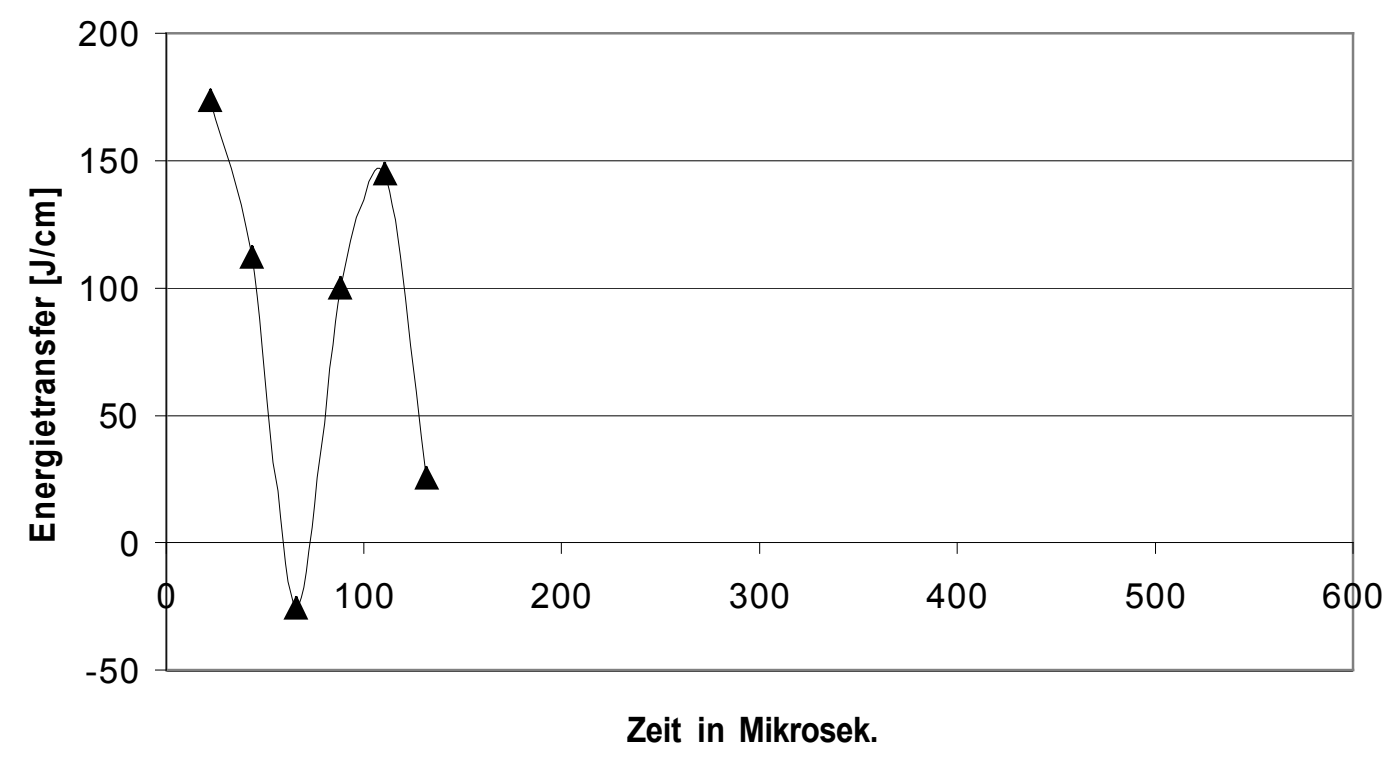

Graph 5.3.2.5b.: Energieverlust von s-03

(nach Beschuss von ballistischer Gelatine mit VMJ)

Es fällt auf, dass die Geschwindigkeit der Fragmente an der Höhlenfront zwischen 66 $\mu s$ und $88 \mu \mathrm{s}$ im Ziel zunimmt. Das ist z.B. möglich, wenn Energie vom Gewebe auf das Geschoss zurück übertragen wird (Sog). Eine zweite Erklärung ist ein möglicher Impuls bei Geschossfragmentation, welcher einzelne Fragmente beschleunigt. Durch den Impuls steigt die Geschwindigkeit eines Teiles der Fragmente, andere bleiben mit niedrigerer Geschwindigkeit zurück. Weitere Schalldruckmessungen und Schallanalysen in unterschiedlichen Medien wären notwendig, um den Einfluss der Eigenresonanz des Zieles auf die ersten Mikrosekunden der Geschoss-ZielWechselwirkung zu klären.

Für diese Arbeit wurde zunächst das zeitliche Fenster der Beobachtung ausgedehnt. 


\subsubsection{Geschwindigkeit einer Höhlenfront in Gelatine (bis $700 \mu \mathrm{s}$ )}

Unter gleichen Bedingungen wie im Kap. 5.3.2.5. wurde die Geschwindigkeit der Höhlenfront (bis $700 \mu \mathrm{s}$ ) ermittelt. Außerdem wurde die Geschwindigkeit eines Geschossfragmentes ermittelt, welches auf der Vergrößerung von s-17.5 (Kap.4.2.6.) abgebildet ist.

Das Geschwindigkeitsprofil der Höhlen- und Fragmentfront ist in folgender Graphik dargestellt:

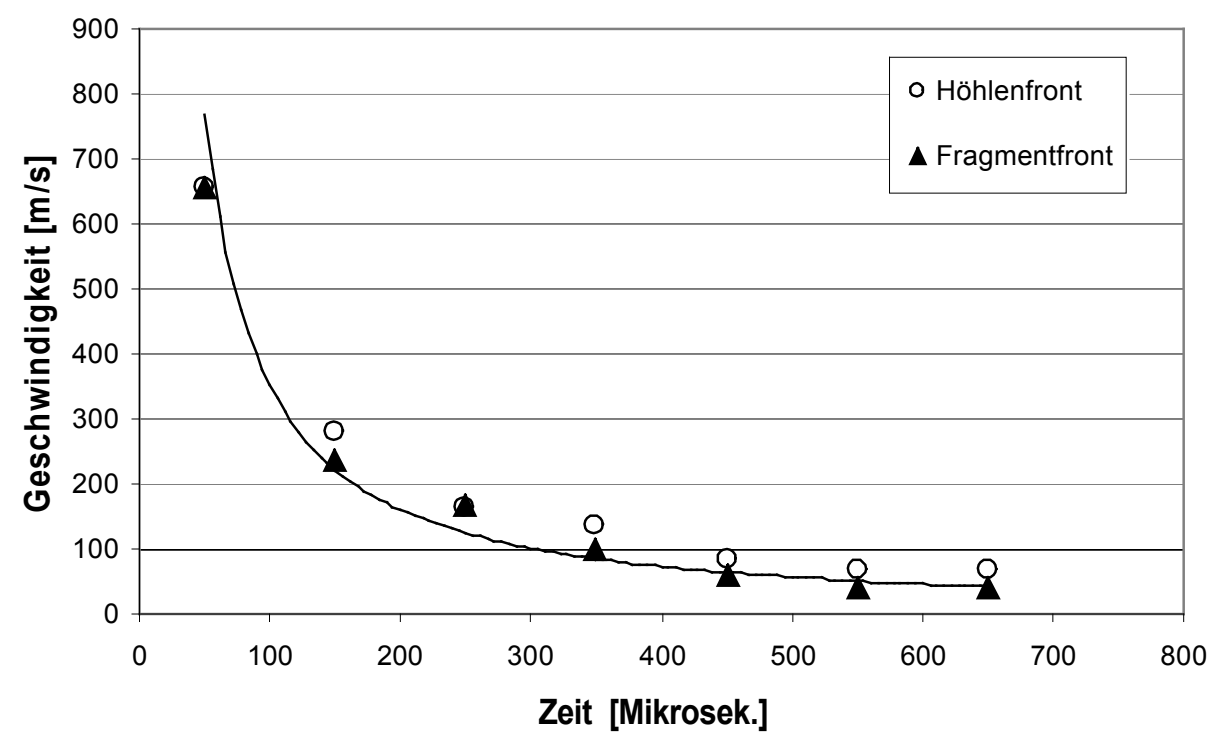

Graph 5.3.2.6a.: Geschwindigkeit der Höhlen- und Fragmentfront (nach Beschuss von ballistischer Gelatine mit VMJ)

Das Fragment hatte ursprünglich die gleiche Geschwindigkeit wie das Geschoss (1083 $\mathrm{m} / \mathrm{s}$ ), ist aber zu späteren Zeitpunkten langsamer als die sich ausbreitende temporäre Höhle und bleibt zurück.

Der größte Energieverlust des Geschosses findet innerhalb der ersten 150 Mikrosekunden statt (Tab. 4.2.6b. im Kapitel 4.2.6.). 
Legt man die Energieverlustkurve von s-17 mit der entsprechenden Kurve von s-03 (Graph 5.3.2.5b. im Kapitel 5.3.2.6.) zusammen, ergibt sich folgendes Bild:

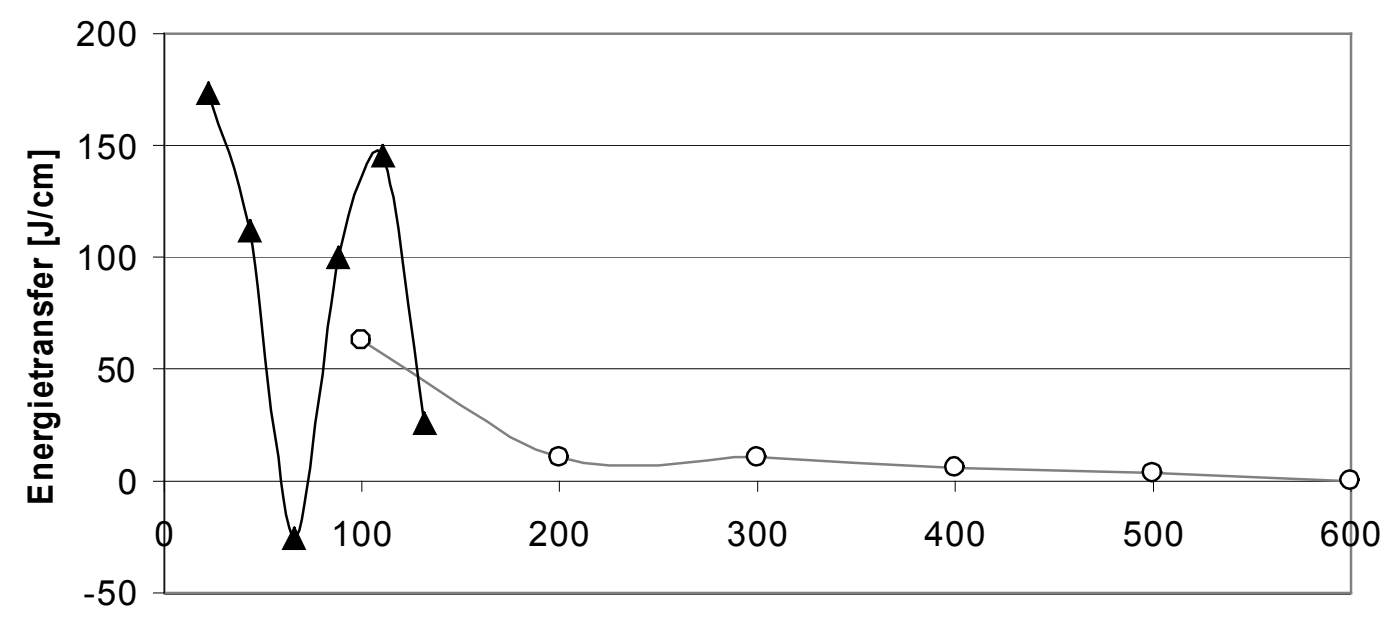

Ze it in Mikrosek.

$$
\text { -0-s-17 ‘-s-03 }
$$

Graph 5.3.2.6b.: Energieverlust von s-17 und s-03

(nach Beschuss von ballistischer Gelatine mit VMJ)

Hier lässt sich der Energieverlust über ein weites Zeitfenster gemeinsam darstellen. Die Zeitabstände zwischen den Messpunkten von s-03 sind konstant (je $22 \mu \mathrm{s}$ ). Die Zeitabstände zwischen den Messpunkten von s-17 sind ebenfalls konstant (je $100 \mu \mathrm{s}$ ). Gegen die Zeit aufgetragen, wird der hohe Energieverlust $[\mathrm{J} / \mathrm{cm}]$ in der frühen Phase im Ziel offensichtlich.

\subsubsection{Geschwindigkeit einer Höhlenfront in Stickstoff}

Unter ähnlichen Bedingungen wie im Kap. 5.3.2.5 und im Kap. 5.3.2.6. wurde die Geschwindigkeit einer Höhlenfront in Stickstoff ermittelt:

Wir haben zudem abgebildet (Kap. 4.2.7.), wie ein Vollmantelgeschoss innerhalb einer Strecke von $4 \mathrm{~cm}$ von $1065 \mathrm{~m} / \mathrm{s}$ auf $765 \mathrm{~m} / \mathrm{s}$ verzögert wird und sich zudem im Stickstoff zerlegt.

Die temporäre Höhle breitet sich in den folgenden $17 \mu \mathrm{s}$ mit zunächst steigender Geschwindigkeit $(924 \mathrm{~m} / \mathrm{s})$ aus. Erst im Anschluss fällt die Geschwindigkeit der Höhlenfront wieder ab. 


\subsubsection{Maximaler Durchmesser einer temporären Höhle}

In der Literatur finden sich viele Veröffentlichungen (zuletzt VELITCHKOV et al. 2000), in denen der Durchmesser von temporären Höhlen in Beziehung zum Geschosskaliber gesetzt wird. Schon STUTZMAN (1977, S. 947) erkannte die „explosive reaction within the wound“ beim Beschuss von intraperitonealen Organen mit mehr als „2.500 fps“ (762 m/s). Für die maximale Ausbreitung der temporären Höhle gab er an, sie sei „30 to 40 times its [Geschosskaliber] size“.

RAGSDALE und JOSSELSON (1988 b) veröffentlichten, wie nach dem Beschuss von Gelatineblöcken und anschließendem Ausmessen der verbleibenden Fissuren auf die maximale Ausdehnung der temporären Höhle Rückschlüsse möglich seien. Die Werte des maximalen Durchmessers der Höhle schwanken in der Literatur zwischen 30 und 40 mal das Geschosskaliber (RYBECK 1974, BELKIN 1978, OWEN-SMITH 1981). FACKLER (1988, S. 2731) gab an, Daten seines Labors hätten „a maximum temporary cavity of only 12,5 sphere diameters" ergeben.

Allerdings gibt es in der Literatur unterschiedliche Angaben zu Herstellung, Wassergehalt und Beschusstemperatur von ballistischer Gelatine (Kap. 4.2.1.4.).

Bei unserem Schuss s-18 lässt sich die expandierende temporäre Höhle gut beobachten. Unser Geschoss hatte einen Durchmesser von 5,56 mm.

Der maximale Durchmesser der temporären Höhle in Gelatine hängt neben dem verwendeten Geschosskaliber auch von der ersten Geschoss-Ziel-Wechselwirkung (Fragmentation), der Geschwindigkeit (RYBECK 1974), dem Taumeln und weiteren Größen ab. Insgesamt sagt der maximale Durchmesser nicht viel über die Verhältnisse in vivo aus. 


\subsubsection{Gasballonkollaps in Wasser abseits vom Schusskanal}

Auf unserer Bildsequenz ist die Verkleinerung einer Luftblase (Luftballon mit $1,73 \mathrm{~cm}$ Durchmesser) abseits der temporären Höhle aufgezeichnet. Bereits HARVEY et al. (1947) erlangten durch einen vergleichbaren Versuch grundlegende Erkenntnisse über die Fernwirkung von Hochgeschwindigkeitsmunition. Es ist davon auszugehen, dass nach Geschosseinschlag eine Überdruckwelle mit Schalleitgeschwindigkeit des entsprechenden Mediums durch das Ziel geht. Wenn wir das Volumen des Ballons unter Annahme einer Kugelform aus dem Durchmesser berechnen ergibt sich folgender Graph:

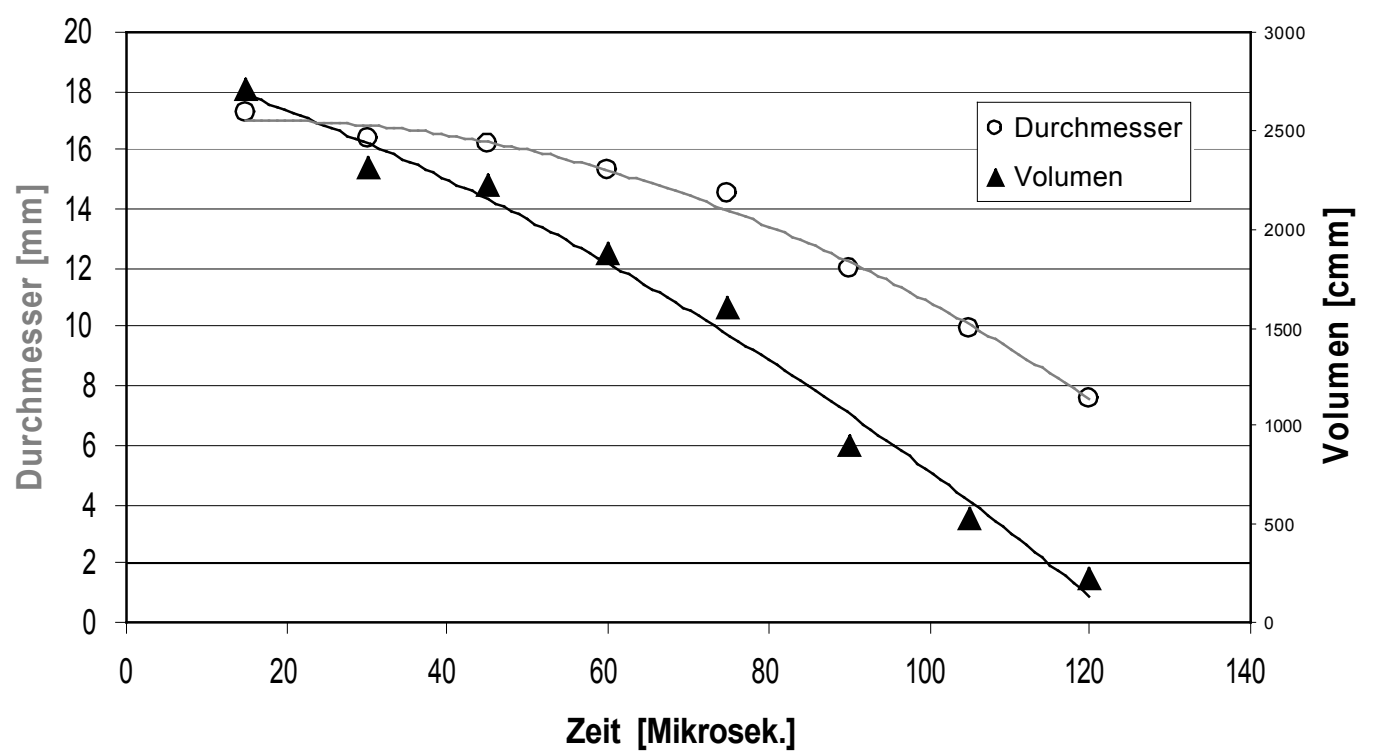

Graph 5.3.2.9.: Gasballonkollaps in Wasser unter Annahme einer Kugelform

Anhand des Ausgangsvolumens einer Gasblase und der Geschwindigkeit des Blasenkollapses lässt sich der einwirkende Druck schätzen (LINDAU 1998).

Nach der Rayleigh-Kollaps-Formel gilt:

$$
t_{c}=0,915 \times r_{0} \times \sqrt{\frac{\rho_{H 2 O}}{p-p_{0}}}
$$

$t_{c}=$ Zeit des Kollapses [s]

$r_{0}=$ Anfangsradius [m]

$p_{0}=$ Normaldruck [bar]

$p=$ Druckpuls [bar]

$\rho_{H 2 O}=$ Dichte von Wasser $\left[\mathrm{kg} / \mathrm{m}^{3}\right]$ 
Wir können die Rayleigh-Kollaps-Formel nach $p$ (Druckpuls) umformen:

$$
p=p_{0}+\frac{\rho_{H 2 O}}{\left(\frac{t_{c}}{0,915 \times r_{0}}\right)^{2}}
$$

Für unseren Versuch (s-66) gelten:

$t_{c} \approx 0,00014 \mathrm{~s}, r_{0}=0,0173 \mathrm{~m}, p_{0}=100 \mathrm{kPa}, \rho_{\mathrm{H} 2 O}=1000 \mathrm{~kg} / \mathrm{m}^{3}$

Damit ergibt sich für den Druckpuls, welcher die Luftblase kollabieren lässt, ca. 129 bar (ca. $12900 \mathrm{kPa}$ ).

\subsubsection{Zielprofil eines massiven Messinggeschosses}

In Kap. 4.2.10. konnten wir das entstehende „Wundprofil“ eines massiven Messinggeschosses in Gelatine zeigen. FACKLER und MALINOWSKI (1985) hatten den Begriff „Wundprofil“ geprägt. „Wundprofile“ beschreiben „die Gesamtheit der Geschosswirkungen“, welche sich aus Eindringtiefe, Geschosszerlegung, Durchmesser der temporären Höhle und Durchmesser der bleibenden Höhle zusammensetzt.

Für die hier vorliegende Arbeit wurde der Begriff „Wundprofil“ durch „Zielprofil“ ersetzt. Letzterer passt für unsere Untersuchung, weil es sich hier nicht um lebendes „Wund"gewebe handelt, sondern um unbelebte „Ziel"simulanzien.

In der Literatur war der Drehwinkel eines Geschosses (hier ein massives Messinggeschoss) um die quere Achse über $180^{\circ} \mathrm{im}$ Ziel bislang nicht beschrieben worden.

Einige Autoren beschrieben Drehungen von sich nicht deformierenden Projektilen von $90^{\circ}$ bis $180^{\circ}$ um die Querachse (AMATO et al. 1971 b, FACKLER und O'BENAR 1987, FACKLER und MALINOWSKI 1988 a, FACKLER et al. 1984 a, 1984 b, 1988 b, SILVIA 1999). SELLIER und KNEUBUEHL (2001, S. 163) schreiben: "in keinem der festgehaltenen Fälle überstieg jedoch der Drehwinkel 180“،.

Dementgegen stellt die vorliegende Arbeit das ungewöhnliche Zielprofil eines massiven Messinggeschosses vor (Kap. 4.2.10.), welches sich im Ziel innerhalb von $294 \mu$ s bereits $>280^{\circ}$ um die Querachse gedreht hat. 
Wenn man die Berechnungen aus Kap. 4.2.10. zu Drehwinkel und Energieverlust zusammenführt, fällt auf, dass auch der Drehwinkel des Messinggeschosses Einfluss auf die Energieabsorption hat. COOPER und RYAN (1990, S. 608) hatten veröffentlicht, "the site of $90^{\circ}$ yaw is coincident with the site of maximum energy transfer". Für unseren Versuch liegt der maximale Energietransfer in dem Bereich, in welchem sich das Projektil zwischen $53^{\circ}$ und $137^{\circ}$ gedreht hat. In dem Bereich, in welchem das Geschoss mit dem Heck voran das Ziel passiert, wird weniger Energie übertragen. Später steilt sich das verlangsamte Geschoss wieder auf und überträgt mehr Energie bei einem Drehwinkel um 270'. Auch hier findet der größte Energietransfer also in dem Bereich statt, in dem sich das Projektil um $90^{\circ}$ um die Querachse aufgesteilt hat:

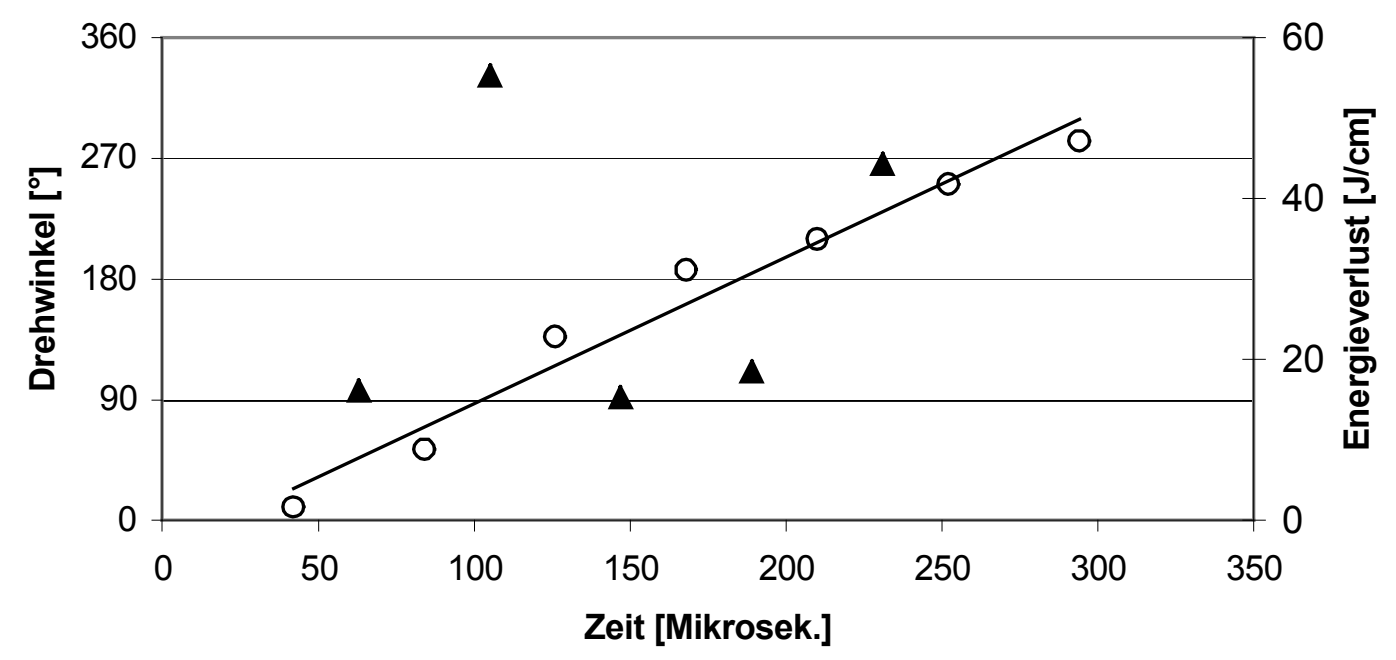

○ Drehwinkel $\Delta$ Energieverlust - Drehwinkel (linear)

Graph 5.3.2.10d.: Energieverlust und Drehwinkel eines Messinggeschosses

Massive Messinggeschosse werden wegen starker Laufverschmierung nur selten verwendet, dennoch finden sich in Veröffentlichungen (FACKLER et al. 1984 a, MacPHERSON 1994, WARD und NOLTE 2000) bereits Ergebnisse zum Thema massive Messing- bzw. Tombakgeschosse. 


\subsubsection{Schwärme von Gasblasen abseits der temporären Höhle}

Die bildlich dargestellten Formen der temporären Höhlen (z.B. s-03, s-17, s-18, s-25, $\mathrm{s}-33$, s-36, s-43, s.46, s-51, s-53, s-54 und s-58) ähnelten sich in unserer Versuchsreihe auch in unterschiedlichen Simulanzien erstaunlich.

LIU et al. (1988 c, S. 13) beschrieben bereits anschaulich die charakteristische Form der temporären Höhle: "looked like a snail with its antennae streched out" und im weiteren Verlauf „appeared the cavity as mushroom“.

Wenn wir den Vergleich der Erscheinung der temporären Höhle aufgreifen, wird der „Pilzstiel“ von dem Schusskanal gebildet, den das Geschoss vor der Fragmentation erzeugt. Einzelne Fragmente (insbesondere des Mantels) wurden in unserer Versuchsreihe mit einem Winkel zwischen $30^{\circ}$ und $50^{\circ}$ zur Schussrichtung abgelenkt: Die entstehende Winkelspitze deutet wahrscheinlich auf den Ort der Geschossfragmentation.

Der eigentliche „Pilzhut“ wird von der wachsenden temporären Höhle gebildet. Das Wissen um die charakteristische Form kann - nach Geschossfragmentation von Hochgeschwindigkeitsmunition ( $1000 \mathrm{~m} / \mathrm{s})$ in wasserreichen Zielen - auch der Beurteilung von Schusswunden dienen. So wiesen ORDOG et al. (1988) darauf hin, dass auch die Kenntnis des Verletzungsmechanismus für den Behandlungsplan relevant sei.

Der Mantelrest wird schräg zur Schussrichtung beschleunigt, obwohl zunächst die größte Kraft direkt entgegengesetzt der Schussrichtung wirkt. Gleichzeitig aber wirkt aufgrund des Geschossdralls (hier 0,305 m) eine Zentrifugalkraft auf die, das Geschoss ummantelnde, Kupferschicht:

Bei einer Geschwindigkeit von 1083 m/s dreht sich das Geschoss (bei einer Drallänge von $0,305 \mathrm{~m}$ ) immerhin 3551 Mal pro Sekunde um die Längsachse. Das Verhältnis zwischen Geschossgeschwindigkeit und drallabhängiger Zentrifugalkraft stellt, neben anderen Faktoren, den individuellen Winkel ein, mit dem die Mantelfragmente von der ursprünglichen Geschossbahn abweichen. Andere Faktoren sind Materialeigenschaften des Zieles und des Geschosses.

Im Zusammenhang mit der charakteristischen Höhlenform innerhalb der ersten $150 \mu \mathrm{s}$ nach Geschosseinschlag sei nochmals (vergl. Kap. 5.3.2.2.) darauf hingewiesen, dass im vorliegenden Fall kein „narrow-channel“ beobachtet wurde.

Ein „narrow-channel“ ist als das erste Teilstück eines Schusskanals beschrieben: während seiner Entstehung wirkt ein großer Druck aus dem Zielmaterial nur auf die Geschossspitze ein; das restliche Geschoss wird nicht umströmt und bleibt kräftefrei (SELLIER und KNEUBUEHL 2001). Erst die Drehung um die quere Achse führt dann wegen rascher Vergrößerung der Oberfläche zur starken Verzögerung und Bildung der temporären Höhle.

In dem hier von uns beschriebenen Fall verzögert sich das Geschoss bereits stark ohne Drehung um die quere Achse und fragmentiert sich sogar. Die Fragmente wandern im Ziel mit der bereits entstehenden temporären Höhle.

Außerdem fallen hier verschattete Bereiche abseits der temporären Zielhöhle auf, welche von LIU et al. (1988 c) nicht und, nach unserem Wissen, auch sonst noch nicht beschrieben wurden. 
Wenn Wasser siedet, entstehen Wasserdampfblasen. Die Siedetemperatur von Wasser beträgt unter Normaldruck $100^{\circ} \mathrm{C}$ und liegt bei niedrigerem Druck unter $100^{\circ} \mathrm{C}$. Bei entsprechend starkem Unterdruck entstehen Wasserdampfblasen also auch bei $20^{\circ} \mathrm{C}$. Wenn kleine Gasblasen in einer Flüssigkeit aufschwingen, wird Licht an der Phasengrenze abgelenkt (Kap. 7.6.). In Abhängigkeit vom Auftreffwinkel kommt es dabei auch zur Totalreflexion und im Durchlicht erscheinen Bereiche mit Gasblasenbildung dunkler.

Solche Blasenschwärme im Bereich vor der sich entwickelnden temporären Höhle wurden abgebildet (Kap. 4.2.11.). Dabei wurden verschattete Bereiche mit Gasblasen auch in $10 \%$ ballistischer Gelatine (Kap. 4.2.6.) abgebildet und bereits besprochen (SIEGMUND et al. 2002, SIEGMUND et al. 2004).

In der Naturwissenschaft wurde bereits viel zu Kavitationsblasen veröffentlicht. Der Begriff Kavitation ist aus dem Lateinischen abgeleitet („cavus“ = hohl) und beschreibt die Bildung von Hohlräumen in flüssigen Medien durch Energieeintrag. Durch Druckabfall können an Kavitationskeimen Kavitationsblasen aufreißen, in welche Gase eindiffundieren, die in der Flüssigkeit gelöst sind (LAUTERBORN 1997, LAUTERBORN und KURZ 2000). Zuerst dehnen sich die Hohlräume im Unterdruckbereich weiter aus. Wenn in der Flüssigkeit der Druck wieder ansteigt, kollabieren die Gasblasen. Bei dem Kollaps einer Blase entsteht im Blaseninneren ein hoher Druck (mehrere hundert bar) und eine hohe Temperatur (mehrere tausend Grad Celsius) (PUTTERMANN 1995), sodass sogar Gas in der Blase, unter Bildung von Radikalen, ionisiert werden kann (LOHSE 2000, DIDENKO und SUSLICK 2002). Eine Kavitationsblase kann sich beim Kollaps auch in viele kleine Gasblasen auflösen (transiente Kavitation), die wieder Kavitationskeime darstellen.

Ein weiteres Phänomen ist, dass die Blasen während ihres Kollapses Stoßwellen und ultrakurze Lichtblitze (PUTTERMANN und WENINGER 2000) emittieren. Kollabiert eine Blase zudem in der Nähe von Grenzflächen (u.a. auch benachbarten Blasen), so ist ihre Dynamik (METTIN et al. 1999) oft asphärisch und ein Flüssigkeitsjet entsteht (Kap. 4.2.17., Kap. 5.3.2.17.). Die mechanischen und chemischen Effekte, die durch emittierte Stoßwellen und Flüsssigkeitsjets entstehen, können Erosionen bewirken.

Solche Erosionen wurden von verschiedenen Autoren, die sich mit Stoßwellentherapie in der Medizin beschäftigen (z.B. durch Lithotripter), unterschiedlich bewertet.

HARVEY et al. (1947, S. 238) veröffentlichten: "Damage occurs in gas-free organs only if the tissue is severely stretched by movement of the temporary cavity". Bei der Untersuchung von "Remote effects" durch "high pressure shock waves" waren Blutzellen, Froschherzen und Darmschlingen starken Druckwechseln ausgesetzt worden.

Hingegen konnten Experimente an Zellsuspensionen (BRÜMMER et al. 1990, SMITS und JAP 1993) mechanische Erosionen bestätigen. In Abhängigkeit von der Anzahl der Stoßwellen und der durch die Stoßwelle übertragenen Energie konnten Zellschäden nachgewiesen werden (SIEBERT und BUCH 1998): Zell-membranriss mit Störung der Permeabilität und Zelloedem, Schädigung des endoplasmatischen Retikulums und des Zellkerns, Vakuolenbildung im Zytoplasma, Läsion des Zytoskeletts oder komplette Zellschädigung (z.B. Hämolyse).

Auch das Ausmaß evtl. gebildeter freier Radikale durch Stoßwellen bleibt umstritten (SUHR und BRÜMMER 1991, ENDL et al. 1995, KUIJPERS et al. 2002):

Diese unterschiedlichen Bewertungen der Gewebeerosionen durch Stoßwellen sind bis heute nicht zusammenhängend dargestellt worden. Auch in aktuellen Büchern zum Thema werden nicht alle der genannten Arbeiten zitiert. 
Für unsere Untersuchung lässt sich folgende Beobachtung an s-25 zusammenfassen: Wenn in einem geschlossenen Zielsystem eine Überdruckwelle entsteht, ist davon auszugehen, dass in Übereinstimmung mit dem Massenerhaltungssatz, dem Impulserhaltungssatz und dem Energieerhaltungssatz auch eine Unterdruckwelle entsteht.

Nach einer Verdichtungswelle können Kavitationsblasenschwärme in dem nachfolgenden Unterdruckbereich entstehen. Ein asymmetrischer Blasenschwarm ist unter diesen Versuchsbedingungen $128 \mu$ s nach Geschosseinschlag (s-25) in einem Abstand von $>0,06 \mathrm{~m}$ von der temporären Höhle deutlich sichtbar geworden (Kap. 4.2.11.).

Die Größe der entstehenden und kollabierenden Gasblasen ist bei der begrenzten Auflösung der Photo-Datei nur schwer zu messen. Sie liegt für Blasen, die aufgrund zentraler Aufhellung in der Vergrößerung als Einzelblasen auszumachen sind, in einem Bereich $<2,4 \mathrm{~mm}$. 


\subsubsection{Fokus von Gasblasen im rotationssymmetrischen Ziel}

Wenn die im Kap. 4.2.11. gemachten Beobachtungen richtig gedeutet (Kap. 5.3.2.11.) wurden, so müssen Kavitationsblasen insbesondere dort entstehen, wo einer starken Überdruckwelle durch Reflexion eine starke Unterdruckwelle folgt.

Druckwellen können zudem durch Grenzflächen fokussiert werden; sie können als Brennpunkt einen „Fokalschlauch“ (KUTTRUFF 1988) ausbilden.

Zur Vereinfachung des Systems wurde ein wassergefüllter Zylinder beschossen (s-58, Kap 4.2.12.). Durch die rotationssymmetrische Form waren die Schwingungsmöglichkeiten und die Druckverteilungen weniger kompliziert.

Beim Beschuss eines wassergefüllten Zylinders kann ein solcher Fokus in seiner Längsachse entstehen. Es ist davon auszugehen, dass Überdruck insbesondere an der rotationssymmetrischen Grenzfläche zur freien Luft reflektiert wird. In der Längsachse, dem „Fokalschlauch“, entsteht Unterdruck. Insbesondere hier, in dem starken Unterdruckbereich, entstehen spontan Gasblasen.

Auf den Abbildungen s-58.7 und s-58.8 (Kap. 4.2.12.) ist ein solcher Unterdruckfokus mit entstehenden Gasblasen zu sehen.

Anders als BARACH et al. (1986 a) gehen wir davon aus, dass eine in einem Blutgefäß fokussierte Zugwelle auch zur Gefäßerosion führen kann. So hatte HUGHES (1954) bereits bei der Analyse von 180 Schusswunden im Korea-Krieg festgestellt, dass es auch zu einer Gefäßschädigung außerhalb der persistierenden Wundhöhle kommen kann. ALLEN et al. (1982) haben verschiedene Formen von Hämorrhagien unter Berücksichtigung der Hydrodynamik von Kopfschüssen beschrieben. SUNESON et al. (1988) beschrieben Schädigungen der Blut-HirnSchranke im Hirn und Stammhirn abseits der eigentlichen Wundhöhle. OEHMICHEN et al. (2000) konnten dann neben dem eigentlichen permanenten Schusskanal sogar vier weitere radiale Zonen mit charakteristischen Gewebsschädigungen in Hirngeweben abgrenzen. CANNON (2001) berichtete dann zuletzt, dass eine Elimination der Penetration nicht unbedingt eine Verletzung (z.B. Contrecoup) verhindere, und vermutet einen Zusammenhang mit „stress-waves reflektion“.

\subsubsection{Wellenfront und Schwärme von Gasblasen}

Wir haben in der Bildsequenz von s-53 eine sich wellenförmig ausbreitende Wellenfront und nachfolgende Blasenschwärme außerhalb der eigentlichen temporären Wundhöhle abgebildet. Später war es auch möglich, die Wellenfront mittels Hydrophon (Kap. 5.3.2.16.) als Überdruckwelle (Verdichtungwelle) zu identifizieren.

Der Nachweis von Unterdruckbereichen war unter den gegebenen Versuchsbedingungen zunächst nicht möglich. Evtl. könnte ein Nachweis mit monochromatischem Licht oder der neuartigen Methode der „Background Oriented Schlieren" (STASICKI und FRAHNERT 2004) gelingen. 
CLASPER (2001) beschrieb, dass vitales Gewebe auch außerhalb der eigentlichen temporären Wundhöhle geschädigt würde und dies mit „radialen Druckwellen und Scherkräften“ erklärt. TAN et al. (1998) veröffentlichten eine Arbeit, in der sie die prozentuale Häufigkeit von Hirnschäden (Hyperämie, Contusionen, fleckige Haemorrhagien) nach Oberkieferbeschuss an lebenden Hunden mit unterschiedlicher Geschossgeschwindigkeit beschrieben. Bei der mit $800 \mathrm{~m} / \mathrm{s}$ beschossenen Gruppe waren in $7 \%$ Hirnschäden nachweisbar, bei der mit 1400 m/s beschossenen Gruppe lebender Hunde waren in $71 \%$ Hirnschäden nachweisbar.

\subsubsection{Wellenfront mit Reflexion}

Ein Geschoss schlägt mit $1125 \mathrm{~m} / \mathrm{s}$ in einen Wassercontainer ein. Auf der ersten Abbildung (Kap. 4.2.14.) ist bereits $90 \mu$ s nach dem Eindringen eines Geschosses eine wellenförmige Zustandsänderung $0,068 \mathrm{~m}$ vor der sich erst entwickelnden temporären Höhle abgebildet.

Bilder von wellenförmigen Zustandsänderungen (z.B. Verdichtungswellen) in unterschiedlichen ballistischen Zielen (auch in Stickstoff, Kap. 5.3.2.18.), fern der temporären Höhle, wurden, soweit wir wissen, bislang nicht veröffentlicht:

Wenn sich in Flüssigkeiten der druckabhängige Brechungsindex ändert, kann die Druckschwankung im Gegenlicht sichtbar gemacht werden. Sobald die Verdichtungswelle dargestellt worden ist, kann aus ihrer Geschwindigkeit auch der Druck der Welle berechnet werden (Kap. 5.3.2.16.).

Der Krümmungsradius der Wellenfront weist auf ihren Ursprung am Einschuss hin.

Anhand der Aufnahme haben wir die Geschwindigkeit der Wellenfront $(1640 \mathrm{~m} / \mathrm{s})$ berechnet. Diese Geschwindigkeit entspricht etwa der Schallgeschwindigkeit in Wasser bei hohem Druck. Wasser $\left(0^{\circ} \mathrm{C}\right)$ unter Normaldruck leitet Schall mit 1402,74 $\mathrm{m} / \mathrm{s}$. Wasser mit $10^{\circ} \mathrm{C}$ und Normaldruck leitet Schall mit $1447,59 \mathrm{~m} / \mathrm{s}$.

Hinter der Druckwelle sieht man Schwärme von Gasblasen (vergl. Kap. 5.3.2.11.), die entstehen und sich zurückbilden.

Auch beim Beschuss von 10 \%iger ballistischer Gelatine haben wir solche Bereiche mit Gasblasen deutlich fern der temporären Höhle abgebildet (s-17 Kap. 4.2.6.). Im Wassercontainer sind Wellenfronten und Gasblasen aber besser abzubilden als in anderen verwendeten Zielmedien.

Wenn Gasblasen aufschwingen, ist davon auszugehen, dass die Anziehungskräfte zwischen den einzelnen Molekülen der Flüssigkeit nicht mehr ausreichen, den flüssigen Aggregatzustand zu halten.

Wenn der Druck anschließend entsprechend hoch steigt, kollabieren die Gasblasen wieder. Gerade beim Blasenkollaps werden immer wieder zerstörende Wirkungen (Kavitationserosion) auf die Umgebung beobachtet. Das am häufigsten genannte Beispiel für Kavitationserosion sind Schäden an Schiffsschrauben. Beim Blasenkollaps wird umgebende Flüssigkeit zum Mikrojet beschleunigt. Dieser Flüssigkeitsstrahl kann beim genannten Beispiel millimetertiefe Löcher in dem Stahl erzeugen.

In der Medizin wird über „Kavitationsblasen“ besonders im Zusammenhang mit der Therapie von Steinleiden gesprochen. Als mögliche Erklärung der Wirkweise von Ultraschall-Lithotriptern gelten unter anderem Gasblasen(rück)bildungen. Die evtl. destruktive Wirkung auf umgebendes Gewebe wird zurzeit noch diskutiert. 
Hirnprellungen ohne Perforation der Dura mater entstehen am Ort der Gewalteinwirkung (dem sog. Stoßherd, Coup) und meist stärker an der Gegenseite (Contrecoup). Dabei treten Petechien, Zerreißungen der intrazereberalen Gefäße und multiple weitere Gewebeschäden auf. In der Medizin hatte sich bereits GROSS (1959) mit seiner "cavitation theory“ zu einer möglichen Ursache des Contrecoup-Effektes geäußert. GROSS (1958) beschrieb, dass „damage is caused mainly by the forceful collapse of tiny cavities produced by tensile stress after the stress subsides". DAWSON et al. (1980, S. 157) fassen hingegen später zusammen, dass „medical observers have indicated repeatedly that negative pressure theories do not provide a satisfactory explanation for the localization of traumatic injuries [...] and the evidence for cavitation in biologic systems is meager". Neben anderen Erklärungsversuchen, könnten entstehende Gasblasen im Unterdruckbereich des Großhirnes nach kontralateraler stumpfer Gewalteinwirkung für Gewebeeinblutungen verantwortlich gemacht werden. Hierzu wären weiterführende Studien mit entsprechendem Versuchsaufbau notwendig. Schon heute möchten wir jedoch darauf hinweisen, dass wahrscheinlich die konkave Form der inneren Schädelhöhle Druckwellen fokussieren kann. Auch bei stumpfer Gewalt mit niedrigerem Energieeintrag von lateral läge der Fokus dann auf der contralateralen Seite.

Der Begriff „Kavitationsblase“ für aufschwingende Gasblasen (Wasserdampfblasen) in der Wund- und Zielballistik ist strikt gegen den bereits früher verwendeten Begriff „Kavität" (für die temporäre Höhle) abzugrenzen. Jedenfalls sind die Entstehungsmechanismen, die räumliche und zeitliche Ausdehnung und nicht zuletzt die Wechselwirkung mit dem Zielmaterial grundsätzlich verschieden.

Über die entstehenden Gewebsschäden auch abseits der temporären Höhle lässt sich bislang nur wenig vorhersagen.

In der Literatur gibt es widersprüchliche Angaben zu „remote-effects“ von Hochgeschwindigkeitsmunition. Während OWEN-SMITH (1981) auch $20 \mathrm{~cm}$ entfernt vom Schusskanal Zelltod im Darm auf die Schussverletzung zurückführte, bestreitet FACKLER (1998) diesen Zusammenhang mit dem Hinweis auf fehlende Beobachtung von Zelltod bei anderen Organsystemen. Auch HARVEY et al. (1947) hatten Schäden an Organsystemen (Blutzellen, Froschherzen und Darmschlingen) nur dann beobachtet, wenn das Gewebe direkt durch die temporäre Höhle heftig gedehnt worden war. Von GEORGI et al. (1991) wurde jedoch eine Studie veröffentlicht, in der 299 Patienten nach penetrierenden Bauchschüssen retrospektiv auch auf begleitende extraabdominelle Verletzungen untersucht worden waren. Bei $24 \%$ der Patienten wurden solche begleitenden Verletzungen festgestellt.

ADAMS (1982) hatte über den Verletzungsmechanismus von Druckschwankungen, die in beschossenen Geweben in Zeitfenstern von 15 bis 25 Mikrosekunden pulsieren, berichtet. JOSEPHSON und THOMPSON (1988) haben dann ein analytisches Modell entwickelt, welches mit begrenzter Übertragbarkeit den Einfluss von Überdruckwellen auf Thorax und Abdomen beschreibt. Im gleichen Jahr veröffentlichten LIDEN et al. (1988) das Ergebnis ihrer Untersuchungen: Auch ohne Geschosspenetration, beim Tragen schusssicherer Westen, könne es zu schweren Verletzungen der Lunge kommen. TREIB et al. (1996, S. 64) beschreiben sogar als "late effect" einer Schussverletzung mit hoher Geschwindigkeit die Ausbildung einer Epilepsie als mögliche Komplikation, „even if the missile did not directly injure the brain“. 
Hier sei noch erwähnt, dass sich anhand der Abbildungen (Kap. 4.2.14., Bild s-54.1 bis Bild s-54.3) die jeweilige Geschwindigkeit der Verdichtungswellen in Wasser bestimmen lässt. Durch Anwendung der Rankine-Hugoniot-Beziehung lässt sich dann auf Druck und Dichte vor und hinter dem Stoß rückschließen (Kap. 5.3.2.16.).

\subsubsection{Wellenfront und einseitige Reflexion}

Auch ohne Druckmessung lassen sich bei diesem Versuch (s-54 in Kap. 4.2.14.) zunächst weiterführende Ergebnisse gewinnen:

$\mathrm{Zu}$ diesem Zweck wurde der Wassercontainer auf einem Block Gelatine gelagert. Die Dichten und Brechungsindexe beider Stoffe sind annähernd identisch. An der oberen Grenzfläche zur freien Luft hingegen liegen andere Verhältnisse vor. Die Wellenfront wird (Vergrößerung s-33.3 in Kap. 4.2.16.) an der Grenzfläche zur Luft schallweich reflektiert. Als Folge der schallweichen Reflexion sollte eine Zugwelle (Unterdruckwelle) entstehen. COLE (1948) hatte seine Untersuchungsergebnisse zu Druckwellenreflexion („acoustic transmission and reflection“) zusammengefasst. GREINER und STOCK (1991) führten die Berechnung von reflektierten Schallwellen dann weiter aus.

Tatsächlich entstehen hier insbesondere hinter der Reflexion an der Grenzfläche zur freien Luft Gasblasen im Gewebe. Die Reflexion der Wellenfront an der Grenzfläche zur freien Luft und die weniger ausgeprägte Reflexion an der Unterseite des Wassercontainers (Grenzfläche zum Gelatineblock) bestärken unsere Vermutung, eine Druckwelle abgebildet $z u$ haben. Im folgenden Kapitel (Kap. 5.3.2.16.) wird eine Wellenfront durch Druckmessung mittels Glasfaserhydrophon als Überdruckwelle (Verdichtungswelle) identifiziert.

\subsubsection{Druckmessung einer Wellenfront}

Die in Folge dargestellten Druckmessungen und insbesondere deren theoretische Interpretation wurden von Mitgliedern unserer Arbeitsgruppe, METTIN et al. (2003, 2004) und WOLFRUM (2004), erarbeitet und bereits zum Teil publiziert.

Deren Ergebnisse sollen hier ergänzend dargestellt werden, sind aber nicht integrierender Bestandteil dieser Arbeit. Andererseits sind die Ergebnisse, die für die vorliegende Arbeit besonders wichtig waren und die, die für die Physiker entscheidend waren, gemeinsam gewonnen worden und sind geeignet, sich gegenseitig zu stützen. Insofern erscheint es sinnvoll, die Ergebnisse der Dissertation von WOLFRUM (2004) und der von METTIN et al. $(2003,2004)$ initiierten Publikationen ad hoc zu zitieren und einzuarbeiten, ohne wesentlicher Bestandteil der vorliegenden Arbeit zu sein.

Durch die Verwendung eines Hydrophons mit Glasfasersonde wurden die starken Druckschwankungen bei Beschuss aufgezeichnet. Bei den Messungen (hier für s-50) ist zu berücksichtigen, in welchem Abstand zum Schusskanal der Messfühler in das Ziel integriert wurde. 


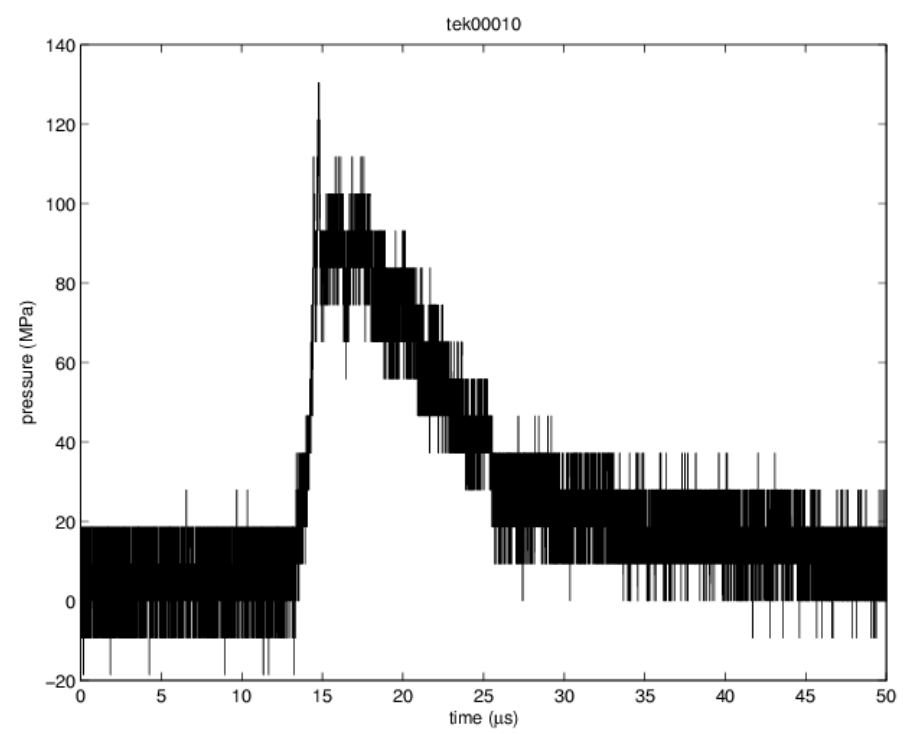

Graph 5.3.2.16a.: Druckmessung s-50 (mit freundlicher Genehmigung von METTIN et al. 2004)

Bei Änderung des Druckes einer Flüssigkeit ändert sich auch ihr Brechungsindex (vergl. Kap. 5.3.2.14.). Die Intensität von reflektiertem Licht kann also zur Druckmessung herangezogen werden.

Bei dem von uns verwendeten Modell (FOPH 300, Kap. 3.1.7.) wird Laserlicht durch einen Messfühler (Glasfaser) in die Flüssigkeit geleitet. An der Grenzfläche zwischen Glasfaser und umgebendem Wasser wird Licht wegen der unterschiedlichen Brechungsindexe reflektiert. Ändert sich der Wasserdruck, ändert sich auch sein Brechungsindex und damit letztlich die Intensität des reflektierten Lichtes. Die von uns verwendete Methode kann die Druckschwankungen zeitlich genauer auflösen als die „piezoresistive pressure transducer“, welche von HARVEY et al. (1947), SUNESON et al. (1987) und WATKINS et al. (1988) verwendet worden waren.

Weil die Druckmessungen in einem gewissen Abstand vom Einschuss durchgeführt wurden, zeigen die gemessenen Spitzendrücke an der Glasfasersonde (z.B. Graph 5.3.2.16 a.: $110 \mathrm{MPa}$ ) geringere Werte als der initiale Spitzendruck am Einschuss. Für s-50 war der Messfühler immerhin 16,5 cm vom Auftreffpunkt entfernt angebracht worden. 
Berücksichtigt man die Druckabnahme bei der Ausbreitung einer Kugelwelle

$$
|p(r)|=p_{a} \frac{r_{a}}{r}
$$

$p(r)=$ Druck bei Radius $r$

$r_{a}, p_{a}=$ Ausgangsradius, Ausgangsdruck

und geht man davon aus, dass der Initialradius zwischen 1 und $3 \mathrm{~mm}$ liegt, ergeben sich Spitzendruckwerte zwischen 500 und 2900 MPa bei Zielkontakt. Als Initialradius kann dabei wegen der ogivalen Geschossspitze nur eine Schätzung (1-3 mm) erfolgen.

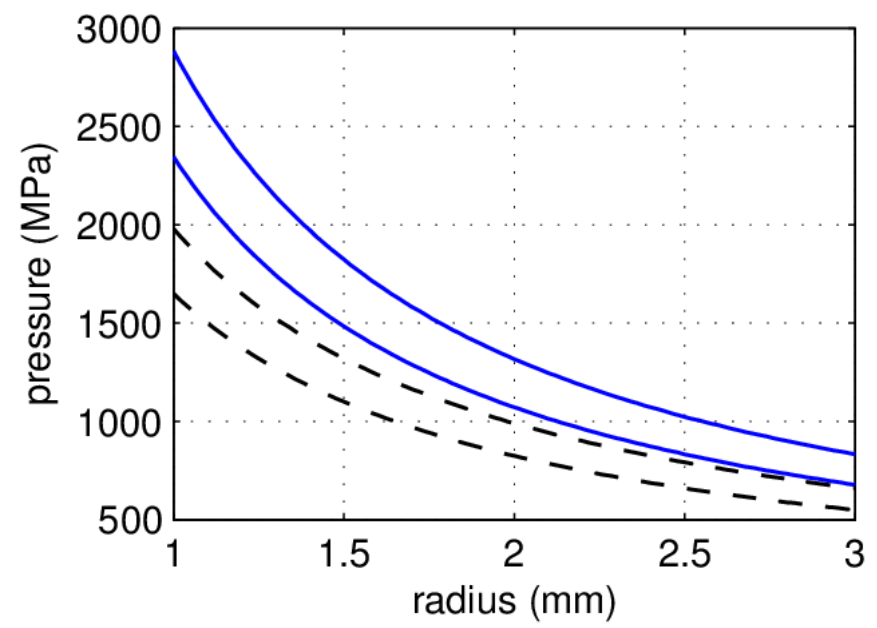

Graph 5.3.2.16b.: Druckberechnung s-50 (mit freundlicher Genehmigung von METTIN et al. 2004)

Zum anderen kann über die Laufgeschwindigkeit der Druckwelle im Wasser und ihren initialen Radius der Druck am Entstehungsort berechnet werden (METTIN et al. 2004). METTIN et al. (2004) und WOLFRUM (2004) verwendeten hierzu die RankineHugoniot-Beziehung. Damit wird die Stoßfrontgeschwindigkeit in Beziehung zu Druck und Dichte gesetzt:

$$
v_{s}(\rho p)=\frac{1}{\rho_{0}}\left(\frac{p-p_{0}}{\rho_{0}^{-1}-\rho^{-1}}\right)^{1 / 2}
$$

$v_{s}=$ Stoßfrontgeschwindigkeit $[\mathrm{m} / \mathrm{s}]$

$\rho_{0}, p_{0}=$ Dichte, Druck vor Stoß

$\rho, p=$ Dichte, Druck hinter Stoß 
Zusammen mit der Tait'schen Zustandsgleichung für Wasser

$$
\frac{p+B}{p_{0}+B}=\left(\frac{\rho}{\rho_{0}}\right)^{n}
$$

$\rho_{0}, p_{0}=$ Dichte, Druck vor Stoß

$\rho, p=$ Dichte, Druck hinter Stoß

$B=3046$ bar

$n=7,025$

und unter Berücksichtigung der Druckabnahme bei Ausbreitung einer Kugelwelle, siehe Gleichung (1), kann die Frontgeschwindigkeit in Abhängigkeit vom Ausbreitungsradius im Wasser berechnet werden:

$$
v_{s}[p(r)]=\rho_{0}^{-1 / 2}\left[\frac{p_{a} r_{a} r^{-1}-p_{0}}{1-\left(\frac{p_{a} r_{a} r^{-1}+B}{p_{0}+B}\right)^{-1 / n}}\right]^{1 / 2}
$$

$v_{s}=$ Stoßfrontgeschwindigkeit $[\mathrm{m} / \mathrm{s}]$

$\rho_{0}, p_{0}=$ Dichte, Druck vor Stoß

$r_{a}, p_{a}=$ Ausgangsradius, Ausgangsdruck

$B=3046$ bar und

$n=7,025$

Damit lassen sich graphisch unterschiedliche Stoßfrontgeschwindigkeiten [m/s] für unterschiedliche Ausgangsdrücke [kbar] in Abhängigkeit des Stoßwellenweges [m] bei einem angenommenen Ausgangsradius r von $2 \mathrm{~mm}$ darstellen.

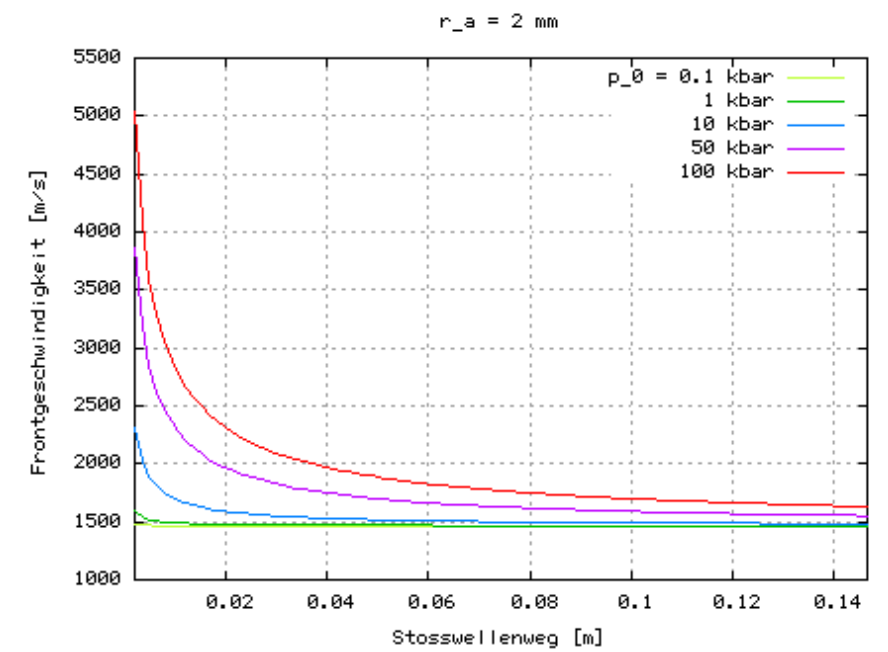

Graph 5.3.2.16c.: Frontgeschwindigkeit nach Wellenweg (mit freundlicher Genehmigung von METTIN et al. 2004) 
Die Laufzeit $T$ eines Stoßes kann bis zum Beobachtungsradius $r_{e}$ berechnet werden:

$$
\Delta r=v_{s}(r) \Delta t \rightarrow \int_{r a}^{r e} \frac{\Delta r}{v_{s}(r)}=\int_{t a}^{t e} \Delta t=T
$$

$r a, t a=$ Anfangsradius, Anfangszeit

$r e, t e=$ Endradius, Endzeit

$T=$ Laufzeit (z.B. s-33.1-3: 85-90 $\mu$ s)

Aus einer (z.B.: s-33.1-3, Kap. 4.2.14.) beobachteten Laufzeit von 85-90 $\mu$ s und der zurückgelegten Wegstrecke $\Delta r$ kann der Spitzendruck $p_{a}$ der Stoßwelle zum Zeitpunkt $t_{a}$ für ein $1125 \mathrm{~m} / \mathrm{s}$ schnelles Geschoss geschätzt werden. Dabei ist zu berücksichtigen, dass der Initalradius wegen der ogivalen Geschossform nicht eindeutig zu ermitteln ist. Wir gehen für unsere Druckschätzung von einem Initialradius von $2 \mathrm{~mm}( \pm 1 \mathrm{~mm})$ aus, wobei das Heck der Geschosse des Kalibers .224 Rem nach Laufdurchtritt sogar einen Durchmesser von 5,69 mm erreicht (Kap. 3.2.1.).

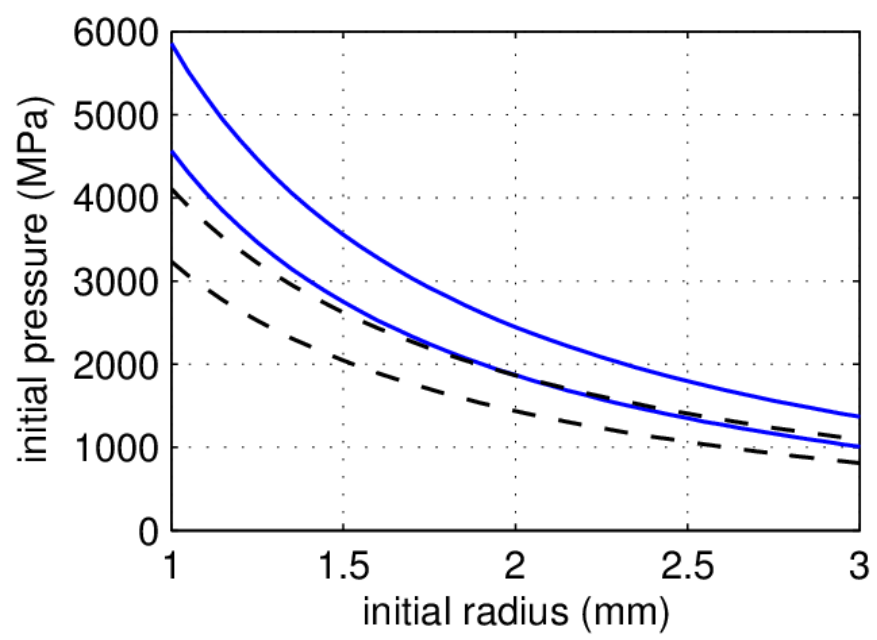

Graph 5.3.2.16d.: Spitzendruck für unterschiedliche Initialradien (mit freundlicher Genehmigung von METTIN et al. 2004) 
Wenn wir nun den Initialradius als $2 \mathrm{~mm}$ annehmen, können wir den Druck der Wellenfront aus der Laufzeit berechnen.

\begin{tabular}{|c|c|c|}
\cline { 2 - 3 } \multicolumn{1}{c|}{} & $\mathbf{v}_{\mathbf{3} \text { (Imacon) }}[\mathrm{m} / \mathbf{s}]$ & $\begin{array}{c}\text { Druck aus Laufzeit } \\
\text { berechnet }\end{array}$ \\
\hline Bild s-51.1-2 & 1648 & \\
\hline Bild s-51.2-3 & 1567 & \\
\hline Bild s-51.3-4 & 1547 & \\
\hline Bild s-51.4-5 & 1527 & \\
\hline Bild s-51.5-6 & 1326 & \\
\hline Bild s-51.6-7 & 1286 & \\
\hline
\end{tabular}

\begin{tabular}{|c|c|c|}
\hline$\sum$ Bild s-51.1-7 & 1483 & \\
\hline
\end{tabular}

Tab. 5.3.2.16.: Druckberechnung der Wellenfront in Wasser s-51

Chrony 1: $\quad 1113 \mathrm{~m} / \mathrm{s}$

Chrony 2: $\quad 16 \mathrm{~m} / \mathrm{s}$

Ganz ohne Druckmessung kann der Maximaldruck am Einschuss außerdem direkt aus der Geschossgeschwindigkeit berechnet werden, wenn man die Methode zur Berechnung des Wasserhammerdruckes (De HALLER 1933, LINDAU 1998) anwendet. Zugrunde liegt ein Modell, in welchem theoretisch ein schneller flüssiger Messingstrahl auf ruhendes flüssiges Wasser trifft.

$$
P_{w h}=\frac{c_{1} p_{1} c_{2} p_{2}}{c_{1} p_{1}+c_{2} p_{2}} v_{g}
$$

$c_{1}=$ Schallgeschwindigkeit von Messing $[\mathrm{m} / \mathrm{s}]$

$c_{2}=$ Schallgeschwindigkeit von Wasser $[\mathrm{m} / \mathrm{s}]$

$p_{1}=$ Dichte von Messing $\left[\mathrm{kg} / \mathrm{m}^{3}\right]$

$p_{2}=$ Dichte von Wasser $\left[\mathrm{kg} / \mathrm{m}^{3}\right]$

$v_{g}=$ Geschossgeschwindigkeit

$\mathrm{p}_{\mathrm{wh}}=$ Wasserhammerdruck

Für s-51 (1113 m/s) beträgt der so berechnete Wasserhammerdruck $\left(\mathrm{c}_{1}=3500 \mathrm{~m} / \mathrm{s}, \mathrm{c}_{2}\right.$ $=1485 \mathrm{~m} / \mathrm{s}, \mathrm{p}_{1}=8500 \mathrm{~kg} / \mathrm{m}^{3}, \mathrm{p}_{2}=1000 \mathrm{~kg} / \mathrm{m}^{3}$ ) dann $1574 \mathrm{MPa}$ (1574 bar) und liegt somit in dem Bereich der aus Messungen berechneten Spitzendruckwerte.

Nachdem eine Verdichtungswelle mit hohem Druck und Schallgeschwindigkeit das ballistische Ziel passiert hat, erhöht sich der Druck später nochmals durch die gewebeverdrängende temporäre Höhle. Im Kap. 4.3.2.9. wurde bereits die Druckerhöhung direkt neben der entstehenden temporären Höhle anhand eines Gasballonkollapses berechnet. Die zweite Druckerhöhung ist im Vergleich zum initialen Spitzendruck relativ klein (128 bar). 
Zur weiteren Veranschaulichung wurde aus den Kameraaufnahmen auch wieder die Geschwindigkeit berechnet, mit denen sich die Druckwelle, die temporäre Höhle und zurückbleibende Geschossfragmente ausbreiten (Kap. 4.2.16.). Die Ergebnisse werden graphisch dargestellt:

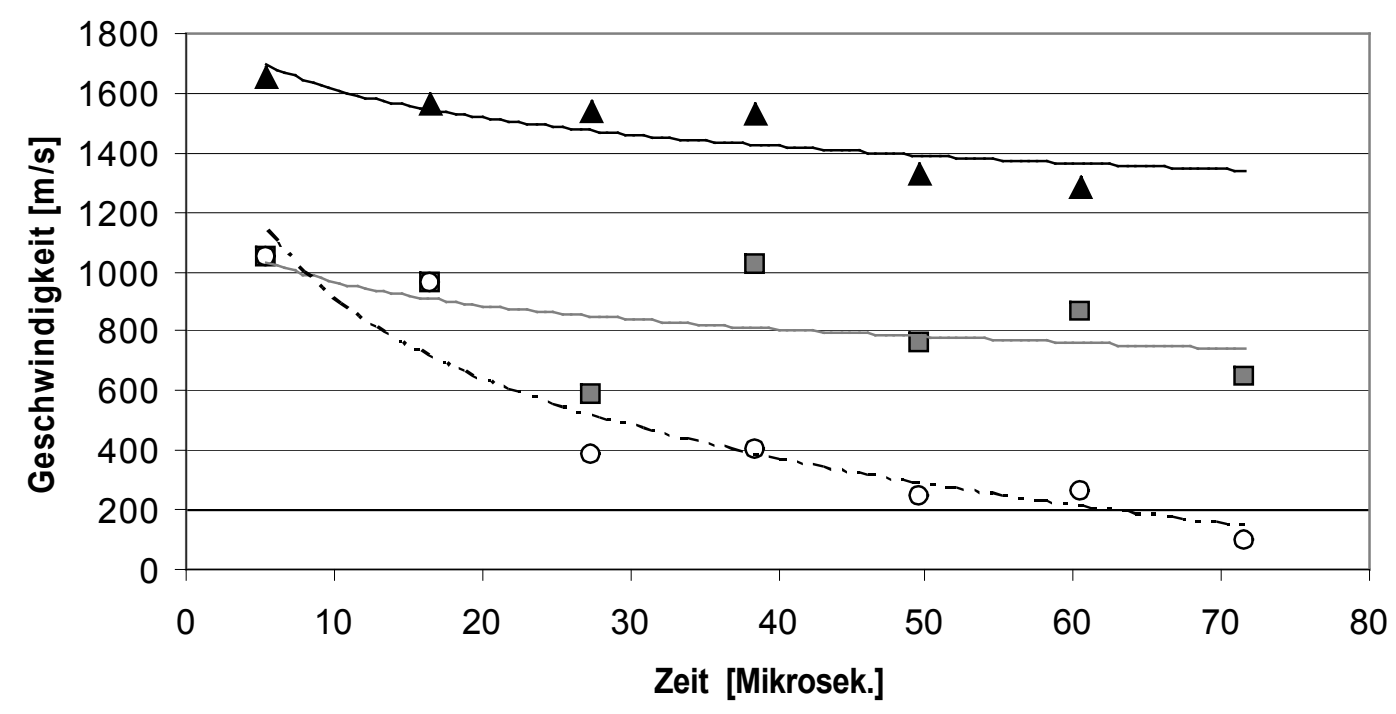

$\Delta$ Verdichtungswelle $\square$ Höhle $\bigcirc$ Fragment

Graph 5.3.2.16e.: Geschwindigkeit der Verdichtungswelle s-51

\subsubsection{Durch Gasblasenkollaps beschleunigtes Zielmaterial}

$\mathrm{Zu}$ sehen ist eine Sequenz, in der ein Vollmantelgeschoss mit vergleichsweise geringer Geschwindigkeit $(932 \mathrm{~m} / \mathrm{s})$ in einen Wassercontainer eindringt. In der Versuchsreihe war Wasser und Gelatine beschossen worden, in die wir Gasblasen eingebracht hatten.

Es war dann auch eine Gasblase unter der Wasseroberfläche, die uns eine weitere Fernwirkung einer Druckwelle aufzeigte.

Die Gasblase kollabierte und an derselben Stelle entstand $40 \mu$ s später ein Wasserstrahl (Vergrößerung s-36.7, Kap. 4.2.17.).

Die Geschwindigkeit, mit der dann Wasser transportiert wurde, wird wie folgt berechnet:

\begin{tabular}{|c|c|c|c|}
\hline & Differenz $[\mathrm{cm}]$ & Zeitspanne $[\mu \mathrm{s}]$ & Zielmaterial $[\mathrm{m} / \mathrm{s}]$ \\
\hline Bild s-36.5-6 & 0,76 & 20 & 380 \\
\hline Bild s-36.6-7 & 0,90 & 20 & 450 \\
\hline$\sum$ Bild s-36.5-7 & 1,66 & 40 & 415 \\
\hline
\end{tabular}

Tab. 5.3.2.17.: durch Gasblasenkollaps beschleunigtes Zielmaterial

Chrony 1:

Chrony 2:

$932 \mathrm{~m} / \mathrm{s}$

$480 \mathrm{~m} / \mathrm{s}$ 
Die Geschwindigkeit des Zielmateriales durch die kollabierende Gasblase ist demzufolge mindestens $450 \mathrm{~m} / \mathrm{s}$.

Auf der schematischen Abbildung sehen Sie die Entstehung eines Mikrojets in der kollabierenden Gasblase und den dann auftretenden Wasserstrahl, den "Splash“ (Blake und Pearson, 2001).

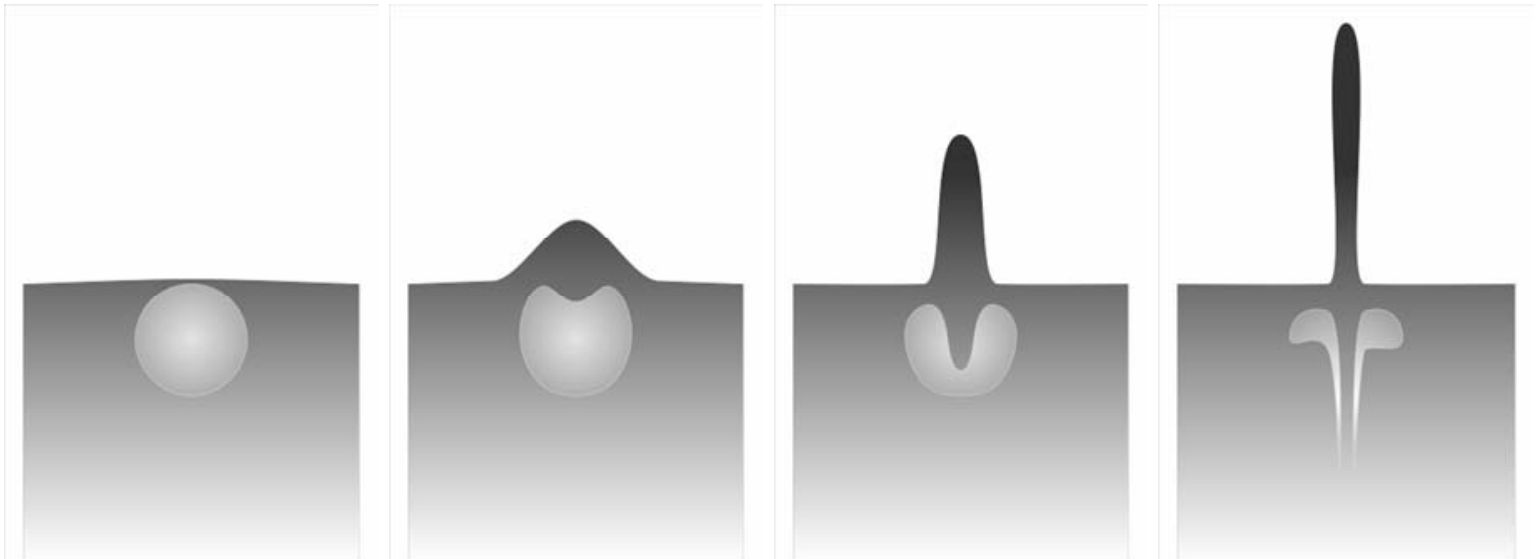

Graph 5.3.2.17.: Blasenkollaps an freier Wasser-Luft-Grenzfläche (modifiziert nach BLAKE und PEARSON 2001)

Solche Mikrojets entstehen nicht nur an Gasblasen unter der Wasseroberfläche oder anderen Grenzflächen. Auch mitten im Medium können kollabierende Blasen (s. Kap 5.3.2.11.) untereinander als Grenzflächen dienen und Wechselwirkungen verursachen. Die dann auftretende Zielmaterialbeschleunigung ist allerdings nur schwer abzubilden.

Andere Autoren bestreiten die Gewebserosion durch Überdruckwellen abseits des Wundkanals. Die Arbeiten von HARVEY et al. (1947), die bis heute als maßgebend und gültig zitiert werden, basieren darauf, dass Erythrozyten beim Beschuss in einer Lösung nicht erodierten.

Diese Untersuchungen sind konsistent mit der vernünftigen Überlegung, dass eine symmetrische Druckänderung auf einen Erythrozyten nicht zu dessen Läsion führen muss. Wir gehen auch in der vorliegenden Untersuchung davon aus, dass ein symmetrischer Gasblasenkollaps nicht zu einem destruktiven Materialtransport führen muss.

Wenn aber entsprechende Objekte an einer Grenzfläche liegen oder wenn Objekte untereinander wechselwirken, ist destruktiver Materialtransport wahrscheinlich. Wenn also Erythrocyten nicht ausreichend räumlich voneinander getrennt sind (auch abhängig von der Verdünnung) kann es wohl doch zu Zellläsionen kommen (s. u.). Auch biochemische Änderungen wurden bereits abseits des Wundkanals beschrieben, „induced a reduction of plasminogen activator activity“ (ALMSKOG et al. 1982, S. 327).

SILVIA (1999, S. 71) hingegen veröffentlichte seine Meinung zum Gewebetransport durch Überdruckwellen beim Gewebebeschuss: „this neither moves nor injures tissues". 
Wir haben mit der Bildsequenz (Bild s-36.6 bis Bild s-36.8 in Kap. 4.2.17.) nun abseits vom Schusskanal Zielmaterial abgebildet, welches innerhalb von Mikrosekunden auf mindestens $450 \mathrm{~m} / \mathrm{s}$ beschleunigt worden war.

Asymmetrisch kollabierende Gasblasen könnten so zu einer lokalen Gewebeerosion führen. Immerhin wird beim Blasenkollaps umgebende Flüssigkeit zum Mikrojet beschleunigt. In der Rechtsmedizin könnten unsere Ergebnisse Detailinformationen zur Interpretation asymmetrisch kollabierender Gasblasen und der Entstehung multipler Gewebsschädigung mit petechialer Einblutung und Zerreißung intrazerebraler Gefäße beim Contrecoup liefern.

Wir möchten noch einmal ausdrücklich darauf hinweisen, dass der Begriff „Kavitationsblase“ für aufschwingende Gasblasen in der Wund- und Zielballistik gegen den schon längere Zeit verwendeten Begriff „Kavität“ (für die temporäre Höhle) abzugrenzen (Kap. 5.3.2.14.) ist. Jedenfalls sind die Entstehungsmechanismen, die räumliche und zeitliche Ausdehnung und nicht zuletzt die Wechselwirkung mit dem Zielmaterial grundsätzlich verschieden. 


\subsubsection{Wellenfront in Stickstoff}

Für die vorliegende Arbeit konnte keine VMJ Munition verschossen werden, deren Auftreffgeschwindigkeit im Bereich über der Schallgeschwindigkeit von Wasser $(1403 \mathrm{~m} / \mathrm{s})$ lag. Das wäre mit den verwendeten Kalibern ohne Missachtung der Sicherheitsvorschriften (Kap. 5.1.) nicht möglich gewesen.

Stattdessen wurde bei einigen Schussversuchen als Zielmedium flüssiger Stickstoff (Schallgeschwindigkeit $869 \mathrm{~m} / \mathrm{s}$ ) eingesetzt.

Die Schallgeschwindigkeit $\mathrm{c}[\mathrm{m} / \mathrm{s}]$ in Flüssigkeiten ist eine Funktion der Dichte $\rho$ und des Kompressionsmoduls $\mathrm{K}$ der Flüssigkeit und berechnet sich wie folgt:

$\mathrm{c}_{\text {Flissigkeit }}=\sqrt{\frac{K}{\rho}}$

Tabellenwerte nach CIBA-GEIGY (1979) der Schallgeschwindigkeit c für flüssiges Wasser $\left(\mathrm{H}_{2} \mathrm{O}\right)$ sind:

Wasser $0^{\circ} \mathrm{C} \quad 1402,74 \mathrm{~m} / \mathrm{s}$

Wasser $10^{\circ} \mathrm{C} \quad 1447,59 \mathrm{~m} / \mathrm{s}$

Die Dichte von Wasser $\left(20^{\circ} \mathrm{C}, 1,013\right.$ bar $)$ beträgt $1000 \mathrm{~kg} / \mathrm{m}^{3}$.

Der Tabellenwert der Schallgeschwindigkeit c für flüssigen Stickstoff $\left(\mathrm{N}_{2}\right)$ ist deutlich geringer (CIBA-GEIGY 1979):

Stickstoff $-197^{\circ} \mathrm{C} \quad 869 \mathrm{~m} / \mathrm{s}$

Die Dichte von Stickstoff $\left(-196^{\circ} \mathrm{C}, 1,013\right.$ bar) beträgt $809 \mathrm{~kg} / \mathrm{m}^{3}$.

Flüssiger Stickstoff $\left(-197^{\circ} \mathrm{C}\right)$ wurde sechsmal (s-41 bis s-46) unter Kamerakontrolle beschossen, wobei die Geschossgeschwindigkeit stets größer als $869 \mathrm{~m} / \mathrm{s}$ war. Außerdem wurde Stickstoff ohne Kamerakontrolle beschossen (s-75 bis s-79, s-83, s-84).

Die Energieabgabe von Munition mit Auftreffgeschwindigkeiten unter (s-84) und über $869 \mathrm{~m} / \mathrm{s}$ (s-41 bis s-46, s-76, s-79, s-84) wurde ermittelt (Kap. 4.2.18.).

Zudem wurde die Geschwindigkeit der Wellenfront im Ziel aus den Bildern s-46.6 bis s-46.8 berechnet (Kap. 4.2.18.).

Wegen der langsameren Schallgeschwindigkeit in Stickstoff, wandert die Verdichtungswelle langsamer als Verdichtungswellen in Wasser.

Um den Energieverlust von Geschossen in Medien mit niedriger Schallgeschwindigkeit zu untersuchen, wurde auch ohne Kamerakontrolle Stickstoff beschossen. Die Geschwindigkeiten der VMJ-Geschosse waren dabei zum Teil größer als die 
Schallgeschwindigkeit in Stickstoff. Die Geschosse übertrugen viel Energie und fragmentierten sich:

Beim Beschuss (s-46) mit schneller Munition (223.7, $1069 \mathrm{~m} / \mathrm{s}$ ) fragmentierte sich das Geschoss und verlor innerhalb des Zieles deutlich an Geschwindigkeit (um 762 m/s auf $301 \mathrm{~m} / \mathrm{s}$ ).

Beim Beschuss (s-84) mit langsamer Munition (223.2, $448 \mathrm{~m} / \mathrm{s}$ ) fragmentierte sich das Geschoss nicht und verlor lediglich geringfügig an Geschwindigkeit (um $21 \mathrm{~m} / \mathrm{s}$ auf $427 \mathrm{~m} / \mathrm{s})$.

Der Einfluss der Schallgeschwindigkeit im Zielmedium auf die Geschoss-ZielWechselwirkung wird unterschiedlich bewertet.

Während CHARTERS und CHARTERS (1976) eine deutliche Zunahme an destruierender Geschosswirkung bei Überschreiten der Schallleitgeschwindigkeit postulieren, bestreiten FACKLER et al. (1988 a, S. 63) eben diesen Zusammenhang und schreiben: "the temporary cavities increased in size with the velocity", "but our findings did not support the proposed hypothesis that temporary cavity shape in tissue changes at velocities above the sonic speed". 


\section{Zusammenfassung und Ausblick}

Bei der vorliegenden Untersuchung wurde im Institut für Rechtsmedizin Göttingen in Zusammenarbeit mit dem Dritten Physikalischen Institut Göttingen erstmals eine digitale Hochgeschwindigkeitskamera und ein Glasfaserhydrophon für die Erfassung zielballistischer Phänomene verwendet. Mit Hilfe der Hochgeschwindigkeitskamera wurden an verschiedenen Simulanzien die Theorien zur Zielballistik überprüft und einzelne Erklärungsversuche zur Energieabsorption verifiziert. Dabei wurden auch Verdichtungswellen in ballistischen Zielen abgebildet. Nach Berechnungen, in welche Laufzeit und Initialradius der Verdichtungswelle und physikalische Parameter des ballistischen Zieles eingingen, wurden Aussagen zum maximalen Druckpuls am Einschuss gemacht. Die Verdichtungswellen wurden unabhängig davon mit einem Glasfaserhydrophon gemessen. Der Druckmesser eignete sich besonders durch sein schnelles Ansprechen im Nanosekundenbereich für Messungen in wasserreichen Zielmedien.

Mit der Hochgeschwindigkeitskamera wurden außerdem aufschwingende Gasblasen abgebildet und Zielmaterial abseits der temporären Höhle an einer asymmetrisch kollabierenden Gasblase nachgewiesen. Die seit Jahren diskutierte Fragmentation von Hochgeschwindigkeitsmunition in ballistischen Zielen wurde in einer frühen Phase im Ziel dokumentiert. Dabei zerlegten sich Vollmantelprojektile, ohne sich zuvor um die quere Achse gedreht zu haben. Die entstehenden temporären Höhlen wurden elektrooptisch festgehalten und bewertet.

Es wurden auch sich schnell fragmentierende Projektile verschossen. Die Geschosse wurden mit Zweikomponentenkleber aus Sand bzw. Messingspänen für die vorliegende Arbeit hergestellt. Die geklebten Geschosse erzeugten typische Einschüsse und fragmentierten sich im Anschluss. Mit solchen Zerlegungsgeschossen können typische Einschüsse produziert werden; das Geschoss (insbesondere das nicht metallhaltige) ist dann kaum mehr nachweisbar. Zur Beurteilung dieser Geschosse wurden die Durchschusstrichter auf Ein- und Ausschussseite ausgemessen und in Beziehung zueinander gesetzt.

Außerdem wurde das ungewöhnliche Zielprofil eines massiven Messinggeschosses im Bild festgehalten. Diese selten verwendeten Geschosse drehten sich im Ziel über $280^{\circ}$ um die Querachse. Ein Drehen um die quere Achse über $180^{\circ}$ war bislang nicht beschrieben worden. FACKLER und MALINOWSKI (1985) hatten zwar verschiedene „Wundprofile“ dargestellt, aber keine Geschosse berücksichtigt, die sich um mehr als $180^{\circ}$ um die Querachse drehen. In theoretischen Modellen der Zielballistik war maximal eine Querstellung der Geschosse abgeklärt worden.

Anhand von Schüssen auf flüssigen Stickstoff $\left(\mathrm{N}_{2}\right)$, Wasser $\left(\mathrm{H}_{2} \mathrm{O}\right)$, ballistische Gelatine und Cucumis melo wurde die Auswirkung der Schallgeschwindigkeit im jeweiligen Ziel auf die Zielballistik gemessen. Außerdem wurde die Geometrie der Ziele variiert. Die frühen Wechselwirkungen wurden mittels Hochgeschwindigkeitskamera (Imacon 468, zeitliche Auflösung $10 \mathrm{~ns}$ ) und Glasfaserhydrophon (FOPH 300, Ansprech-Anstiegszeit 6,5-7,5 ns) gleichlaufend messend verfolgt. Die Energieabsorption der Geschosse in der frühen Phase wurde aus den Kurzzeitaufnahmen ermittelt. Zusätzlich wurde die Endgeschwindigkeit der Geschosse mittels Lichtschranke und ballistischen Pendeles bestimmt, sobald das Ziel durchschlagen wurde. In der frühen Phase ( $\mu$ s-Bereich) kam es zu starken Wechselwirkungen mit partieller Fragmentation der Vollmantelmunition. Die entsprechenden Energieverlustkurven wurden in Hinblick auf die Schallgeschwindigkeit der unterschiedlichen Zielsimulanzien verglichen und diskutiert. 
Die Militärs verwenden in den letzten Jahrzehnten (DOTZAUER 1979) und bis heute weltweit immer häufiger kleine Langwaffenkaliber (Kap. 4.2.2.1.) und Hochgeschwindigkeitsmunition. In der rechtsmedizinischen Praxis gibt es allerdings regionale Unterschiede in der Entwicklung des prozentualen Anteiles von Hochgeschwindigkeitsmunition bei Tötungsdelikten oder Jagdunfällen (JANSSEN et al. 1996). Während CARUSO et al. (1999) in New York und der westlichen Welt den prozentualen Zuwachs von großen, aber langsamen Kurzwaffenkalibern beschreiben, sehen INCl et al. (1998) einen alarmierenden Zuwachs an Thorax-Verletzungen durch Hochgeschwindigkeitsmunition in der Türkei.

Wie sich die Ausbreitung terroristischer Gewalt, Granatsplitter erreichen immerhin bis zu $2000 \mathrm{~m} / \mathrm{s}$ (FISCHER 1962), und das in der Entwicklung stehende (SCHILLER 2004) neue Miliärkaliber $6,8 \times 43 \mathrm{~mm} \mathrm{SPC}$ auf die Verletzungsform auswirken, ist noch unklar. Die Entwicklung ganz neuer Waffensysteme im 21. Jahrhundert ist wahrscheinlich (GALBRAITH 2001) und wohl auch nicht aufzuhalten.

Munition wird häufig nach ihrer Geschosskonstruktion eingeteilt: Seit 1886 (Deklaration von St. Petersburg) sind im Körper explodierende Geschosse, seit 1899 (Haager Konvention) Zerlegungsgeschosse völkerrechtlich verboten (EZZ 1988). Eine Unterscheidung der Munition nach Energieverlust im Schusskanal feuchter Zielmedien (COUPLAND 1999) ist jedoch fast noch wichtiger. Denn die "stopping power" eines Geschosses hängt jedenfalls sehr auch von der Reaktion des Gewebes, seiner Elastizität, ab (ROCCA et al. 1998). Dabei gehen Wehrtechniker davon aus, dass die völkerrechtliche Vereinbarung erfüllt wird, wenn Infanteriewaffen innerhalb der ersten $12 \mathrm{~cm}$ im Ziel nicht wesentlich mehr als $25 \mathrm{~J} / \mathrm{cm}$ abgeben.

Obwohl "nicht alle Untersuchungsmethoden in allen Fällen auch eingesetzt werden können“ (KIJEWSKI und KROPP 2000, S. 751), können heute neben den alten auch neue Techniken - wie z.B. das MRT nach Ausschluss von ferromagnetischen Fremdkörpern (HESS und HARMS 2000) - eingesetzt werden. Aber auch praktische Erfahrungsberichte (KIJEWSKI 1981) und das Erforschen weiterer grundlegender physikalischer Prinzipien der Ziel- und Wundballistik erscheinen wichtig. Dabei ist „die gedankliche Kontrolle und Steuerung [...] komplexer Systeme eine wissenschaftliche Aufgabe [...], die auch durch aufwendige ,Technik' nicht vollständig ersetzt werden“ kann (KIJEWSKI und KROPP 2000, S. 748). So wären weitere Untersuchungen mit Schallanalysen in ballistischen Zielen sinnvoll. Immerhin sollten Routine und etablierte Denkmuster bei der Interpretation von ballistischen Wunden vermieden werden.

Zum Beispiel hatten bei PIETTE et al. (2002) erst eigene Schussversuche zur eindeutigen Zuordnung von Ein- und Ausschuss führen können. In dem von innen beschriebenen Fall lag ein großer atypischer Einschuss durch „high velocity centerfire hunting ammunition" mit verheerendem Effekt der temporären Höhle vor.

Fazit und Sinn der hier vorliegenden Arbeit ist ein tiefer greifendes Verständnis der Wundentstehung durch Hochgeschwindigkeitsmunition. Das betrifft und verbessert auch die Klassifikation (BOWYER 1995), das Debridement (DAHLGREN et al. 1979, 1982, ROBERTSON und MANSON 1999) und die chirurgische Versorgung von Gefäßverletzungen (JAHNKE und HOWARD 1953, JAHNKE und SEELEY 1953, MOORE et al. 1954, WOLF und RIVKIND 2002), von Frakturen (ATESALP et al. 2002, CLASPER 2001, RYAN 1981, SMITH und WHEATLEY 1984), sowie Verletzungen der einzelnen Organe (DÜSEL et al. 2005, ERSAY und AKGÜN 1999, LIROFF et al. 1977, SHARMA et al. 2004, ROBERTS et al. 2005) oder die Indikation zu einer Amputation (NAIR et al. 2000) in vivo. 


\section{Anhang}

\subsection{Schusstabelle}

\subsubsection{Mit Kamerakontrolle}

\begin{tabular}{|c|c|c|c|c|c|c|c|c|}
\hline $\mathrm{Nr}$. & Laborierung & Geschoss & $\begin{array}{c}\text { Ch. 1: } \\
v_{a} \\
{[\mathrm{~m} / \mathrm{s}]}\end{array}$ & $\begin{array}{c}\text { Ch. 2: } \\
\mathbf{v}_{\text {rst }} \\
{[\mathrm{m} / \mathrm{s}]}\end{array}$ & $\begin{array}{c}\text { Aus- } \\
\text { schlag } \\
\text { [m] }\end{array}$ & Ziel & $\begin{array}{c}\text { Ein- } \\
\text { dring- } \\
\text { tiefe } \\
{[\mathrm{m}]} \\
\end{array}$ & Fragmente \\
\hline$s-01$ & 223.5 & VMJ $3,0 \mathrm{~g}$ & 932 & 927 & 0,0210 & - & - & - \\
\hline s-02 & 223.6 & VMJ 3,0 g & 1077 & 1061 & 0,0240 & - & - & - \\
\hline s-03 & 223.6 & VMJ $3,0 \mathrm{~g}$ & 1083 & - & - & $\begin{array}{c}\text { Gelatine } 10^{\circ} \mathrm{C} \\
(0,15 \times 0,15 \times 0,40 \mathrm{~m})\end{array}$ & 0,140 & $\mathrm{Ja}$ \\
\hline s-04 & 223.6 & VMJ 3,0 g & 1077 & - & - & $\begin{array}{c}\text { Gelatine } 10^{\circ} \mathrm{C} \\
(0,15 \times 0,15 \times 0,40 \mathrm{~m})\end{array}$ & 0,160 & $\mathrm{Ja}$ \\
\hline s-05 & 223.6 & VMJ 3,0 g & 1061 & - & - & $\begin{array}{c}\text { Gelatine } 10^{\circ} \mathrm{C} \\
(0,15 \times 0,15 \times 0,40 \mathrm{~m})\end{array}$ & 0,150 & Ja \\
\hline$s-06$ & 223.6 & VMJ 3,0 g & 1066 & 1058 & 0,0240 & - & - & - \\
\hline s-07 & 223.6 & VMJ 3,0 g & 1075 & 1080 & 0,0250 & - & - & - \\
\hline s-08 & 223.6 & VMJ $3,0 \mathrm{~g}$ & - & - & - & $\begin{array}{c}\text { Gelatine } 10^{\circ} \mathrm{C} \\
(0,15 \times 0,15 \times 0,40 \mathrm{~m})\end{array}$ & k.A. & Ja \\
\hline$s-09$ & 223.6 & VMJ 3,0 g & 1072 & - & - & Cucumis melo & k.A. & $\mathrm{Ja}$ \\
\hline$s-10$ & 223.6 & VMJ 3,0 g & 1058 & - & 0,0240 & - & - & - \\
\hline $\mathrm{s}-11$ & 223.6 & VMJ 3,0 g & 1066 & - & - & Cucumis melo $(1,110 \mathrm{~kg})$ & k.A. & Ja \\
\hline s-12 & 223.6 & VMJ 3,0 g & 1086 & - & - & Cucumis melo $(0,870 \mathrm{~kg})$ & k.A. & $\mathrm{Ja}$ \\
\hline$s-13$ & 223.6 & VMJ $3,0 \mathrm{~g}$ & 1063 & - & - & Cucumis melo $(1,200 \mathrm{~kg})$ & k.A. & Ja \\
\hline$s-14$ & 223.4 & VMJ $3,0 \mathrm{~g}$ & 809 & 811 & 0,0190 & - & - & - \\
\hline s-15 & 223.4 & VMJ 3,0 g & 772 & 703 & 0,0160 & Cucumis melo $(1,110 \mathrm{~kg})$ & k.A. & - \\
\hline$s-16$ & 223.6 & VMJ $3,0 \mathrm{~g}$ & 1063 & 1069 & 0,0260 & - & - & - \\
\hline s-17 & 223.6 & VMJ $3,0 \mathrm{~g}$ & 1069 & - & - & $\begin{array}{c}\text { Gelatine } 10^{\circ} \mathrm{C} \\
(0,15 \times 0,15 \times 0,40 \mathrm{~m})\end{array}$ & 0,155 & Ja \\
\hline $\mathrm{s}-18$ & 223.6 & VMJ $3,0 \mathrm{~g}$ & 1069 & - & - & $\begin{array}{c}\text { Gelatine } 10^{\circ} \mathrm{C} \\
(0,15 \times 0,15 \times 0,40 \mathrm{~m})\end{array}$ & 0,155 & Ja \\
\hline s-19 & 223.6 & VMJ $3,0 \mathrm{~g}$ & 1075 & - & - & $\begin{array}{c}\text { Gelatine } 10^{\circ} \mathrm{C} \\
(0,15 \times 0,15 \times 0,40 \mathrm{~m})\end{array}$ & 0,150 & $\mathrm{Ja}$ \\
\hline$s-20$ & 222.solid & Solid 2,916 g & 981 & - & - & - & - & - \\
\hline $\mathrm{s}-21$ & 222.solid & Solid 2,916 g & 938 & - & - & $\begin{array}{c}\text { Gelatine } 10^{\circ} \mathrm{C} \\
(0,15 \times 0,15 \times 0,40 \mathrm{~m})\end{array}$ & $>0,40$ & - \\
\hline$s-22$ & 222.solid & Solid 2,916 g & 1044 & 1042 & - & - & - & - \\
\hline$s-23$ & 222.solid & Solid 2,916 g & 1027 & - & - & $\begin{array}{c}\text { Gelatine } 10^{\circ} \mathrm{C} \\
(0,15 \times 0,15 \times 0,60 \mathrm{~m})\end{array}$ & $>0,60$ & - \\
\hline$s-24$ & 223.6 & VMJ 3,0 g & 1080 & 1086 & 0,0250 & - & - & - \\
\hline
\end{tabular}




\begin{tabular}{|c|c|c|c|c|c|c|c|c|}
\hline $\mathrm{Nr}$. & Laborierung & Geschoss & $\begin{array}{c}\text { Ch. 1: } \\
v_{a} \\
{[\mathrm{~m} / \mathrm{s}]}\end{array}$ & $\begin{array}{c}\text { Ch. 2: } \\
v_{\text {rst }} \\
{[\mathrm{m} / \mathrm{s}]}\end{array}$ & $\begin{array}{c}\text { Aus- } \\
\text { schlag } \\
\text { [m] }\end{array}$ & Ziel & $\begin{array}{c}\text { Ein- } \\
\text { dring- } \\
\text { tiefe } \\
{[\mathrm{m}]}\end{array}$ & Fragmente \\
\hline $\mathrm{s}-25$ & 223.6 & VMJ $3,0 \mathrm{~g}$ & 1080 & 13 & - & Wasser Typ f & k.A. & $\mathrm{Ja}$ \\
\hline s-26 & 223.6 & VMJ 3,0 g & 1086 & - & - & Wasser Typ f & k.A. & $\mathrm{Ja}$ \\
\hline s-27 & 223.7 & VMJ 3,0 g & 1132 & 1144 & 0,0300 & - & - & - \\
\hline $\mathrm{s}-28$ & 223.7 & VMJ 3,0 g & 1132 & 14 & - & Wasser Typ f & k.A. & Ja \\
\hline s-29 & 223.7 & VMJ 3,0 g & 1113 & - & 0,0020 & Wasser Typ f & k.A. & $\mathrm{Ja}$ \\
\hline$s-30$ & 223.7 & VMJ 3,0 g & 1107 & 1122 & 0,0280 & - & - & - \\
\hline s-31 & 223.7 & VMJ 3,0 g & 1135 & - & - & Wasser Typ c & k.A. & $\mathrm{Ja}$ \\
\hline$s-32$ & 223.7 & VMJ 3,0 g & 1116 & 1119 & 0,0280 & - & - & - \\
\hline$s-33$ & 223.7 & VMJ 3,0 g & 1125 & - & - & Wasser Typ c & k.A. & Ja \\
\hline s-34 & 223.7 & VMJ $3,0 \mathrm{~g}$ & 1119 & - & - & $\begin{array}{c}\text { Gelatine } 10^{\circ} \mathrm{C} \\
\text { und Wasser Typ a }\end{array}$ & k.A. & $\mathrm{Ja}$ \\
\hline$s-35$ & 223.5 & VMJ 3,0 g & 969 & 969 & 0,0220 & - & - & - \\
\hline s-36 & 223.5 & VMJ $3,0 \mathrm{~g}$ & 932 & 480 & - & Wasser Typ a & k.A. & $\mathrm{Ja}$ \\
\hline s-37 & 223.5 & VMJ $3,0 \mathrm{~g}$ & 938 & 434 & 0,0040 & Wasser Typ a & k.A. & $\mathrm{Ja}$ \\
\hline $\mathrm{s}-38$ & 223.6 & VMJ 3,0 g & 1055 & 1028 & 0,0220 & - & - & - \\
\hline s-39 & 223.6 & VMJ 3,0 g & 1086 & 1066 & 0,0230 & - & - & - \\
\hline $\mathrm{s}-40$ & 223.6 & VMJ 3,0 g & 1085 & 1075 & - & - & - & - \\
\hline s-41 & 223.6 & VMJ 3,0 g & 1068 & 20 & - & $\mathrm{N}_{2}$ Typ e & k.A. & Ja \\
\hline s-42 & 223.6 & VMJ $3,0 \mathrm{~g}$ & 1075 & 228 & - & $\mathrm{N}_{2}$ Typ e & k.A. & Ja \\
\hline$s-43$ & 223.6 & VMJ 3,0 g & 1065 & 455 & 0,0040 & $\mathrm{~N}_{2}$ Typ b & k.A. & Ja \\
\hline s-44 & 223.6 & VMJ 3,0 g & 1063 & 439 & - & $\mathrm{N}_{2}$ Typ b & k.A. & $\mathrm{Ja}$ \\
\hline s-45 & 223.6 & VMJ $3,0 \mathrm{~g}$ & 1061 & 301 & - & $\mathrm{N}_{2}$ Typ b & k.A. & $\mathrm{Ja}$ \\
\hline s-46 & 223.6 & VMJ 3,0 g & 1063 & 301 & - & $\mathrm{N}_{2}$ Typ b & k.A. & $\mathrm{Ja}$ \\
\hline s-47 & 223.6 & VMJ 3,0 g & 1060 & 1077 & - & - & - & - \\
\hline s-48 & 223.6 & VMJ $3,0 \mathrm{~g}$ & - & - & 0,0240 & - & - & - \\
\hline$s-49$ & 223.7 & VMJ 3,0 g & 1125 & 1119 & 0,0230 & - & - & - \\
\hline$s-50$ & 223.7 & VMJ $3,0 \mathrm{~g}$ & 1125 & 43 & - & Wasser Typ e & k.A. & $\mathrm{Ja}$ \\
\hline$s-51$ & 223.7 & VMJ $3,0 \mathrm{~g}$ & 1113 & 16 & - & Wasser Typ e & k.A. & Ja \\
\hline$s-52$ & 223.7 & VMJ $3,0 \mathrm{~g}$ & 1104 & 55 & - & Wasser Typ e & k.A. & Ja \\
\hline$s-53$ & 223.7 & VMJ $3,0 \mathrm{~g}$ & 1113 & - & 0,0230 & Wasser Typ e & k.A. & - \\
\hline
\end{tabular}




\begin{tabular}{|c|c|c|c|c|c|c|c|c|}
\hline Nr. & Laborierung & Geschoss & $\begin{array}{c}\text { Ch. 1: } \\
v_{a} \\
{[\mathrm{~m} / \mathrm{s}]}\end{array}$ & $\begin{array}{c}\text { Ch. 2: } \\
v_{\text {rst }} \\
{[\mathrm{m} / \mathrm{s}]}\end{array}$ & $\begin{array}{c}\text { Aus- } \\
\text { schlag } \\
\text { [m] }\end{array}$ & Ziel & $\begin{array}{c}\text { Ein- } \\
\text { dring- } \\
\text { tiefe } \\
{[\mathrm{m}]}\end{array}$ & Fragmente \\
\hline$s-54$ & 223.7 & VMJ 3,0 g & 1132 & 11 & - & Wasser Typ c & k.A. & $\mathrm{Ja}$ \\
\hline$s-55$ & 223.7 & VMJ 3,0 g & 1125 & 8 & - & Wasser Typ c & k.A. & $\mathrm{Ja}$ \\
\hline s-56 & 223.7 & VMJ 3,0 g & 1132 & 30 & - & Wasser Typ b & k.A. & $\mathrm{Ja}$ \\
\hline s-57 & 223.7 & VMJ $3,0 \mathrm{~g}$ & 1151 & - & 0,0050 & Wasser Typ a & k.A. & $\mathrm{Ja}$ \\
\hline s-58 & 223.7 & VMJ 3,0 g & 1104 & 36 & - & Wasser Typ d & k.A. & $\mathrm{Ja}$ \\
\hline$s-59$ & 223.7 & VMJ 3,0 g & - & 38 & - & Wasser Typ d & k.A. & $\mathrm{Ja}$ \\
\hline$s-60$ & 223.7 & VMJ 3,0 g & 1138 & 38 & - & Wasser Typ d & k.A. & $\mathrm{Ja}$ \\
\hline$s-61$ & 223.7 & VMJ 3,0 g & - & - & - & Wasser Typ h & k.A. & $\mathrm{Ja}$ \\
\hline$s-62$ & 223.7 & VMJ $3,0 \mathrm{~g}$ & 1110 & - & - & Wasser Typ h & k.A. & $\mathrm{Ja}$ \\
\hline$s-63$ & 223.7 & VMJ $3,0 \mathrm{~g}$ & 1110 & - & - & Wasser Typ h & k.A. & $\mathrm{Ja}$ \\
\hline$s-64$ & PMC & $\begin{array}{l}\text { VMJ-BT } \\
3.564 \mathrm{~g} \\
\end{array}$ & 887 & - & 0,0320 & - & - & - \\
\hline$s-65$ & PMC & $\begin{array}{l}\text { VMJ-BT } \\
3.564 \mathrm{~g} \\
\end{array}$ & 891 & - & - & Wasser Typ d & k.A. & - \\
\hline$s-66$ & PMC & $\begin{array}{l}\text { VMJ-BT } \\
3.564 \mathrm{~g}\end{array}$ & 889 & - & - & Wasser Typ d & k.A. & - \\
\hline$s-67$ & PMC & $\begin{array}{l}\text { VMJ-BT } \\
3.564 \mathrm{~g}\end{array}$ & 886 & - & - & Wasser Typ d & k.A. & - \\
\hline
\end{tabular}

Tab. 7.1.1.: Schussversuche mit Kamerakontrolle

7.1.2. Ohne Kamerakontrolle

\begin{tabular}{|c|c|c|c|c|c|c|c|c|}
\hline Nr. & Laborierung & Geschoss & $\begin{array}{c}\text { Ch. 1: } \\
v_{a} \\
{[\mathrm{~m} / \mathrm{s}]}\end{array}$ & $\begin{array}{c}\text { Ch. 2: } \\
v_{\text {rst }} \\
{[\mathrm{m} / \mathrm{s}]}\end{array}$ & $\begin{array}{c}\text { Aus- } \\
\text { schlag } \\
\text { [m] }\end{array}$ & Ziel & $\begin{array}{c}\text { Ein- } \\
\text { dring- } \\
\text { tiefe } \\
\text { [m] }\end{array}$ & Fragmente \\
\hline$s-68$ & 223.1 & VMJ $3,0 \mathrm{~g}$ & 132 & - & - & $\begin{array}{c}\text { Gelatine } 10^{\circ} \mathrm{C} \\
(0,15 \times 0,15 \times 0,40 \mathrm{~m})\end{array}$ & 0,220 & - \\
\hline$s-69$ & 223.2 & VMJ $3,0 \mathrm{~g}$ & 495 & - & - & $\begin{array}{c}\text { Gelatine } 10^{\circ} \mathrm{C} \\
(0,15 \times 0,15 \times 0,40 \mathrm{~m})\end{array}$ & $>0,40$ & - \\
\hline$s-70$ & 223.2 & VMJ $3,0 \mathrm{~g}$ & 476 & - & - & $\begin{array}{c}\text { Gelatine } 10^{\circ} \mathrm{C} \\
(0,15 \times 0,15 \times 0,80 \mathrm{~m})\end{array}$ & 0,520 & - \\
\hline s-71 & 223.3 & VMJ $3,0 \mathrm{~g}$ & 547 & - & - & $\begin{array}{c}\text { Gelatine } 10^{\circ} \mathrm{C} \\
(0,15 \times 0,15 \times 0,80 \mathrm{~m})\end{array}$ & 0,580 & - \\
\hline$s-72$ & 223.4 & VMJ $3,0 \mathrm{~g}$ & 785 & - & - & $\begin{array}{c}\text { Gelatine } 10^{\circ} \mathrm{C} \\
(0,15 \times 0,15 \times 0,80 \mathrm{~m})\end{array}$ & 0,510 & $\mathrm{Ja}$ \\
\hline s-73 & 223.5 & VMJ $3,0 \mathrm{~g}$ & 925 & - & - & $\begin{array}{l}\text { Blasengelatine } 10^{\circ} \mathrm{C} \\
(0,15 \times 0,15 \times 0,40 \mathrm{~m})\end{array}$ & 0,330 & $\mathrm{Ja}$ \\
\hline$s-74$ & 223.1 & VMJ $3,0 \mathrm{~g}$ & 247 & - & - & $\begin{array}{c}\text { Gelatine } 10^{\circ} \mathrm{C} \\
(0,15 \times 0,15 \times 0,80 \mathrm{~m})\end{array}$ & 0,425 & - \\
\hline s-75 & 223.7 & VMJ $3,0 \mathrm{~g}$ & - & - & - & $\mathrm{N}_{2}$ Typ c & k.A. & $\mathrm{Ja}$ \\
\hline s-76 & 223.7 & VMJ $3,0 \mathrm{~g}$ & 1157 & 6 & - & $\mathrm{N}_{2}$ Typ c & k.A. & $\mathrm{Ja}$ \\
\hline
\end{tabular}




\begin{tabular}{|c|c|c|c|c|c|c|c|c|}
\hline Nr. & Laborierung & Geschoss & $\begin{array}{c}\text { Ch. 1: } \\
v_{a} \\
{[\mathrm{~m} / \mathrm{s}]}\end{array}$ & $\begin{array}{c}\text { Ch. 2: } \\
v_{\text {rst }} \\
{[\mathrm{m} / \mathrm{s}]}\end{array}$ & $\begin{array}{c}\text { Aus- } \\
\text { schlag } \\
\text { [m] }\end{array}$ & Ziel & $\begin{array}{c}\text { Ein- } \\
\text { dring- } \\
\text { tiefe } \\
{[\mathrm{m}]}\end{array}$ & Fragmente \\
\hline s-77 & 223.7 & VMJ $3,0 \mathrm{~g}$ & 1135 & 524 & - & $\mathrm{N}_{2}$ Typ c quer & k.A. & 4 Fragmente \\
\hline $\mathrm{s}-78$ & 223.7 & VMJ $3,0 \mathrm{~g}$ & 1141 & - & - & $\mathrm{N}_{2}$ Typ g & k.A. & $\mathrm{Ja}$ \\
\hline s-79 & 223.7 & VMJ $3,0 \mathrm{~g}$ & 1141 & 49 & - & $2 x \mathrm{~N}_{2}$ Typ b & k.A. & $\mathrm{Ja}$ \\
\hline $\mathrm{s}-80$ & 223.7 & VMJ 3,0 g & 1129 & 1142 & k.A. & - & - & - \\
\hline s-81 & 223.2 & VMJ $3,0 \mathrm{~g}$ & 463 & 388 & k.A. & - & - & - \\
\hline $\mathrm{s}-82$ & 223.7 & VMJ 3,0 g & 1135 & 1128 & k.A. & - & - & - \\
\hline$s-83$ & 223.solid & Solid 2,916 g & 1575 & 71 & 0,0030 & $\mathrm{~N}_{2}$ Typ g & k.A. & - \\
\hline $\mathrm{s}-84$ & 223.2 & VMJ $3,0 \mathrm{~g}$ & 448 & 427 & 0,0060 & $\mathrm{~N}_{2}$ Typ b & $>0,08$ & - \\
\hline $\mathrm{s}-85$ & 223.5 & VMJ $3,0 \mathrm{~g}$ & 926 & 922 & 0,0340 & - & - & - \\
\hline $\mathrm{s}-86$ & 223.5 & VMJ $3,0 \mathrm{~g}$ & 924 & - & - & $\begin{array}{c}\text { Gelatine } 10^{\circ} \mathrm{C} \\
(0,15 \times 0,15 \times 0,40 \mathrm{~m})\end{array}$ & 0,340 & $\mathrm{Ja}$ \\
\hline $\mathrm{s}-87$ & 223.5 & VMJ $3,0 \mathrm{~g}$ & - & - & - & $\begin{array}{c}\text { Gelatine } 10^{\circ} \mathrm{C} \\
(0,15 \times 0,15 \times 0,40 \mathrm{~m})\end{array}$ & k.A. & k.A. \\
\hline s-88 & 223.5 & VMJ $3,0 \mathrm{~g}$ & - & - & - & $\begin{array}{c}\text { Gelatine } 10^{\circ} \mathrm{C} \\
(0,15 \times 0,15 \times 0,40 \mathrm{~m})\end{array}$ & k.A. & $\mathrm{Ja}$ \\
\hline s-89 & 222.sand & Typ3 0,324 g & - & - & - & Schlachttierteil & 0,022 & Ja \\
\hline $\mathrm{s}-90$ & 222.sand & Typ3 0,324 g & 424 & - & - & Schlachttierteil & 0,006 & $\mathrm{Ja}$ \\
\hline s-91 & 223.sand & Typ3 0,324 g & 461 & - & - & $\begin{array}{l}\text { Hartschaum und Gelatine } \\
(0,10 \times 0,10 \times 0,10 \mathrm{~m})\end{array}$ & 0,035 & $\mathrm{Ja}$ \\
\hline $\mathrm{s}-92$ & 223.sand & Typ3 0,324 g & 377 & - & - & $\begin{array}{l}\text { Hartschaum und Gelatine } \\
(0,10 \times 0,10 \times 0,10 \mathrm{~m})\end{array}$ & 0,038 & $\mathrm{Ja}$ \\
\hline s-93 & 223.sand & Typ3 0,324 g & - & - & - & $\begin{array}{l}\text { Hartschaum und Gelatine } \\
(0,10 \times 0,10 \times 0,10 \mathrm{~m})\end{array}$ & 0,038 & $\mathrm{Ja}$ \\
\hline s-94 & 223.sand & Typ3 0,324 g & - & - & - & $\begin{array}{l}\text { Hartschaum und Gelatine } \\
(0,10 \times 0,10 \times 0,10 \mathrm{~m})\end{array}$ & 0,040 & $\mathrm{Ja}$ \\
\hline s-95 & 223.sand & Typ3 0,324 g & 417 & - & - & $\begin{array}{l}\text { Hartschaum und Gelatine } \\
(0,10 \times 0,10 \times 0,10 \mathrm{~m})\end{array}$ & 0,036 & $\mathrm{Ja}$ \\
\hline s-96 & 223.sand & Typ3 0,324 g & 422 & - & - & $\begin{array}{l}\text { Hartschaum und Gelatine } \\
(0,10 \times 0,10 \times 0,10 \mathrm{~m})\end{array}$ & 0,033 & $\mathrm{Ja}$ \\
\hline s-97 & 223.sand & Typ3 0,324 g & 363 & - & - & $\begin{array}{l}\text { Hartschaum und Gelatine } \\
(0,10 \times 0,10 \times 0,10 \mathrm{~m})\end{array}$ & 0,020 & $\mathrm{Ja}$ \\
\hline $\mathrm{s}-98$ & 223.sand & Typ3 0,324 g & - & - & - & $\begin{array}{l}\text { Hartschaum und Gelatine } \\
(0,10 \times 0,10 \times 0,10 \mathrm{~m})\end{array}$ & 0,032 & $\mathrm{Ja}$ \\
\hline s-99 & 223.sand & Typ3 0,324 g & 446 & - & - & $\begin{array}{l}\text { Hartschaum und Gelatine } \\
(0,10 \times 0,10 \times 0,10 \mathrm{~m})\end{array}$ & 0,027 & $\mathrm{Ja}$ \\
\hline$s-100$ & 223.sand & Typ3 0,324 g & 402 & - & - & $\begin{array}{l}\text { Hartschaum und Gelatine } \\
(0,10 \times 0,10 \times 0,10 \mathrm{~m})\end{array}$ & 0,024 & $\mathrm{Ja}$ \\
\hline s-101 & 223.mess & Typ4 0,454 g & - & - & - & $\begin{array}{l}\text { Hartschaum und Gelatine } \\
(0,10 \times 0,10 \times 0,10 \mathrm{~m})\end{array}$ & 0,050 & $\mathrm{Ja}$ \\
\hline s-102 & 223.mess & Typ4 0,454 g & 478 & - & - & $\begin{array}{l}\text { Hartschaum und Gelatine } \\
(0,10 \times 0,10 \times 0,10 \mathrm{~m})\end{array}$ & 0,031 & $\mathrm{Ja}$ \\
\hline s-103 & 223.mess & Typ4 0,454 g & 490 & - & - & $\begin{array}{l}\text { Hartschaum und Gelatine } \\
(0,10 \times 0,10 \times 0,10 \mathrm{~m})\end{array}$ & 0,052 & $\mathrm{Ja}$ \\
\hline s-104 & 223.mess & Typ4 0,454 g & 501 & - & - & $\begin{array}{l}\text { Hartschaum und Gelatine } \\
(0,10 \times 0,10 \times 0,10 \mathrm{~m})\end{array}$ & 0,043 & $\mathrm{Ja}$ \\
\hline s-105 & 223.mess & Typ4 0,454 g & 458 & - & - & $\begin{array}{l}\text { Hartschaum und Gelatine } \\
(0,10 \times 0,10 \times 0,10 \mathrm{~m})\end{array}$ & 0,045 & $\mathrm{Ja}$ \\
\hline
\end{tabular}




\begin{tabular}{|c|c|c|c|c|c|c|c|c|}
\hline Nr. & Laborierung & Geschoss & $\begin{array}{c}\text { Ch. 1: } \\
v_{a} \\
{[\mathrm{~m} / \mathrm{s}]}\end{array}$ & $\begin{array}{c}\text { Ch. 2: } \\
v_{\text {rst }} \\
{[\mathrm{m} / \mathrm{s}]}\end{array}$ & $\begin{array}{c}\text { Aus- } \\
\text { schlag } \\
\text { [m] }\end{array}$ & Ziel & $\begin{array}{c}\text { Ein- } \\
\text { dring- } \\
\text { tiefe } \\
{[\mathrm{m}]}\end{array}$ & Fragmente \\
\hline s-106 & 223.mess & Typ4 0,454 g & 498 & - & - & $\begin{array}{l}\text { Hartschaum und Gelatine } \\
(0,10 \times 0,10 \times 0,10 \mathrm{~m})\end{array}$ & $>0,10$ & - \\
\hline s-107 & 223.mess & Typ4 0,454 g & 452 & - & - & $\begin{array}{l}\text { Hartschaum und Gelatine } \\
(0,10 \times 0,10 \times 0,10 \mathrm{~m})\end{array}$ & 0,022 & Ja \\
\hline s-108 & 223.mess & Typ4 0,454 g & 506 & - & - & $\begin{array}{l}\text { Hartschaum und Gelatine } \\
(0,10 \times 0,10 \times 0,10 \mathrm{~m})\end{array}$ & 0,033 & $\mathrm{Ja}$ \\
\hline s-109 & 223.mess & Typ4 0,454 g & 479 & - & - & $\begin{array}{l}\text { Hartschaum und Gelatine } \\
(0,10 \times 0,10 \times 0,10 \mathrm{~m})\end{array}$ & 0,023 & $\mathrm{Ja}$ \\
\hline$s-110$ & 223.mess & Typ4 0,454 g & 475 & - & - & $\begin{array}{l}\text { Hartschaum und Gelatine } \\
(0,10 \times 0,10 \times 0,10 \mathrm{~m})\end{array}$ & $>0,10$ & - \\
\hline $\mathrm{s}-111$ & 223.holz & Typ5 0,259 g & 395 & - & - & $\begin{array}{l}\text { Hartschaum und Gelatine } \\
(0,10 \times 0,10 \times 0,10 \mathrm{~m})\end{array}$ & 0,016 & - \\
\hline $\mathrm{s}-112$ & 223.holz & Typ5 0,259 g & 228 & - & - & $\begin{array}{l}\text { Hartschaum und Gelatine } \\
(0,10 \times 0,10 \times 0,10 \mathrm{~m})\end{array}$ & 0,015 & - \\
\hline$s-113$ & 223.holz & Typ5 0,259 g & 389 & - & - & $\begin{array}{l}\text { Hartschaum und Gelatine } \\
(0,10 \times 0,10 \times 0,10 \mathrm{~m})\end{array}$ & 0,013 & - \\
\hline$s-114$ & 223.holz & Typ5 0,259 g & 437 & - & - & $\begin{array}{l}\text { Hartschaum und Gelatine } \\
(0,10 \times 0,10 \times 0,10 \mathrm{~m})\end{array}$ & 0,025 & $\mathrm{Ja}$ \\
\hline s-115 & 223.holz & Typ5 0,259 g & 163 & - & - & $\begin{array}{l}\text { Hartschaum und Gelatine } \\
(0,10 \times 0,10 \times 0,10 \mathrm{~m})\end{array}$ & - & - \\
\hline$s-116$ & 223.holz & Typ5 0,259 g & 115 & - & - & $\begin{array}{l}\text { Hartschaum und Gelatine } \\
(0,10 \times 0,10 \times 0,10 \mathrm{~m})\end{array}$ & - & - \\
\hline s-117 & 223.holz & Typ5 0,259 g & 129 & - & - & $\begin{array}{l}\text { Hartschaum und Gelatine } \\
(0,10 \times 0,10 \times 0,10 \mathrm{~m})\end{array}$ & - & - \\
\hline $\mathrm{s}-118$ & 223.holz & Typ5 0,259 g & 255 & - & - & $\begin{array}{l}\text { Hartschaum und Gelatine } \\
(0,10 \times 0,10 \times 0,10 \mathrm{~m})\end{array}$ & 0,016 & - \\
\hline s-119 & 223.holz & Typ5 0,259 g & 226 & - & - & $\begin{array}{l}\text { Hartschaum und Gelatine } \\
(0,10 \times 0,10 \times 0,10 \mathrm{~m})\end{array}$ & 0,026 & $\mathrm{Ja}$ \\
\hline$s-120$ & 223.holz & Typ5 0,259 g & 428 & - & - & $\begin{array}{l}\text { Hartschaum und Gelatine } \\
(0,10 \times 0,10 \times 0,10 \mathrm{~m})\end{array}$ & 0,009 & - \\
\hline$s-121$ & 223.1 & VMJ $3,0 \mathrm{~g}$ & 128 & 126 & 0,0015 & - & - & - \\
\hline$s-122$ & 223.1 & VMJ $3,0 \mathrm{~g}$ & 132 & 131 & 0,0015 & - & - & - \\
\hline$s-123$ & 223.1 & VMJ $3,0 \mathrm{~g}$ & 128 & 127 & 0,0015 & - & - & - \\
\hline$s-124$ & 223.1 & VMJ $3,0 \mathrm{~g}$ & 127 & 126 & 0,0010 & - & - & - \\
\hline $\mathrm{s}-125$ & 223.1 & VMJ $3,0 \mathrm{~g}$ & 132 & 132 & 0,0010 & - & - & - \\
\hline$s-126$ & 223.1 & VMJ $3,0 \mathrm{~g}$ & 132 & 130 & 0,0015 & - & - & - \\
\hline s-127 & 223.1 & VMJ $3,0 \mathrm{~g}$ & 130 & 129 & 0,0010 & - & - & - \\
\hline $\mathrm{s}-128$ & 223.1 & VMJ $3,0 \mathrm{~g}$ & 131 & 129 & 0,0015 & - & - & - \\
\hline$s-129$ & 223.1 & VMJ $3,0 \mathrm{~g}$ & 128 & 126 & 0,0015 & - & - & - \\
\hline$s-130$ & 223.1 & VMJ $3,0 \mathrm{~g}$ & 130 & 128 & 0,0015 & - & - & - \\
\hline$s-131$ & 223.7 & VMJ $3,0 \mathrm{~g}$ & 1101 & 1075 & 0,0140 & $\mathrm{~N}_{2}(0,01 \mathrm{~m})$ & k.A. & $\mathrm{Ja}$ \\
\hline$s-132$ & 223.7 & VMJ $3,0 \mathrm{~g}$ & 1125 & 510 & 0,0120 & $\mathrm{~N}_{2}(0,04 \mathrm{~m})$ & k.A. & $\mathrm{Ja}$ \\
\hline$s-133$ & 223.7 & VMJ $3,0 \mathrm{~g}$ & 1125 & 570 & - & $\mathrm{N}_{2}(0,08 \mathrm{~m})$ & k.A. & $\mathrm{Ja}$ \\
\hline$s-134$ & 223.7 & VMJ $3,0 \mathrm{~g}$ & 1125 & 30 & 0,0050 & $\mathrm{~N}_{2}(0,12 \mathrm{~m})$ & k.A. & $\mathrm{Ja}$ \\
\hline
\end{tabular}




\begin{tabular}{|c|c|c|c|c|c|c|c|c|}
\hline Nr. & Laborierung & Geschoss & $\begin{array}{c}\text { Ch. 1: } \\
v_{a} \\
{[\mathrm{~m} / \mathrm{s}]}\end{array}$ & $\begin{array}{c}\text { Ch. 2: } \\
v_{\text {rst }} \\
{[\mathrm{m} / \mathrm{s}]}\end{array}$ & $\begin{array}{c}\text { Aus- } \\
\text { schlag } \\
\text { [m] }\end{array}$ & Ziel & $\begin{array}{c}\text { Ein- } \\
\text { dring- } \\
\text { tiefe } \\
{[\mathrm{m}]} \\
\end{array}$ & Fragmente \\
\hline $\mathrm{s}-135$ & 223.7 & VMJ $3,0 \mathrm{~g}$ & 1116 & 7 & - & $\mathrm{N}_{2}(0,16 \mathrm{~m})$ & k.A. & $\mathrm{Ja}$ \\
\hline$s-136$ & 223.7 & VMJ $3,0 \mathrm{~g}$ & 1122 & 501 & 0,0110 & $\mathrm{~N}_{2}(0,04 \mathrm{~m})$ & k.A. & $\mathrm{Ja}$ \\
\hline s-137 & 223.7 & VMJ $3,0 \mathrm{~g}$ & 1114 & 501 & 0,0085 & $\mathrm{~N}_{2}(0,08 \mathrm{~m})$ & k.A. & $\mathrm{Ja}$ \\
\hline $\mathrm{s}-138$ & 223.7 & VMJ $3,0 \mathrm{~g}$ & 1121 & - & - & $\mathrm{N}_{2}(0,12 \mathrm{~m})$ & k.A. & $\mathrm{Ja}$ \\
\hline$s-139$ & 223.6 & VMJ $3,0 \mathrm{~g}$ & 972 & - & 0,0180 & $\mathrm{~N}_{2}(0,04 \mathrm{~m})$ & k.A. & - \\
\hline$s-140$ & 223.6 & VMJ $3,0 \mathrm{~g}$ & 998 & 689 & 0,0160 & $\mathrm{~N}_{2}(0,08 \mathrm{~m})$ & k.A. & - \\
\hline$s-141$ & 223.6 & VMJ $3,0 \mathrm{~g}$ & 988 & 218 & - & $\mathrm{N}_{2}(0,12 \mathrm{~m})$ & k.A. & $\mathrm{Ja}$ \\
\hline$s-142$ & 223.6 & VMJ $3,0 \mathrm{~g}$ & 993 & - & 0,0220 & $\mathrm{~N}_{2}(0,04 \mathrm{~m})$ & k.A. & - \\
\hline$s-143$ & 223.6 & VMJ $3,0 \mathrm{~g}$ & 991 & 949 & 0,0180 & $\mathrm{~N}_{2}(0,04 \mathrm{~m})$ & k.A. & - \\
\hline$s-144$ & 223.6 & VMJ $3,0 \mathrm{~g}$ & 988 & 960 & 0,0185 & $\mathrm{~N}_{2}(0,04 \mathrm{~m})$ & k.A. & - \\
\hline$s-145$ & 223.6 & VMJ $3,0 \mathrm{~g}$ & 989 & 945 & 0,0190 & $\mathrm{~N}_{2}(0,06 \mathrm{~m})$ & k.A. & - \\
\hline$s-146$ & 223.6 & VMJ $3,0 \mathrm{~g}$ & 967 & 829 & 0,0170 & $\mathrm{~N}_{2}(0,07 \mathrm{~m})$ & k.A. & - \\
\hline s-147 & 223.6 & VMJ $3,0 \mathrm{~g}$ & 961 & 640 & 0,0140 & $\mathrm{~N}_{2}(0,08 \mathrm{~m})$ & k.A. & - \\
\hline$s-148$ & 223.6 & VMJ $3,0 \mathrm{~g}$ & 984 & 619 & 0,0150 & $\mathrm{~N}_{2}(0,08 \mathrm{~m})$ & k.A. & - \\
\hline$s-149$ & 223.6 & VMJ $3,0 \mathrm{~g}$ & 991 & 467 & 0,0100 & $\mathrm{~N}_{2}(0,10 \mathrm{~m})$ & k.A. & $\mathrm{Ja}$ \\
\hline$s-150$ & 223.6 & VMJ $3,0 \mathrm{~g}$ & 986 & 653 & 0,0120 & $\mathrm{~N}_{2}(0,09 \mathrm{~m})$ & k.A. & $\mathrm{Ja}$ \\
\hline s-151 & 223.6 & VMJ $3,0 \mathrm{~g}$ & 972 & 8 & k.A. & $\mathrm{N}_{2}(0,09 \mathrm{~m})$ & k.A. & $\mathrm{Ja}$ \\
\hline$s-152$ & 223.1 & VMJ $3,0 \mathrm{~g}$ & 125 & 119 & - & $\mathrm{N}_{2}(0,08 \mathrm{~m})$ & k.A. & - \\
\hline s-153 & 223.7 & VMJ $3,0 \mathrm{~g}$ & 1122 & 403 & 0,0080 & $\begin{array}{l}\text { Wasser mit Blasen } \\
\qquad(0,08 \mathrm{~m})\end{array}$ & k.A. & $\mathrm{Ja}$ \\
\hline s-154 & 223.7 & VMJ 3,0 g & 1144 & 1066 & 0,0140 & $\begin{array}{l}\text { Wasser mit Blasen } \\
\qquad(0,02 \mathrm{~m})\end{array}$ & k.A. & $\mathrm{Ja}$ \\
\hline s-155 & 223.6 & VMJ $3,0 \mathrm{~g}$ & 974 & 925 & 0,0210 & $\begin{array}{l}\text { Wasser mit Blasen } \\
\qquad(0,09 \mathrm{~m})\end{array}$ & k.A. & - \\
\hline s-156 & 223.6 & VMJ 3,0 g & 965 & 63 & - & $\begin{array}{l}\text { Wasser mit Blasen } \\
\qquad(0,12 \mathrm{~m})\end{array}$ & k.A. & $\mathrm{Ja}$ \\
\hline s-157 & 223.6 & VMJ $3,0 \mathrm{~g}$ & 969 & 853 & - & $\begin{array}{c}\text { Wasser mit Blasen } \\
(0,12 \mathrm{~m})\end{array}$ & k.A. & $\mathrm{Ja}$ \\
\hline s-158 & 223.6 & VMJ $3,0 \mathrm{~g}$ & 965 & 71 & - & Wasser $(0,12 \mathrm{~m})$ & k.A. & $\mathrm{Ja}$ \\
\hline s-159 & 223.7 & VMJ $3,0 \mathrm{~g}$ & 1100 & - & - & Cucumis melo in Paketband & k.A. & $\mathrm{Ja}$ \\
\hline s-160 & 223.7 & VMJ $3,0 \mathrm{~g}$ & - & k.A. & 0,0050 & $1 / 2$ Cucumis melo $(0,06 \mathrm{~m})$ & k.A. & $\mathrm{Ja}$ \\
\hline s-161 & 223.7 & VMJ $3,0 \mathrm{~g}$ & - & k.A. & 0,0090 & $1 / 2$ Cucumis melo $(0,06 \mathrm{~m})$ & k.A. & $\mathrm{Ja}$ \\
\hline s-162 & 223.4 & VMJ $3,0 \mathrm{~g}$ & 799 & k.A. & 0,0110 & $\mathrm{~N}_{2}(0,08 \mathrm{~m})$ & k.A. & - \\
\hline $\mathrm{s}-163$ & 223.4 & VMJ $3,0 \mathrm{~g}$ & 792 & k.A. & 0,0080 & $\mathrm{~N}_{2}(0,08 \mathrm{~m})$ & k.A. & - \\
\hline
\end{tabular}




\begin{tabular}{|c|c|c|c|c|c|c|c|c|}
\hline $\mathrm{Nr}$. & Laborierung & Geschoss & $\begin{array}{c}\text { Ch. 1: } \\
v_{a} \\
{[\mathrm{~m} / \mathrm{s}]}\end{array}$ & $\begin{array}{c}\text { Ch. 2: } \\
v_{\text {rst }} \\
{[\mathrm{m} / \mathrm{s}]}\end{array}$ & $\begin{array}{c}\text { Aus- } \\
\text { schlag } \\
\text { [m] }\end{array}$ & Ziel & $\begin{array}{c}\text { Ein- } \\
\text { dring- } \\
\text { tiefe } \\
{[\mathrm{m}]} \\
\end{array}$ & Fragmente \\
\hline s-164 & 223.2 & VMJ $3,0 \mathrm{~g}$ & 400 & k.A. & 0,0075 & $\mathrm{~N}_{2}(0,08 \mathrm{~m}$ tief $)$ & k.A. & - \\
\hline s-165 & 223.3 & VMJ 3,0 g & 563 & k.A. & 0,0085 & $\mathrm{~N}_{2}(0,08 \mathrm{~m})$ & k.A. & - \\
\hline s-166 & 223.solid & Solid 2,916 g & 1058 & k.A. & k.A. & $\mathrm{N}_{2}(0,08 \mathrm{~m})$ & k.A. & - \\
\hline s-167 & 223.solid & Solid 2,916 g & 1077 & k.A. & k.A. & $\mathrm{N}_{2}(0,08 \mathrm{~m})$ & k.A. & - \\
\hline s-168 & 223.solid & Solid 2,916 g & 1068 & k.A. & 0,0240 & $\mathrm{~N}_{2}(0,12 \mathrm{~m})$ & k.A. & - \\
\hline s-169 & 223.2 & VMJ 3,0 g & 378 & k.A. & - & Wasser $(0,10 \mathrm{~m})$ & k.A. & - \\
\hline s-170 & 223.2 & VMJ $3,0 \mathrm{~g}$ & 291 & 219 & - & Wasser $(0,10 \mathrm{~m})$ & k.A. & - \\
\hline s-171 & $.22 \mathrm{lr}$ & Typ6 2,592 g & 331 & - & k.A. & Hartschaum & k.A. & - \\
\hline s-172 & $.22 \mathrm{lr}$ & Typ6 2,592 g & 336 & - & k.A. & Hartschaum & k.A. & - \\
\hline s-173 & $.22 \mathrm{lr}$ & Typ6 2,592 g & 335 & - & k.A. & Hartschaum & k.A. & - \\
\hline s-174 & $.22 \mathrm{Ir}$ & Typ6 2,592 g & 338 & - & k.A. & Hartschaum & k.A. & - \\
\hline s-175 & $.22 \mathrm{lr}$ & Typ6 2,592 g & 330 & - & k.A. & Hartschaum & k.A. & - \\
\hline s-176 & $.22 \mathrm{lr}$ & Typ6 2,592 g & 329 & - & k.A. & Hartschaum & k.A. & - \\
\hline s-177 & $.22 \mathrm{Ir}$ & Typ6 2,592 g & 331 & - & k.A. & Hartschaum & k.A. & - \\
\hline s-178 & $.22 \mathrm{lr}$ & Typ6 2,592 g & 332 & - & k.A. & Hartschaum & k.A. & - \\
\hline s-179 & $.22 \mathrm{lr}$ & Typ6 2,592 g & 336 & - & k.A. & Hartschaum & k.A. & - \\
\hline s-180 & $.22 \mathrm{Ir}$ & Typ6 2,592 g & 332 & - & k.A. & Hartschaum & k.A. & - \\
\hline s-181 & $.22 \mathrm{lr}$ & Typ6 2,592 g & 333 & 329 & k.A. & - & - & - \\
\hline s-182 & $.22 \mathrm{lr}$ & Typ6 2,592 g & 335 & 332 & k.A. & - & - & - \\
\hline s-183 & $.22 \mathrm{lr}$ & Typ6 2,592 g & 337 & 333 & k.A. & - & - & - \\
\hline s-184 & $.22 \mathrm{lr}$ & Typ6 2,592 g & 343 & 339 & k.A. & - & - & - \\
\hline s-185 & $.22 \mathrm{lr}$ & Typ6 2,592 g & 339 & 336 & k.A. & - & - & - \\
\hline s-186 & $.22 \mathrm{Ir}$ & Typ6 2,592 g & 336 & 338 & k.A. & - & - & - \\
\hline s-187 & $.22 \mathrm{Ir}$ & Typ6 2,592 g & 341 & 338 & k.A. & - & - & - \\
\hline s-188 & $.22 \mathrm{lr}$ & Typ6 2,592 g & 333 & 339 & k.A. & - & - & - \\
\hline s-189 & $.22 \mathrm{Ir}$ & Typ6 2,592 g & 338 & 337 & k.A. & - & - & - \\
\hline s-190 & $.22 \mathrm{Ir}$ & Typ6 2,592 g & 337 & 340 & k.A. & - & - & - \\
\hline s-191 & 223.sand & Тур3 0,324 g & 456 & k.A. & k.A. & Rigips $(0.95 \mathrm{~cm})$ & k.A. & k.A. \\
\hline s-192 & 223.sand & Тур3 0,324 g & 422 & k.A. & k.A. & Rigips $(0.95 \mathrm{~cm})$ & k.A. & k.A. \\
\hline
\end{tabular}




\begin{tabular}{|c|c|c|c|c|c|c|c|c|}
\hline Nr. & Laborierung & Geschoss & $\begin{array}{c}\text { Ch. 1: } \\
v_{a} \\
{[\mathrm{~m} / \mathrm{s}]}\end{array}$ & $\begin{array}{c}\text { Ch. 2: } \\
v_{\text {rst }} \\
{[\mathrm{m} / \mathrm{s}]}\end{array}$ & $\begin{array}{c}\text { Aus- } \\
\text { schlag } \\
\text { [m] }\end{array}$ & Ziel & $\begin{array}{c}\text { Ein- } \\
\text { dring- } \\
\text { tiefe } \\
{[\mathrm{m}]} \\
\end{array}$ & Fragmente \\
\hline s-193 & 223.sand & Typ3 0,324 g & 397 & k.A. & k.A. & Rigips $(0.95 \mathrm{~cm})$ & k.A. & k.A. \\
\hline s-194 & 223.sand & Typ3 0,324 g & & k.A. & k.A. & Rigips $(0.95 \mathrm{~cm})$ & k.A. & k.A. \\
\hline s-195 & 223.sand & Typ3 0,324 g & 405 & k.A. & k.A. & Rigips $(0.95 \mathrm{~cm})$ & k.A. & k.A. \\
\hline s-196 & 223.sand & Typ3 0,324 g & 387 & k.A. & k.A. & Rigips $(0.95 \mathrm{~cm})$ & k.A. & k.A. \\
\hline s-197 & 223.sand & Typ3 0,324 g & 489 & k.A. & k.A. & Rigips $(0.95 \mathrm{~cm})$ & k.A. & k.A. \\
\hline s-198 & 223.sand & Typ3 0,324 g & 423 & k.A. & k.A. & Rigips $(0.95 \mathrm{~cm})$ & k.A. & k.A. \\
\hline s-199 & 223.sand & Typ3 0,324 g & 419 & k.A. & k.A. & Rigips $(0.95 \mathrm{~cm})$ & k.A. & k.A. \\
\hline s-200 & 223.sand & Typ3 0,324 g & 397 & k.A. & k.A. & Rigips $(0.95 \mathrm{~cm})$ & k.A. & k.A. \\
\hline s-201 & 223.mess & Typ4 0,454 g & 512 & k.A. & k.A. & Rigips $(0.95 \mathrm{~cm})$ & k.A. & k.A. \\
\hline s-202 & 223.mess & Typ4 0,454 g & 492 & k.A. & k.A. & Rigips $(0.95 \mathrm{~cm})$ & k.A. & k.A. \\
\hline s-203 & 223.mess & Typ4 0,454 g & 498 & k.A. & k.A. & Rigips $(0.95 \mathrm{~cm})$ & k.A. & k.A. \\
\hline s-204 & 223.mess & Typ4 0,454 g & 516 & k.A. & k.A. & Rigips $(0.95 \mathrm{~cm})$ & k.A. & k.A. \\
\hline s-205 & 223.mess & Typ4 0,454 g & 493 & k.A. & k.A. & Rigips $(0.95 \mathrm{~cm})$ & k.A. & k.A. \\
\hline s-206 & 223.mess & Typ4 0,454 g & 524 & k.A. & k.A. & Rigips $(0.95 \mathrm{~cm})$ & k.A. & k.A. \\
\hline s-207 & 223.mess & Typ4 0,454 g & 472 & k.A. & k.A. & Rigips $(0.95 \mathrm{~cm})$ & k.A. & k.A. \\
\hline s-208 & 223.mess & Typ4 0,454 g & 447 & k.A. & k.A. & Rigips $(0.95 \mathrm{~cm})$ & k.A. & k.A. \\
\hline s-209 & 223.mess & Typ4 0,454 g & 521 & k.A. & k.A. & Rigips $(0.95 \mathrm{~cm})$ & k.A. & k.A. \\
\hline $\mathrm{s}-210$ & 223.mess & Typ4 0,454 g & 504 & k.A. & k.A. & Rigips $(0.95 \mathrm{~cm})$ & k.A. & k.A. \\
\hline $\mathrm{s}-211$ & $.22 \mathrm{lr}$ & Typ6 2,592 g & 335 & k.A. & k.A. & Rigips $(0.95 \mathrm{~cm})$ & k.A. & k.A. \\
\hline $\mathrm{s}-212$ & $.22 \mathrm{lr}$ & Typ6 2,592 g & 327 & k.A. & k.A. & Rigips $(0.95 \mathrm{~cm})$ & k.A. & k.A. \\
\hline $\mathrm{s}-213$ & $.22 \mathrm{lr}$ & Typ6 2,592 g & 341 & k.A. & k.A. & Rigips $(0.95 \mathrm{~cm})$ & k.A. & k.A. \\
\hline $\mathrm{s}-214$ & $.22 \mathrm{lr}$ & Typ6 2,592 g & 336 & k.A. & k.A. & Rigips $(0.95 \mathrm{~cm})$ & k.A. & k.A. \\
\hline $\mathrm{s}-215$ & $.22 \mathrm{lr}$ & Typ6 2,592 g & 324 & k.A. & k.A. & Rigips $(0.95 \mathrm{~cm})$ & k.A. & k.A. \\
\hline $\mathrm{s}-216$ & $.22 \mathrm{lr}$ & Typ6 2,592 g & 331 & k.A. & k.A. & Rigips $(0.95 \mathrm{~cm})$ & k.A. & k.A. \\
\hline s-217 & $.22 \mathrm{lr}$ & Typ6 2,592 g & 379 & k.A. & k.A. & Rigips $(0.95 \mathrm{~cm})$ & k.A. & k.A. \\
\hline $\mathrm{s}-218$ & $.22 \mathrm{lr}$ & Typ6 2,592 g & 338 & k.A. & k.A. & Rigips $(0.95 \mathrm{~cm})$ & k.A. & k.A. \\
\hline $\mathrm{s}-219$ & $.22 \mathrm{lr}$ & Typ6 2,592 g & 338 & k.A. & k.A. & Rigips $(0.95 \mathrm{~cm})$ & k.A. & k.A. \\
\hline $\mathrm{s}-220$ & $.22 \mathrm{Ir}$ & Typ6 2,592 g & 332 & k.A. & k.A. & Rigips $(0.95 \mathrm{~cm})$ & k.A. & k.A. \\
\hline
\end{tabular}

Tab. 7.1.2.: Schussversuche ohne Kamerakontrolle 


\subsection{Umrechnungsfaktoren}

Bei dem Umgang mit Waffen und Munition bleiben Umrechnungen von „Grain“ und „Inch“ (entspricht unserem „Zoll“) nicht aus. Obwohl die Amerikaner vor längerer Zeit beschlossen haben, sich unserem metrischen System mit Gramm (g) und Millimeter $(\mathrm{mm})$ anzupassen, sind diverse Geräte, insbesondere Waagen, in „Grain (gr.)" noch für das Zoll-System ausgelegt. Geschossdurchmesser werden stets in "Inch (in.)“ gekennzeichnet.

Zur Vereinheitlichung wurden in der vorliegenden Arbeit stets Angaben in Gramm und Millimeter (oder anderen Si-Grundeinheiten) gemacht und evtl. durch entsprechende Angaben in „Grain“ oder „Inch“ ergänzt.

$$
\begin{array}{ll}
1 \text { Gramm (g) } & =15,43236 \text { Grain (gr.) } \\
1 \text { Grain (gr) } & =0,0647989 \text { Gramm (g) } \\
1 \text { Millimeter (mm) } & =0,03937 \text { Inch (in.) } \\
1 \text { Inch (“) } & =25,4 \mathrm{~mm}(\mathrm{~mm})
\end{array}
$$

Die Geschwindigkeit wurde stets in Meter pro Sekunde [m/s] gemessen. Üblich ist aber auch die Angabe in ,feet per second (fps)“, wobei $1 \mathrm{fps}=0,3048 \mathrm{~m} / \mathrm{s}$ und $1 \mathrm{~m} / \mathrm{s}=$ 3,281 fps entsprechen. Des Weiteren sind Angaben in engl. Pfund (pound; Lb./lbs.) üblich, das mit 7000 Grain $(453,66 \mathrm{~g})$ gefüllt ist.

Länge:

$\begin{array}{ll}1 \mathrm{~mm}=0,03937 \text { in. } & 1 \mathrm{in} .=25,4 \mathrm{~mm} \\ 1 \mathrm{~m}=3,2808 \mathrm{ft} . & 1 \mathrm{ft} .=0,3048 \mathrm{~m}\end{array}$

Fläche:

$1 \mathrm{~m}^{2}=10,764$ sq. ft. $\quad 1$ sq. ft. $=0,092903 \mathrm{~m}^{2}$

$1 \mathrm{~cm}^{2}=0,155 \mathrm{sq}$. in. $\quad 1 \mathrm{sq}$. in. $=6,4516 \mathrm{~cm}^{2}$

Raum:

$1 \mathrm{~cm}^{3}=0,061 \mathrm{cu}$. in.

$1 \mathrm{~m}^{3}=35,3148 \mathrm{cu}$. ft.

$1 \mathrm{cu}$. in. $=16,387 \mathrm{~cm}^{3}$

$1 \mathrm{cu}$. ft. $=0,028317 \mathrm{~m}^{3}$

Gewicht:

$1 \mathrm{~g}=15,432 \mathrm{gr}$.

$1 \mathrm{~g}=0,035274 \mathrm{oz}$.

$1 \mathrm{gr} .=0,0648 \mathrm{~g}$

$1 \mathrm{~kg}=2,2046 \mathrm{lbs}$.

$1 \mathrm{oz} .=28,35 \mathrm{~g}$

$1 \mathrm{lb} .=0,4536 \mathrm{~kg}$

Gasdruck:

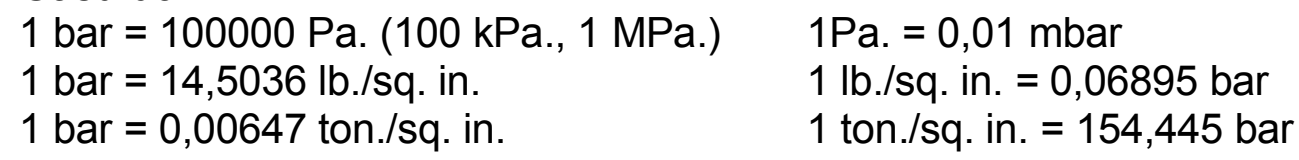

Energie:

1 Joule $=0,73757 \mathrm{ft}$. lbs.

1 ft.lb. = 1,3558 Joule 
7.3. Photographien

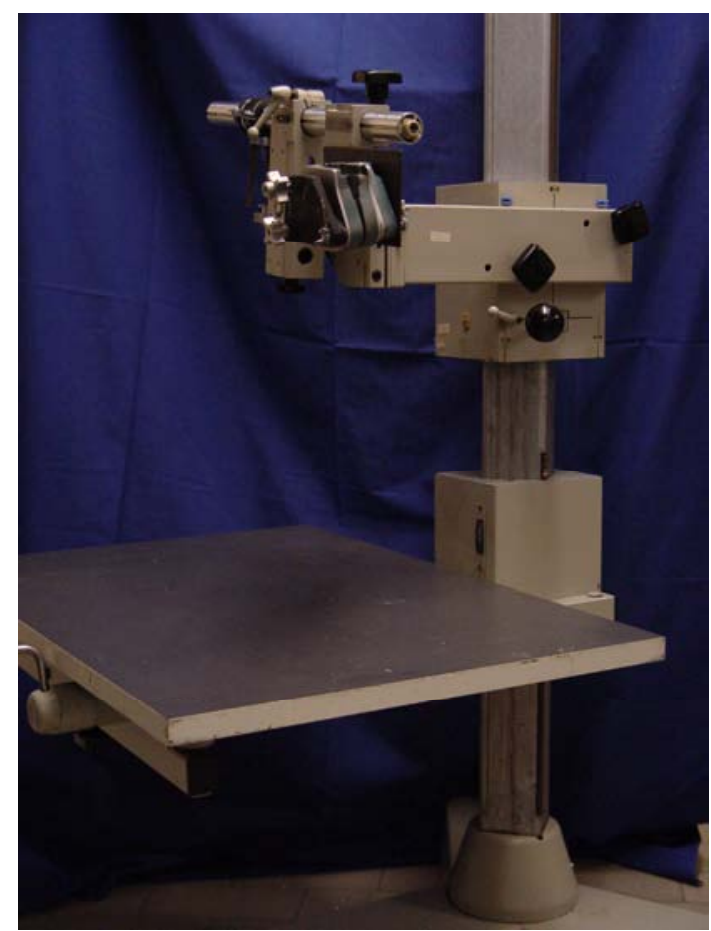

Photo 1: Stativ

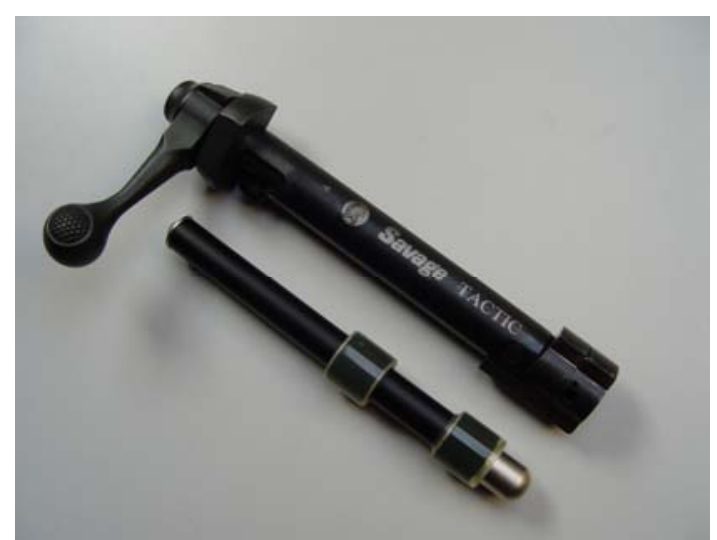

Photo 2: Kammerverschluss und Laserpointer

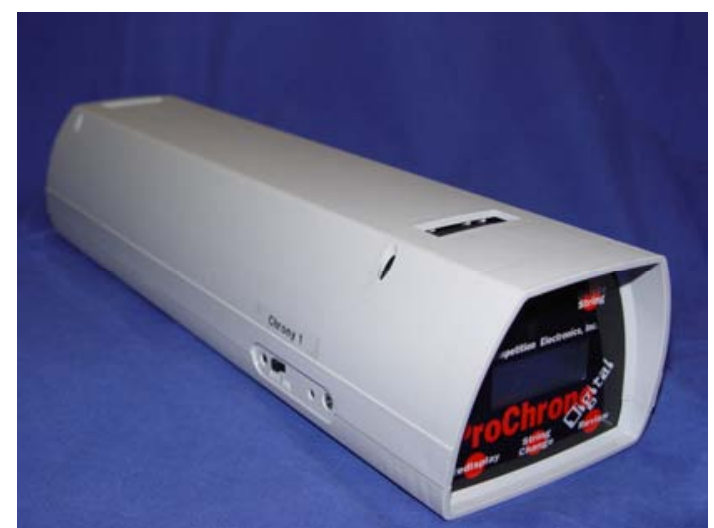

Photo 3: Chronygraph

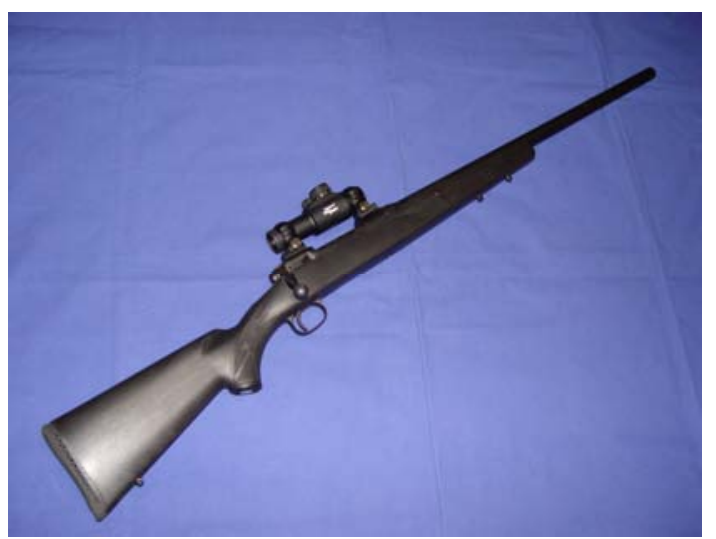

Photo 4: Savage

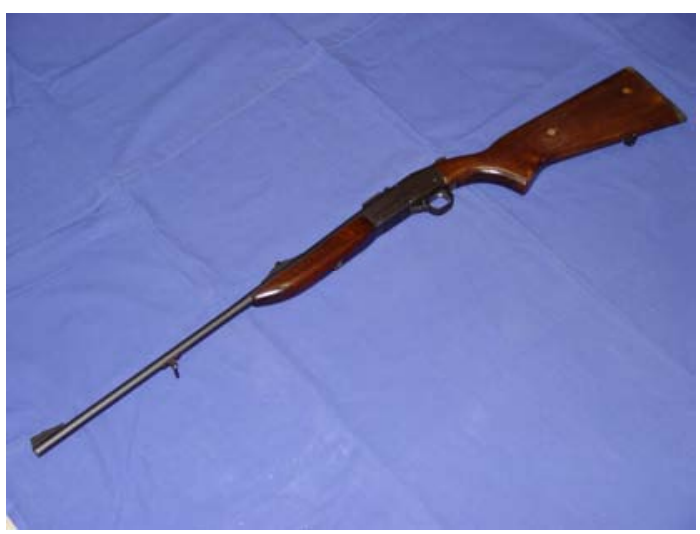

Photo 5: Brünner

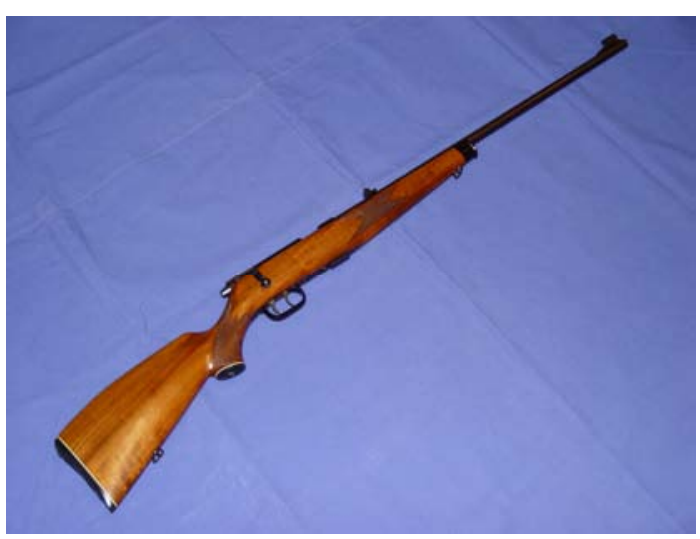

Photo 6: Krico 


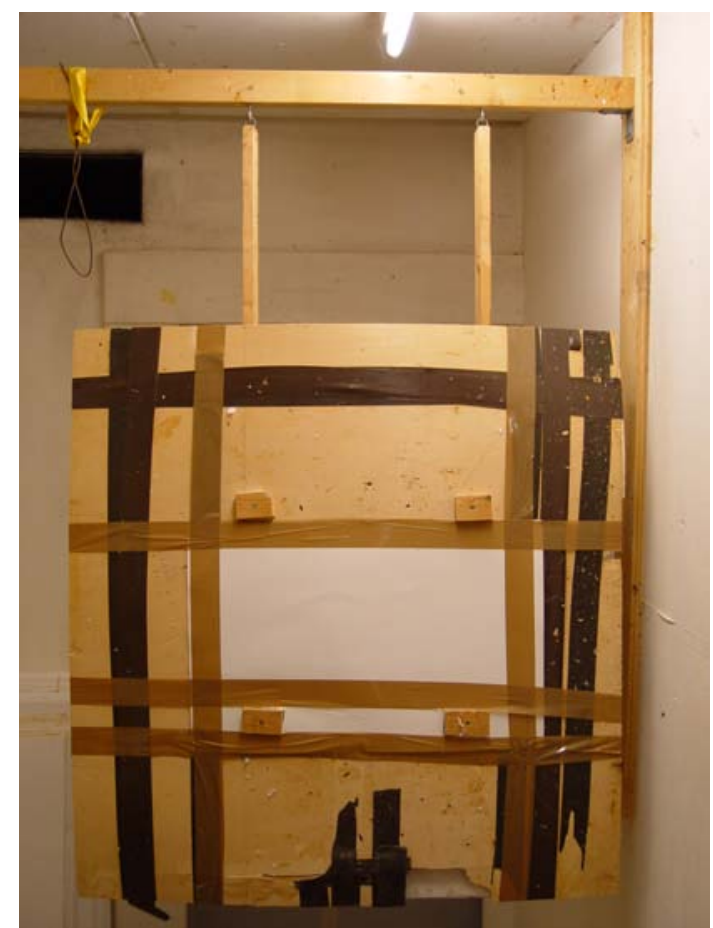

Photo 7: Pendel

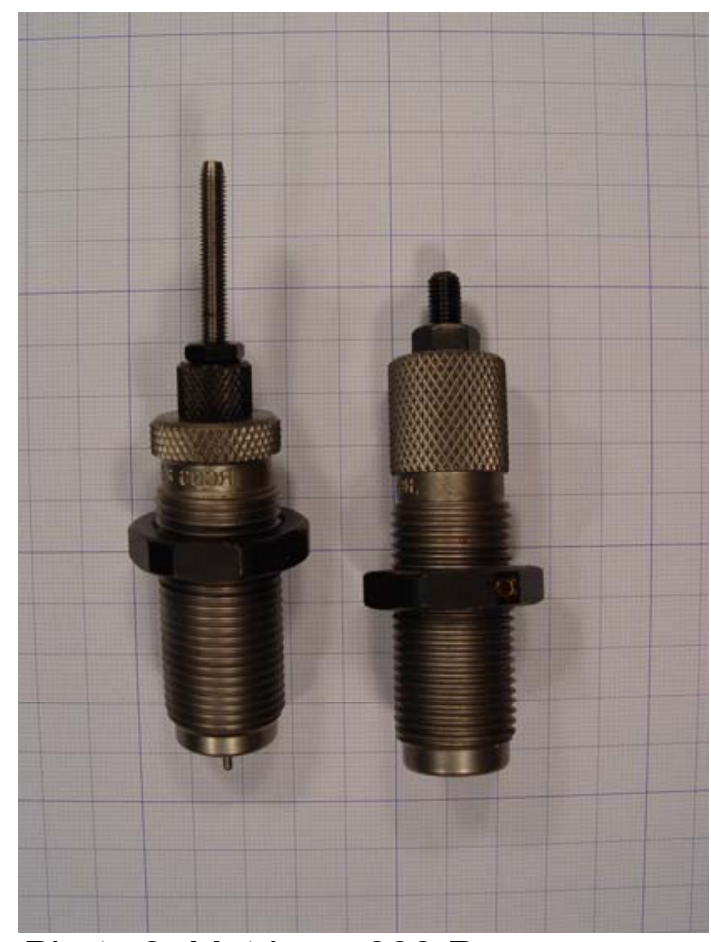

Photo 8: Matrizen .223 Rem

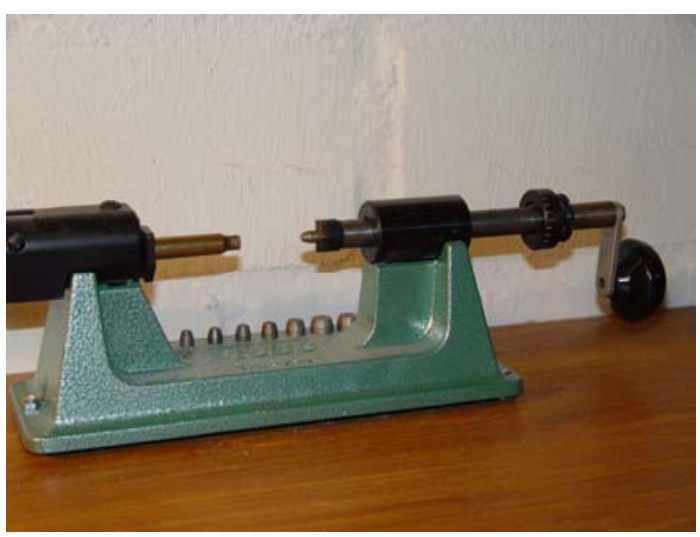

Photo 9: Hülsentrimmer

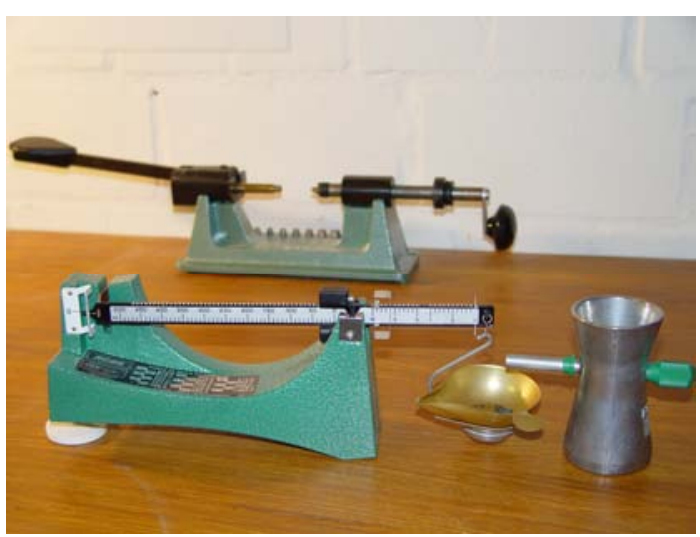

Photo 10: Pulverwaage

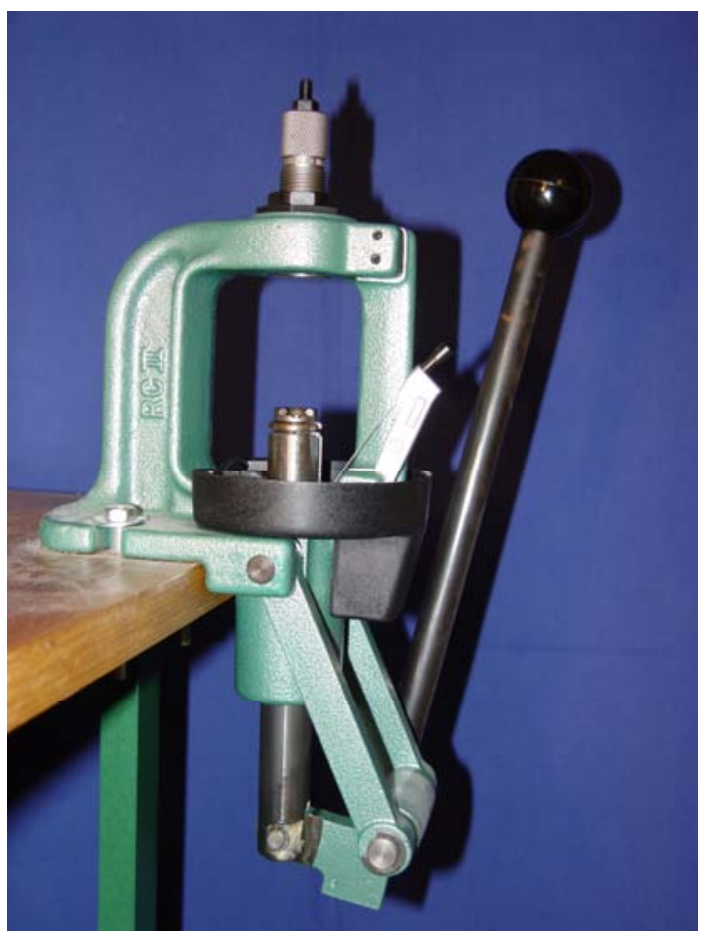

Photo 11: Ladepresse 


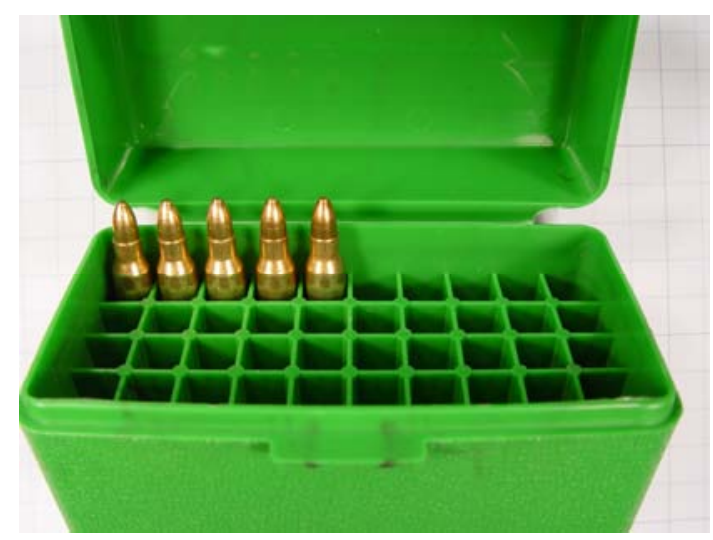

Photo 12: Verwahrung

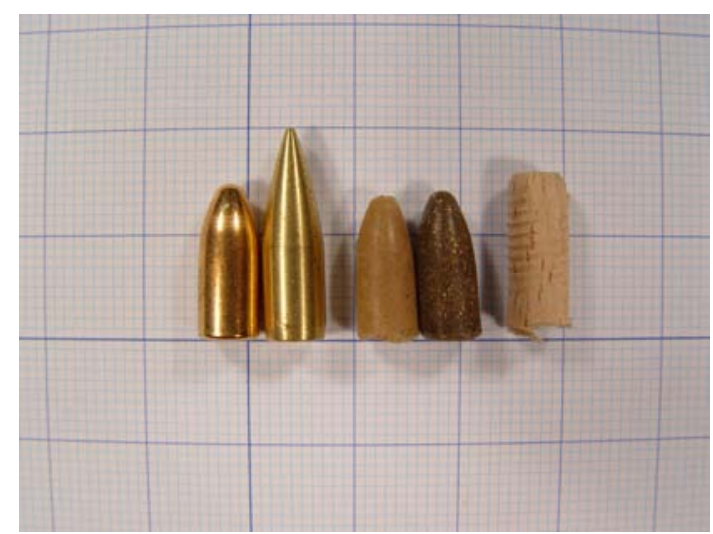

Photo 13: VMJ, Solid, Sand, Messingspäne, Holzdübel

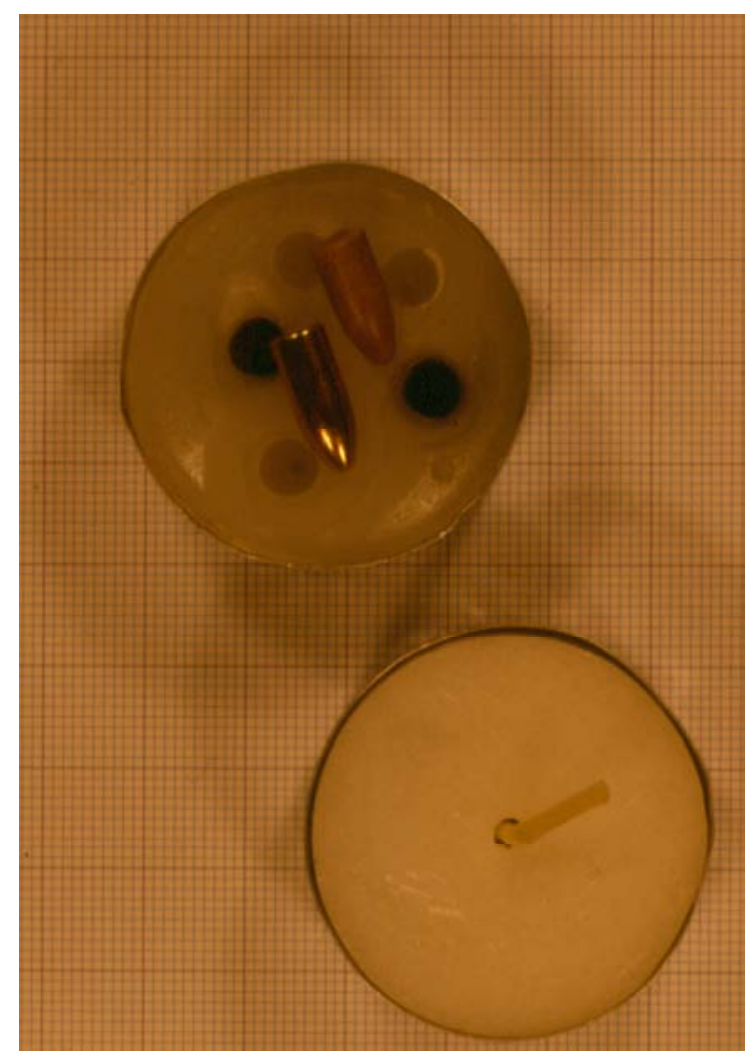

Photo 14: Wachsmatrize

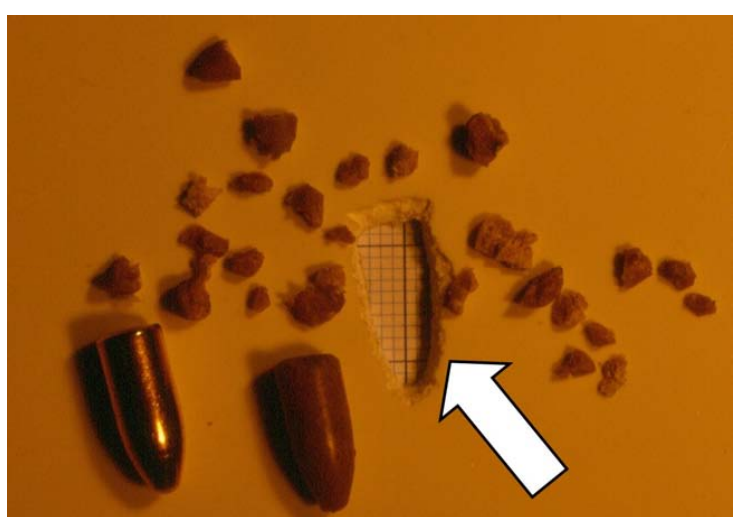

Photo 15: Fragmente s-100

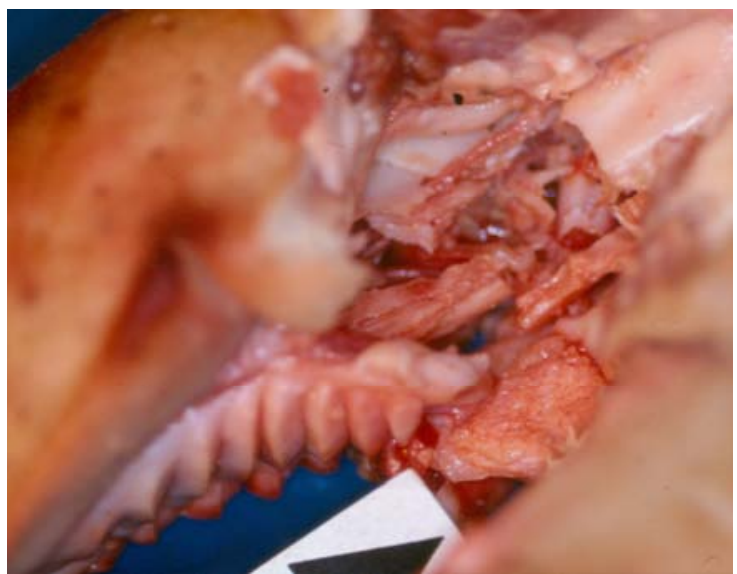

Photo 16: Maxilla Schlachttier

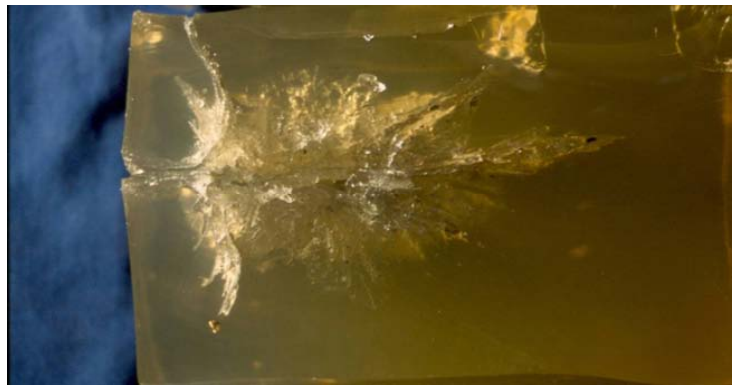

Photo 17: Eindringtiefe s-03

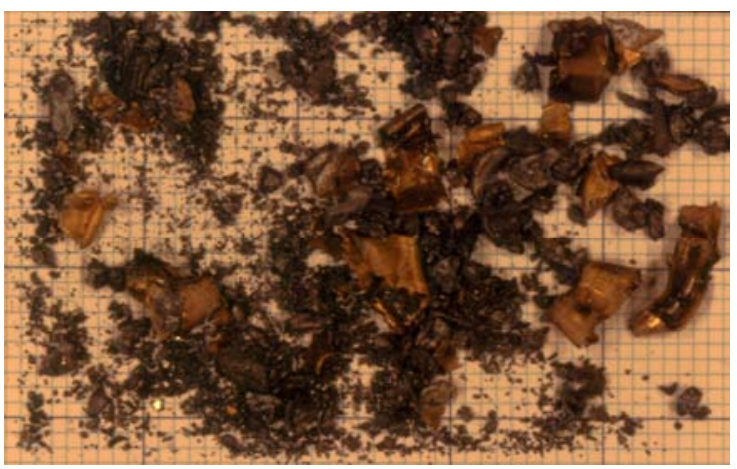

Photo 18: VMJ Fragmente s-03 


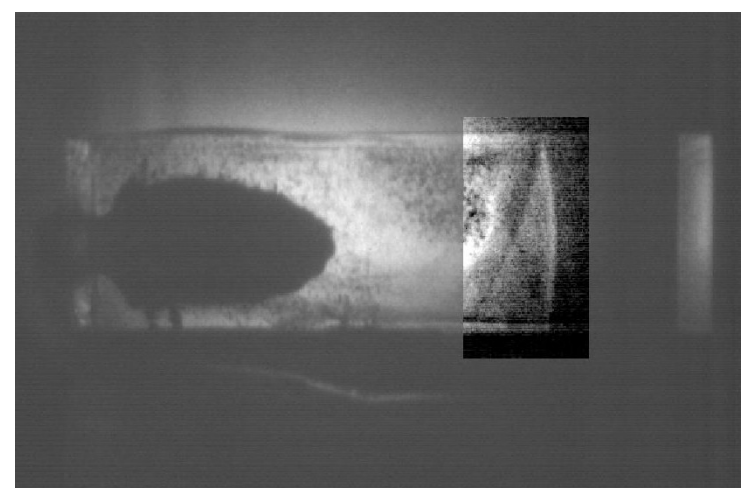

Photo 19: Reflexion s-33

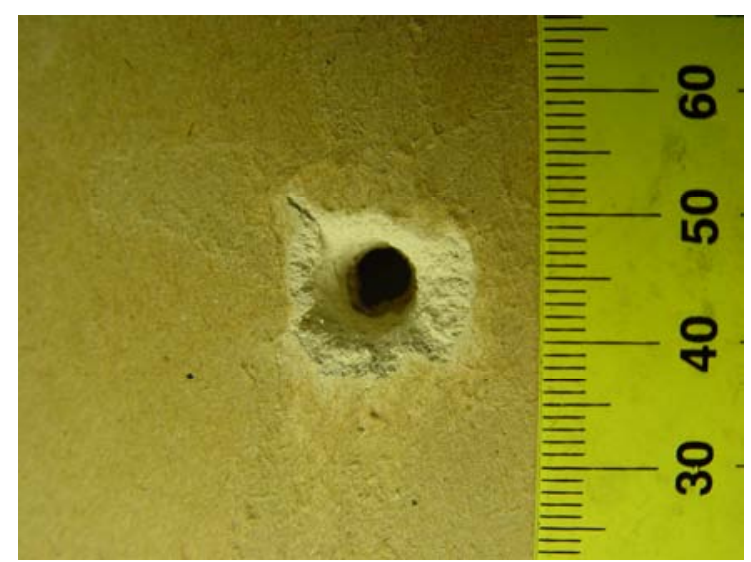

Photo 20: Einschusstrichter s-206

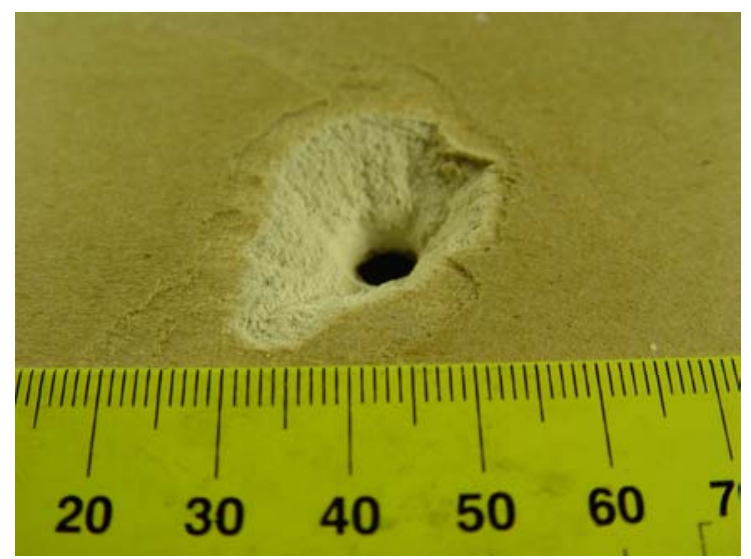

Photo 21: Einschusstrichter s-207

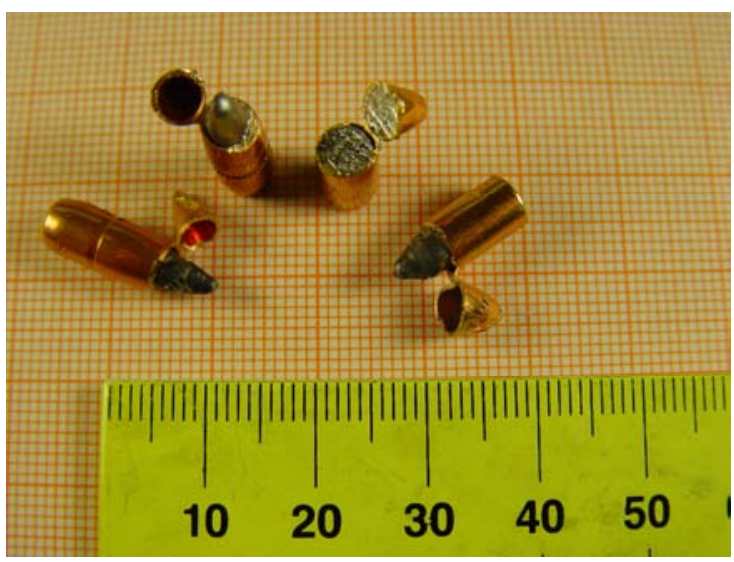

Photo 22: VMJ 3,56 g und VMJ 3,0 $\mathrm{g}$ 


\subsection{Das ballistische Pendel}

Die mathematisch-physikalischen Grundlagen des ballistischen Pendels wurden erörtert und zur Berechnung unter idealisierten Bedingungen bei Vernachlässigung von unvermeidbaren Reibungsverlusten die folgende Überlegung angestellt:

$\mathrm{Da}$ auf das ballistische Pendel auftreffende Geschosse, beziehungsweise Geschossreste, dieses nicht wieder verlassen, sondern stets darin stecken bleiben, findet eine vollständige Impulsübertragung statt. Somit liegt ein unelastischer Stoß vor, für welchen der Impulserhaltungssatz gilt:

$$
\mathrm{m}_{1} \times \mathrm{v}_{1}+\mathrm{m}_{2} \times \mathrm{v}_{2}=\left(\mathrm{m}_{1}+\mathrm{m}_{2}\right) \times \mathrm{v}^{*}
$$

$\mathrm{m}_{1}=$ Geschossmasse $[\mathrm{kg}]$

$\mathrm{v}_{1}=$ Geschossaufprallgeschwindigkeit $[\mathrm{m} / \mathrm{s}]$

$\mathrm{m}_{2}=$ Pendelmasse $[\mathrm{kg}]$

$\mathrm{v}_{2}=$ Pendelgeschwindigkeit $[\mathrm{m} / \mathrm{s}]$

$\mathrm{v}^{*}=$ Ausschlagsgeschwindigkeit des Pendels nach Stoß

Da die Geschwindigkeit des Pendels vor dem Schuss $0[\mathrm{~m} / \mathrm{s}]$ beträgt, erhält man durch Einsetzen und Umformen

$$
\mathrm{v}_{1}=\frac{\left(\mathrm{m}_{1}+\mathrm{m}_{2}\right)}{\mathrm{m}_{1}} \times \mathrm{v}^{*}
$$

Um die gesuchte Geschossgeschwindigkeit $v_{1}$ ermitteln zu können, muss zunächst die Ausschlagsgeschwindigkeit des Pendels $v^{*}$ bestimmt werden. Diese ist mit der uns zur Verfügung stehenden Versuchsanordnung nicht direkt messbar. Sie ist aber mittels der Höhe $\mathrm{h}$ des Pendels bei Maximalauslenkung zu errechnen. 


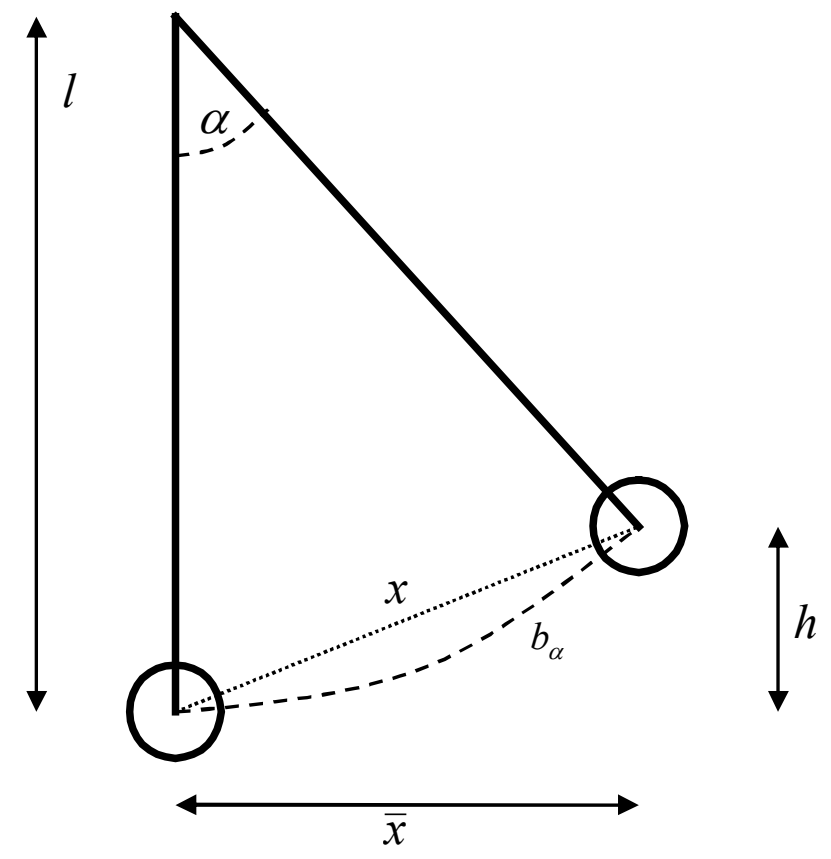

Skizze 7.4.: Ballistisches Pendel

Für kleine Winkel $\alpha\left(\alpha<5^{\circ}\right)$ darf man die gekrümmte Bahn $b_{\alpha}$ als geradlinig betrachten und $b_{\alpha} \approx x \approx \bar{x}$ setzen.

Für die Pendelschwingung gilt der Energieerhaltungssatz:

$$
\frac{\left(\mathrm{m}_{1}+\mathrm{m}_{2}\right)}{2} \times \mathrm{v} * 2=\left(\mathrm{m}_{1}+\mathrm{m}_{2}\right) \times g \times h
$$

$g=$ Erdbeschleunigung $\left(=9,81[\mathrm{~m} / \mathrm{s}]^{2}\right)$

$h=$ Anhebung des Pendel-Geschoss-Systems bei maximalem Pendelausschlag [m]

Durch Umformung erhält man:

$$
\mathrm{v}^{*}=\sqrt{2 \times g \times h}
$$


wobei sich $h$ wiederum als Funktion des gemessenen Pendelausschlages formulieren lässt. Unter Anwendung des Höhensatzes folgt für $h$ und $\bar{x}$ :

$$
\bar{x}^{2}=h \times(2 \times l-h)
$$

oder, da $h$ gegen die Pendellänge $l$ und den Ausschlag $\bar{x}$ sehr klein ist:

$$
\bar{x}^{2}=2 \times l \times h=\frac{2 \times l \times v^{*^{2}}}{2 \times g}
$$

Daraus folgt für die Geschwindigkeit $v^{*}$ :

$$
v^{*}=\bar{x} \times \sqrt{\frac{g}{l}}
$$

$v^{*}$ ist somit mit (7) durch die Messung von $\bar{x}$ und $l$ zu bestimmen. Diese Formel bezieht sich jedoch auf die Bedingungen des mathematischen Pendels. In den Versuchen wurde ein physikalisches Pendel eingesetzt. Es sind die dafür gültigen Formeln anzuwenden. Beim physikalischen Pendel tritt an die Stelle von $l$ die reduzierte Pendellänge $l^{*}=\frac{\Theta_{0}}{\mathrm{~m} \times l_{s}}$

Dabei bezeichnet $\Theta_{0}$ das für die Drehachse 0 geltende Trägheitsmoment und $l_{s}$ den Abstand des Schwingungsmittelpunktes von 0.

$l^{*}$ beschreibt den Abstand des Schwingungsmittelpunktes vom Drehpunkt. Im Schwingungsmittelpunkt kann man die Masse des Pendels $m$ vereinigen, ohne die Schwingungsdauer $T$ zu verändern.

Die Bestimmung von $l^{*}$ ist ohne Kenntnis von $\Theta_{0}$ und $l_{s}$ möglich und erfolgt über den Ansatz

$$
T=2 \times \pi \times \sqrt{\frac{l^{*}}{g}}
$$

Durch eine Umformung gelangt man zu:

$$
l^{*}=\frac{T^{2} \times g}{4 \times \pi^{2}}
$$

Für die Versuchsanordnung wurde $T$ mit 1,9352 s (s.u.) bestimmt, woraus sich eine reduzierte Pendellänge $l^{*}$ von 0,93 m ergibt. 
Durch Einsetzen in (7) und Umformen ergibt sich:

$$
v^{*}=\frac{2 \times \pi}{T} \times \bar{x}
$$

Da sich bei dem verwendeten Pendel die gesamte Pendelmasse unterhalb der Drehachse befindet, fallen Schwerpunkt und Schwingungsmittelpunkt praktisch zusammen. Deshalb ist $v^{*}$ und nachfolgend $v_{l}$ aus der Messung von $\bar{x}$ zu bestimmen. In den Experimenten wurde die Auslenkung $x$ bezogen auf eine Pendellänge von $1,37 \mathrm{~m}$ gemessen. Um zu den für die Geschwindigkeitsbestimmung relevanten Auslenkungen $\bar{x}$ zu gelangen, müssen die gemessenen $x$-Werte mit Hilfe von (9) bezogen auf die reduzierte Pendellänge $l^{*}$ umgerechnet werden:

$$
\bar{x}=\frac{l^{*}}{l} \times x=0,68 \times x
$$

Zur Berechnung der Auftreffgeschwindigkeit $v_{1}$ des Geschosses ist (10) in (2) einzusetzen, wodurch man zu:

$$
v_{1}=\frac{\mathrm{m}_{1}+\mathrm{m}_{2}}{\mathrm{~m}_{1}} \times \frac{2 \cdot \pi}{T} \times \bar{x}
$$

gelangt, womit eine Berechnung von $v_{1}$ mit Hilfe der bekannten Größen: Geschossmasse (0,00298 kg), Pendelmasse (37,3 kg), Schwingungsdauer (1,9352 s) und Ausschlag des Pendels möglich ist, in der Realität auftretende Reibungskräfte jedoch nicht berücksichtigt werden.

In der folgenden Tabelle sind die Schwingungsdauern des Pendels in Sekunden festgehalten. Die Zeit für 25 Vollschwingungen wurde fünfmal mit einer Stoppuhr ermittelt und ergab die zur weiteren Auswertung gemittelte Schwingungsdauer T von $1,935 \mathrm{~s}$.

Die Pendelmasse betrug 37,3 kg. Der Auszugswiderstand des Fadenreiters zur Messung des Pendelausschlages betrug 0,4 $\mathrm{N} \pm 0,1 \mathrm{~N}$.

\begin{tabular}{|c|c|c|}
\hline \multicolumn{2}{|c|}{ Schwingungsdauer [s] } & \multirow{2}{*}{$\begin{array}{c}\text { Mittelwert u. } \\
\text { Standardabweichung einer } \\
\text { Vollschwingung T [s] }\end{array}$} \\
\hline 25 Vollschwingungen ( $\boldsymbol{t})$ & 1 Vollschwingung (t/25) & \\
\hline 48,40 & 1,936 & $\bar{x}=1,935$ \\
\hline 48,39 & 1,936 & $\mathrm{~s}_{\mathrm{x}}=0,002$ \\
\hline 48,43 & 1,937 & \\
\hline 48,37 & 1,935 & \\
\hline
\end{tabular}

Tab.7.4.: Vollschwingung des ballistischen Pendels 


\subsection{Maximale Rückstoßberechnung}

Das Impulserhaltungsgesetz besagt, dass jede „Actio“ eine gleich starke „Reactio“ bewirkt. Bei der Schussabgabe wird eine Masse (Geschoss und Pulver) beschleunigt, die Reaktion ist die Rückwärtsbewegung der Waffe (der Rückstoß).

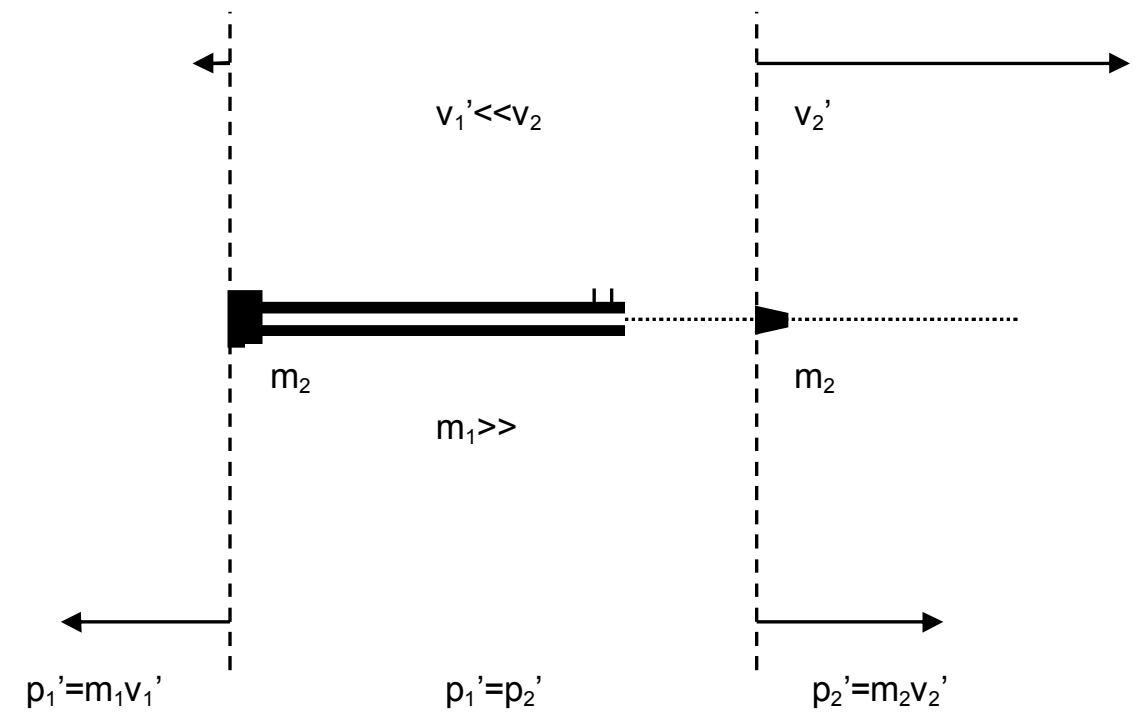

Skizze 7.5.: Rückstoß

Der Impuls $(p)$ ist das Produkt aus Masse mal Geschwindigkeit ist ( $p=m \times v)$. Der Rückstoßimpuls setzt sich aber aus 3 Anteilen zusammen:

1) Geschossimpuls (siehe Skizze 7.5.)

2) Impuls der Pulvergase

3) Nachwirkungsimpuls 


\subsubsection{Geschossimpuls}

Bei bekannter Geschossmasse und Mündungsgeschwindigkeit ist der Geschossimpuls einfach zu berechnen:

$p_{g}=m_{g} \times v_{0}$

(Geschossimpuls [Ns] = Geschossmasse [kg] mal Mündungsgeschwindigkeit [m/s])

Geschossmasse Solid $=0,00292 \mathrm{~kg}$

Mündungsgeschwindigkeit $1575 \mathrm{~m} / \mathrm{s}$

Geschossimpuls: 4,599 Ns

\subsubsection{Impuls der Pulvergase}

Bei der Schussabgabe wird nicht nur das Geschoss beschleunigt, sondern auch die Pulvergase. Die Masse der Pulvergase entspricht der Pulvermasse. Die am Geschossheck befindlichen Gase bewegen sich mit der gleichen Geschwindigkeit wie das Geschoss $\left(v_{0}\right)$, die Gase am Hülsenboden sind in Ruhe. Die Gassäule wird sich also insgesamt betrachtet halb so schnell bewegen wie das Geschoss:

$p_{p}=m_{p} \times\left(1 / 2 v_{0}\right)$

(Impuls der Pulvergase $[\mathrm{Nd}]=$ Pulvermasse $\left[\mathrm{m}_{p}\right]$ mal $1 / 2$ Geschossgeschwindigkeit $[\mathrm{m} / \mathrm{s}])$

Pulvermasse: $0,00166 \mathrm{~kg}$

Geschossgeschwindigkeit 1575 m/s

Impuls der Pulvergase: 1,307 Ns

Die Summe aus dem Geschossimpuls $\left(p_{g}\right)$ und dem Impuls der Pulvergase $\left(p_{p}\right)$ wird als Mündungsimpuls $\left(p_{M}\right)$ bezeichnet:

$p_{M}=p_{g}+p_{p}$

Geschossimpuls: 4,599 Ns

Impuls der Pulvergase: 1,307 Ns

Mündungsimpuls: $5,906 \mathrm{Ns}$

Der Impuls der Pulvergase $(1,307 \mathrm{Ns})$ trägt relativ wenig $(22,1 \%)$ zum gesamten Mündungsimpuls bei. 


\subsubsection{Nachwirkungsimpuls}

Wenn das Geschoss den Lauf verlassen hat, stehen die Pulvergase noch unter hohem Druck. Dieser Druck ist abhängig von der Abbrenngeschwindigkeit des Pulvers und der Lauflänge. Wenn die Laufmündung das Geschoss freigibt, strömen die Pulvergase aus und werden gleichzeitig stark beschleunigt. Der Impuls der nach dem Geschossaustritt expandierenden Gase heißt Nachwirkungsimpuls $\left(p_{N}\right)$. Dieser Impuls (Raketeneffekt) bewirkt ebenfalls einen Rückstoß. Der Nachwirkungsimpuls berechnet sich wie folgt:

$p_{N}=m_{p} \times v_{a}$

(Nachwirkungsimpuls $[\mathrm{Ns}]=$ Pulvermasse $[\mathrm{kg}]$ mal Ausströmgeschwindigkeit $[\mathrm{m} / \mathrm{s}]$ )

Die Ausströmgeschwindigkeit zu berechnen erfordert Daten über das Lauf- und Hülsenvolumen und den Mündungsdruck (welcher von uns nicht zu ermitteln war). Für die Rückstoßberechnung reicht eine grobe Schätzung:

Pulvermasse: $0,00166 \mathrm{~kg}$

Ausströmgeschwindigkeit: $900 \mathrm{~m} / \mathrm{s}$

Nachwirkungsimpuls: 1,494 Ns

\subsubsection{Rückstoßimpuls}

Der Rückstoßimpuls setzt sich aus dem Mündungsimpuls (Geschossimpuls + Impuls der Pulvergase) und dem Nachwirkungsimpuls zusammen:

$p_{R}=p_{M}+p_{N}$

(Rückstoßimpuls [Ns] = Mündungsimpuls [Ns] plus Nachwirkungsimpuls [Ns])

Geschoss: Solid 2,916 g

Mündungsimpuls: $5,906 \mathrm{Ns}$

Nachwirkungsimpuls: $1,494 \mathrm{Ns}$

Rückstoßimpuls: 7,40 Ns

Der Nachwirkungsimpuls trägt zu 20,2 \% zum gesamten Rückstoßimpuls bei, weil der verwendete Lauf über keine Mündungsbremse verfügte. 
7.5.5. Rücklaufgeschwindigkeit und Rückstoßenergie

Was sagt dieser Wert nun aus? Anhand des Rückstoßimpulses kann berechnet werden, wie schnell die Waffe mit der Masse 3,4 kg zurücklaufen würde, wenn sie frei und reibungsarm gelagert wäre:

$v_{R}=p_{R} / m_{W}$

(Rücklaufgeschwindigkeit [m/s] = Rückstoßimpuls [Ns] geteilt durch Masse der Waffe $[\mathrm{kg}])$

Rückstoßimpuls: $7,40 \mathrm{Ns}$

Masse der Waffe: $3,4 \mathrm{~kg}$

Rücklaufgeschwindigkeit: 7,4 Ns / 3,4 kg =2,18 m/s

Die von der Waffenhalterung maximal aufzunehmende Rückstoßenergie des Gewehres beim Beschuss mit Munition der Laborierung 223.solid war demnach:

$E_{R}=1 / 2 p_{R}^{2} / m_{W}$

(Rückstoßenergie [J] = 1/2 Quadrat des Rückstoßimpulses [Ns] geteilt durch die Waffenmasse [kg])

Geschossmasse: 0,00292 kg

Mündungsgeschwindigkeit: $1575 \mathrm{~m} / \mathrm{s}$

Waffengewicht: $3,4 \mathrm{~kg}$

Rückstoßimpuls $p_{R}=7,40 \mathrm{Ns}$

Rückstoßenergie $\mathrm{E}_{\mathrm{R}}:$ 8.05J

Im Vergleich zur Geschossenergie (223.solid: $3622 \mathrm{~J}$ ) ist die Rückstoßenergie vergleichsweise gering und von der Waffenhalterung leicht aufzunehmen. 


\subsection{Lichtreflexion an Grenzflächen (Gasblasen)}

Gasblasen in Wasser erscheinen im Durchlicht dunkler als die umgebende Flüssigkeit. Die offensichtliche Ablenkung der Lichtstrahlen begründet sich in der unterschiedlichen Ausbreitungsgeschwindigkeit von Licht in Luft und Wasser.

Dabei wird das Verhalten der elektromagnetischen Welle durch die rapide Änderung der optischen Dichte $\rho$ und Absorption $\beta$ bzw. des Brechungsindex $n$ an Grenzflächen beeinflusst. Dabei ist die optische Dichte die Eigenschaft lichtdurchlässiger Stoffe, eine spezifische Lichtgeschwindigkeit zuzulassen. Der Brechungsindex $n$ ist als ein dimensionsloses Maß jedem Stoff zugeordnet und steht mit der Lichtgeschwindigkeit c $(n)$ in dem Stoff in folgendem Zusammenhang:

$c(n)=c_{0} / n$

(Lichtgeschwindigkeit in dem Stoff [m/s] = Lichtgeschwindigkeit im Vakuum [m/s] geteilt durch Brechungsindex)

Die Lichtgeschwindigkeit in Vakuum (Brechungsindex $=1$ ) beträgt $\mathrm{c}_{0}=2,9799 \times 10^{8} \mathrm{~m} / \mathrm{s}$ und ist in Luft (Brechungsindex $=1,00027$ ) und Wasser (Brechungsindex $=1,33$ ) entsprechend geringer.

Wenn elektromagnetische Wellen die Grenzflächen zweier Stoffe mit unterschiedlichen Brechungsindexen passieren, ändert sich ihre Richtung. Die Richtungsänderung wird durch das Snelliussche Brechungsgesetz beschrieben:

$n_{1} \times \sin \left(\theta_{1}\right)=n_{2} \times \sin \left(\theta_{2}\right)$

(mit den Lotwinkeln $\Theta_{i}$ in den Medien $i=1,2$ und deren Brechungsindexen $n_{1}, n_{2}$ )

Lichtstrahlen werden demzufolge beim Übertritt ins optisch weniger dichte Medium vom Lot weggebrochen (u.a. an Gasblasen in Wasser). Ab einem Grenzwinkel findet keine Brechung mehr statt, der Lichtstrahl wird als Totalreflexion in das optisch dichtere Medium zurückgeworfen. Ohnehin wird bei jeder Brechung stets ein kleiner Anteil der Lichtleistung reflektiert, was man als Teilreflexion bezeichnet.

Gasblasen im Zielmedium führen zu Brechung, Teilreflexion und Totalreflexion von Lichtstrahlen. Im Durchlicht erscheinen die Blasen demnach dunkler (Versuchsaufbau), im Auflicht heller als das Zielmedium. 


\subsection{Datenblatt der Laborierung 223.5}

Kommentar

PATRONE / KALIBER

Maximal zulässiger Gasdruck

Zugkaliber

Hülsenvolumen randvoll

Hülsenlänge L3

Patronenlänge L6

Anfangsgasdruck

\section{TREIBLADUNG}

Pulversorte

Ladungsmasse

Spezif. Explosionswärme Qex

Abbrandkoeffizient $\mathrm{Ba}$

sind gültig bis Grenze Z1

Abbrandkoeffizient b
Pulverdichte

Laborierung 223.5

\begin{tabular}{lll}
.223 Rem. & \multicolumn{2}{c}{ GESCHOSSTYP } \\
$4300 \mathrm{bar}$ & $62366 \mathrm{psi}$. (Piezo CIP) \\
$5,69 \mathrm{~mm}$ & $0,224 \mathrm{in}$. & Geschossmasse \\
$2,006 \mathrm{~cm}^{3}$ & $30,9 \mathrm{gr}$. H2O & Geschosslänge \\
$44,68 \mathrm{~mm}$ & $1,759 \mathrm{in}$. & Geschosseinsetztiefe \\
$53,5 \mathrm{~mm}$ & $2,106 \mathrm{in}$. & Gesamtlauflänge \\
$250,0 \mathrm{bar}$ & $3626 \mathrm{psi}$ & Wirksamer Querschnitt
\end{tabular}

Vihtavuori N120

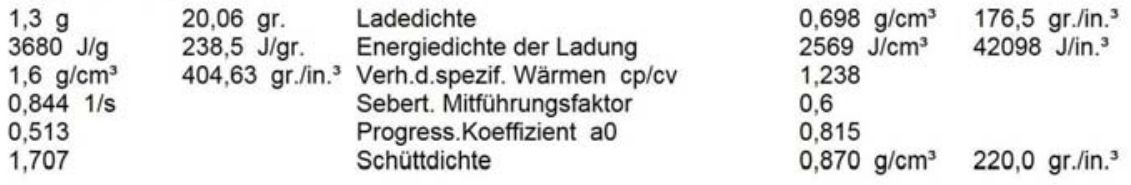

Berechnet / abgeschätzt wurde:

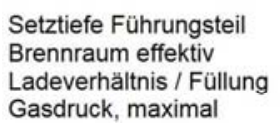

$5,66 \mathrm{~mm}$

$1,862 \mathrm{~cm}^{3}$

$80.2 \%$

0,223 in.

0,1136 in. $^{3}$

Verdrängtes Volumen

Geschossweg gesamt

2435 bar

35313 psi.

Vor Start umgesetzte Ladung

Geschossweg bei Pmax

Werte bei Mündungsdurchgang:

Geschossgeschwindigkeit

Geschossenergie

$937,7 \mathrm{~m} / \mathrm{s}$

$1319 \mathrm{~J}$

$99,8 \%$
3076 fps.
973 ft.lbs.

Mündungsgasdruck
Geschossdurchlaufzeit ca.
Thermischer Wirkungsgrad
$.224,46$, RWS VMS

mit Flachboden,

$3,0 \mathrm{~g} \mathrm{~m} \quad 46,3 \mathrm{gr}$.

$5,66 \mathrm{~mm}$

$609,6 \mathrm{~mm} \quad 24,0 \mathrm{in}$

$0,2503 \mathrm{~cm}^{2} \quad 0,0388$ in. $^{2}$

Prüfe in Ladetafeln die empfohlene Minimalladung zur Vermeidung von Anzündproblemen und den daraus resultierenden Gefahren ! Der Gasdruck durchläuft ein echtes Maximum.

Die Verbrennung ist unvollständig. Brennschluss nach Mündungsdurchgang des Geschossbodens.

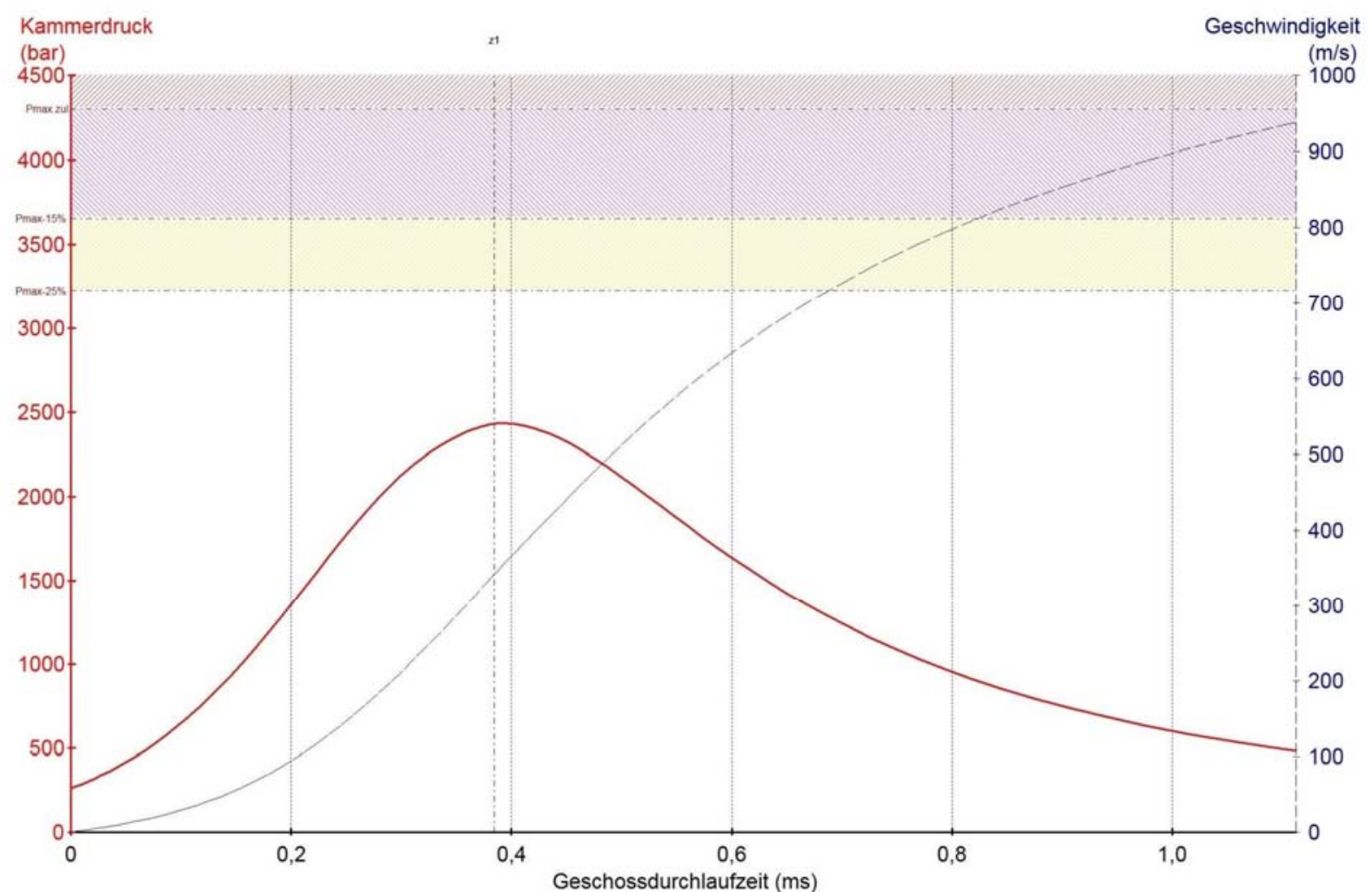




\subsection{Historische Entwicklung der Kaliber}

Das typische Kleinkaliber .22 long rifle wurde 1887 von dem Amerikaner Joshua Stevens entwickelt (PAREY 2000). Seit 1857 hatten H. Smith und D.N. Wesson die .22 short für ihren Taschenrevolver produziert. 1871 erschien auf dem amerikanischen Markt die .22 long mit längerer Hülse und bereits 1880 das Kaliber .22 extra long mit einem 0,648 g schwereren Bleigeschoss. Stevens kombinierte die Hülse der .22 long mit dem Geschoss der .22 extra long. Erfolgreich wurde diese Kombination erst mit der Entwicklung der rauchschwachen Nitro-Pulver. Der problemlose Wechsel zum raucharmen Treibmittel bei gesteigerter Leistung dieses Kalibers war Grundlage für seine weite Verbreitung um die Wende zum 20. Jahrhundert.

Mit gleichem Geschossdurchmesser wurden Jahrzehnte später neue Kaliber entwickelt. Nachdem die .222 im Frühjahr 1950 von Remington (insbesondere ChefKonstrukteur Mike Walker) herausgebracht worden war, verbreitete sie sich seit 1953 auch in Europa schnell als spezielle Jagdpatrone. Sie war völlig neu konstruiert worden. Nur der Geschossdurchmesser von 5,69 mm (.224 Zoll) war von den bereits vorhandenen .22 Zoll-Patronen (.22 Hornet, .218 Bee, .219 Zipper und .220 Swift) übernommen worden. Zudem gilt eine gewisse maßstäbliche Verkleinerung der legendären .30-06 Springfield als unbestritten übernommen. Die meisten Werksladungen sind mit 3,2 Gramm Geschossen versehen. Benchrest-Schützen gebrauchen dieses Kaliber heute ebenso gerne wie Jäger für die Schonzeit und für Rehwild.

Für den zivilen Markt haben Gewehre des Kalibers .222 Rem eine Drallänge von $0,356 \mathrm{~m}$ (14-Zoll).

Eugen Stoner und Robert Hutton entwickelten 1957 eine Experimentalpatrone mit Flaschenhals auf Basis der .222 Rem für das damals neue Sturmgewehr Armalite AR 15. Das Gewehr sollte preisgünstigere und leichtere und somit logistisch besser zu handhabende Kleinpatronen verschießen können; das Geschoss (Durchmesser .224 Zoll) sollte außerdem eine Mündungsgeschwindigkeit von $1000 \mathrm{~m} / \mathrm{s}$ überschreiten (PEREY und TIGGES 1997, PAREY 2000). 1964 wurde sie dann von der US-Armee als „5,56 mm Ball Cartridge M193“ eingeführt. Remington brachte in demselben Jahr die Version für die Jagd unter dem zivilen Namen „.223 Remington“ auf den Markt. Mit dem AR15/M16 von Colt wurden zu Beginn der 60er Jahre in dem Vietnamkrieg erstmals Gefechte geführt. Durch Unterstabilisierung der Geschosse infolge zu langen Dralls kamen diese häufig taumelnd und sich überschlagend im Ziel an und führten zu unerklärlichen Verletzungen (CAREY et al. 1982). Anfang der 1970er Jahre wurde die amerikanische Bevölkerung auf die Schwächen des AR15/M16 in Kombination mit der 5,56 mm Ball Cartridge M193 aufmerksam: nach Pannen und Prozessen hatten die Colt-Werke aus Connecticut zwischen 1963 und 1967 bereits über 150 Nachbesserungen an der Waffe vornehmen müssen.

Bei Laien halten sich bis heute Gerüchte über die „Vietnam-Killerpatrone“, die auch bei Streifschüssen oder Treffern in die distalen Extremitäten tödlich wirke. Einige Jahre lang wurden unterschiedliche Parameter der Patrone (Pulver, Setztiefe, Geschossgewicht) und die Drallänge immer wieder verändert, um mehr Drallstabilität zu erreichen. 1980 übernahmen die Nato-Staaten die Patrone als 5,56 x $45 \mathrm{~mm}$ Nato. Mit ihren 12 Gramm war sie insgesamt nur halb so schwer wie die bis dahin verbreitete $7,62 \times 51 \mathrm{~mm}$. 
Zunächst noch mit dem 3,56 Gramm schweren Spitzer-Geschoss (.224 Zoll) mit der Bezeichnung „M193“ versehen, erreichte sie 1984 die geforderte höhere Flugstabilität. Das belgische SS 109-Geschoss (.224 Zoll) von 4 Gramm Gewicht nutzt eine abermals verkürzte Drallänge (DEVETH 1982) und findet mit seinem Stahlkern nun auch bei der US-Armee als „M855“ Verwendung.

OLIVER und WHITTY (1988) bestätigten dem „SS109“ eine höhere Stabilität und spätere Energieabgabe im Vergleich zum „M193“.

Die verbreiteten Drallängen der Militärgewehre reduzierten sich mit den Jahren von ursprünglich 14-Zoll $(0,356 \mathrm{~m})$ über 12-Zoll $(0,305 \mathrm{~m})$ und 10-Zoll $(0,254 \mathrm{~m})$ auf heute zum Teil nur 7-Zoll $(0,178 \mathrm{~m}$, G36 Heckler\&Koch).

Für den zivilen Markt haben Gewehre des Kalibers .223 Rem eine Drallänge von 0,305 m (12-Zoll). 


\section{Literaturverzeichnis}

ADAMS DB (1982): Wound ballistics: a review. Mil Med 147, 831-835

AEBI F, BRÖNNIMANN E, MAYOR J (1977): Some observations on the behaviour of small calibre projectiles in soap targets. Acta Chir Scand Suppl $\underline{477}, 49-57$

ALBREHT M, SCEPANOVIC D, CERAMILAC A, MILIVOJEVIC V, BERGER S, TASIC G, TATIC V, TODORIC M, POPOVIC D, NANUSEVIC N (1979): Experimental soft tissue wounds caused by standard military rifles. Acta Chir Scand Suppl $\underline{489}$, 185-98

ALLEN IV, SCOTT R, TANNER JA (1982): Experimental high-velocity missile head injury. Injury $\underline{14}, 183-193$

ALMSKOG B, RISBERG B, TEGER-NILSSON AC, SEEMAN T (1982): Early local and systemic fibrinolytic response to high energy missile trauma. Acta Chir Scand Suppl $\underline{508}$, 327-336

AMATO JJ, RICH NM (1972): Temporary cavity effects in blood vessel injury by high velocity missiles. J Cardiovasc Surg $\underline{13}, 147-155$

AMATO JJ, BILLY LJ, GRUBER RP, LAWSON NS, RICH NM (1971 a): Vascular injuries: an experimental study of high and low velocity missile wounds. Arch Surg 101, 167-174

AMATO JJ, RICH NM, BILLY LJ, GRUBER RP, LAWSON NS (1971 b): Highvelocity arterial injury: a study of mechanism of injury. J Trauma $\underline{11}, 412-416$

AMATO JJ, BILLY LJ, LAWSON NS, RICH NM (1974): High-velocity missile injury: an experimental study of the retentive forces of tissue. Am J Surg $\underline{127}$, 454-459

ATESALP AS, YILDIZ C, BASBOZKURT M, GÜR E (2002): Treatment of type IIla open fractures with Ilzarov fixation and delayed primary closure in highvelocity gunshot wounds. Mil Med $\underline{167}, 56-62$

BAKER AM, KELLER G, GARCIA D (2001): A novel hunting accident: discharge of a firearm by a hunting dog. Am J Forensic Med Pathol 22, 285287

BARACH E, TOMLANOVICH M, NOWAK R (1986 a): A pathophysiologic examination of the wounding mechanisms of firearms: Part I. J Trauma $\underline{26}$, 225-235

BARACH E, TOMLANOVICH M, NOWAK R (1986 b): A pathophysiologic examination of the wounding mechanisms of firearms: Part II. J Trauma $\underline{26}$, 374-383 
BARTLETT CS, HELFET DL, HAUSMAN MR, STRAUSS E (2000): Ballistics and gunshot wounds: effects on musculoskeletal tissues. J Am Acad Orthop Surg $\underline{8}, 21-36$

BELKIN M (1978): Wound ballistics. Prog Surg 16, 7-24

BERG S, KIJEWSKI H (1982): Vermeintliche und wirkliche Nahschußzeichen am Knocheneinschußloch des Schädels. Z Rechtsmed 요, 103-111

BERG SO: Supersonic gun shot wounds, Vortrag auf: $9^{\text {th }}$ Congress of the international academy of legal medicine and social medicine, Rome, 23.-28. September 1973

BERLIN R (1979): Energy transfer and regional blood flow changes following missile trauma. J Trauma $\underline{19}$, 170-176

BERLIN R, GELIN L, JANZON B, LEWIS DH, RYBECK B, SANDEGARD J, SEEMAN T (1976): Local effects of assault rifle bullets in live tissues. Acta Chir Scand Suppl $\underline{459}, 1-76$

BERLIN R, JANZON B, RYBECK B, SANDEGARD J, SEEMAN T (1977): Local effects of assault rifle bullets in live tissues part II, Further studies in live tissues and relations to some simulant media. Acta Chir Scand Suppl $\underline{477}$, 1-48

BERLIN R, JANZON B, RYBECK B, SEEMAN T (1979): Retardation of spherical missiles in live tissue. Acta Chir Scand Suppl $\underline{489}, 91-100$

BERLIN R, JANZON B, RYBECK B, SCHANTZ B, SEEMAN T (1982): A proposed standard methodology for estimating the wounding capacity of small calibre projectiles or other missiles. Acta Chir Scand Suppl $\underline{508}, 11-28$

BERLIN R, JANZON B, LIDEN E, NORDSTRÖM G, SCHANTZ B, SEEMAN T, WESTLING $F(1988$ a): Terminal behaviour of deforming bullets. J Trauma Suppl $\underline{28}, 58-62$

BERLIN R, JANZON B, LIDEN E, NORDSTRÖM G, SCHANTZ B, SEEMAN T, WESTLING F (1988 b): Wound ballistics of Swedish 5.56-mm assault rifle AK 5. J Trauma Suppl 21, 75-83

BLAKE JR, PEARSON A, OTTO SR (2001): Boundary integral methods for cavitation bubbles near boundaries. Cavitation 2001 4, 1-8

BOWYER G (1995): Afghan war wounded: application of the red cross wound classification. J Trauma $\underline{38}, 64-67$

BRÜMMER F, BRÄUNER T, HÜLSER D (1990): Biological effects of shock waves. World J Urol $\underline{8}, 224 f f$

CANNON L (2001): Behind armour blunt trauma - an emerging problem. J Army Med Corps 147, 87-96 
CAREY M, SACCO W, MERKLER J (1982): An analysis of fatal and non-fatal head wounds incurred during combat in Vietnam by U.S. forces. Acta Chir Scand Suppl $\underline{508}, 351-356$

CAREY M, HERZ M, CORNER B, MCENTIRE J, MALABARBA D, PAQUETTE S, SAMPSON J (2000): Ballistic helmets and aspects of their design. Neurosurgery $\underline{47}, 678-689$

CARUSO RP, JARA DI, SWAN KG (1999): Gunshot wounds: bullet caliber is increasing. J Trauma $\underline{46}, 462-465$

CHARTERS AC III, CHARTERS AC (1976): Wounding mechanism of very high-velocity projectils. J Trauma $\underline{16}, 464-470$

CHENG XY, FENG TS, LIU YQ, MA YY, WU BJ, FU RX, XIE GP, LI M, CHEN ZC, WANG DT, XU GW (1988): Wounding properties of steel pellets with different velocities and quality on soft tissue of dogs. J Trauma Suppl $\underline{28}$, 33-36

CIBA-GEIGY: Wissenschaftliche Tabellen Geigy, 8. Auflage, Basel 1979

CLASPER $J$ (2001): The interaction of projectiles with tissues and the management of ballistic fractures. J R Army Med Corps 147, 52-61

CLEMEDSON CJ, FALCONER B, FRANKENBERG L, JÖNSSON A, WENNERSTRAND J (1973): Head injuries caused by small-calibre, high velocity bullets, an experimental study. Z Rechtsmed $\underline{73}$, 103-114

COLE RH: Underwater explosions; Princeton University Press, Princeton (New Jersey) 1948

COLLINS PS, GOLOCOVSKY M, SALANDER JM, CHAMPION H, RICH, NM (1988): Intra-abdominal vascular injury secondary to penetrating trauma. J Trauma Suppl $\underline{28}, 165-197$

COOPER GJ, RYAN JM (1990): Interaction of penetrating missiles with tissues: some common misapprehensions and implications for wound management. $\mathrm{Br}$ J Surg $\underline{77}, 606-610$

COUPLAND R (1999): Clinical and legal significance of fragmentation of bullets in relation to size of wounds: retrospective analysis. BMJ $\underline{319}, 403-406$

COUPLAND RM, KNEUBUEHL BP, ROWLEY DI, BOWYER GW (2000): Wound ballistics, surgery and the law of war. Trauma 2, 1-10

DAHLGREN B, BERLIN R, JANZON B, NORDSTRÖM G, NYLÖF U, RYBECK B, SCHANTZ B, SEEMAN T (1979): The extent of muscle tissue damage following missile trauma one, six and twelve hours after the infliction of trauma, studied by the current method of debridement. Acta Chir Scand Suppl $\underline{489}$, 137-144

DAHLGREN B, ALMSKOG B, BERLIN R, NORDSTRÖM G, RYBECK B, SCHANTZ B, SEEMAN T (1982): Local effect of antibacterial therapy (benzyl- 
penicillin) on missile wound infection rate and tissue devitalization when debridement is delayed for twelve hours. Acta Chir Scand Suppl 508, 271-279

DAMM R (Münster): persönliche Mitteilung vom 15.04.2002

DAWSON SL, HIRSCH CS, LUCAS FV, SEBEK BA (1980): The contrecoup phenomenon. Hum Pathol 11/2, 155-166

DE HALLER P (1933): Untersuchungen über die durch Kavitation hervorgerufenen Korrosionen. Schweiz Bauzeit 101, 243-246.

DEMUTH WE JR (1966): Bullet velocity and design as determinants of wounding capability: an experimental study. J Trauma $\underline{6}$, 222-232

DEMUTH WE JR (1969): Bullet velocity as applied to military rifle wounding capacity. J Trauma $\underline{9}$, 27-38

DEMUTH WE JR, SMITH JM (1966): High-velocity bullet wounds of muscle and bone: the basis of rational early treatment. J Trauma $\underline{6}, 744-755$

DEMUTH WE JR, NICHOLAS GG, MUNGER BL (1976): Buckshot wounds. J Trauma 18, 53-57

DEVA*: Wiederladen: Vorbereitung und Praxis. 3. Auflage; o. Verf.; NimrodVerlag, Suderburg 1995 ( ${ }^{*}$ Deutsche Versuchs- und Prüfanstalt für Jagd- und Sportwaffen e.V.)

DEVETH C (1982): Development of the new second NATO calibre: The "5.56" with the SS 109 projectile. Acta Chir Scand Suppl $\underline{508}, 129-134$

DIDENKO YT, SUSLICK KD (2002): The energy efficiency of formation of photons, radicals and ions during single-bubble cavitation. Nature $\underline{418}, 394-397$

DIMOND FC JR, RICH NM (1967): M-16 rifle wounds in Vietnam. J Trauma $\underline{7}$, 619-625

DOTZAUER G (1979): Verletzungen durch Hochgeschwindigkeitsgeschosse. Hefte Unfallheilkd $\underline{138}, 85-90$

DREYE JC, SCHUSTER G (1953): Shotgun wounds. Am J Surg 7ㅁ, 438-443

DÜSEL W, LIEBER S, LENZ S; DOLL D (2005): Penetrierendes Bauchtrauma aus der Sicht der Bundeswehr. Chirurg 76, 935-944

DYNAMIT NOBEL: Wiederladen. 8. ergänzte Auflage; o. Verf.; Dynamit Nobel Aktiengesellschaft, Troisdorf 1998

EISENMENGER W, WILSKE J, STIEFEL D (1989): Short-stop-munition. Z Rechtsmed $\underline{103}, 137-145$ 
ENDL E, STEINBACH P, HOFSTADTER F (1995): Flow cytometric analysis of cell suspension exposed to shock waves in the presence of the radical sensitive dye hydrethidine. Ultrasound Med Biol 21: 569-577

ERSAY A, AKGÜN Y (1999): Experience with renal gunshot injuries in a rural setting. Urology $\underline{54}, 972-975$

EZZ EA (1988): Medical knowledge - an important factor in disarmament negotiations and increased international cooperation. J Trauma Suppl $\underline{28}, 1-4$

FACKLER ML (1988): Wound ballistics. A review of common misconceptions. JAMA 18, 2730-2736

FACKLER ML (1998): Civilian gunshot wounds and ballistics: dispelling the myths. Emerg Med Clin North Am 1, 17-28

FACKLER ML, O'BENAR J (1987): Basic physics of the projectile-tissue interaction. Mil Med 10, 531-534

FACKLER ML, MALINOWSKI JA (1985):The wound profile: a visual method for quantifying gunshot wound cmponents. J Trauma $\underline{25}, 522-529$

FACKLER ML, MALINOWSKI JA (1988 a): Internal Deformation of the AK-74; A possible cause for its erratic path in tissue. J Trauma Suppl $\underline{28}, 72-75$

FACKLER ML, MALINOWSKI JA (1988 b): Ordnance gelatin for ballistic studies. Am J Forensic Med Pathol $\underline{3}, 218-219$

FACKLER ML, SLURINCHAK JS, MALINOWSKI JA, BOWEN RE (1984 a): Bullet fragmentation: a major cause of tissue disruption. J Trauma 24, 35-39

FACKLER ML, SURINCHAK JS, MALINOWSKI JA, BOWEN RE (1984 b): Wounding potential of the Russian AK-47 assault rifle. J Trauma 24, 263-266

FACKLER ML, BELLAMY RF, MALINOWSKI JA (1986): Wounding mechanism of projectiles striking at more than 1,5 km/sec. J Trauma $\underline{26}, 250-254$

FACKLER ML, BELLAMY RF, MALINOWSKI JA (1988 a): A reconsideration of the wounding mechanism of very high velocity projectiles - importance of projectile shape. J Trauma Suppl $\underline{28}$, 63-67

FACKLER ML, BELLAMY RF, MALINOWSKI JA (1988 b): The wound profile: illustration of the missile-tissue interaction. J Trauma Suppl $\underline{28}, 21-29$

FALLER-MARQUARDT M, POLLAK S (2000): Gemeinschaftlicher Suizid mit Schussabgabe in die Scheitelregion. Rechtsmedizin 10, 148-152

FENG TS, MA YY, FU RX, LI M (1988): The wounding characteristics of spherical steel fragments in live tissues. J Trauma $\underline{28}, 37-40$

FISCHER H (1962): Schußverletzungen durch moderne Feuerwaffen und die Folgerungen für die Behandlung. Munch Med Wochenschr 104, 2001-2006 
GALBRAITH KA (2001): Combat casualties in the first decade of the 21st century - new and emerging weapon systems. J R Army Med Corps 147, 7-14

GEORGI BA, MASSAD M, OBEID M (1991): Ballistic trauma to the abdomen: shell fragments versus bullets. J Trauma $\underline{31}, 711-715$

GRAHAM JW, PETTY CS, FLOHR DM, PETERSON WE (1966): Forensic aspects of frangible bullets. J Forensic Sci 11, 507-515

GREINER W, STOCK H: Hydrodynamik; 4. erweiterte Auflage; Verlag Harri Deutsch, Frankfurt 1991

GRIMAL Q, WATZKY A, NAILI S (2002): An one-dimensional model for the propagation of transient pressure waves through the lung. J Biomech $\underline{35}$, 10811989

GROSS AG (1958): A new theory on the dynamics of brain concusion and brain injury. J Neurosurg $\underline{15}, 548$

GROSSE PERDEKAMP M, VENNEMANN B, MATTERN D, SERR A, POLLAK S (2005): Tissue defect at the gunshot entrance wound: what happens to the skin? Int J Legal Med 119, 217-222

GUSTAFSSON U, SUNESON A, KJELLSTRÖM BT (1997): Effects of peripheral high energy missile trauma on the oxygenation of the lung tissue in the pig. Ann Acad Med Singapore 26, 22-26

HARREL JB (1979): Hollowpoint ammunition injuries: experience in a police group. J Trauma $\underline{19}, 115-116$

HARVEY EN, KORR IM, OSTER G, McMILLEN JH (1947): Secondary damage in wounding due to pressure changes accompanying the passage of high velocity missiles. Surgery $\underline{21}, 218-239$

HARVEY EN, MCMILLEN JH, BUTLER EG, PUCKETT WO: Mechanism of wounding. In: Wound ballistics; hrsg. v. Heaton LD, Office of the Surgeon General department of the army, Washington D. C. 1962, 143-235

HASSELGREN PO, ALMSKOG B, LUND B, VON DER DECKEN A, NORDSTRÖM G, SEEMAN T (1982): Leucine incorporation into skeletal muscle proteins in vitro and protein synthesis by isolated ribosomes from skeletal muscle around a high velocity missile injury. Acta Chir Scand Suppl $\underline{508}, 337-344$

HAUCK JG (1990): Ergebnisse und Tendenzen der HandfeuerwaffenEntwicklung in den siebziger und achtziger Jahren. Kriminal Forensic Wiss $\underline{79}$, 192

HEIDEMAN M, GELIN LE (1979): The general and local response to injury related to complement activation. Acta Chir Scand Suppl $\underline{489}$, 215-223 
HESS U, HARMS J (2000): Die MRT zur Beurteilung von Schußverletzungen. Rechtsmedizin $\underline{10}$, 90-95

HODGDON: Basic reloaders manual. O. Verf.; o. Verl., Shawnee, USA 1996

HOLMSTRÖM A, LARSSON J, LILJEDAHL SO, LEWIS DH (1979): Effect of bullet wounding on pig skeletal muscle electrolytes and water content. Acta Chir Scand Suppl $\underline{489}, 173-178$

HORSLEY V (1894): The destructive effects of small projectiles. Nature $\underline{50}$, 104-108

HUELKE DF, BUEGE LJ, KARGER JH (1967): Bone fractures produced by high velocity impacts. Am J Anat $\underline{120}, 123-132$

HUGHES CW (1954): Acute vascular trauma in Korean war casualties: an analysis of 180 cases. Surg Gynecol Obstet $\underline{99}, 91-100$

INCI I, OZCELIK C, TACYILDIZ I, NIZAM O.EREN N, OZGEN G (1998): Penetrating chest injuries: unusually high incidence of high-velocity gunshot wounds in civilian practice. World J Surg 22, 438-442

JAHNKE EJ Jr, HOWARD JM (1953): Primary of major arterial injuries: report of fifty-eight battle casualties. Arch Surg $\underline{66}, 646-649$

JAHNKE EJ Jr, SEELEY SF (1953): Acute vascular injuries in the Korean war: an analysis of 77 consecutive cases. Ann Surg 138, 158-177

JAIN SK, BHATTACHARAYYA CN, BADONIA B, SINGH RP (2003): Study of unusual phenomenon of contact firing on gelatine block using .38 special revolver - forensic importance. Forensic Sci Int 133, 183-189

JANSSEN W, MIYAISHI S, KOOPS E, HILDEBRAND E, PÜSCHEL K (1996): Schusstodesfälle im Zusammenhang mit der Jagd sowie durch Jagdwaffen Ursachen, Verhütung und Beurteilung. Arch Kriminol 197, 1-15

JANZON B (1982 a): Edge, size and temperature effects in soft soap block simulant targets used for wound ballistic studies. Acta Chir Scand Suppl $\underline{508}$, 105-122

JANZON B (1982 b): Soft soap as a tissue simulant medium for wound ballistic studies investigated by comperative firings with assault rifle AK 4 and M 16 A 1 into live, anesthetized animals. Acta Chir Scand Suppl $\underline{508}, 79-88$

JANZON B, SEEMAN T (1985): Muscle devitalization in high-energy missile wounds and its dependence on energy transfer. J Trauma $\underline{25}, 138-144$

JANZON B, BERLIN R, NORDSTRAND I, RYBECK B, SCHANTZ B (1979): Drag and tumbling behaviour of small calibre projectiles in tissue simulant. Acta Chir Scand Suppl $\underline{489}$, 57-70 
JANZON B, SCHANTZ B, SEEMAN T (1988): Scale effects in ballistic wounding. J Trauma Suppl 르, 29-32

JOHANSSON L, HOLMSTRÖM A, NORRBY K, NYSTRÖM PO, LENNQUIST $S$ (1982): Intramural haemorrhage of the intestine as an indirect effect of abdominal missile trauma-classification and prognosis. Acta Chir Scand Suppl $\underline{508}, 175-177$

JOSEPHSON LH, TOMLINSON P (1988): Predicted thoraco-abdominal response to complex blast waves. J Trauma Suppl $\underline{28}, 116-124$

JOSSELSON AR, JOHNSON AC, WASHINGTON WD, WAGNER GN, GARNER DD, JOHNSON FB, LUNDY DR (1985): A study of .22 caliber rimfire exploding bullets: effects in ordnance gelatin. J Forensic Sci $\underline{30}$, 760-772

JUSSILA J (2005): Measurement of kinetic energy dissipation with gelatine fissure formation with spezial reference to gelatine validation. Forensic Sci Int $150,53-62$

JUSSILA J, KJELLSTRÖM BT, LEPPÄNIEMI A (2005 a): Ballistic variables and tissue devitalisation in penetrating injury - establishing relationship through meta-analysis of a number of pig tests. Injury $\underline{36}, 282-292$

JUSSILA J, LEPPÄNIEMI A, PARONEN M, KULOMÄKI E (2005 b): Ballistic skin stimulant. Forensic Sci Int 150, 63-71

KAMPMANN H, KIJEWSKI H (1986): Untypische Einschußverletzungen. Ein kasuistischer und experimenteller Beitrag. Z Rechtsmed 97, 185-193

KEGEL CD: Die Untersuchung von Geschosswirkungen in Zielmedien bei Veränderung physikalischer Parameter. Med. Diss. Göttingen 2003

KEGEL CD, KLATT A, KIJEWSKI H: Zur dynamischen Pathomechanik der Einschusswunde - Konsequenzen für die Begutachtung. Zitiert aus dem Programm der 79. Jahrestagung der Deutschen Gesellschaft für Rechtsmedizin, Essen, 27.-30. September 2000, Programm und Inhaltsangaben in Rechtsmedizin Supplement 1 zu 10, 34

KIJEWSKI H (1974 a): Die Spannungsdoppelbrechung von Polyvinylbutyral als Hilfsmittel zur Unterscheidung von Schuß und Schlag an Verbundglasscheiben. Arch Kriminol 154, 83-89

KIJEWSKI H (1974 b): Probleme bei der Beurteilung von Schüssen durch Glasscheiben. Z Rechtsmed $\underline{74}$, 167-175

KIJEWSKI H (1979): Möglichkeiten zur Bestimmung von Kaliber, Geschoßart und -geschwindigkeit aus der Morphologie des Schußkanals im Schädelknochen. Arch Kriminol 164, 107-121

KIJEWSKI H (1981): Die Bedeutung der Schußentfernungsbestimmung für die Rekonstruktion von Schußwaffendelikten. Kriminalistik $\underline{9}$, 369-371 
KIJEWSKI H: Zur Rekonstruktion von Kopfschüssen. Aus: Kopfschuß Spannungsfeld zwischen Medizin und Recht; hrsg. v. Saternus K-S, Verlag Max Schmidt-Römhild, Lübeck 1992, 25-35

KIJEWSKI H, KAMPMANN H (1986): Zur Reproduktion atypischer Ausschußwunden. Z Rechtsmed $\underline{97}, 195-200$

KIJEWSKI H, KROPP S (2000): Dichotomien bei der Rekonstruktion von Schussverletzungen. Kriminalistik 11, 748-751

KIJEWSKI H, BERG S, SPRUNG R (1980): Suizid mit Luftgewehr. Untersuchung zur Wundballistik von Druckluftwaffen. Z Rechtsmed 84, 209220

KLAGES U, WEITHOENER D (1973): Untersuchung zur Perforationsgröße bei Schußverletzungen der Schädelkalotte durch Kleinkaliberwaffen. Z Rechtsmed $\underline{73}, 35-44$

KLATT A: Geschwindigkeitsabhängigkeit von Geschoßwirkungen in Zielmedien mit unterschiedlichen Wassergehalten. Med. Diss. Göttingen 1996

KLATT A, KIJEWSKI H (1998): The influence of target water content on wound ballistic effects. An experimental study. Rom J Leg Med $\underline{6}$, 239-247

KLUPS N: Das Buch der Geschosse; Nimrod-Verlag, Suderburg 1998

KNEUBUEHL BP: Geschosse - Ballistik, Treffsicherheit, Wirkungsweise; 2. Auflage; Verlag Stocker-Schmidt AG, Dietikon-Zürich 1998

KNEUBUEHL BP, THALI MJ (2003): The evaluation of a synthetic long bone structure as a substitute for human tissue in gunshot experiments. Forensic Sci Int $138,44-49$

KNIGHT B (1982): Explosive bullets: a new hazard for doctors. Br Med J $\underline{284}$, 768-769

KNUDSEN PJT, SORENSEN OH (1994): The initial yaw of some commonly encountered military rifle bullets. Int J Leg Med 107, 141-146

KNUDSEN PJT, SVENDER J (1994): Doppler radar velocity measurements for wound ballistics experiments. Int J Leg Med 107, 1-6

KUIJPERS MWA, VAN ECK D; KEMMERE MF; KEURENTJES JTF (2002): Cavitation-induced reactions in high-pressure carbon dioxide. Science $\underline{298}$, 1969-1971

KUTTERER RE: Ballistik; 3. Auflage; Verlag F. Vieweg \& Sohn, Braunschweig 1959

KUTTRUFF H: Physik und Technik des Ultraschalls; Verlag S. Hirzel, Stuttgart 1988 
LARSSON J, HOLMSTRÖM A, LILJEDAHL SO, LEWIS DH (1979): Effect of bullet wounding on pig skeletal muscle metabolism. ActaChir Scand Suppl $\underline{489}$, 179-184

LARSSON J, LENNQUIST S, LOVEN L, LEWIS DH, LILJEDAHL SO (1982): Systemic metabolic effects observed in muscle tissue after high energy missile trauma. Acta Chir Scand Suppl $\underline{508}$, 323-326

LAUTERBORN W (1997): Cavitation. Encyc Acoust 1, 263-270

LAUTERBORN W, KURZ T: Nonlinear acoustics at the turn of the millennium; 1. Auflage; American Institute of Physics, Melville, New York 2000

LENNQUIST S, HOLMSTRÖM A, JOHANSSON L, NORRBY K (1979): Intestinal haematomas due to abdominal missile wounds-pathophysiology and principles of treatment. Acta Chir Scand Suppl $\underline{489}$, 211-213

LEWIS DH, BENGTSSON MB, LARSSON J, LILJEDAHL SO (1979): Activation of the kallikrein-kinin system in bullet wounding. Acta Chir Scand Suppl $\underline{489}$, 225-230

LI B, WU G, CHEN J, WANG J, ZHANG L, CHEN Z, CHEN X (2001): Observation of wounding characteristics in dogs wounded by super velocity projectile. Chin J Traumatol $\underline{4}, 97-101$

LI M, MA YY, FU RX, FENG TS (1988): The characteristics oft the pressure waves generated in the soft target by impact and its contribution to indirect bone fractures. J Trauma Suppl $\underline{28}, 104-109$

LIDEN E, BERLIN R, JANZON B, SCHANTZ B, SEEMAN T (1988): Some observations relating to behind-body armour blunt trauma effects caused by ballistic impact. J Trauma Suppl $\underline{28}, 145-148$

LINDAU O: Dynamik und Lumineszenz lasererzeugter Kavitationsblasen. Physik-Diplomarbeit Göttingen 1998

LIROFF SA, PONTES JES, PIERCE JM (1977): Gunshot wounds of the ureter. J Urol $\underline{118}, 551-553$

LIU YQ, WU BJ, XIE GP, CHEN ZC, TANG CG, WANG ZG (1982): Wounding effects of two types of bullets on soft tissue of dogs. Acta Chir Scand Suppl $\underline{508}, 211-221$

LIU YQ, CHEN XY, LI SG, CHEN XM, GUO RF, WANG D, FU XB, JIANG SP, XU GW (1988 a): Wounding effects of small fragments of different shapes at different velocities on soft tissues of dogs. J Trauma Suppl $\underline{28}, 95-98$

LIU YQ, GUO RF, WU BJ, LI SG, WANG DT (1988 b): Pressure variation in temporary cavities trailing three different projectiles penetrating water and gelatin. J Trauma Suppl $\underline{28}, 9-13$ 
LIU YQ, LI SG, WU BJ, WANG DT, HANG SP, CHEN XY, MA QG, GUO RF, CHEN ZC (1988 c): Characteristics of cavities trailing different projectiles penetrating water. J Trauma Suppl $\underline{28}, 13-16$

LOHSE D (2002): Inside a micro-reactor. Nature $\underline{418}, 381-383$

MA YY, FENG TS, FU RX, MING L (1988): An analysis of the wounding factors of four different shapes of fragments. J Trauma Suppl $\underline{28}, 230-235$

MacPHERSON D: Bullet penetration; 1. Auflage; Ballistic Publications, El Segundo 1994

MADEA B, HENSSGE C, LOCKHOVEN HB (1986): Priorität bei mehrfachen Schußverletzungen des Schädels. Z Rechtsmed 97, 213-218

MANDRACCHIA VJ, BUDDECKE DE Jr., STATLER TK, NELSON SC (1999): Gunshot wounds to the lower extremity. A comprehensive review. Clin Podiatr Med Surg 16, 597-615

MARKAKIS E, MURSCH K, OELJESCHLÄGER OR; KOLENDA H: Zivile Kopfschußverletzungen. Klinische Kriterien bei 36 Fällen. In: Kopfschuß Spannungsfeld zwischen Medizin und Recht; hrsg. v. Saternus K-S; Verlag Max Schmidt-Römhild, Lübeck 1992, 59-79

MENZIES RC, ANDERSON LE (1980): The Glaser safety slug and the Velex/Velet exploding bullet. J Forensic Sci $\underline{25}$, 44-52

METTER D, SCHULZ E (1983): Morphologische Merkmale der Schußwunden in Leber und Milz. Z Rechtsmed $\underline{90}$, 167-172

METTIN R, OHL CD, LAUTERBORN W: Particle approach to structure formation in acoustic cavitation, in: CRUM LA, MASON TJ, REISSE JL, Suslick KS (eds.): Sonochemistry and Sonoluminescence (Proceedings of the NATO Advanced Study Institute, Leavenworth (WA), USA), Kluwer Academic Publishers, Dordrecht 1999, 138-144

METTIN R, WOLFRUM B, SIEGMUND B, KIJEWSKI H: Druckwelleninduzierte Kavitation in der Wundballistik. Aus: Fortschritte der Akustik - DAGA 03; hrsg. v. Vorländer M; DEGA e.V., Oldenburg 2003, 838-839 (CD-Rom: DAGA03_1656.pdf)

METTIN R, WOLFRUM B, SIEGMUND B, KIJEWSKI H: Druckwelle und Kavitation bei Hochgeschwindigkeitsgeschossen: Experimentelle Untersuchungen und theoretische Modellierung. Zitiert aus dem Programm der 83. Jahrestagung der Deutschen Gesellschaft für Rechtsmedizin, Göttingen, 22.-25. September 2004, Programm und Inhaltsangaben in Rechtsmedizin 14, 320

MISSLIWETZ J, WIESER I (1989): Schädelschüsse bei Trägern militärischer Schutzhelme - Allgemeines sowie Experimente und Beobachtungen zur Biomechanik und Wundmorphologie. Z Rechtsmed 102, 41-54 
MOORE HG, NYHUS LM, KANAR EA (1954): Gunshot wounds of major arteries: an experimental study with clinical implications. Surg Gynecol Obstet $\underline{98}, 129-147$

MULLINS JF: Frangible ammunition - the new wave in firearms ammunition; 1. Auflage; Paladin Press, Boulder (Colorado) 2001

NAIR R, ABDOOL-CARRIM ATO, ROBBS JV (2000): Gunshot injuries of the popliteal artery. Br J Surg $\underline{87}, 602-607$

NORDSTRAND I, JANZON B, RYBECK B (1979): Break-up behaviour of some small calibre projectiles when penetrating a dens medium. Acta Chir Scand Suppl $\underline{489}, 81-90$

O'CONNELL KJ, CLARK M, LEWIS RH, CHRISTENSON PJ (1988): Comparison of low-and high-velocity ballistic trauma to genitourinary organs. $\mathrm{J}$ Trauma Suppl $\underline{28}, 139-144$

ÖBERG PA, NILLSON GE, TENLAND T, HOLMSTRÖM A, LEWIS DH (1979): Use of a new laser doppler flowmeter for measurement of capillary blood flow in skeletal muscle after bullet wounding. Acta Chir Scand Suppl $\underline{489}, 145-150$

OEHMICHEN M: Neuropathologie des Kopfschusses. In: Kopfschuß Spannungsfeld zwischen Medizin und Recht; hrsg. V. Saternus K-S; Verlag Max Schmidt Römhild, Lübeck 1992, 37-50

OEHMICHEN M, MEISSNER C, KÖNIG H-G (2000): Brain injury after gunshot wounding: morphometric analysis of cell destruction caused by temporary cavitation. J Neurotrauma 17, 155-162

OLIVER JD, WHITTY GF (1988): Wound-dynamic studies of Australia. J Trauma Suppl $\underline{28}, 54-57$

ORDOG GJ, WASSERBERGER J, BALASUBRAMANIAM S (1988): Shotgun wound ballistics. J Trauma $\underline{28}$, 624-631

ORLOWSKI T, DOMANIECKI J, BADOWSKJ A (1982 a): Effect of missile velocity on the pathophysiology of injuries. Acta Chir Scand Suppl $\underline{508}, 315-$ 320

ORLOWSKI T, PIECUCH T, DOMANIECKI J, BADOWSKI A (1982 b): Mechanism of development of shot wounds caused by missiles of different initial velocity. Acta Chir Scand Suppl $\underline{508}, 123-127$

OTTOSON R (1964): Cavitation produced by different projectiles. Mil Med $\underline{129}$, 1017-1024

OWEN-SMITH MS: High Velocity Missile Wounds. Edward Arnold Ltd, London $1981,21-33$

PADOSCH SA, SCHMIDT P, MODEST I; MILBRADT H, MADEA B: Suizid durch hölzerne „Tandem - Projektile“ mittels zwei Schüssen aus einem 
manipulierten Schreckschussrevolver. Zitiert aus dem Programm der 81. Jahrestagung der Deutschen Gesellschaft für Rechtsmedizin, RostockWarnemünde, 24.-28. September 2002, Programm und Inhaltsangaben in Rechtsmedizin 12, 295

PANKRATZ H, FISCHER H (1985): Zur Wundballistik des Krönlein-Schusses. Z Rechtsmed 95, 213-215

PAREY P: Selbstladegewehre Visier Special Nr.19; o. Verf.; Paul-PareyVerlag, Nassau 2000

PEREY S, TIGGES J (1997): Selbstladebüchsen in .223 Rem. Caliber 1, 59-65

PEREY S, TIGGES J (2003): Klein \& gemein!. Caliber 1, 6-11

PIETTE M, DE DURPLE E, DE LETTER E, CORDONNIER J: How routine interpretation of gunshot wounds could be quite misleading. Zitiert aus dem Programm der 81. Jahrestagung der Deutschen Gesellschaft für Rechtsmedizin, Rostock-Warnemünde, 24.-28. September 2002, Programm und Inhaltsangaben in Rechtsmedizin 12, 295

POLLAK S (1980): Zur Morphologie der Einschußwunden im Palmar- und Plantarbereich. Z Rechtsmed $\underline{86}$, 41-47

POLLAK S (1982): Zur Makro- und Mikromorphologie der durch Faustfeuerwaffen erzeugten Einschußwunden. Beitr Gerichtl Med 40, 493-520

POLLAK S, ROTHSCHILD MA (2004): Gunshot injuries as a topic of medicolegal research in the german-speaking countries from the beginning of the $20^{\text {th }}$ century up to the present time. Forensic Sci Int 144, 201-210

POST C, LEWIS DH (1979): Effect of bullet wounding in thigh on the uptake of lidocaine by the lung. Acta Chir Scand Suppl $\underline{489}$, 205-209

PUCKETT WO, MC ELROY WD, HARVEY EN (1946): Studies on wounds of the abdomen and thorax produced by high velocity missiles. Mil Surg $\underline{98}, 427-$ 439

PUTTERMAN SJ: Sonoluminescenz. Spektrum Wiss 1995,4, 50-55

PUTTERMAN SJ, WENINGER KR (2000): Sonoluminescence: How bubbles turn sound into light. Annu Rev Fluid Mech $\underline{32}$, 445-476

RAGSDALE BD, JOSSELSON A (1988 a): Experimental gunshot fractures. J Trauma Suppl $\underline{28}, 109-115$

RAGSDALE BD, JOSSELSON A (1988 b): Predicting temporary cavity size from radial fissure measurements in ordnance gelatin. J Trauma Suppl $\underline{28}, 5-9$

REINHARDT G, MATTERN R: Rechtsmedizin. Aus: Ökologisches Stoffgebiet, 3. Auflage, hrsg. v. Reinhardt G, Bob A, Bob K; Hippokrates Verlag, Stuttgart 1999 
REMINGTON JW, HAMILTON WF, CADELL HM (1950): Vasoconstriction as precipitating factor in traumatic shock in the dog. Am J Physiol 161, 125-132

RESCHELEIT T, ROTHSCHILD MA, SCHNEIDER V (2001): Zur Frage der Differenzierung von Ein- und Ausschuss bei auf fester Unterlage anliegenden bekleideten Opfern. Rechtsmedizin 11, 212-216

RICH NM (1980): Missile injuries. Am J Surg $\underline{139}$, 414-420

RISSE M, WEILER G (1988): Beitrag zur hydrodynamischen Geschoßwirkung bei Schädel-Sprengschüssen. Arch Kriminol 182, 75-82

ROBERTS JC, O'CONNOR JV, WARD EE (2005): Modeling the effect of nonpenetrating ballistic impact as a means of detecting behind armor blunt trauma. J Trauma $\underline{58}, 1241-1251$

ROBERTSON BC, MANSON PN (1999): High-energy ballistic and avulsive injuries. A management protocol for the next millenium. Surg Clin North Am $\underline{79}$, 1489-1502

ROCCA A, LEONETTI G, PAOLI JR (1998): Ballistic data for plastic surgeons. Ann Chir Plast Esthet 43, 117-124

ROSE SC, FUJISAKI CK, MOORE EE (1988): Incomplete fractures associated with penetrating trauma etiology, appearance and natural history. J Trauma 28, 106-109

RYAN JR, HENSEL RT, SALCICCIOLI GG, PEDERSEN HE (1981): Fractures of the femur secondary to low-velocity gunshot wounds. J Trauma 21, 160-162

RYBECK B (1974): Missile wounding and haemodynamic effects of energy absorption. Acta Chir Scand Suppl $\underline{450}$, 1-32

RYBECK B, JANZON B (1976): Absorption of missile energy in soft tissue. Acta Chir Scand 142, 201-207

RYBECK B, LEWIS DH, SANDEGÄRD J, SEEMAN T (1975 a): Early changes in capillary flow and transport following missile wounds. Microvasc Res 10 , 267275

RYBECK B, LEWIS DH, SANDEGÄRD J, SEEMAN T (1975 b): The immediate circulatory response to high-velocity missiles. J Trauma $\underline{15}$, 328-335

SCEPANOVIC D (1979): Steel ball effect - investigation of shooting at blocks of soap. Acta Chir Scand Suppl $\underline{489}, 71-80$

SCEPANOVIC D, ALBREHT M (1982): Effects of small calibre arms projectiles in soap. Acta Chir Scand Suppl $\underline{508}$, 49-60

SCEPANOVIC D, ALBREHT M, ERDELJAN D (1982): A method for predicting effects of military rifles. Acta Chir Scand Suppl $\underline{508}$, 29-36 
SCEPANOVIC D, ALBREHT M, ERDELJAN D, MILIVOJEVIC V, PETROVIC M, CUK V, DJUKNIC M (1988): Evaluation of the new type of military bullet and rifling. J Trauma Suppl $\underline{28}, 68-72$

SCHANTZ B (1979): Aspects on the choice of experimental animals when reproducing missile trauma. Acta Chir Scand Suppl $\underline{489}, 121-129$

SCHILLER D TH (2004): Paketlösung. Visier 2, 38-47

SCHMECHTA H (1990): Gerichtsmedizinische und kriminalistische Aspekte der kleinkalibrigen Schützenwaffen unter besonderer Berücksichtigung der AKS 74 (5,45 mm). Kriminal Forensic Wiss $\underline{77-78}, 152-153$

SCHYMA C (1996): Schußfolgen. Dtsch Jagd Z 2 , 78-79

SCHYMA C, SCHYMA P (1999): Das Verletzungspotential von Kartuschenmunition im Gelatinemodell. Rechtsmedizin $\underline{\text { 9, 210-214 }}$

SELLIER K: Schußentfernungsbestimmung. 1. Auflage; Verlag Max SchmidtRömhild, Lübeck 1967

SELLIER K: Schußwaffen und Schußwirkungen - Ballistik, Medizin und Kriminalistik.

Verlag Max Schmidt-Römhild, Lübeck 1969

SELLIER K (1976): Verletzungsmöglichkeiten von Geschossen, die an Sand oder Beton abgeprallt sind. Z Rechtsmed $\underline{78}, 149-158$

SELLIER K: Schußwaffen und Schußwirkungen II - Forensische Ballistik, Wundballistik. Verlag Max Schmidt-Römhild, Lübeck 1977

SELLIER K (1979): Effectiveness of small calibre ammunition. Acta Chir Scand Suppl $\underline{489}, 13-26$

SELLIER K, KNEUBUEHL BP: Wundballistik und ihre ballistischen Grundlagen. Springer-Verlag, Berlin Heidelberg 2001

SHARMA OP, OSWANSKI MF, WHITE PW (2004): Injuries to the colon from blast effect of penetrating extra-peritoneal thoraco-abdominal trauma. Injury $\underline{35}$, 320-324

SIEBERT W, BUCH M: Extracorporeal shock waves in orthopaedics. SpringerVerlag, Berlin Heidelberg 1998

SIEGMUND B, METTTIN R., KEGEL CD, KIJEWSKI H: Systematische Untersuchungen zur Zielballistik bei Variation der Eigenschaften des Zielmaterials, der Geschossgeschwindigkeit und der Festigkeit der Geschosse - Konsequenzen der Begutachtung. Zitiert aus dem Programm der 81. Jahrestagung der Deutschen Gesellschaft für Rechtsmedizin, RostockWarnemünde, 24.-28. September 2002, Programm und Inhaltsangaben in Rechtsmedizin 12, 261 
SIEGMUND B, METTTIN R, WOLFRUM B, KIJEWSKI H: Untersuchungen zur Zielballistik von HV-Munition in der frühen Phase in unterschiedlichen Materialien mittels Hochgeschwindigkeitskamera und schneller Druckmessung. Zitiert aus dem Programm der 83. Jahrestagung der Deutschen Gesellschaft für Rechtsmedizin, Göttingen, 22.-25. September 2004, Programm und Inhaltsangaben in Rechtsmedizin 14, 320

SILVIA AJ (1999): Mechanism of injury in gunshot wounds: myths and reality. Crit Care Nurse Q 22, 69-74

SMIALEK JE, SPITZ WU (1976): Short-range ammunition - a possible antihijacking device. J Forensic Sci 21, 856-861

SMITH HW, WHEATLEY KK (1984): Biomechanics of femur fractures secondary to gunshot wounds. J Trauma $\underline{24}$, 970-977

SMITS G, JAP P (1993): Biological effects of high energy shock waves in mouse skeletal muscle: Correlation between 31P magnetic resonance spectroscopic and microscopic alterations. Ultrasound Med Biol 19, 399-409

STANGE K: Das Problem der Flugbahnberechnung; Verlag E.S. Mittler u. Sohn, Berlin 1940

STASICKI B, FRAHNERT H: Sichtbarmachung und Aufzeichnung der Schallwellenausbreitung beim Schuss aus einer Feuerwaffe. Zitiert aus dem Programm der 83. Jahrestagung der Deutschen Gesellschaft für Rechtsmedizin, Göttingen, 22.-25. September 2004, Programm und Inhaltsangaben in Rechtsmedizin 14, 319

STONE IC, PETTY CS (1991): Interpretation of unusual wounds caused by firearms. J Forensic Sci $\underline{36}, 736-740$

STUTZMAN RE (1977): Ballistics and the management of ureteral injuries from high velocity missiles. J Urol 118, 947-949

SUHR D, BRÜMMER F (1991): Cavitation generated free radicals during shock wave exposure: Investigations with cell free solutions and suspended cells. Ultrasound Med Biol 17, 761ff

SUNESON A, HANSSON HA, SEEMAN T (1987): Peripheral high-energy missile hits cause pressure changes and damage to the nervous system: experimental studies on pigs. J Trauma Suppl $\underline{27}, 782-789$

SUNESON A, HANSSON HA, SEEMAN T (1988): Central and peripheral nervous damage following high-energy missile wounds in the thigh. J Trauma Suppl $\underline{28}, 197-203$

SWAN KG, SWAN RC, LEVINE MG, ROCKO JM (1983): The U.S. M-16-rifle versus the russian AK-47 rifle. A comparison of terminal ballistics. Am Surg $\underline{49}$, 472-379 
SYKES LN, CHAMPION HR, FOUTY WJ (1988): Dum-dums, hollow-points and devastors: techniques designed to increase wounding potential of bullets. $J$ Trauma $\underline{28}$, 618-623

TAN Y, ZHOU S, LIU Y, LI Z (1998): A gross and microscopic study of cerebral injuries accompanying maxillofacial high-velocity projectile wounding in dogs. J Oral Maxillofac Surg $\underline{56}, 345-348$

TAN Y, ZHOU S, JIANG H (2002): Biomechanical changes in the head associated with penetrating injuries of the maxilla and mandible: an experimental investigation. J Oral Maxillofac Surg $\underline{60}, 552-558$

THALI MJ, KNEUBUEHL BP, DIRNHOFER R, ZOLLINGER U (2001): Body models in forensic ballistics: reconstruction of a gunshot injury of the chest by bullet fragmentation after shooting through a finger. Forensic Sci Int 123, 54-57

THALI MJ, KNEUBUEHL BP, ZOLLINGER U, DIRNHOFER R (2002 a): The "skin-skull-brain-model": a new instrument for the study of gunshot effects. Forensic Sci Int 125, 178-189

THALI MJ, KNEUBUEHL BP, ZOLLINGER U, DIRNHOFER R (2002 b): A study of the morphology of gunshot entrance wounds, in connection with their dynamic creation, utilizing the "skin-skull-brain-model". Forensic Sci Int $\underline{125}$, 190-194

THALI MJ, KNEUBUEHL BP, DIRNHOFER R (2002 c): A "skin-skull-brainmodel" for the biomechanical reconstruction of blunt forces to the human head. Forensic Sci Int 125, 195-200

TIKKA S, CEDERBERG A, LEVÄNEN J, LÖTJÖNEN V, ROKKANEN P (1982 a): Local effects of three standard assault rifle projectiles in live tissue. Acta Chir Scand Suppl $\underline{508}, 61-77$

TIKKA S, CEDERBERG A, ROKKANEN P (1982 b): Remote effects of pressure waves in missile trauma. The intra-abdominal pressure changes in anesthetized pigs wounded in one thigh. Acta Chir Scand Suppl 508, 167-173

TIKKA S, LÖTJÖNEN V, CEDERBERG A, ROKKANEN P (1982 c): The behaviour of three standard small calibre projectiles in soap blocks. Acta Chir Scand Suppl $\underline{508}, 89-104$

TREIB J, HAASS A, GRAUER MT (1996): High-velocity bullet causing indirect trauma to the brain and symptomatic epilepsy. Mil Med 161, 61-64

VELITCHKOV NG, LOSANOFF JE, KJOSSEV KT, KATROV ET, MIRONOV MB, LOSANOFF HE (2000): Delayed small bowel injury as a result of penetrating extraperitoneal high-velocity ballistic trauma to the abdomen. $\mathrm{J}$ Trauma $\underline{48}, 169-170$

VERHOFF MA, KARGER B (2003): Atypical gunshot entrance wound and extensive backspatter. Int J Legal Med 117, 229-231 
VIHTAVUORI: Vihtavuori reloading guide for rifles and handguns. Seventh edition; o. Verf.; Vihtavuori OY, Vihtavouri/Finnland 1998

VON HOFMANN ER: Lehrbuch der gerichtlichen Medizin. Urban und Schwarzberg Verlag, Wien Leipzig 1895

WANG ZG, FENG JX, LIU YQ (1982): Pathomorphological observations of gunshot wounds. Acta Chir Scand Suppl $\underline{508}, 185-195$

WANG ZG, TANG CG, CHEN XY, SHI TZ (1988): Early pathomorphologic characteristics of the wound track caused by fragments. J Trauma Suppl $\underline{28}$, 89-95

WARD ME, NOLTE KB (2000): Ballistic characterization of the Remington premier copper solid sabot shotgun slug. J Forensic Sci $\underline{45}$, 1259-1266

WATKINS FP, PEARCE BP, STAINER MC (1982): Assessment of terminal effects of high velocity projectiles using tissue simulants. Acta Chir Scand Suppl $\underline{508}, 39-47$

WATKINS FP, PEARCE BP, STAINER MC (1988): Physical effects of the penetration of head simulants by steel spheres. J Trauma Suppl $\underline{28}, 40-54$

WEIS H (Meppen): persönliche Mitteilung vom 08.05.2002

WILLIAMS AJ, HARTINGS JA, LU XC, ROLLI ML, DAVE JR, TORTELLA FC (2005): Characterization of a new rat model of penetrating ballistic brain injury. J Neurotrauma 22, 313-331

WIND G, FINLEY RW, RICH NM (1988): Three-dimensional computer graphic modeling of ballistic injuries. J Trauma Suppl $\underline{28}, 16-20$

WOLF YG, RIVKIND A (2002): Vaskular Trauma in high-velocity gunshot wounds and shrapnel-blast injuries in Israel. Surg Clin North Am 82, 237-244

WOLFRUM B: Cavitation and shock wave effects on biological systems. Physik. Diss. Göttingen 2004

ZHANG D, QIAN C, LIU Y, SHI T, LI D; HUANG M (1988): Morphopathologic observations on high-velocity steel bullet wounds at various intervals after wounding. J Trauma Suppl 28, 98-104

ZIEGLER M (1990): Sektionsfrequenz von Schußverletzungen und naturwissenschaftlich-kriminaltechnische Untersuchungen in den letzten zehn Jahren: Situationsbericht, Probleme, Schlußfolgerungen. Kriminal Forensic Wiss $\underline{79}, 194$

ZIERVOGEL JF (1979): A study of the muscle damage caused by the 7.62 NATO rifle. Acta Chir Scand Suppl $\underline{489}$, 131-135 


\section{Danksagung}

Mein Dank gilt all denen, die mich bei dieser Arbeit unterstützt haben.

Namentlich Herrn Priv.-Doz. Dr. med. Dr. rer. nat. H. KIJEWSKI, meinem Doktorvater, sage ich herzlich Dank für die gute Betreuung. Seine unermüdlichen Anregungen haben mir sehr geholfen. Von inm durfte ich lernen, den Dingen auf den Grund zu gehen. Seine vorurteilsfreien Gedankengänge beeindrucken mich nachhaltig.

Mein Dank gilt auch dem Ordinarius der Abteilung Rechtsmedizin Herrn Prof. Dr. med. Dr. jur. h.c. K.-S. SATERNUS. Er stellte uns das ballistische Labor seines Institutes zur Verfügung und begleitete unsere Untersuchungen mit Wohlwollen.

Für die interdisziplinäre Zusammenarbeit danke ich insbesondere den Herren Prof. Dr. W. LAUTERBORN, Dr. R. METTIN und Dr. B. WOLFRUM vom Dritten Physikalischen Institut Göttingen. Ohne Ihre Unterstützung hätten die Versuchsergebnisse in dieser Form nicht erlangt werden können. 


\section{Lebenslauf}

Als viertes Kind der Eheleute Wolfdietrich und Lydia Siegmund wurde ich, Bernward Siegmund, am 30. August 1974 in Telgte/NRW geboren. Mein Vater Wolfdietrich Siegmund ist Psychiater und Neurologe, meine Mutter Lydia Siegmund, geborene Kotulla, ist gelernte Kindergärtnerin.

Von 1980 bis 1984 besuchte ich die Grundschule in Telgte, von 1984 bis 1993 das Gymnasium Johanneum (Schloss Loburg) in Ostbevern.

Nach Abschluss der Reifeprüfung leistete ich bis September 1994 Zivildienst im Altenheim Maria-Rast in Telgte und blieb dort bis Ende 1997 neben dem Studium tätig. Von 1995 bis 1997 war ich als Student der Biologie an der Westfälischen-WilhelmsUniversität zu Münster eingeschrieben und wechselte zum Sommersemester 1998 Studienort und Studienfach. Seitdem studierte ich Medizin an der Georg-AugustUniversität zu Göttingen, legte im Frühjahr 2000 meine Ärztliche Vorprüfung und im Frühjahr 2001 den ersten Abschnitt der Ärztlichen Prüfung ab. Das Pflegepraktikum leistete ich in der Neurologie (Göttingen) ab. Ich famulierte in der Inneren Medizin (Warendorf), in der Allgemein- und Gefäßchirurgie (Warendorf), in der Poliklinik der Psychiatrie (Göttingen) und in der Allgemeinmedizin (Hamm).

Nach seiner sehr ansprechenden Vorlesung über Wundballistik kam ich mit PD Dr. med. Dr. rer. nat. H. KIJEWSKI ins Gespräch. Im Winter 2001/2002 erhielt ich von inm das Thema der und die Möglichkeit zur vorliegenden Doktorarbeit.

Mein zweites Staatsexamen legte ich im Herbst 2003 in Göttingen, mein drittes Staatsexamen im Herbst 2004 im Evangelischen Krankenhaus Oldenburg ab. Seit Anfang 2005 arbeite ich als Assistenzarzt in der Westfälischen Klinik Lengerich in der Abteilung für klinische Psychiatrie.

Bernward Siegmund

Göttingen, 2006 